\title{
Unravelling disease activity in IBD ; a key to personalized medicin
}

Citation for published version (APA):

Wintjens, D. S. J. (2021). Unravelling disease activity in IBD ; a key to personalized medicin:

Epidemiological patterns, modifiable risk factors, and treatment implications. [Doctoral Thesis, Maastricht University]. Maastricht University. https://doi.org/10.26481/dis.20211022dw

Document status and date:

Published: 01/01/2021

DOI:

10.26481/dis.20211022dw

Document Version:

Publisher's PDF, also known as Version of record

\section{Please check the document version of this publication:}

- A submitted manuscript is the version of the article upon submission and before peer-review. There can be important differences between the submitted version and the official published version of record.

People interested in the research are advised to contact the author for the final version of the publication, or visit the DOI to the publisher's website.

- The final author version and the galley proof are versions of the publication after peer review.

- The final published version features the final layout of the paper including the volume, issue and page numbers.

Link to publication

\footnotetext{
General rights rights.

- You may freely distribute the URL identifying the publication in the public portal. please follow below link for the End User Agreement:

www.umlib.nl/taverne-license

Take down policy

If you believe that this document breaches copyright please contact us at:

repository@maastrichtuniversity.nl

providing details and we will investigate your claim.
}

Copyright and moral rights for the publications made accessible in the public portal are retained by the authors and/or other copyright owners and it is a condition of accessing publications that users recognise and abide by the legal requirements associated with these

- Users may download and print one copy of any publication from the public portal for the purpose of private study or research.

- You may not further distribute the material or use it for any profit-making activity or commercial gain

If the publication is distributed under the terms of Article $25 \mathrm{fa}$ of the Dutch Copyright Act, indicated by the "Taverne" license above, 


\section{Unravelling disease activity in IBD; a key to personalized medicine}

Epidemiological patterns, modifiable risk factors, and treatment implications 
CCopyright D.S.J. Wintjens, Maastricht 2021

All rights reserved. No parts of this thesis may be reproduced or transmitted in any form or by any means, without prior permission in writing by the author, or when appropriate, by the publishers of the publications.

Cover design: Gilles Nijsten

Cover image: Mark Fuller (mark-fuller.artistwebsites.com) - The Unraveling

(https://fineartamerica.com/featured/the-unraveling-mark-fuller.html)

Layout: Tiny Wouters

Printed by: Proefschriftmaken.nl

ISBN: 978-94-6423-365-0

The work presented in this thesis was performed within the framework of NUTRIM School of Nutrition and Translational Research in Metabolism (Maastricht University). Part of this work was supported by funding from the European Union Seventh Framework Programme (FP7/2007-2013), under grant agreement $n^{\circ} 305564$.

The MylBDcoach trial was supported by an academic incentive fund of Maastricht University Medical Centre+ (31962340B). MylBDcoach was developed by Sananet B.V. using an unrestricted grant from Ferring B.V.

Printing of this thesis was financially supported by Maastricht University, Nederlandse Vereniging voor Gastroenterologie, Dr. Falk Pharma Benelux B.V., and Ferring B.V. 


\section{Unravelling disease activity in IBD; a key to personalized medicine}

Epidemiological patterns, modifiable risk factors,

and treatment implications

Proefschrift

ter verkrijging van de graad van doctor aan de Universiteit Maastricht,

op gezag van de Rector Magnificus, Prof.dr. Rianne M. Letschert, volgens het besluit van het College van Decanen,

in het openbaar te verdedigen op

vrijdag 22 oktober 2021 om 12.00 uur

door

Dion Suzanne Justus Wintjens 


\section{Promotores}

Prof. dr. D.M.A.E. Jonkers

Prof. dr. M.J. Pierik

\section{Co-promotor}

Dr. J.W. Straathof

\section{Beoordelingscommissie}

Prof. dr. M.L. Smidt, voorzitter

Prof. dr. M.H. Hemmelder

Prof. dr. E. Louis, CHU de Liège

Prof. dr. J.J.M.H. Strik

Prof. dr. C.J. van der Woude, Erasmus MC 


\section{Table of contents}

$\begin{array}{lll}\text { Chapter } 1 \text { General introduction and thesis outline } & 7\end{array}$

$\begin{array}{lll}\text { Part I Disease activity in a real-world IBD population } & 23\end{array}$

Chapter 2 Disease activity patterns of Crohn's disease in the first 10 years 25 after diagnosis in the population-based IBD South Limburg cohort

$\begin{array}{lll}\text { Part II } & \text { Associations between modifiable environmental factors and } & 47\end{array}$ disease activity in IBD

Chapter 3 Ambient air quality is not a major risk factor in the onset nor disease course of Crohn's disease - an ecologic analysis in a Dutch population-based cohort

Chapter $4 \quad$ Novel perceived stress and life events precede flares of inflammatory 71 bowel disease: a prospective 12-month follow-up study

Chapter 5 Risk of impaired nutritional status and flare occurrence in IBD 87 outpatients

Part III Intestinal and extra-intestinal cancer in IBD; consequences 101 of long-standing disease activity and inherent treatments

Chapter 6 Inflammatory bowel disease, cancer and medication: Cancer risk in 103 the Dutch population-based IBDSL cohort

Chapter 7 Incidence and classification of postcolonoscopy colorectal cancers in inflammatory bowel disease: A Dutch populationbased cohort study

Chapter 8 General discussion

Addendum Summary 163 $\begin{array}{ll}\text { Nederlandse samenvatting } & 169\end{array}$ Impact paragraph $\quad 175$

List of publications $\quad 181$

Dankwoord 185

$\begin{array}{ll}\text { Curriculum vitae } & 191\end{array}$ 


$$
20
$$




\section{Chapter 1}

General introduction 



\section{General introduction}

\section{A brief history of inflammatory bowel disease}

Hippocrates already distinguished multiple aetiologies of diarrhoea and from the $18^{\text {th }}$ century onwards, case reports were published in which transmural inflammation of the colon with ulceration and even perforations was described. ${ }^{1}$ However, sir Samuel Wilks was the first to specify a clinical disease entity in 1859 that nowadays is part of the umbrella term inflammatory bowel disease (IBD). ${ }^{2}$ His report, and several others afterwards, described ulcerative colitis (UC) as a 'severe and persistent diarrheal disease not caused by infectious pathogens'. Whether these case reports would currently be classified as UC is doubtful since Crohn's disease (CD), a disease analogue to UC, was only acknowledged as distinct disease entity (i.e 'regional enteritis') in 1932 by Burrill B. Crohn et al. ${ }^{3}$ Key aspects included transmural and necrotizing intestinal inflammation and the occurrence of strictures and fistulas in the terminal ileum. Only since 1960, a clear distinction was made between UC and colonic CD by Hugh E. Lockhart-Mummery. ${ }^{4}$

IBD is thought to arise from an inappropriate immune response to the intestinal microbiome with subsequent or simultaneous weakening of the intestinal barrier in a genetically susceptible host which can be affected by environmental factors. ${ }^{5,6}$ Differences between UC and CD exist, including genetics (i.e. disease-specific genetic loci and distinct effect sizes for shared loci in genome-wide association studies (GWAS)), ${ }^{7}$ contribution of heritability (i.e. monozygotic twin concordance rate of 10 $15 \%$ in UC and $30-58 \%$ in CD), environmental risk factors (i.e. cigarette smoking, appendectomy, and tonsillectomy are associated with CD while an inverse association is found with UC) ${ }^{9}$, microbiome perturbations, ${ }^{10}$ and the immune response (i.e. Th2 celltype-like cytokine profile in UC and an excessive Th1 and Th17 cell response in CD). ${ }^{11}$ Though, genome-wide association studies showed that $68 \%$ of the identified genetic loci are associated with both UC and $C D,{ }^{7}$ implying overlap in inflammatory pathways at least to some extent.

From a clinical perspective, IBD is characterized by recurring mucosal disease activity, which results in symptoms like abdominal pain, (bloody) diarrhoea, urgency, weight loss, and fatigue. ${ }^{5,6} \mathrm{CD}$ patients can also present with (recurrent) fistulas, perianal inflammation, or symptoms due to complications like perforations and strictures. $^{5,6}$ Furthermore, extra-intestinal manifestations such as arthropathy, aphthous stomatitis, ocular inflammation, dermatological inflammation, and primary sclerosing cholangitis occur in approximately $31 \%$ and $43 \%$ of UC and CD patients, respectively. ${ }^{12}$ On endoscopic evaluation, UC is characterized by a continuous inflammatory pattern of the colonic mucosa starting at the linea dentata in the rectum, while $C D$ mostly presents with skip lesions, ileal or even upper gastrointestinal involvement, and a tendency for inflammation to be worse in the proximal colon. ${ }^{13}$ No 
pathognomonic histological features exist, yet the combination of mucosal plasmacytosis, diffuse crypt atrophy and distortion, crypt abscesses, and mucin depletion are suggestive for UC, while focal, patchy inflammation, focal crypt distortion, and the presence of granulomas point towards $C D .{ }^{5,6}$ Rectal sparing (occurring in $>3 \%$ of the patients), the presence of a caecal patch, and a backwash ileitis (occurring in up to $20 \%$ of the patients) in UC and isolated colonic disease activity in CD may complicate the discrimination between the two disease entities. ${ }^{13}$ Consequently, approximately $3 \%$ of UC patients will be reclassified as $C D$ and 1-3\% change opposingly during follow-up. Besides, approximately 5-7\% of IBD patients cannot be diagnosed as either UC or CD and is considered as IBD-unclassified (IBD-U) from diagnosis. ${ }^{14,15}$

At diagnosis, IBD patients are further classified into distinct disease phenotypes using the Montreal classification. This classification system was developed in 2005 and includes age in both UC and CD (i.e. $<17$ years, 17-40 years, and $>40$ years), disease localization in $\mathrm{CD}$ (i.e. ileal, colonic, or ileocolonic with/without involvement of upper gastrointestinal tract), disease behaviour in $\mathrm{CD}$ (i.e. inflammatory, stricturing, or penetrating with/without peri-anal disease), and disease extent in UC (i.e. proctitis, leftsided colitis, or pancolitis). ${ }^{16}$ Heterogeneity exists in presenting phenotypes as depicted by various population-based studies. ${ }^{17,18}$ Regardless of the phenotype and severity of inflammation, the cornerstone of IBD treatment is resolution of disease activity, which can be achieved by the use of immunosuppressive drugs, encompassing local acting drugs (e.g. 5-ASA and budesonide), systemic corticosteroids, systemic immunomodulators (e.g. thiopurines and methotrexate) and biologics (e.g. infliximab, adalimumab, vedolizumab, and ustekinumab). ${ }^{5,6}$ These drugs are used for both induction and maintenance of remission, but are associated with group-specific mild to serious side-effects. Some patients eventually require surgical resection of the inflamed bowel segment(s) as a definite treatment option. Selecting the designated treatment strategy for each patient remains challenging and will be discussed later in further detail.

In the previous decades, epidemiologic studies depicted that the incidence and prevalence is increasing over time worldwide. ${ }^{19,20}$ Also in our population-based IBD South Limburg (IBDSL) cohort the increasing incidence was observed with estimated incidence rates of 21.5/100,000 inhabitants and 17.9/100,000 inhabitants in UC and CD, respectively, which is higher than the average incidence rates in Europe. ${ }^{20,21}$ In 2010, the Dutch prevalence rate for IBD in total was estimated at $830 / 100,000$ inhabitants. ${ }^{21}$ This large number of patients generates a high amount of direct (e.g. due to use of medication, hospitalizations, and surgery) as well as indirect healthcare costs (e.g. by cessation or reduction of work productivity or sick leave). In 2012, direct and indirect healthcare costs in the Netherlands were obtained through a web-based questionnaire and were estimated to be 595 and 395 Euro per 3 months for UC and 1625 and 326 Euro per 3 months for $C D$, respectively. ${ }^{22}$ The direct costs have been increasing over the past decades with a shift from surgery and hospitalizations towards medication use. ${ }^{23-25}$ 
Next to high healthcare costs, quality of life is significantly lower, at least for CD patients compared to the general population. ${ }^{26}$ Altogether, the burden of IBD is increasing over time due to the increasing incidence, relatively low mortality, and potentially disabling disease features. For a large part, this depends on disease activity and subsequent consequences. Further insight in the disease course of IBD patients may guide gastroenterologists to counteract this escalating burden.

\section{The conundrum of IBD's disease course}

Analogous to the heterogeneity in the presenting phenotype of IBD patients, the disease course may vary substantially between patients with similar features at diagnosis. Need for aggressive immunosuppressive drugs, surgery, and hospitalization are traditionally considered negative disease outcomes and vary between and within both UC en CD. In the IBDSL UC cohort, the use of immunomodulators and biologics has been found to increase significantly over time with exposure rates of $21.7 \%$ and $10.6 \%$ in 2010 , respectively, whereas the cumulative use of corticosteroids decreased. ${ }^{27,28}$ Although early colectomy rates declined from $1.5 \%$ in the ' 90 s to $0.5 \%$ in 2010 , late colectomy rates $(4.0 \%$ vs. $3.6 \%)$ and hospitalization rates $(22.3 \%$ vs. $18.3 \%)$ at 5 years after diagnosis remained more or less stable. ${ }^{28}$ In $C D$, disease course can be complicated due to the occurrence of disease progression (i.e. development of fistulas and strictures). In our IBDSL CD cohort, the exposure to immunomodulator (70.8\%) and biologics (41.2\%) in 2010 is much higher in comparison to UC and again was accompanied by a decreased cumulative exposure to steroids. ${ }^{27,29}$ Although hospitalization rates ( $65.9 \%$ vs. $44.2 \%)$ and surgery rates $(42.9 \%$ vs. $17.4 \%)$ at five years after diagnosis declined, disease progression rates at 5 years after diagnosis remained similar $(21.2 \%$ vs. $21.3 \%)$, regardless of the given treatment. ${ }^{29}$ So despite the implementation of novel drugs and treatment strategies, some of the presumed negative outcomes remain unchanged.

The lag of major improvements in IBD disease course is probably multifactorial, but may in part be subject to the lack of personalized treatment. Nowadays, the aforementioned Montreal classification together with the severity of inflammation guide gastroenterologists in the stratification of patients to different treatment strategies. ${ }^{30}$ Several studies identified additional clinical characteristics that may predict a patient's disease course such as the presence of primary sclerosing cholangitis (PSC) or early progression of disease extent (i.e. the extensiveness of inflamed colonic mucosa) in UC and the use of steroids at diagnosis and during the first year in both UC and $\mathrm{CD}{ }^{31,32}$ Also some endoscopic (e.g. extent of mucosal lesions), histopathological (e.g. presence of epithelioid granulomas), serological (e.g. ASCA, anti-OmpC, anti-CBir1, pANCA) and genetic markers (e.g. NOD2/CARD15-mutations) for a severe IBD disease course have been identified, though the level of evidence is only moderate and their predictive value remains limited. ${ }^{30}$ 
Most of the variables currently used for stratification are derived from cohort studies in which severe disease was solely defined by drug exposure, need for hospitalization or surgery, and disease progression. ${ }^{17,18}$ However, most of these outcomes heavily depend on local treatment strategies and recommendations in guidelines. For example, Beaugerie et al. performed a large retrospective study in which $C D$ patients were classified as 'disabling disease' when they were treated with more than two courses of steroids, required hospitalization, needed immunomodulators, or needed surgery. ${ }^{33}$ In that study, the prevalence of disabling disease was $64.9-80.5 \%$ (1985-1999). In our IBD South Limburg (IBDSL) cohort, during the most recent era (patients diagnosed between 2006 until 2011), 70.8\% of the CD patients would be classified as having a disabling disease, merely based on the exposure to immunomodulators using this definition, while this would be only $30.6 \%$ in the first era (1991 until 1998). ${ }^{29}$ This underlines the time-dependency of certain outcomes and the complexity of defining disease severity in IBD.

In order to achieve the ambitious goal of tailored medicine, identification of better markers for patient stratification is pivotal. Many prominent research groups have therefore stressed the need for better patient phenotyping and new disease severity classifications. $^{34}$ Since disease flares (i.e. exacerbations of luminal inflammation) precede unfavourable outcomes, ${ }^{35}$ analysing long-term disease activity patterns in large cohorts may be used for improved disease course description, but until now only a limited number of studies have analysed population-based relapse rates and even fewer studies defined distinctive disease activity patterns. ${ }^{17,36-41}$

\section{Current challenges in disease course modification}

Besides better stratification of patients at diagnosis, disease course may be modified by controlling mucosal inflammation afterwards. During the past years, mucosal healing has become the primary treatment goal in both CD and UC since this is associated with long-term clinical remission and a lower risk of hospitalisations and surgery. ${ }^{35,42}$ More aggressive treatment using biologics and/or a combination of drugs (i.e. top-down approach instead of step-up approach) has been advocated to achieve this goal and has been associated with improved disease outcome. ${ }^{43,44}$ While selecting patients for these aggressive and potentially harmful treatment regimens remains challenging due to the difficulties in patient stratification, treatment duration and strategies for de-escalation are far from clear as well. ${ }^{45}$ Once remission is achieved and/or treatment is deescalated, prevention of disease flares is essential to improve long-term outcome and was therefore subject to many studies already.

Although clinical risk factors may help in the selection of patients who are at risk for flares or a severe disease course, modifiable risk factors might be interesting targets to maintain remission. Genome-wide association studies and studies on twin concordance, spatial distribution within countries, and altering incidences in 
immigrants have indicated that environmental factors are associated with the development of IBD. ${ }^{7,46-50}$ Meta-analyses so far confirmed many associations for factors related to lifestyles and hygiene, drug exposures, surgeries, microorganisms, vaccinations, and diet, although it is unclear whether these are truly causative factors. ${ }^{9}$ Moreover, to what extent environmental factors contribute to the disease course is still far from clear, since only smoking has consistently been associated with the natural history of IBD, remarkably with an opposed effect in UC (associated with an indolent disease course) and CD (associated with a more complicated disease course).$^{31,32,51-53}$ Other environmental factors with contradicting results considering disease course encompass concomitant use of drugs (e.g. NSAIDs, contraceptives and antibiotics), psychosocial status (e.g. anxiety, depression and perceived stress), lifestyle (e.g. diet and exercise), air pollution, traveling, and socio-economic status. ${ }^{51,54}$ Although mechanisms underlying flare triggering can be postulated for every factor independently, many include a disturbance of the gut microbiome and/or gut permeability. These can be either direct effects of environmental factors (e.g. smoking) as well as indirect immunomodulatory effects through multiple immuneneuroendocrine and/or brain-gut interaction pathways (e.g. psychosocial status). ${ }^{51,54-56}$

It should be noted that a lot of the published studies comprise methodological limitations that complicate interpretation of results. Most importantly, associations are often found in cross-sectional studies in which possible bidirectional effects are neglected. Besides that, sample sizes are mostly small and limit statistical power. Finally, many studies only use a single outcome measure to define disease course or use clinical disease activity indices to define flares, whereas these are poor predictors of mucosal inflammation. ${ }^{57}$ The overall scarcity of methodologically solid studies and the potential of some environmental factors to become targets for intervention underline the need for further evaluation of this subject in large, longitudinal studies.

\section{The complex risk-benefit balance of IBD treatment}

Although a broad spectrum of drugs is available and general treatment strategies have been adapted over time, a considerable number of patients fail to achieve clinical remission or experience loss of treatment response or recurrent disease flares. ${ }^{43}$ Moreover, some patients may achieve clinical remission without complete disappearance of mucosal inflammation. ${ }^{35,58}$ Untreated inflammation may lead to serious complications such as the development of fistulas and strictures in CD and the need for colectomy in UC. ${ }^{5,6}$ Also malnutrition, psychosocial disorders, and work loss can be considered as a consequence of untreated disease activity. ${ }^{22,59,60}$ Moreover, many studies have linked chronic inflammation to carcinogenesis. ${ }^{61}$ Therefore, a big concern in IBD patients is the development of colorectal cancer (CRC), especially in patients with refractory disease activity, ${ }^{62}$ with the first associations being described in $1925 .^{63}$ Despite this longstanding association, guidelines for CRC surveillance were not 
available until $2002 .{ }^{64}$ Over the past decades, the incidence of CRC in patients with IBD appears to decrease in many countries, probably due to improved treatment strategies and the implementation of the surveillance programs. ${ }^{65-67}$ Although some populationbased studies indicate that the general CRC risk in IBD patients is not even increased anymore, subgroups of patients (e.g. CD patients with colonic involvement) may remain at increased risk for developing CRC. ${ }^{65,66,68-70}$ Since treatment strategies are constantly evolving and new treatment options became available, treatment effects on the CRC risks are important to consider but often not analysed in available studies. Also, special attention should be paid to potentially preventable postcolonoscopy CRCs (PCCRCs) which develop by definition within 6 to 60 months after a full colonoscopy that was negative for CRC. Although it is known that PCCRC rates are higher in IBD patients compared to the general population found, ${ }^{71-73}$ data on PCCRC incidence from population-based cohorts are scarce. ${ }^{73-75}$ CRC risk in general and PCCRC risk in particular should be further analysed in large population-based cohorts to gain insight into current risks, medication effects, and the effectiveness of surveillance programs.

The overt way to prevent aforementioned complications of longstanding mucosal inflammation, is aggressive treatment. As stated before, current guidelines advocate the use of top-down strategies in selected patient groups to eventually achieve and maintain endoscopic healing. ${ }^{35,43,76}$ Despite the efficacy of these therapies, many drugs are associated with toxic side effects and (opportunistic) infections. ${ }^{77,78}$ Moreover, extra-intestinal cancer risks are increased in IBD patients and have been linked to use of immunosuppressive drugs as well. ${ }^{79-81}$ However, large population-based studies on the risk for extra-intestinal cancer subtypes are scarce and often do not stratify risks according to IBD phenotype and medication. To reliably establish cancer risks in an era of major changes in IBD management, population-based cancer risk updates are required in settings detailed enough to study these associations.

\section{Aims and outline of the thesis}

IBD is a heterogeneous disease with a complex aetiology and a major impact on a patient's quality of life. The societal and economic burden is increasing and new treatment strategies have been introduced to clamp down this trend. Though, the complexity of patient stratification at diagnosis and the unpredictability of IBD's disease course remain a major challenge for gastroenterologists worldwide, who struggle with risk-benefit balances in their attempts towards personalized medicine. In this thesis, several epidemiological aspects of the disease course of IBD are being explored to find new insights and eventually contribute to the improvement of tailored medicine.

In the first part (Chapter 2), longitudinal data of the well-characterized populationbased IBDSL cohort ${ }^{82}$ are used to study disease course by disease activity patterns in a 
real-life Crohn's disease population to allow improvements in patient phenotyping. Additionally, clinical characteristics are evaluated for their predictive value of discriminating between both mild and severe disease courses.

In an attempt to improve disease course, we looked further into modifiable risk factors for IBD flares. Since smoking has the strongest association with disease course so far, ambient air pollution, which is a source of airborne toxins and an emerging problem worldwide, ${ }^{83}$ is assessed as a risk factor for a severe CD disease course in Chapter 3. Since conflicting and mostly low-quality evidence exists in the field of psychosocial status and flares, we also analyse several psychosocial risk factors in a prospective cohort using the telemedicine tool MylBDcoach ${ }^{84}$ (Chapter 4). Malnutrition is frequently encountered in IBD patients and has been linked to disease severity and diminished quality of life, while the prospective association with flares is unclear and is therefore studied in Chapter 5.

During the past decades, a shift towards more aggressive medical interventions is observed to prevent complications of longstanding inflammation such as colorectal carcinoma. On the other hand, this may have caused a possible increase in side effects, including drug-induced cancer. We assess the overall and site-specific cancer risk and its relation to therapy in Chapter 6 and zoom in on preventable postcolonoscopy CRCS in Chapter 7. Finally, in Chapter 8, the findings of this thesis are discussed and implications for current clinical practice and future research will be addressed. 


\section{References}

1. Mulder DJ, Noble AJ, Justinich CJ, Duffin JM. A tale of two diseases: the history of inflammatory bowel disease. J Crohns Colitis. 2014;8(5):341-8.

2. Wilks S. Morbid appearances in the intestines of Miss Bankes. Lond Med Gaz. 1859;2:264-5.

3. Crohn BB, Ginzburg L, Oppenheimer GD. Regional ileitis: a pathologic and clinical entity. JAMA. 1932;99:1323-9.

4. Lockhart-Mummery HE, Morson BC. Crohn's disease (regional enteritis) of the large intestine and its distinction from ulcerative colitis. Gut. 1960;1:87-105.

5. Feuerstein JD, Moss AC, Farraye FA. Ulcerative Colitis. Mayo Clinic proceedings. 2019;94(7):1357-73.

6. Roda G, Chien Ng S, Kotze PG, Argollo M, Panaccione R, Spinelli A, et al. Crohn's disease. Nat Rev Dis Primers. 2020;6(1):22.

7. Jostins L, Ripke S, Weersma RK, Duerr RH, McGovern DP, Hui KY, et al. Host-microbe interactions have shaped the genetic architecture of inflammatory bowel disease. Nature. 2012;491(7422):119-24.

8. Ramos GP, Papadakis KA. Mechanisms of Disease: Inflammatory Bowel Diseases. Mayo Clin Proc. 2019;94(1):155-65.

9. Piovani D, Danese S, Peyrin-Biroulet L, Nikolopoulos GK, Lytras T, Bonovas S. Environmental Risk Factors for Inflammatory Bowel Diseases: An Umbrella Review of Meta-analyses. Gastroenterology. 2019; 157(3):647-59 e4.

10. Clooney AG, Eckenberger J, Laserna-Mendieta E, Sexton KA, Bernstein MT, Vagianos K, et al. Ranking microbiome variance in inflammatory bowel disease: a large longitudinal intercontinental study. Gut. 2021;70(3):499-510.

11. Bouma $G$, Strober $W$. The immunological and genetic basis of inflammatory bowel disease. Nat Rev Immunol. 2003;3(7):521-33.

12. Vavricka SR, Brun L, Ballabeni P, Pittet V, Prinz Vavricka BM, Zeitz J, et al. Frequency and risk factors for extraintestinal manifestations in the Swiss inflammatory bowel disease cohort. Am J Gastroenterol. 2011;106(1):110-9.

13. Lamb CA, Kennedy NA, Raine T, Hendy PA, Smith PJ, Limdi JK, et al. British Society of Gastroenterology consensus guidelines on the management of inflammatory bowel disease in adults. Gut. 2019;68(Suppl 3):s1-s106.

14. Romberg-Camps MJ, Dagnelie PC, Kester AD, Hesselink-van de Kruijs MA, Cilissen M, Engels LG, et al. Influence of phenotype at diagnosis and of other potential prognostic factors on the course of inflammatory bowel disease. Am J Gastroenterol. 2009;104(2):371-83.

15. Henriksen M, Jahnsen J, Lygren I, Sauar J, Schulz T, Stray N, et al. Change of diagnosis during the first five years after onset of inflammatory bowel disease: results of a prospective follow-up study (the IBSEN Study). Scand J Gastroenterol. 2006;41(9):1037-43.

16. Satsangi J, Silverberg MS, Vermeire S, Colombel JF. The Montreal classification of inflammatory bowel disease: controversies, consensus, and implications. Gut. 2006;55(6):749-53.

17. Peyrin-Biroulet L, Loftus EV, Jr., Colombel JF, Sandborn WJ. The natural history of adult Crohn's disease in population-based cohorts. Am J Gastroenterol. 2010;105(2):289-97.

18. Fumery M, Singh S, Dulai PS, Gower-Rousseau C, Peyrin-Biroulet L, Sandborn WJ. Natural History of Adult Ulcerative Colitis in Population-based Cohorts: A Systematic Review. Clin Gastroenterol Hepatol. 2018;16(3):343-56 e3.

19. Molodecky NA, Soon IS, Rabi DM, Ghali WA, Ferris M, Chernoff G, et al. Increasing incidence and prevalence of the inflammatory bowel diseases with time, based on systematic review. Gastroenterology. 2012;142(1):46-54 e42; quiz e30.

20. Ng SC, Shi HY, Hamidi N, Underwood FE, Tang W, Benchimol El, et al. Worldwide incidence and prevalence of inflammatory bowel disease in the 21st century: a systematic review of population-based studies. Lancet. 2018;390(10114):2769-78. 
21. van den Heuvel TRA, Jeuring SFG, Zeegers MP, van Dongen DHE, Wolters A, Masclee AAM, et al. A 20Year Temporal Change Analysis in Incidence, Presenting Phenotype and Mortality, in the Dutch IBDSL Cohort-Can Diagnostic Factors Explain the Increase in IBD Incidence? J Crohns Colitis. 2017;11(10):1169-79.

22. van der Valk ME, Mangen MJ, Leenders M, Dijkstra G, van Bodegraven AA, Fidder HH, et al. Healthcare costs of inflammatory bowel disease have shifted from hospitalisation and surgery towards antiTNFalpha therapy: results from the COIN study. Gut. 2014;63(1):72-9.

23. Targownik LE, Kaplan GG, Witt J, Bernstein CN, Singh H, Tennakoon A, et al. Longitudinal Trends in the Direct Costs and Health Care Utilization Ascribable to Inflammatory Bowel Disease in the Biologic Era: Results From a Canadian Population-Based Analysis. Am J Gastroenterol. 2020;115(1):128-37.

24. Peery AF, Crockett SD, Murphy CC, Lund JL, Dellon ES, Williams JL, et al. Burden and Cost of Gastrointestinal, Liver, and Pancreatic Diseases in the United States: Update 2018. Gastroenterology. 2019;156(1):254-72 e11.

25. Burisch J, Vardi H, Schwartz D, Friger M, Kiudelis G, Kupcinskas J, et al. Health-care costs of inflammatory bowel disease in a pan-European, community-based, inception cohort during 5 years of follow-up: a population-based study. Lancet Gastroenterol Hepatol. 2020;5(5):454-64.

26. Hoivik ML, Bernklev T, Solberg IC, Cvancarova M, Lygren I, Jahnsen J, et al. Patients with Crohn's disease experience reduced general health and vitality in the chronic stage: ten-year results from the IBSEN study. J Crohns Colitis. 2012;6(4):441-53.

27. Jeuring SFG, Biemans VBC, van den Heuvel TRA, Zeegers MP, Hameeteman WH, Romberg-Camps MJL, et al. Corticosteroid Sparing in Inflammatory Bowel Disease is More Often Achieved in the Immunomodulator and Biological Era-Results from the Dutch Population-Based IBDSL Cohort. Am J Gastroenterol. 2018;113(3):384-95.

28. Jeuring SF, Bours PH, Zeegers MP, Ambergen TW, van den Heuvel TR, Romberg-Camps MJ, et al. Disease Outcome of Ulcerative Colitis in an Era of Changing Treatment Strategies: Results from the Dutch Population-Based IBDSL Cohort. J Crohns Colitis. 2015;9(10):837-45.

29. Jeuring SF, van den Heuvel TR, Liu LY, Zeegers MP, Hameeteman WH, Romberg-Camps MJ, et al. Improvements in the Long-Term Outcome of Crohn's Disease Over the Past Two Decades and the Relation to Changes in Medical Management: Results from the Population-Based IBDSL Cohort. Am J Gastroenterol. 2017;112(2):325-36.

30. Yarur AJ, Strobel SG, Deshpande AR, Abreu MT. Predictors of aggressive inflammatory bowel disease. Gastroenterol Hepatol (N Y). 2011;7(10):652-9.

31. Wanderas $\mathrm{MH}$, Moum BA, Hoivik ML, Hovde O. Predictive factors for a severe clinical course in ulcerative colitis: Results from population-based studies. World J Gastrointest Pharmacol Ther. 2016;7(2):235-41.

32. Veloso FT. Clinical predictors of Crohn's disease course. Eur J Gastroenterol Hepatol. 2016;28(10):11225.

33. Beaugerie L, Seksik P, Nion-Larmurier I, Gendre JP, Cosnes J. Predictors of Crohn's disease. Gastroenterology. 2006;130(3):650-6.

34. Peyrin-Biroulet L, Panes J, Sandborn WJ, Vermeire S, Danese S, Feagan BG, et al. Defining Disease Severity in Inflammatory Bowel Diseases: Current and Future Directions. Clin Gastroenterol Hepatol. 2016;14(3):348-54 e17.

35. Klenske E, Bojarski C, Waldner M, Rath T, Neurath MF, Atreya R. Targeting mucosal healing in Crohn's disease: what the clinician needs to know. Therap Adv Gastroenterol. 2019;12:1756284819856865.

36. Jess T, Riis L, Vind I, Winther KV, Borg S, Binder V, et al. Changes in clinical characteristics, course, and prognosis of inflammatory bowel disease during the last 5 decades: a population-based study from Copenhagen, Denmark. Inflamm Bowel Dis. 2007;13(4):481-9.

37. Gollop JH, Phillips SF, Melton LJ, 3rd, Zinsmeister AR. Epidemiologic aspects of Crohn's disease: a population based study in Olmsted County, Minnesota, 1943-1982. Gut. 1988;29(1):49-56.

38. Solberg IC, Vatn MH, Hoie O, Stray N, Sauar J, Jahnsen J, et al. Clinical course in Crohn's disease: results of a Norwegian population-based ten-year follow-up study. Clin Gastroenterol Hepatol. 2007;5(12):1430-8. 
39. Romberg-Camps MJ, Hesselink-van de Kruijs MA, Schouten LJ, Dagnelie PC, Limonard CB, Kester AD, et al. Inflammatory Bowel Disease in South Limburg (the Netherlands) 1991-2002: Incidence, diagnostic delay, and seasonal variations in onset of symptoms. J Crohns Colitis. 2009;3(2):115-24.

40. Hoie O, Wolters F, Riis L, Aamodt G, Solberg C, Bernklev T, et al. Ulcerative colitis: patient characteristics may predict 10-yr disease recurrence in a European-wide population-based cohort. Am J Gastroenterol. 2007;102(8):1692-701.

41. Solberg IC, Lygren I, Jahnsen J, Aadland E, Hoie O, Cvancarova M, et al. Clinical course during the first 10 years of ulcerative colitis: results from a population-based inception cohort (IBSEN Study). Scand J Gastroenterol. 2009;44(4):431-40.

42. Shah SC, Colombel JF, Sands BE, Narula N. Mucosal Healing Is Associated With Improved Long-term Outcomes of Patients With Ulcerative Colitis: A Systematic Review and Meta-analysis. Clin Gastroenterol Hepatol. 2016;14(9):1245-55 e8.

43. Torres J, Bonovas S, Doherty G, Kucharzik T, Gisbert JP, Raine T, et al. ECCO Guidelines on Therapeutics in Crohn's Disease: Medical Treatment. J Crohns Colitis. 2020;14(1):4-22.

44. Harbord M, Eliakim R, Bettenworth D, Karmiris K, Katsanos K, Kopylov U, et al. Third European Evidence-based Consensus on Diagnosis and Management of Ulcerative Colitis. Part 2: Current Management. J Crohns Colitis. 2017;11(7):769-84.

45. Doherty G, Katsanos KH, Burisch J, Allez M, Papamichael K, Stallmach A, et al. European Crohn's and Colitis Organisation Topical Review on Treatment Withdrawal ['Exit Strategies'] in Inflammatory Bowel Disease. J Crohns Colitis. 2018;12(1):17-31.

46. Halfvarson J, Bodin L, Tysk C, Lindberg E, Jarnerot G. Inflammatory bowel disease in a Swedish twin cohort: a long-term follow-up of concordance and clinical characteristics. Gastroenterology. 2003;124(7):1767-73.

47. Orholm M, Binder V, Sorensen TI, Rasmussen LP, Kyvik KO. Concordance of inflammatory bowel disease among Danish twins. Results of a nationwide study. Scand J Gastroenterol. 2000;35(10):1075-81.

48. Burisch J, Pedersen N, Cukovic-Cavka S, Brinar M, Kaimakliotis I, Duricova D, et al. East-West gradient in the incidence of inflammatory bowel disease in Europe: the ECCO-EpiCom inception cohort. Gut. 2014;63(4):588-97.

49. Shivananda S, Lennard-Jones J, Logan R, Fear N, Price A, Carpenter L, et al. Incidence of inflammatory bowel disease across Europe: is there a difference between north and south? Results of the European Collaborative Study on Inflammatory Bowel Disease (EC-IBD). Gut. 1996;39(5):690-7.

50. Barreiro-de Acosta M, Alvarez Castro A, Souto R, Iglesias M, Lorenzo A, Dominguez-Munoz JE. Emigration to western industrialized countries: A risk factor for developing inflammatory bowel disease. J Crohns Colitis. 2011;5(6):566-9.

51. Maaser C, Langholz E, Gordon H, Burisch J, Ellul P, Ramirez VH, et al. European Crohn's and Colitis Organisation Topical Review on Environmental Factors in IBD. J Crohns Colitis. 2017;11(8):905-20.

52. Mahid SS, Minor KS, Soto RE, Hornung CA, Galandiuk S. Smoking and inflammatory bowel disease: a meta-analysis. Mayo Clin Proc. 2006;81(11):1462-71.

53. To N, Gracie DJ, Ford AC. Systematic review with meta-analysis: the adverse effects of tobacco smoking on the natural history of Crohn's disease. Aliment Pharmacol Ther. 2016;43(5):549-61.

54. Singh S, Graff LA, Bernstein CN. Do NSAIDs, antibiotics, infections, or stress trigger flares in IBD? Am J Gastroenterol. 2009;104(5):1298-313; quiz 314.

55. Bonaz BL, Bernstein CN. Brain-gut interactions in inflammatory bowel disease. Gastroenterology. 2013;144(1):36-49.

56. Martin-Subero M, Anderson G, Kanchanatawan B, Berk M, Maes M. Comorbidity between depression and inflammatory bowel disease explained by immune-inflammatory, oxidative, and nitrosative stress; tryptophan catabolite; and gut-brain pathways. CNS Spectr. 2016;21(2):184-98.

57. Gracie DJ, Williams CJ, Sood R, Mumtaz S, Bholah MH, Hamlin PJ, et al. Poor Correlation Between Clinical Disease Activity and Mucosal Inflammation, and the Role of Psychological Comorbidity, in Inflammatory Bowel Disease. Am J Gastroenterol. 2016;111(4):541-51.

58. Maaser C, Sturm A, Vavricka SR, Kucharzik T, Fiorino G, Annese V, et al. ECCO-ESGAR Guideline for Diagnostic Assessment in IBD Part 1: Initial diagnosis, monitoring of known IBD, detection of complications. J Crohns Colitis. 2019;13(2):144-64. 
59. Casanova MJ, Chaparro M, Molina B, Merino O, Batanero R, Duenas-Sadornil C, et al. Prevalence of Malnutrition and Nutritional Characteristics of Patients With Inflammatory Bowel Disease. J Crohns Colitis. 2017;11(12):1430-9.

60. Neuendorf R, Harding A, Stello N, Hanes D, Wahbeh H. Depression and anxiety in patients with Inflammatory Bowel Disease: A systematic review. J Psychosom Res. 2016;87:70-80.

61. Elinav E, Nowarski R, Thaiss CA, Hu B, Jin C, Flavell RA. Inflammation-induced cancer: crosstalk between tumours, immune cells and microorganisms. Nat Rev Cancer. 2013;13(11):759-71.

62. Flores BM, O'Connor A, Moss AC. Impact of mucosal inflammation on risk of colorectal neoplasia in patients with ulcerative colitis: a systematic review and meta-analysis. Gastrointest Endosc. 2017;86(6):1006-11 e8.

63. Crohn BB, Rosenberg $\mathrm{H}$. The sigmoidoscopic picture of chronic ulcerative colitis. Am J Med Sci. 1925;170:220-8.

64. Eaden JA, Mayberry JF, British Society for G, Association of Coloproctology for Great B, Ireland. Guidelines for screening and surveillance of asymptomatic colorectal cancer in patients with inflammatory bowel disease. Gut. 2002;51 Suppl 5:V10-2.

65. Lutgens MW, van Oijen MG, van der Heijden GJ, Vleggaar FP, Siersema PD, Oldenburg B. Declining risk of colorectal cancer in inflammatory bowel disease: an updated meta-analysis of population-based cohort studies. Inflamm Bowel Dis. 2013;19(4):789-99.

66. Castano-Milla C, Chaparro M, Gisbert JP. Systematic review with meta-analysis: the declining risk of colorectal cancer in ulcerative colitis. Aliment Pharmacol Ther. 2014;39(7):645-59.

67. Andersen NN, Jess T. Has the risk of colorectal cancer in inflammatory bowel disease decreased? World J Gastroenterol. 2013;19(43):7561-8.

68. Jess T, Gamborg M, Matzen P, Munkholm P, Sorensen TI. Increased risk of intestinal cancer in Crohn's disease: a meta-analysis of population-based cohort studies. Am J Gastroenterol. 2005;100(12): 2724-9.

69. Jess T, Rungoe C, Peyrin-Biroulet L. Risk of colorectal cancer in patients with ulcerative colitis: a metaanalysis of population-based cohort studies. Clin Gastroenterol Hepatol. 2012;10(6):639-45.

70. Jess T, Horvath-Puho E, Fallingborg J, Rasmussen HH, Jacobsen BA. Cancer risk in inflammatory bowel disease according to patient phenotype and treatment: a Danish population-based cohort study. Am J Gastroenterol. 2013;108(12):1869-76.

71. Singh S, Singh PP, Murad MH, Singh H, Samadder NJ. Prevalence, risk factors, and outcomes of interval colorectal cancers: a systematic review and meta-analysis. Am J Gastroenterol. 2014;109(9):1375-89.

72. le Clercq CM, Bouwens MW, Rondagh EJ, Bakker CM, Keulen ET, de Ridder RJ, et al. Postcolonoscopy colorectal cancers are preventable: a population-based study. Gut. 2014;63(6):957-63.

73. Wang YR, Cangemi JR, Loftus EV, Jr., Picco MF. Rate of early/missed colorectal cancers after colonoscopy in older patients with or without inflammatory bowel disease in the United States. Am J Gastroenterol. 2013;108(3):444-9.

74. Choi CH, Rutter MD, Askari A, Lee GH, Warusavitarne J, Moorghen M, et al. Forty-Year Analysis of Colonoscopic Surveillance Program for Neoplasia in Ulcerative Colitis: An Updated Overview. Am J Gastroenterol. 2015;110(7):1022-34.

75. Mooiweer E, van der Meulen-de Jong AE, Ponsioen CY, van der Woude CJ, van Bodegraven AA, Jansen $\mathrm{JM}$, et al. Incidence of Interval Colorectal Cancer Among Inflammatory Bowel Disease Patients Undergoing Regular Colonoscopic Surveillance. Clin Gastroenterol Hepatol. 2015;13(9):1656-61.

76. Rubin DT, Ananthakrishnan AN, Siegel CA, Sauer BG, Long MD. ACG Clinical Guideline: Ulcerative Colitis in Adults. Am J Gastroenterol. 2019;114(3):384-413.

77. Goldberg R, Irving PM. Toxicity and response to thiopurines in patients with inflammatory bowel disease. Expert Rev Gastroenterol Hepatol. 2015;9(7):891-900.

78. Cohen BL, Sachar DB. Update on anti-tumor necrosis factor agents and other new drugs for inflammatory bowel disease. BMJ. 2017;357:j2505.

79. Kappelman MD, Farkas DK, Long MD, Erichsen R, Sandler RS, Sorensen HT, et al. Risk of cancer in patients with inflammatory bowel diseases: a nationwide population-based cohort study with 30 years of follow-up evaluation. Clin Gastroenterol Hepatol. 2014;12(2):265-73 e1. 
80. Pedersen N, Duricova D, Elkjaer M, Gamborg M, Munkholm P, Jess T. Risk of extra-intestinal cancer in inflammatory bowel disease: meta-analysis of population-based cohort studies. Am J Gastroenterol. 2010;105(7):1480-7.

81. Mason M, Siegel CA. Do inflammatory bowel disease therapies cause cancer? Inflamm Bowel Dis. 2013;19(6):1306-21.

82. van den Heuvel TR, Jonkers DM, Jeuring SF, Romberg-Camps MJ, Oostenbrug LE, Zeegers MP, et al. Cohort Profile: The Inflammatory Bowel Disease South Limburg Cohort (IBDSL). Int J Epidemiol. 2017;46(2):e7.

83. WHO. Ambient air pollution: a global assessment of exposure and burden of disease. 2016.

84. de Jong MJ, van der Meulen-de Jong AE, Romberg-Camps MJ, Becx MC, Maljaars JP, Cilissen M, et al. Telemedicine for management of inflammatory bowel disease (mylBDcoach): a pragmatic, multicentre, randomised controlled trial. Lancet. 2017;390(10098):959-68. 


$$
20
$$




\section{Part I}

Disease activity in a real-world IBD population

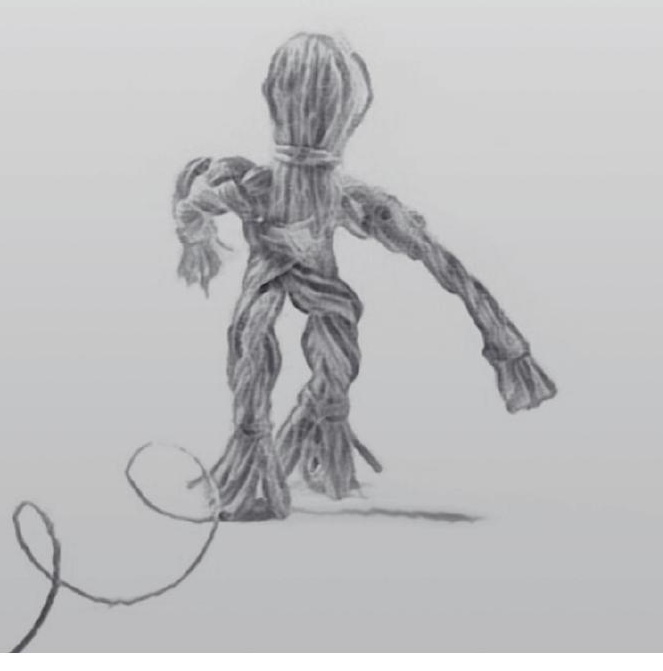




$$
20
$$




\section{Chapter 2}

Disease activity patterns of Crohn's disease in the first $\mathbf{1 0}$ years after diagnosis in the population-based IBD South Limburg cohort

Dion S.J. Wintjens, Francois Bergey, Edoardo Saccenti, Steven F.G. Jeuring, Tim R.A. van den Heuvel, Mariëlle J.L. Romberg-Camps, Liekele E. Oostenbrug, Ad A.M. Masclee, Vitor Martins dos Santos, Daisy M.A.E. Jonkers, Marie J. Pierik J Crohns Colitis 2020;15(3):391-400. 


\begin{abstract}
Background

Real-life data on long-term disease activity in Crohn's disease (CD) are scarce. Most studies describe disease course by using proxies, such as drug exposure, need for surgery or hospitalisations, and disease progression. We aimed to describe disease course by long-term disease activity and to identify distinctive disease activity patterns in the population-based IBD South Limburg cohort (IBDSL).
\end{abstract}

\title{
Methods
}

All CD patients in IBDSL with $\geq 10$ years follow-up $(n=432)$ were included. Disease activity was defined for each yearly quarter by mucosal inflammation on endoscopy or imaging, hospitalisation, surgery or treatment adjustment for increased symptoms. Six distinct disease activity clusters were defined. Subsequently, the association between clinical characteristics and the patterns were assessed using multivariable logistic regression models.

\section{Results}

On average, patients experienced 5.44 (SD 3.96) quarters of disease activity during the first 10 years after diagnosis. Notably, $28.2 \%$ of the patients were classified to a quiescent pattern ( $\leq 2$ active quarters in 10 years), and $89.8 \%$ of those never received immunomodulators nor biologics. Surgery at diagnosis (OR 2.99; 95\%-Cl 1.07-8.34) and higher age (OR 1.03; $95 \% \mathrm{Cl} 1.01-1.06)$ were positively associated with the quiescent pattern, whereas inverse associations were observed for ileocolonic location (OR 0.44; $95 \% \mathrm{Cl} 0.19-1.00)$, smoking (OR $0.43 ; 95 \% \mathrm{Cl} 0.24-0.76)$ and need for steroids $<6$ months (OR $0.24 ; 95 \% \mathrm{Cl} 0.11-0.52$ ).

\section{Conclusions}

Considering long-term disease activity, $28.2 \%$ of CD patients were classified to a quiescent cluster. Given the complex risk-benefit balance of immunosuppressive drugs, our findings underline the importance of identifying better predictive markers to prevent both overtreatment and undertreatment. 


\section{Introduction}

Crohn's disease $(C D)$ is a chronic inflammatory disease characterised by intermittent periods of mucosal inflammation. Ongoing disease activity and recurrent flares predispose to structural bowel damage and an unfortunate disease outcome. Novel treatment options, strategies and goals have been introduced in order to improve the long-term disease outcome. Previously, we showed, in line with other population-based studies, that the exposure of patients to immunomodulators and biologics increased significantly over recent decades. ${ }^{1}$ Despite their efficacy, these drugs are associated with toxic side effects, (opportunistic) infections and malignancies. ${ }^{2-4}$ Due to the complex risk-benefit balance of immunosuppressive drugs, there is an increasing need to distinguish patients at risk for an unfavourable outcome from patients who are prone to a more quiescent course in order to prevent both undertreatment and overtreatment, respectively. ${ }^{5}$

In most cohorts, the severity of the disease course in $C D$ is described by drug exposure, hospitalisation, surgery, and disease progression. ${ }^{6}$ However, most of these outcomes heavily depend on local treatment strategies and recommendations in guidelines. For example, Beaugerie et al. performed a large retrospective study in which patients were classified as 'disabling disease' when they were treated with more than two courses of steroids, required hospitalisation, needed immunomodulators or needed surgery. ${ }^{7}$ In that study, the prevalence of disabling disease was $64.9-80.5 \%$ (1985-1999). In our IBD South Limburg (IBDSL) cohort, during the most recent era (2006 until 2011), $70.8 \%$ of the patients would be classified as having a disabling disease merely based on the exposure to immunomodulators, whereas this would be only $30.6 \%$ in the first era (1991 until 1998). ${ }^{8}$ This underlines the time-dependency of certain outcomes and the need for a new classification of CD disease course severity, better reflecting the actual varying disease activity.

Since chronically active bowel inflammation or frequent flares precede unfavourable outcomes, analysing long-term disease activity patterns in large cohorts may contribute to a better classification of patients. ${ }^{9}$ Until now, only a limited number of studies have analysed population-based relapse rates and even less studies defined distinctive disease activity patterns. ${ }^{6,10-13}$ Solberg et al. asked patients in the IBSEN cohort to assign themselves to one of four pre-defined disease activity patterns: decreasing disease activity over time, increasing disease activity over time, chronic continuous disease activity, or chronic intermittent disease activity. ${ }^{12}$ Irrespective of the clinical relevance of this information, the survey-based approach employed in that study is subject to recall bias and reflects only subjective disease activity rather than overall disease activity. Moreover, a pattern of 'quiescent disease' was missing, although being of added value, supported by older findings of Jess et al. showing that $18.4 \%$ of the patients experienced no flares during the first 5 years after diagnosis. ${ }^{10}$ 
In the present study, we aimed to describe CD disease course by long-term disease activity and to identify distinctive disease activity patterns in the IBDSL cohort. We also aimed to define early clinical predictors of the distinctive disease activity patterns.

\section{Materials and methods}

\section{Study design, data collection and patient involvement}

All CD patients included in the population-based IBDSL cohort were eligible for this study. This cohort was previously described in detail. ${ }^{14}$ In brief, all patients diagnosed with IBD between January 1991 and June 2011, being at least 18 years of age at diagnosis and living in the region of South Limburg were included. IBD was diagnosed by certified gastroenterologists based on the combination of endoscopic, radiological and/or histological findings. A multifaceted identification strategy including hospitals, the nationwide Dutch pathology database (PALGA) ${ }^{15}$ and general practitioners, resulted in $93 \%$ completeness of our cohort. The remaining $7 \%$ of patients may have had an IBD diagnosis without meeting the aforementioned IBDSL inclusion criteria, may have been misdiagnosed, or may have attended Belgian or German hospitals. As health care provided in these neighbouring countries is comparable to that in The Netherlands, it is unlikely that this is associated with a specific IBD phenotype. Altogether, the risk for selection bias is limited. The IBDSL study design has been approved by the Ethics Committee of the Maastricht University Medical Centre (NL31636.068.10), is registered in ClinicalTrial.gov (NCT02130349) and meets the ethical standards of the revised version of the Declaration of Helsinki. ${ }^{16}$

CD patients in the IBDSL cohort were followed as from the date of diagnosis to the end of data collection (i.e. October 2014) or to date of migration, death, or last outpatient clinic visit. For this study, only patients with a follow-up (FU) of at least 10 years were included (i.e. date of diagnosis between 1991 and 2005). Data on demographics, disease phenotype, complications (i.e. fistula or strictures), medication use, hospitalisations and surgery were collected from medical records using standardised case report forms. In addition, all endoscopy and imaging reports were analysed for disease activity.

\section{Definitions}

As from diagnosis, each yearly quarter was assessed for disease activity in all patients retrospectively using the obtained case report forms. Disease activity was defined by either i) active disease on endoscopy or imaging, ii) hospitalisation, iii) surgery or iv) treatment adjustment due to symptoms. i) Active disease on endoscopy or imaging comprised all reports in which the gastroenterologist or radiologist who performed the 
endoscopy or judged the imaging, respectively, considered lesions to be due to active CD. ii) Hospitalisations were only taken into account when patients were admitted for exacerbations of IBD. Elective admissions for endoscopy, drug administration, and surgery, and admissions due to side effects of medication use, were excluded. iii) Surgical procedures were taken into account when the indication for surgery was either active luminal disease, active internal fistula, stricturing complications or active perianal disease. Diagnostic procedures and procedures secondary to surgical complications were excluded. iv) Finally, a patient was considered as having disease activity when a treatment adjustment was made by the treating physician based on highly suggestive biochemical changes or symptoms alone. Changes solely due to trough levels or side effects were excluded. Also the prescription of 5-aminosalicyate (5-ASA) drugs was not taken into account, since the effectiveness of these drugs in CD is barely supported by evidence. ${ }^{17}$

Subsequently, patterns were defined partly based on the four previously published survey-based disease activity patterns by Solberg et al. ${ }^{12}$ All definitions were discussed in expert meetings with multiple gastroenterologists from both academic and nonacademic hospitals. The first pattern (Active to remission) was defined by $>2$ quarters of disease activity in first 5 years and $<2$ quarters of disease activity in second 5 years. The second pattern (Remission to active) was inversely defined by $<2$ quarters of disease activity in first 5 years and $>2$ quarters of disease activity in second 5 years. The third pattern (Chronic continuous) was defined by at least 1 quarter of disease activity per year in $\geq 8$ years. Supported by a rough, unsupervised pilot analysis, the 'Chronic intermittent' pattern of Solberg et al. was divided into a 'Mild-moderate' pattern ( $\leq 5$ quarters of disease activity) and 'Severe' intermittent pattern ( $>5$ quarters of disease activity, but not meeting the criteria of the 'Chronic continuous' pattern) and a quiescent pattern ( $\leq 2$ quarters of disease activity in total) was added. Patients who could not be classified using mathematical formulas were reviewed by two independent researchers and assigned to one of the patterns. In case of disagreement, final assignment was determined during another expert meeting. Eventually, graphs for each pattern were generated by plotting the percentage of patients with active disease per yearly quarter of follow-up (Figure 2.1).

\section{Statistics}

Baseline characteristics are presented as means with corresponding standard deviations (SD) for numerical variables and as number and percentage of patients (\%) for categorical variables. For comparison between groups, the independent-samples $t$-test, chi-square test or Fisher's exact test, where appropriate, were used for numerical and categorical variables, respectively.

A multivariable logistic regression model was used to analyse the association between baseline characteristics and the disease activity patterns. In order to increase 
sample size and power, the two most severe groups (i.e. 'Chronic continuous' and 'Moderate-severe chronic intermittent') were combined as the 'Most severe' pattern. We compared the 'Quiescent' pattern with the 'Most severe' pattern, the 'Quiescent' pattern with all other patterns, and the 'Most severe' pattern with all other patterns. The following baseline variables were included in the model: age, gender, smoking status, disease location, disease behaviour, perianal disease, and upper gastrointestinal involvement (according to the Montreal classification ${ }^{18}$ ), and need for surgery at diagnosis. The latter was defined as surgery within a week after diagnosis and includes acute abdominal surgery when this was attributed to CD after histological evaluation.

Next, we compared outcome variables after 6 months of follow-up between the same groups using multivariable logistic regression models adjusted for baseline variables with a p-value $<0.1$ and clinically relevant baseline variables (i.e. disease location and behaviour according to the Montreal classification ${ }^{18}$ ). The following outcome variables after 6 months of follow-up were included in the model: disease progression (Montreal B1 to B2/B3), need for surgery (baseline excluded), need for hospitalisation, need for systemic corticosteroids, need for immunomodulators, and need for biologics.

A partial least square discriminant analysis (PLS-DA) model was built to evaluate the predictive power of several subsets of variables in order to differentiate between the 'Quiescent', 'Most severe' and other patterns. In this model, the following three subsets of variables were tested: the Montreal classification alone (i.e. age, disease localization, disease behaviour, perianal disease, upper gastrointestinal involvement), all of the aforementioned baseline variables, and all baseline variables and outcome variables after 6 months. PLS models were double cross-validated for metaparameter estimation and to assess model reproducibility. In detail, the data was split in three parts: validation, training and test. The training and test data were used to calibrate the prediction model by optimising the metaparameters (i.e. the number of latent components) as described elsewhere. ${ }^{19}$ The validation data were used to determine the predictive power of the model in an unbiased fashion by predicting the class of samples that were not used to train the model. The overall procedure was repeated 10 times with different data split to assess variability and generalisability of the models and results (specificity, sensitivity and area under the receiver operating characteristic curve, AUROC) were averaged over the repetition. Finally a permutation test was applied to obtain a measure of statistical significance of the predictive models and to ascertain that the model was not overfitting the data as described elsewhere. ${ }^{20}$

In general, two-sided $p$-values $(p)$ lower than 0.05 were considered statistically significant. Statistical analyses were performed with SPSS (version 25.0, SPSS Inc., Chicago, IL, USA) to describe cohort characteristics. PLS-DA was performed in Matlab (version R2018a). Natick, MA, The MathWorks Inc.) using in-house written routines. 


\section{Results}

In the population-based IBDSL cohort, 626 patients were diagnosed with CD between January 1991 and January 2005. Of these, 11 patients (1.8\%) were lost to follow-up (LTFU) due to migration out of the region and 31 patients $(5.0 \%)$ were LTFU due to death. For the remaining patients, we decided to include only those with a completely documented follow-up (i.e. outpatient clinic visits exceeding 10 years of follow-up) in order to guarantee full documentation of disease activity. Since end of data collection for each individual patient was determined by the last outpatient clinic visit, patients who visit the hospital only once a year or less, could be considered LTFU in this calculation ( $n=152)$.

Baseline characteristics of both patients with a complete and patients with incomplete 10-year follow-up are presented in Table 2.1. Patients who died or migrated during follow-up were excluded from the table. In general, patients who were LTFU for other reasons were more recently diagnosed $(p<0.001)$ and less often had perianal disease at diagnosis $(p=0.026)$. On average, patients experienced 5.44 (SD 3.96) quarters of disease activity during the first 10 years after diagnosis.

The distribution of patients over the six disease activity patterns is presented in Figure 2.1. In summary, patients were classified to either the 'Active to remission' ( $n=110 ; 25.5 \%)$, 'Remission to active' ( $n=14 ; 3.2 \%)$, 'Chronic continuous' ( $n=25 ; 5.8 \%$ ), 'Moderate-severe chronic intermittent' $(n=120 ; 27.8 \%)$, 'Mild chronic intermittent' ( $n=41 ; 9.5 \%)$, and 'Quiescent' $(n=122 ; 28.2 \%)$ pattern. CD diagnosis was based on histopathological findings in $87.0 \%$ of the patients. Other baseline characteristics corresponding with all patterns are presented in Table 2.2. Of note, patients with the 'Quiescent' pattern were diagnosed most frequently in the first era (70.5\%). Group sizes are too small to analyse baseline characteristics in further detail. Disease outcome after 10 years of follow-up is presented in Table 2.3 for all patterns. Patients with a 'Quiescent' pattern experienced only 1.49 yearly quarters of disease activity. Disease progression from inflammatory to stricturing $(4.2 \%)$ or penetrating disease $(2.1 \%)$ in this group was rare. Notably, $89.8 \%$ of the patients with this pattern never received any immunomodulator or biologic. Also, even though the percentage of patients with surgery at diagnosis was the highest in patients with a 'Quiescent' pattern (23.8\%), the mean number of surgical procedures after 10 years of follow-up (0.21; SD 0.41) is the lowest of all groups. It can also be appreciated from Table 2.3 that the total number of colorectal carcinomas $(n=1)$ and extra-intestinal malignancies $(n=20)$ in all groups was low during the first 10 years of follow-up. 
Table 2.1 Baseline characteristics of CD patients diagnosed between 1991 and 2005 in the IBDSL cohort.

\begin{tabular}{|c|c|c|c|}
\hline & $\begin{array}{l}\text { Complete 10-year FU } \\
(n=432)\end{array}$ & LTFU (n=152) & $p$-value \\
\hline Age at diagnosis, mean (SD) & $34.1(13.6)$ & $37.0(16.1)$ & 0.051 \\
\hline Male, n (\%) & $153(35.4)$ & $62(40.8)$ & 0.242 \\
\hline Era of diagnosis, $\mathrm{n}(\%)$ & & & $<0.001$ \\
\hline 1991-1998 & $243(56.2)$ & $55(36.2)$ & \\
\hline $1999-2005$ & $189(43.8)$ & $97(63.8)$ & \\
\hline \multirow[t]{2}{*}{ Smoking at diagnosis, $\mathrm{n}(\%)$} & $219(55.6)$ & $58(47.2)$ & 0.120 \\
\hline & NA: $38(8.8)$ & NA: 29 (19.1) & \\
\hline Disease location at diagnosis*, n (\%) & & & $\begin{array}{c}0.005 \text { ( } 0.921 \text { if } L 4 \\
\text { excluded) }\end{array}$ \\
\hline L1 & $210(48.6)$ & $68(44.7)$ & \\
\hline L2 & $127(29.4)$ & $45(29.6)$ & \\
\hline L3 & $92(21.3)$ & $31(20.4)$ & \\
\hline L4 & $3(0.7)$ & $8(5.3)$ & \\
\hline $\begin{array}{l}\text { Concomitant upper GI disease at } \\
\text { diagnosis, } \mathrm{n}(\%)\end{array}$ & $39(9.0)$ & $14(9.2)$ & 1.000 \\
\hline Disease behaviour at diagnosis*, n (\%) & & & 0.965 \\
\hline B1 & $325(75.2)$ & $115(75.7)$ & \\
\hline B2 & $67(15.5)$ & $24(15.8)$ & \\
\hline B3 & $40(9.3)$ & $13(8.6)$ & \\
\hline Perianal disease at diagnosis, $\mathrm{n}(\%)$ & $43(10.0)$ & $6(3.9)$ & 0.026 \\
\hline
\end{tabular}

$\mathrm{N}$, number of patients / SD, standard deviation / NA, not available /*, phenotype according to Montreal Classification. Disease location of CD was defined as ileal involvement (L1), exclusive colonic involvement (L2), ileocolonic involvement (L3) or isolated upper gastrointestinal disease (L4). Disease behaviour of CD was defined as non-stricturing/non-penetrating (B1), stricturing (B2) or penetrating (B3). / GI, gastrointestinal. 

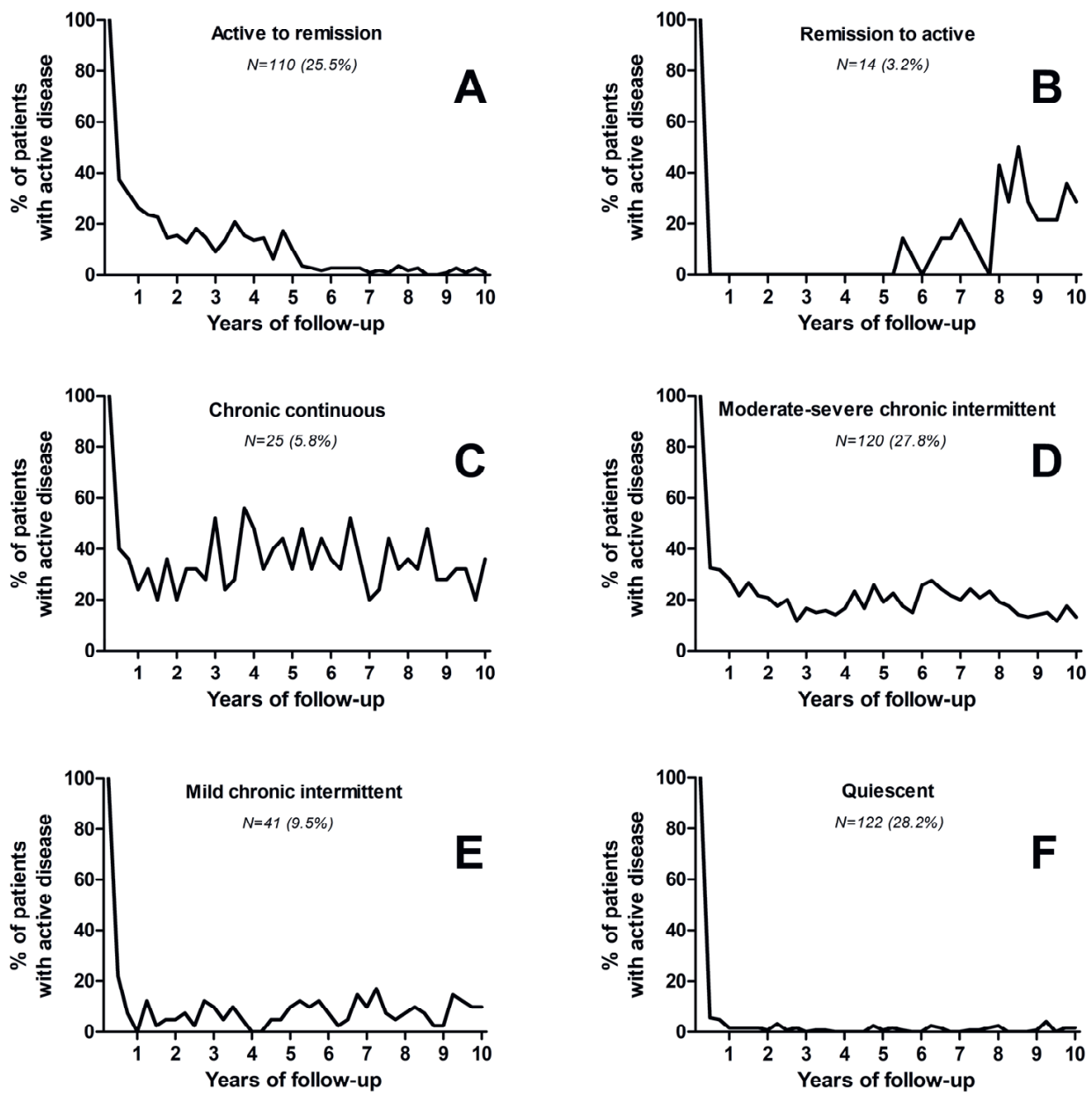

Figure 2.1 Distribution of CD patients over six disease activity patterns.

Definitions: A: $>2$ quarters of disease activity in first 5 years, $<2$ quarters of disease activity in second 5 years; $\mathrm{B}$ : $<2$ quarters of disease activity in first 5 years, $>2$ quarters of disease activity in second 5 years; C: At least 1 quarter of disease activity per year in $\geq 8$ years; D: Chronic intermittent pattern with $>5$ quarters of disease activity (but not fulfilling criteria of C); E: Chronic intermittent pattern with $\leq 5$ quarters of disease activity $F$ : $\leq 2$ quarters of disease activity in total. $\mathrm{N}$, number of patients. 
Table 2.2 Baseline characteristics of CD patients for each of the six patterns of disease activity.

\begin{tabular}{|c|c|c|c|c|c|c|}
\hline & $\begin{array}{l}\text { Active to } \\
\text { remission } \\
(n=110)\end{array}$ & $\begin{array}{c}\text { Remission } \\
\text { to active } \\
(n=14)\end{array}$ & $\begin{array}{c}\begin{array}{c}\text { Chronic } \\
\text { continuous }\end{array} \\
(n=25)\end{array}$ & $\begin{array}{c}\text { Moderate- } \\
\text { severe chronic } \\
\text { intermittent } \\
(n=120)\end{array}$ & $\begin{array}{l}\text { Mild chronic } \\
\text { intermittent } \\
\quad(n=41)\end{array}$ & Quiescent \\
\hline $\begin{array}{l}\text { Age at diagnosis, mean } \\
\text { (SD) }\end{array}$ & $34.5(13.7)$ & $32.5(8.6)$ & $29.0(12.3)$ & $30.8(11.3)$ & $35.8(15.0)$ & $37.6(14.9)$ \\
\hline Male, n (\%) & $38(34.5)$ & $10(71.4)$ & $9(36.0)$ & $37(30.8)$ & $13(31.7)$ & $46(37.7)$ \\
\hline \multicolumn{7}{|l|}{ Era of diagnosis, $\mathrm{n}(\%)$} \\
\hline 1991-1998 & $54(49.1)$ & $11(78.6)$ & $14(56.0)$ & $61(50.8)$ & $17(41.5)$ & $86(70.5)$ \\
\hline 1999-2005 & $56(50.9)$ & $3(21.4)$ & $11(44.0)$ & $59(49.2)$ & $24(58.5)$ & $36(29.5)$ \\
\hline Smoking at diagnosis, $\mathrm{n}$ & $60(54.5)$ & $9(64.3)$ & $15(60.0)$ & $73(60.8)$ & $19(46.3)$ & $43(35.2)$ \\
\hline (\%) & NA: $8(7.3)$ & NA: $0(0.0)$ & NA: $0(0.0)$ & NA: $7(5.8)$ & NA: $3(7.3)$ & NA: 20 (16.4) \\
\hline \multicolumn{7}{|l|}{$\begin{array}{l}\text { Disease location at } \\
\text { diagnosis*, n (\%) }\end{array}$} \\
\hline L1 & $46(41.8)$ & $10(71.4)$ & $12(48.0)$ & $46(38.7)$ & $21(51.2)$ & $75(61.5)$ \\
\hline L2 & 37 (33.6) & $1(7.1)$ & $8(32.0)$ & $35(29.4)$ & $14(34.1)$ & $32(26.2)$ \\
\hline L3 & $27(24.5)$ & $2(14.3)$ & $5(20.0)$ & $38(31.7)$ & $6(14.6)$ & $14(11.5)$ \\
\hline L4 & $0(0.0)$ & $1(7.1)$ & $0(0.0)$ & $1(0.8)$ & $0(0.0)$ & $1(0.8)$ \\
\hline $\begin{array}{l}\text { Concomitant upper } \mathrm{GI} \\
\text { disease at diagnosis, } \mathrm{n}(\%)\end{array}$ & $13(11.8)$ & $3(21.4)$ & $1(4.0)$ & $10(8.3)$ & $7(17.1)$ & $5(4.1)$ \\
\hline \multicolumn{7}{|l|}{$\begin{array}{l}\text { Disease behaviour at } \\
\text { diagnosis*, n (\%) }\end{array}$} \\
\hline B1 & $76(69.1)$ & $10(71.4)$ & $20(80.0)$ & 93 (77.5) & $30(73.2)$ & $96(78.7)$ \\
\hline B2 & $17(15.5)$ & $1(7.1)$ & $4(16.0)$ & $21(17.5)$ & $6(14.6)$ & $18(14.8)$ \\
\hline B3 & $17(15.5)$ & $3(21.4)$ & $1(4.0)$ & $6(5.0)$ & $5(12.2)$ & $8(6.6)$ \\
\hline $\begin{array}{l}\text { Perianal disease at } \\
\text { diagnosis, } \mathrm{n}(\%)\end{array}$ & $13(11.8)$ & $2(14.3)$ & $2(8.0)$ & $11(9.2)$ & $6(14.6)$ & $9(7.4)$ \\
\hline Surgery at diagnosis, n (\%) & $8(7.3)$ & $3(21.4)$ & $2(8.0)$ & $6(5.0)$ & $2(4.9)$ & $29(23.8)$ \\
\hline
\end{tabular}

$\mathrm{N}$, number of patients / SD, standard deviation / NA, not available /*, phenotype according to Montreal Classification. Disease location of CD was defined as ileal involvement (L1), exclusive colonic involvement (L2), ileocolonic involvement (L3) or isolated upper gastrointestinal disease (L4). Disease behaviour of CD was defined as non-stricturing/non-penetrating (B1), stricturing (B2) or penetrating (B3). / GI, gastrointestinal. 
Table 2.3 Disease outcome after 10 years of follow-up for each of the six patterns of disease activity.

\begin{tabular}{|c|c|c|c|c|c|c|}
\hline & $\begin{array}{l}\text { Active to } \\
\text { remission } \\
(n=110)\end{array}$ & $\begin{array}{l}\text { Remission } \\
\text { to active } \\
(n=14)\end{array}$ & $\begin{array}{c}\begin{array}{c}\text { Chronic } \\
\text { continuous }\end{array} \\
(n=25)\end{array}$ & $\begin{array}{l}\text { Moderate- } \\
\text { severe chronic } \\
\text { intermittent } \\
(n=120)\end{array}$ & $\begin{array}{l}\text { Mild chronic } \\
\text { intermittent } \\
\quad(n=41)\end{array}$ & Quiescent \\
\hline $\begin{array}{l}\text { Number of yearly quarters } \\
\text { with disease activity, mean } \\
\text { (SD) }\end{array}$ & $4.77(1.63)$ & $4.79(1.97)$ & $14.48(3.04)$ & $8.74(2.52)$ & $4.02(0.82)$ & $1.49(0.50)$ \\
\hline $\begin{array}{l}\text { Disease progression*, } \\
\text { inflammatory (B1) to } \\
\text { stricturing (B2), n (\%) }\end{array}$ & $16(21.1)$ & $4(40.0)$ & $10(50.0)$ & $26(28.0)$ & $2(6.7)$ & $4(4.2)$ \\
\hline $\begin{array}{l}\text { Disease progression*, } \\
\text { inflammatory (B1) to } \\
\text { penetrating (B3), n (\%) }\end{array}$ & $5(6.6)$ & $0(0.0)$ & $3(15.0)$ & $8(8.6)$ & $1(3.3)$ & $2(2.1)$ \\
\hline $\begin{array}{l}\text { Stricturing disease* (B2), n } \\
\text { (\%) }\end{array}$ & $42(38.2)$ & $8(57.1)$ & $15(60.0)$ & $53(44.2)$ & $11(26.8)$ & $26(21.3)$ \\
\hline $\begin{array}{l}\text { Penetrating disease* (B3), } \\
\text { n (\%) }\end{array}$ & $25(22.7)$ & $3(21.4)$ & $4(16.0)$ & $17(14.2)$ & $6(14.6)$ & $10(8.2)$ \\
\hline $\begin{array}{l}\text { Need for systemic } \\
\text { corticosteroids, n (\%) }\end{array}$ & $84(76.4)$ & $7(50.0)$ & $23(92.0)$ & $108(90.0)$ & $20(48.8)$ & $28(23.0)$ \\
\hline $\begin{array}{l}\text { Need for } \\
\text { immunomodulators, n (\%) }\end{array}$ & $71(64.5)$ & $12(85.7)$ & $25(100)$ & $104(86.7)$ & $21(51.2)$ & $12(9.8)$ \\
\hline Need for biologics, $n(\%)$ & $15(13.6)$ & $2(14.3)$ & $16(64.0)$ & $57(47.5)$ & $11(26.8)$ & $3(2.5)$ \\
\hline $\begin{array}{l}\text { Number of hospitalisations, } \\
\text { mean (SD) }\end{array}$ & $1.27(1.53)$ & $1.14(0.95)$ & $2.72(2.26)$ & $1.67(1.91)$ & $0.56(0.84)$ & $0.33(0.54)$ \\
\hline $\begin{array}{l}\text { Number of surgical } \\
\text { procedures, mean (SD) }\end{array}$ & $0.50(0.63)$ & $0.79(0.89)$ & $1.00(1.00)$ & $0.53(0.69)$ & $0.29(0.60)$ & $0.21(0.41)$ \\
\hline Development of CRC, n (\%) & $0(0.0)$ & $0(0.0)$ & $0(0.0)$ & $0(0.0)$ & $0(0.0)$ & $1(0.8)$ \\
\hline $\begin{array}{l}\text { Development of extra- } \\
\text { intestinal malignancy, } n(\%)\end{array}$ & $5(4.5)$ & $1(7.1)$ & $1(4.0)$ & $4(3.3)$ & $2(4.9)$ & $7(5.7)$ \\
\hline
\end{tabular}

$\mathrm{N}$, number of patients / SD, standard deviation $/{ }^{*}$, phenotype according to Montreal Classification. Disease behaviour of $C D$ was defined as non-stricturing/non-penetrating (B1), stricturing (B2) or penetrating (B3) / CRC, colorectal cancer.

Results from the multivariable logistic regression analysis using all baseline variables are presented in Table 2.4. The 'Quiescent' pattern was compared with both the combination of most severe patterns (i.e. combination of 'Chronic continuous' and 'Moderate-severe chronic intermittent') as well as the combination of all other patterns. Significant positive associations were observed with surgery at diagnosis and an older age at diagnosis, whereas significant inverse associations were observed with an ileocolonic (L3) disease location and with smoking at diagnosis. When comparing the 'Most severe' patterns combined with the other patterns, only a younger age and active smoking at diagnosis were significantly associated. 
Table 2.4 Results from multivariable logistic regression analysis at baseline.

\begin{tabular}{|c|c|c|c|c|c|c|}
\hline & $\begin{array}{c}\text { Quiescent vs. } \\
\text { Most severe, OR } \\
(95 \% \mathrm{Cl})\end{array}$ & $p$-value & $\begin{array}{l}\text { Quiescent vs. all } \\
\text { other patients, } \\
\text { OR }(95 \% \mathrm{Cl})\end{array}$ & $p$-value & $\begin{array}{l}\text { Most severe vs. } \\
\text { all other patients, } \\
\text { OR }(95 \% \mathrm{Cl})\end{array}$ & $p$-value \\
\hline Age at diagnosis, year & $1.03(1.01-1.06)$ & $0.010^{\wedge}$ & $1.02(1-1.04)$ & 0.093 & $0.97(0.95-0.99)$ & $0.003^{\wedge}$ \\
\hline \multicolumn{7}{|l|}{ Montreal location* } \\
\hline L1 & $R E F$ & & $R E F$ & & $R E F$ & \\
\hline L2 & 0.79 (0.39-1.60) & 0.508 & $0.71(0.39-1.30)$ & 0.268 & $1.04(0.60-1.81)$ & 0.900 \\
\hline L3 & $0.44(0.19-1.00)$ & $0.050^{\wedge}$ & $0.44(0.21-0.92)$ & $0.029^{\wedge}$ & $1.54(0.86-2.74)$ & 0.144 \\
\hline \multicolumn{7}{|l|}{ Montreal behaviour* } \\
\hline B1 & $R E F$ & & $R E F$ & & $R E F$ & \\
\hline B2 & $0.70(0.31-1.56)$ & 0.383 & $0.78(0.39-1.57)$ & 0.487 & $1.16(0.64-2.11)$ & 0.629 \\
\hline B3 & $0.96(0.26-3.46)$ & 0.944 & $0.44(0.17-1.16)$ & 0.096 & $0.39(0.15-1.02)$ & 0.054 \\
\hline Perianal disease & $0.91(0.35-2.36)$ & 0.912 & $0.77(0.34-1.74)$ & 0.533 & $0.72(0.35-1.46)$ & 0.357 \\
\hline Upper GI involvement & $0.44(0.12-1.64)$ & 0.221 & $0.33(0.11-1.02)$ & 0.540 & $0.77(0.34-1.72)$ & 0.517 \\
\hline Gender, male & $1.04(0.56-1.91)$ & 0.910 & $0.88(0.52-1.48)$ & 0.625 & $0.97(0.61-1.56)$ & 0.906 \\
\hline Smoking at diagnosis & $0.43(0.24-0.76)$ & $0.004^{\wedge}$ & $0.44(0.27-0.73)$ & $0.001^{\wedge}$ & $1.63(1.05-2.55)$ & $0.031^{\wedge}$ \\
\hline Surgery at diagnosis & $2.99(1.07-8.34)$ & $0.036^{\wedge}$ & 2.93 (1.34-6.39) & $0.007^{\wedge}$ & $0.52(0.21-1.30)$ & 0.160 \\
\hline
\end{tabular}

*, phenotype according to Montreal Classification. Disease location was defined as ileal involvement (L1), exclusive colonic involvement (L2) or ileocolonic involvement (L3). Disease behaviour was defined as nonstricturing/non-penetrating (B1), stricturing (B2) or penetrating (B3) / GI, gastrointestinal / OR, Odds ratio / $95 \%-\mathrm{Cl}, 95 \%$-Confidence Interval / ^, $p$-value below $0.05 / \mathrm{REF}$, reference category.

Results from the multivariable logistic regression analysis using outcome variables after 6 months of follow-up (adjusted for (nearly) significant baseline variables) are presented in Table 2.5. From all the variables included, only the absence of the need for systemic corticosteroids was strongly associated with the 'Quiescent' pattern. No associations were found with early disease progression, need for immunomodulators or biologics, or the need for hospitalisation or surgery in the first 6 months after diagnosis.

Results from the PLS-DA prediction models are presented in Table 2.6. Predictive power using the Montreal variables alone was moderate for all models (AUROC 0.680.72). Adding other baseline variables and variables collected during the first 6 months of follow-up generated a slight improvement of the models with an increase in AUROC ranging from 0.02 (Most severe vs. all other patients) to 0.07 (Quiescent vs. Most severe). 
Table 2.5 Results from multivariable logistic regression analysis with outcome variables after six months follow-up.

\begin{tabular}{|c|c|c|c|c|c|c|}
\hline & $\begin{array}{c}\text { Quiescent vs. } \\
\text { Most severe, OR } \\
(95 \% \mathrm{Cl})\end{array}$ & $p$-value & $\begin{array}{c}\text { Quiescent vs. all } \\
\text { other patients, } \\
\text { OR }(95 \% \mathrm{Cl})\end{array}$ & $p$-value & $\begin{array}{c}\text { Most severe vs. } \\
\text { all other patients, } \\
\text { OR }(95 \% \mathrm{Cl})\end{array}$ & $p$-value \\
\hline $\begin{array}{l}\text { Disease progression*, } \\
\text { inflammatory (B1) to } \\
\text { stricturing (B2) }\end{array}$ & $0.09(0.01-1.67)$ & 0.107 & $0.18(0.02-1.84)$ & 0.148 & $1.33(0.22-8.12)$ & 0.761 \\
\hline $\begin{array}{l}\text { Disease progression*, } \\
\text { inflammatory (B1) to } \\
\text { penetrating (B3) }\end{array}$ & NA & & NA & & NA & \\
\hline $\begin{array}{l}\text { Need for systemic } \\
\text { corticosteroids }\end{array}$ & $0.24(0.11-0.52)$ & $0.000^{\wedge}$ & $0.29(0.14-0.57)$ & $0.000^{\wedge}$ & $1.98(1.16-3.35)$ & $0.012^{\wedge}$ \\
\hline $\begin{array}{l}\text { Need for } \\
\text { immunomodulators }\end{array}$ & $0.90(0.29-2.78)$ & 0.858 & $0.84(0.31-2.28)$ & 0.731 & $0.76(0.37-1.55)$ & 0.445 \\
\hline Need for biologics & $0.39(0.03-5.14)$ & 0.473 & $0.62(0.06-7.00)$ & 0.702 & $4.43(0.66-29.7)$ & 0.126 \\
\hline $\begin{array}{l}\text { Need of } \\
\text { hospitalization }\end{array}$ & $1.20(0.53-2.76)$ & 0.661 & $1.18(0.59-2.37)$ & 0.639 & $0.98(0.53-1.78)$ & 0.936 \\
\hline $\begin{array}{l}\text { Need for surgery } \\
\text { (excl. baseline) }\end{array}$ & $2.02(0.59-6.94)$ & 0.266 & $1.83(0.66-5.07)$ & 0.246 & $0.73(0.28-1.89)$ & 0.512 \\
\hline
\end{tabular}

*, phenotype according to Montreal Classification. Disease behaviour was defined as non-stricturing/nonpenetrating (B1), stricturing (B2) or penetrating (B3). / OR, Odds ratio / 95\%-Cl, 95\%-Confidence Interval / NA, not applicable /,$p$-value below 0.05. Adjusted for age, disease location/behaviour according to the Montreal classification, smoking, and surgery at diagnosis.

Table 2.6 Results from PLS discriminant analysis for prediction of quiescent and severe patterns.

\begin{tabular}{|c|c|c|c|c|c|c|c|c|c|c|c|c|}
\hline & \multicolumn{4}{|c|}{ Quiescent vs. Most severe } & \multicolumn{4}{|c|}{$\begin{array}{l}\text { Quiescent vs. all other } \\
\text { patients }\end{array}$} & \multicolumn{4}{|c|}{$\begin{array}{c}\text { Most severe vs. all other } \\
\text { patients }\end{array}$} \\
\hline & Sens & Spec & AUROC & Cp-value & Sens & Spec & AUROC & Ep-value & Sens & Spec & AUROC & $\overline{p \text {-value }}$ \\
\hline $\begin{array}{l}\text { Montreal } \\
\text { classification* }\end{array}$ & 0.678 & 0.638 & 0.715 & $<0.001$ & 0.678 & 0.594 & 0.697 & $<0.001$ & 0.610 & 0.656 & 0.683 & $<0.001$ \\
\hline $\begin{array}{l}\text { All baseline } \\
\text { variables** }\end{array}$ & 0.617 & 0.766 & 0.770 & $<0.001$ & 0.593 & 0.722 & 0.722 & $<0.001$ & 0.553 & 0.710 & 0.687 & $<0.001$ \\
\hline $\begin{array}{l}\text { Baseline } \\
\text { variables and } \\
6 \text { month } \\
\text { follow-up } \\
\text { combined } * * *\end{array}$ & 0.677 & 0.755 & 0.793 & $<0.001$ & 0.634 & 0.754 & 0.779 & $<0.001$ & 0.589 & 0.679 & 0.701 & $<0.001$ \\
\hline
\end{tabular}

PLS, partial least square / Sens, sensitivity / Spec, specificity / AUROC, area under the receiver operating characteristic curve $/ *$, i.e. age, disease localization, disease behaviour, perianal disease, upper gastrointestinal involvement) $/^{* *}$, i.e. the Montreal classification and gender, smoking status, and surgery at diagnosis $/ * * *$, i.e. all baseline variables and disease progression, need for resective surgery, need for prednisone, need for immunomodulators, need for biologics, and need for hospitalisation within the first 6 months after diagnosis. 


\section{Discussion}

We defined disease course in CD patients in a real life cohort based on analyses of disease activity in the first 10 years after diagnosis. Remarkably, 28.2\% of the patients were classified to a quiescent pattern. Older age at diagnosis and surgery at baseline were positively associated with this pattern, whereas inverse associations were observed for ileocolonic disease location at diagnosis, active smoking at diagnosis and treatment with steroids in the first 6 months. Predictive modelling showed that, despite the associations found, the disease course can be only moderately predicted using clinical parameters.

This is the first study assessing disease activity patterns in $C D$ in a more recent era. We classified CD patients as 'Active to remission' (25.5\%), 'Remission to active' (3.2\%), 'Chronic continuous' (5.8\%), 'Moderate-severe chronic intermittent' (27.8\%), 'Mild chronic intermittent' (9.5\%), or 'Quiescent' (28.2\%). The classification based on disease activity patterns of CD patients described in our study partly overlap with the limited number of previous studies and underline the heterogeneity of the CD population. The first cohort in which distinctive patterns were described was the Olmsted cohort (1943-1982). ${ }^{11}$ They reported three different patterns, namely unremitting (12.6\%), chronic intermittent (72.8\%) and 'cured' (9.7\%); it was however unclear how these groups were defined. As previously described, Solberg et al. performed a survey-based study (IBSEN-cohort; 1990-2004) in which up to $51 \%$ of the patients experienced a chronic continuous or chronic intermittent activity pattern. Also, $10 \%$ of the patients did not relapse during 10 years of follow-up. ${ }^{12}$ Jess et al. (Denmark; 1962-2005) found that $24.5 \%$ of the patients experienced at least one flare every year (i.e. chronic continuous) and $18.4 \%$ experienced no flares at all during a 5 year follow-up. ${ }^{10}$ In the past decade, no further studies have been performed. The largest proportion of patients $(28.2 \%)$ were classified to the 'Quiescent' pattern and experienced only 1.49 yearly quarters of disease activity on average during the total follow-up of 10 years. The majority of patients with this pattern (89.9\%) were never exposed to immunosuppressives nor biologics, though $23.8 \%$ of the patients underwent surgery at diagnosis. A lower proportion of patients with a quiescent course was found in two other cohorts. As stated, $9.7 \%$ of the patients in the Olmsted cohort were considered to be 'cured' for 10 years (i.e. no recurrence after resection or no disease activity on imaging for at least 10 years without disease progression) and $10 \%$ of the patients in the IBSEN cohort did not relapse during 10 years of follow-up. The EC-IBD European inception cohort assessed relapse-free survival after diagnosis and reported that $26.8 \%$ of the patients did not have any surgical or non-surgical recurrence within 10 years, which is in line with our results. ${ }^{21}$ Differences in definitions complicate direct comparisons, but most studies only used surgery and treatment adjustments as markers of disease activity. ${ }^{10,12,13,21}$ Since we also included imaging, endoscopy, and 
hospitalisations, our definition is more extensive and therefore the proportion of quiescent patients might even have been larger if less outcome measures were used. Remarkably, patients with the 'Quiescent' pattern were more often (70.5\%) diagnosed in the first era (i.e. 1991-1998). Although the number of patients is too small to further analyse this finding, it may indicate that despite the introduction of biologics, disease activity patterns did not improve. This is supported by the observed lack of improvement of disease progression rates over time in other studies. ${ }^{1}$ Some may hypothesise that these quiescent patients may experience low grade inflammation and therefore are at risk for disease progression, though we observed very low progression rates (6.3\%) after 10 years of follow-up. Given the delicate risk/benefit balance of immunosuppressive therapy, especially in older patients, and the increasing exposure to biologics and immunosuppressives early after diagnosis, identification of this quiescent group at diagnosis is important to prevent overtreatment. However, we also found a 'Remission to active' pattern. Although this is a small proportion of our cohort, this indicates that some patients still relapse after a longer period of sustained remission. Continued monitoring therefore remains essential, also in patients with a predicted beneficial long-term outcome.

With regard to the Montreal classification, a higher age at diagnosis was associated with the quiescent pattern, whereas ileocolonic disease location was associated with the severe patterns. In line with our finding, Solberg et al. observed that a young age was associated with a chronic intermittent pattern. ${ }^{12}$ Other available studies on distinctive disease patterns do not report predictors. ${ }^{10,11}$ Previous analysis on relapse rates in our own cohort also showed an association between younger age and relapses. ${ }^{13}$ Ileocolonic disease location has not been linked to flares specifically, but it was found to be associated with disease progression and surgery compared with colonic disease. ${ }^{22-25}$ Though, ileal disease has been even more frequently linked to these negative outcomes. ${ }^{8,22-27}$ Complicated disease behaviour at diagnosis was not associated with either 'Severe' or 'Quiescent' disease in our study, although this has been linked to surgery, hospitalisations, and disabling disease as a composite score previously. ${ }^{7,8,24,25,27-30}$ This can be explained by the fact that most hospitalisations and surgical resections are a direct consequence of a complicated disease behaviour. Perianal disease at diagnosis was also not associated with any of the patterns, although this has been linked to disease progression, hospitalisations, and disabling disease previously. ${ }^{7,22,25,30}$ These contradictory results support our hypothesis that the current classification of patients, based upon the Montreal consensus alone, may not be sufficient for the classification of patients at diagnosis.

Smoking at diagnosis and the use of systemic corticosteroids in the first 6 months were associated with the 'Most severe' patterns and were negatively associated with the 'Quiescent' course in all analyses. Smoking has been widely accepted as a risk factor for negative outcomes in $C D$ and the association with disease activity was confirmed by 
a recent meta-analysis. ${ }^{31}$ However, Solberg et al. observed no differences in smoking status between their disease activity patterns. ${ }^{12}$ This may be due to differences in the definition of disease activity patterns. As in our study, the association between early corticosteroid use and disease activity was observed in their study. ${ }^{12} \mathrm{~A}$ limited number of population-based studies analysed the association of early prednisone use and subsequent negative outcomes. An association was seen with surgery ${ }^{26}$ and a 'disabling disease $^{32}$, but not with hospitalisations ${ }^{30}$ or disease progression ${ }^{23,27}$. The association between early steroid use and subsequent disease activity or flares has not been reported by any population-based cohort study before.

Notably, surgery at baseline was strongly associated with the 'Quiescent' disease activity pattern. Most of these surgical procedures were ileocecal resections (79.3\%) and, of these, most were performed due to luminal inflammation without fistula or stenosis (31.0\%) or as diagnostic procedure (48.0\%). Very limited population-based evidence on this topic is available, but our findings are supported by Golovics et al. who studied disease outcome after early resective surgery in Hungary. They observed significantly lower prednisone exposure, lower biologic use and lower steroid dependency rates after a long period of follow-up. ${ }^{33}$ However, since a considerable proportion of our patients with surgery at baseline were classified to other patterns (42.0\%), our findings should be interpreted with care. In particular, postoperative recurrence rates in an older population-based cohort were as high as $33 \%$ and $44 \%$ within 5 and 10 years after surgery, respectively, and a more recent meta-analysis reported that $24.2 \%$ and $35 \%$ of the patients require second surgery within 5 and 10 years, respectively. ${ }^{34,35}$ However, a retrospective study showed important differences between early and late surgery by means of clinical recurrence in favour of early surgery. ${ }^{36}$ Another retrospective study comparing $C D$ diagnoses during surgery for acute abdominal complaints with $C D$ diagnoses by conventional diagnostics showed decreased use of steroids and immunosuppressants in the first group. ${ }^{37}$ Of note, the LIR!C trial recently showed that, in a highly selected population with pre-treated patients, surgery is a reasonable alternative for biologic therapy in consideration of recurrence rates, even in the long term. ${ }^{38,39}$ Thus early surgery may be beneficial in selected patient groups and should not be considered as a marker of a severe disease course by definition, despite the bias by indication in observational cohorts.

Using the Montreal variables alone, a limited predictive value for distinguishing the 'Quiescent' and the 'Most severe' patterns from the other groups in our PLS discriminant analysis was found. If we combine the Montreal classification variables with the other baseline variables and with the variables collected during the first 6 months of follow-up in our prediction models, the AUROC remains stable for the prediction of the 'Most severe' patterns and increases by only 0.10 for the prediction of the 'Quiescent' pattern. Although prediction of patterns is essential in order to stratify patients at diagnosis, this seems not possible using available clinical parameters. 
Analysis of big data including baseline pathology, genetics, gut microbiota and other molecular markers would be of interest to improve the predictive models.

The major strength of this study is the real-world design with high case certainty, long-term follow-up and a relatively large sample size. Hereby, we were able to define solid patterns which are likely to be representative for other IBD populations as well. Also, due to our prospective registration of newly diagnosed patients and extensive case report forms, reliable and detailed clinical characteristics and data on follow-up were available to use in our models. Another strength of our study is the well-defined criteria for disease activity. As noted, disease activity is mostly defined by surgical or non-surgical interventions, and we also include imaging, endoscopy, and hospitalisations.

Some limitations need to be addressed. Most importantly, a relatively large proportion of patients were considered LTFU due to the lack of outpatient clinic visits exceeding the 10 years of follow-up as described earlier in the discussion. Patients in long-term remission without treatment only visit the hospital once a year or even less. This may lead to an underrepresentation of quiescent patients in our study, which is supported by the fact that out of the 152 patients within this LTFU group, 95 had a follow-up longer than 5 years and they experienced 2.88 active quarters during this follow-up, compared with 3.54 active quarters in the first 5 years of the included patients $(p=0.015)$. Including these patients would possibly lead to bias, since this would be based on the assumption that no event has occurred, and most probably will not change our conclusion. Next, we were not able to include biochemical parameters (e.g. calprotectin) in our definition for disease activity since these parameters were not available at the start of data collection. It should also be noted that in some populationbased cohorts, patients may be misclassified and subsequently add to the number of 'quiescent' patients. However, our IBDSL cohort has stringent inclusion criteria at time of diagnosis which limits the inclusion of non-IBD cases. Moreover, most of the patients with the 'Quiescent' pattern have a histologically proven CD $(82.0 \%)$ and when only histologically proven CD cases are included in the analysis, still $26.6 \%$ of all patients are classified to the 'Quiescent' pattern. Furthermore, 70.5\% of the patients had more than one endoscopic or radiological examination during follow-up and all patients are considered $C D$ cases for at least 10 years by gastroenterologists. Altogether, we believe it is safe to assume that the patients included in this study are true CD cases. As a final limitation, some patients may experience disease activity or even disease progression without attending a hospital and therefore may be missed in our analysis. However, our follow-up of 10 years captures a very long period and it is highly likely that if a patient develops disease progression due to long-term low grade inflammation, he or she will show up at the hospital at some point during follow-up in line with health care organisation in The Netherlands. 
In conclusion, in this real-life cohort, we classified CD patients according to disease activity patterns. A substantial proportion of patients were classified to a quiescent disease pattern during the first 10 years after diagnosis, underlining the importance of patient stratification to prevent both undertreatment and overtreatment. Early clinical markers can only moderately predict patients' disease course. Further studies are warranted to confirm our findings and to identify better (molecular) markers in order to select the optimal treatment strategy for every patient at diagnosis. Alternatively novel treatment strategies with introduction of the most potent medication or even surgery at diagnosis in combination with subsequent discontinuation and monitoring are of interest to prevent delay in patients prone to a severe course and at the same time to protect patients with a favourable outcome from long-term exposure to potentially harmful drugs. 


\section{References}

1. Jeuring SF, van den Heuvel TR, Liu LY, Zeegers MP, Hameeteman WH, Romberg-Camps MJ, et al. Improvements in the Long-Term Outcome of Crohn's Disease Over the Past Two Decades and the Relation to Changes in Medical Management: Results from the Population-Based IBDSL Cohort. Am J Gastroenterol. 2017;112(2):325-36.

2. Goldberg R, Irving PM. Toxicity and response to thiopurines in patients with inflammatory bowel disease. Expert Rev Gastroenterol Hepatol. 2015;9(7):891-900.

3. Cohen BL, Sachar DB. Update on anti-tumor necrosis factor agents and other new drugs for inflammatory bowel disease. BMJ. 2017;357:j2505.

4. van den Heuvel TR, Wintjens DS, Jeuring SF, Wassink MH, Romberg-Camps MJ, Oostenbrug LE, et al. Inflammatory bowel disease, cancer and medication: Cancer risk in the Dutch population-based IBDSL cohort. Int J Cancer. 2016;139(6):1270-80.

5. Gomollon F, Dignass A, Annese V, Tilg H, Van Assche G, Lindsay JO, et al. 3rd European Evidence-based Consensus on the Diagnosis and Management of Crohn's Disease 2016: Part 1: Diagnosis and Medical Management. J Crohns Colitis. 2017;11(1):3-25.

6. Peyrin-Biroulet L, Loftus EV, Jr., Colombel JF, Sandborn WJ. The natural history of adult Crohn's disease in population-based cohorts. Am J Gastroenterol. 2010;105(2):289-97.

7. Beaugerie L, Seksik P, Nion-Larmurier I, Gendre JP, Cosnes J. Predictors of Crohn's disease. Gastroenterology. 2006;130(3):650-6.

8. Jeuring SF, van den Heuvel TR, Liu LY, Zeegers MP, Hameeteman WH, Romberg-Camps MJ, et al. Improvements in the Long-Term Outcome of Crohn's Disease Over the Past Two Decades and the Relation to Changes in Medical Management: Results from the Population-Based IBDSL Cohort. Am J Gastroenterol. 2017;112(2):325-36.

9. Torres J, Mehandru S, Colombel JF, Peyrin-Biroulet L. Crohn's disease. Lancet. 2017;389(10080): 174155.

10. Jess T, Riis L, Vind I, Winther KV, Borg S, Binder V, et al. Changes in clinical characteristics, course, and prognosis of inflammatory bowel disease during the last 5 decades: a population-based study from Copenhagen, Denmark. Inflamm Bowel Dis. 2007;13(4):481-9.

11. Gollop JH, Phillips SF, Melton LJ, 3rd, Zinsmeister AR. Epidemiologic aspects of Crohn's disease: a population based study in Olmsted County, Minnesota, 1943-1982. Gut. 1988;29(1):49-56.

12. Solberg IC, Vatn MH, Hoie O, Stray N, Sauar J, Jahnsen J, et al. Clinical course in Crohn's disease: results of a Norwegian population-based ten-year follow-up study. Clin Gastroenterol Hepatol. 2007;5(12):1430-8.

13. Romberg-Camps MJ, Hesselink-van de Kruijs MA, Schouten LJ, Dagnelie PC, Limonard CB, Kester AD, et al. Inflammatory Bowel Disease in South Limburg (the Netherlands) 1991-2002: Incidence, diagnostic delay, and seasonal variations in onset of symptoms. J Crohns Colitis. 2009;3(2):115-24.

14. van den Heuvel TR, Jonkers DM, Jeuring SF, Romberg-Camps MJ, Oostenbrug LE, Zeegers MP, et al. Cohort Profile: The Inflammatory Bowel Disease South Limburg Cohort (IBDSL). Int J Epidemiol. 2017;46(2):e7.

15. National pathology database: PALGA. (Accessed November 1, 2015, at https://www.palga.nl/).

16. World Medical A. World Medical Association Declaration of Helsinki: ethical principles for medical research involving human subjects. JAMA. 2013;310(20):2191-4.

17. Lim WC, Wang Y, MacDonald JK, Hanauer S. Aminosalicylates for induction of remission or response in Crohn's disease. Cochrane Database Syst Rev. 2016;7:CD008870.

18. Satsangi J, Silverberg MS, Vermeire S, Colombel JF. The Montreal classification of inflammatory bowel disease: controversies, consensus, and implications. Gut. 2006;55(6):749-53.

19. Filzmoser P, Liebmann B, Varmuza K. Repeated double cross validation. Journal of Chemometrics. 2009;23(4):160-71.

20. Szymanska E, Saccenti E, Smilde AK, Westerhuis JA. Double-check: validation of diagnostic statistics for PLS-DA models in metabolomics studies. Metabolomics. 2012;8(Suppl 1):3-16.

21. Wolters FL, Russel MG, Sijbrandij J, Ambergen T, Odes S, Riis L, et al. Phenotype at diagnosis predicts recurrence rates in Crohn's disease. Gut. 2006;55(8):1124-30. 
22. Tarrant KM, Barclay ML, Frampton CM, Gearry RB. Perianal disease predicts changes in Crohn's disease phenotype-results of a population-based study of inflammatory bowel disease phenotype. Am J Gastroenterol. 2008;103(12):3082-93.

23. Thia KT, Sandborn WJ, Harmsen WS, Zinsmeister AR, Loftus EV, Jr. Risk factors associated with progression to intestinal complications of Crohn's disease in a population-based cohort. Gastroenterology. 2010;139(4):1147-55.

24. Sjoberg D, Holmstrom T, Larsson M, Nielsen AL, Holmquist L, Ekbom A, et al. Incidence and clinical course of Crohn's disease during the first year - results from the IBD Cohort of the Uppsala Region (ICURE) of Sweden 2005-2009. J Crohns Colitis. 2014;8(3):215-22.

25. Lakatos PL, Golovics PA, David G, Pandur T, Erdelyi Z, Horvath A, et al. Has there been a change in the natural history of Crohn's disease? Surgical rates and medical management in a population-based inception cohort from Western Hungary between 1977-2009. Am J Gastroenterol. 2012;107(4):579-88.

26. Ramadas AV, Gunesh S, Thomas GA, Williams GT, Hawthorne AB. Natural history of Crohn's disease in a population-based cohort from Cardiff (1986-2003): a study of changes in medical treatment and surgical resection rates. Gut. 2010;59(9):1200-6.

27. Ng SC, Zeng Z, Niewiadomski O, Tang W, Bell S, Kamm MA, et al. Early Course of Inflammatory Bowel Disease in a Population-Based Inception Cohort Study From 8 Countries in Asia and Australia. Gastroenterology. 2016;150(1):86-95 e3; quiz e13-4.

28. Burisch J, Pedersen N, Cukovic-Cavka S, Turk N, Kaimakliotis I, Duricova D, et al. Initial disease course and treatment in an inflammatory bowel disease inception cohort in Europe: the ECCO-EpiCom cohort. Inflamm Bowel Dis. 2014;20(1):36-46.

29. Ronnblom A, Holmstrom T, Karlbom U, Tanghoj H, Thorn M, Sjoberg D. Clinical course of Crohn's disease during the first 5 years. Results from a population-based cohort in Sweden (ICURE) diagnosed 20052009(). Scand J Gastroenterol. 2017;52(1):81-6.

30. Golovics PA, Lakatos L, Mandel MD, Lovasz BD, Vegh Z, Kurti Z, et al. Prevalence and predictors of hospitalization in Crohn's disease in a prospective population-based inception cohort from 2000-2012. World J Gastroenterol. 2015;21(23):7272-80.

31. To N, Gracie DJ, Ford AC. Systematic review with meta-analysis: the adverse effects of tobacco smoking on the natural history of Crohn's disease. Aliment Pharmacol Ther. 2016;43(5):549-61.

32. Niewiadomski O, Studd C, Hair C, Wilson J, Ding NS, Heerasing N, et al. Prospective population-based cohort of inflammatory bowel disease in the biologics era: Disease course and predictors of severity. J Gastroenterol Hepatol. 2015;30(9):1346-53.

33. Golovics PA, Lakatos L, Nagy A, Pandur T, Szita I, Balogh M, et al. Is early limited surgery associated with a more benign disease course in Crohn's disease? World J Gastroenterol. 2013;19(43):7701-10.

34. Frolkis AD, Lipton DS, Fiest KM, Negron ME, Dykeman J, deBruyn J, et al. Cumulative incidence of second intestinal resection in Crohn's disease: a systematic review and meta-analysis of population-based studies. Am J Gastroenterol. 2014;109(11):1739-48.

35. Bernell O, Lapidus A, Hellers G. Risk factors for surgery and postoperative recurrence in Crohn's disease. Ann Surg. 2000;231(1):38-45.

36. Aratari A, Papi C, Leandro G, Viscido A, Capurso L, Caprilli R. Early versus late surgery for ileo-caecal Crohn's disease. Aliment Pharmacol Ther. 2007;26(10):1303-12.

37. Latella G, Cocco A, Angelucci E, Viscido A, Bacci S, Necozione S, et al. Clinical course of Crohn's disease first diagnosed at surgery for acute abdomen. Dig Liver Dis. 2009;41(4):269-76.

38. Ponsioen CY, de Groof EJ, Eshuis EJ, Gardenbroek TJ, Bossuyt PMM, Hart A, et al. Laparoscopic ileocaecal resection versus infliximab for terminal ileitis in Crohn's disease: a randomised controlled, open-label, multicentre trial. Lancet Gastroenterol Hepatol. 2017;2(11):785-92.

39. Stevens T, Haasnoot L, D'Haens G, Buskens C, Groof EJ, Eshuis E, et al. OP03 Reduced need for surgery and medical therapy after early ileocaecal resection for Crohn's disease: Long-term follow-up of the LIR!C trial [abstract]. Journal of Crohn's and Colitis. 2020;14:S003-S4. 
82 


\section{Part II}

Associations between modifiable environmental factors and disease activity in IBD 


$$
20
$$




\section{Chapter 3}

Ambient air quality is not a major risk factor in the onset nor disease course of Crohn's disease - an ecologic analysis in a Dutch population-based cohort

Dion S.J. Wintjens*, Tim R.A. van den Heuvel*, Esmee M. Bijnens, Bas P.M. Verhaegh, Steven F.G. Jeuring, Tim S. Nawrot, Maurice P. Zeegers, Ad A.M. Masclee, Liekele E. Oostenbrug, Mariëlle J.L. Romberg-Camps, Jan Willem A. Straathof, Daisy M.A.E. Jonkers, Marieke J. Pierik

*Authors contributed equally

Submitted 


\section{Abstract}

\section{Background}

Cigarette smoking is associated with unfavourable clinical outcomes of Crohn's disease (CD). Only a limited number of studies is available on the association between $\mathrm{CD}$ and ambient air pollution, a source of airborne toxins analogous to smoking. Here, we aimed to study associations between ambient air quality and both CD diagnosis and disease course in the population-based Inflammatory Bowel Disease South Limburg (IBDSL) cohort.

\section{Methods}

In this prospective study, $389 \mathrm{CD}$ patients were included and matched to controls on gender, age, and residential address. Air pollution levels, traffic exposure, land use, and urbanicity were estimated on the residential addresses. Disease course was analysed in the first three years after diagnosis by both disease activity per quarter of follow-up and a composite score of outcomes. Uni- and multivariable regression analyses were performed to study associations between ambient air quality and both $\mathrm{CD}$ onset and disease course, hereby correcting for confounders.

\section{Results}

No parameters of ambient air quality were associated with disease onset or disease course in the main multivariable analyses. In these models, smoking at inclusion was associated with both $C D$ diagnosis (odds ratio: $3.05,95 \%$ confidence intervals: 2.20 4.24, p-value: $<0.01$ ) and the number of quarters of disease activity (B-coefficient: 0.46 , standard error: $0.19, p$-value: 0.02 ). Multivariable sensitivity analyses in nonsmokers revealed similar results.

\section{Conclusions}

Despite previous hypotheses, ambient air quality is not a strong contributing factor in the onset nor disease course of CD in the South Limburg region of the Netherlands. 


\section{Introduction}

Crohn's disease (CD) is a chronic relapsing inflammatory disorder of the gastrointestinal tract with an increasing incidence worldwide. ${ }^{1}$ The disease course is characterized by sequences of exacerbation and remission, and can vary highly between patients. ${ }^{2}$ An aberrant intestinal immune response, intestinal microbiota, and (genetic) susceptibility are involved in its aetiology. ${ }^{3}$ Twin concordance studies, ${ }^{4}$ ecological studies on spatial distribution within countries, ${ }^{5}$ and epidemiologic studies in immigrants ${ }^{6}$ have indicated that environmental factors play a large role as well. However, to what extent environmental factors contribute to the disease onset and/or the variable disease course is still far from clear. Further insight is warranted, especially since environmental factors are modifiable and may become targets for intervention.

Many environmental factors have been studied (e.g. smoking, socio-economic status, urbanization, childhood factors, and hygiene), ${ }^{7}$ but only smoking has been consistently and positively associated with the onset of $C D$ and a subsequent severe course. $^{8,9}$ Components of cigarette smoke, especially nicotine, are thought to promote gut inflammation by affecting the intestinal epithelium, immune system and microbiome in both direct and indirect manners. ${ }^{10}$ Ambient air pollution, which can be regarded analogous to smoking, is a source of airborne toxins and is an emerging problem worldwide. They have been proposed to reach the gastrointestinal tract either through mucociliary clearance of inhaled pollutants from the lungs, or by dietary intake of contaminated food, and may there affect the intestinal epithelium and/or microbiota in similar ways as described for cigarette smoke. ${ }^{11}$ In addition, ambient air pollution has previously been associated with several gastrointestinal disorders, such as appendicitis, ${ }^{12}$ gastroenteritis, ${ }^{13}$ and colorectal cancer. ${ }^{14}$

Ambient air pollution as a risk factor for $C D$ onset and subsequent disease course has only scarcely been studied. Available studies show conflicting results and have methodological limitations (i.e. small sample size, use of administrative databases, and the lack of ambient air quality data on patient level). ${ }^{15-17}$ We aimed to study whether residential ambient air quality is associated with CD onset and disease course in a population-based IBD cohort in the Netherlands. 


\section{Materials and methods}

\section{Setting and study population}

This prospective cohort study was performed in the region of South Limburg, the Netherlands. South Limburg is nearly enclosed by Belgium and Germany, and because of its limited cross-border health care and migration rates, this region is ideal for population-based research.

Patients were retrieved from the population-based IBDSL cohort, which has been described in detail elsewhere. ${ }^{18}$ In brief, patients diagnosed with IBD between 1991 and 2011, while living in South Limburg and being over 18 years of age at diagnosis, were included. IBD was diagnosed by certified gastroenterologists based on the combination of endoscopic, radiological and/or histological findings. The date of the first examination with evidence of IBD was set as the date of diagnosis. A multifaceted identification strategy, including hospitals, the nationwide Dutch pathology database (PALGA), and general practitioners, resulted in the capture of $>93 \%$ of eligible patients. As patients that were not captured were not likely to be associated with a certain IBD phenotype, ${ }^{18}$ an unselected population was assured. Included patients were prospectively followed on surgery, hospitalizations, extra-intestinal manifestations, complications, phenotype (according to Montreal classification), ${ }^{19}$ and medication, using standardized registration forms.

For this study, only CD patients diagnosed since 2001 were included, due to the availability of ambient air quality data. To ensure sufficient time for ambient air to affect disease course, included patients also had to have a stable residential address of at least three years prior to and three years after diagnosis. Residential address history was retrieved from the official authority database, and the date of diagnosis was set as the index date.

Controls were retrieved from the South Limburg population. Study invitation letters were sent to 7000 households, randomly selected on postal code. All adult members of these households were asked consent for retrieval of their residential address history, and to complete a questionnaire on demographics and IBD risk factors. In total, 1611 controls responded. Controls were randomly matched to cases in a 1:1 ratio on year of birth (+/- 3 years) and gender. Only 1 member per household was allowed in the matching procedure. Controls were assigned the same index date as their matched case and had to have a stable residential address in the 3 years before the index date as well. To ensure that controls were evenly distributed over South Limburg, the expected number of controls per municipality was determined and matches were adjusted when the observed number deviated from the expected by more than $20 \%$. 


\section{Data on ambient air quality}

Residential addresses at diagnosis were coded into geographic coordinates, and subsequently used to calculate individual exposure to direct and indirect parameters of ambient air quality, being (A) air pollutants, and parameters related to (B) land use, (C) urbanicity and (D) traffic, since these are related to air quality in previous studies. ${ }^{20-22}$ Data on ambient air quality were calendar year specific and data closest to the diagnosis date were used. All analyses were carried out using Geographic Information Systems (GIS) functions (ArcGIS 9.3).

Data on air pollutants was obtained from the Dutch Ministry of Health, Welfare and Sport. Air pollutant concentrations were measured at 60 fixed monitoring stations in the Netherlands. These concentrations were then used in a validated simulation model to estimate the concentrations per $\mathrm{km}^{2}$, hereby taking into account local and foreign influences on air quality. ${ }^{23}$ The air pollutants analysed in the present study were nitrogen dioxide $\left(\mathrm{NO}_{2}\right)$, ozone $\left(\mathrm{O}_{3}\right)$, and particulate matter with a diameter $\leq 10$ micron $\left(\mathrm{PM}_{10}\right)$. Sulfur dioxide ( $\left.\mathrm{SO} 2\right)$, a fourth common pollutant was not included as regional concentrations were too low to expect health risks. ${ }^{23}$ Maps were available for every year between 2001 and 2011. Average concentrations for the three years preceding the index date were calculated.

Percentages of land use were calculated within $500 \mathrm{~m}$ and $2500 \mathrm{~m}$ buffer zones from each residential address. Data were obtained from the European Union CORINE land cover registry. Every $100 \mathrm{~m}^{2}$ of South Limburg ground surface was assigned to its major type of land use. Four types of land use were included in this study, being residential (CORINE class 1.1), industrial (class 1.2.1), agricultural (class 2 ) and nature (class 3, 4, and 5). Maps were available for the years 2000, 2006 and 2012.

All residential addresses were assigned to wards (the smallest geographic entity in the Netherlands, not larger than a couple of $\mathrm{km}^{2}$ and having approximately 3000 inhabitants on average). Data on urbanicity was obtained from Statistics Netherlands, responsible for official governmental statistics. The ward's population density and address density were included in this study. Maps were available for the year 2009.

Traffic indicators included in this study were total road length within $200 \mathrm{~m}$ and $500 \mathrm{~m}$ buffer zones from each residential address, and the distance to the nearest major road (functional road class $0-2$ ) or nearest highway (functional road class 0 ). Data on traffic for the year 2008 were obtained from Tele Mart (Tele Atlas Multinet).

\section{Data on possible risk factors}

Several environmental, demographic and clinical factors were included as possible risk factors, because of their expected or previously observed associations with disease onset (smoking at index date ${ }^{8}$ and socio-economic status $(\mathrm{SES})^{24}$ ) and the disease course of CD (smoking at diagnosis, ${ }^{9} \mathrm{SES}^{24}$ gender, $^{25}$ age at diagnosis ${ }^{25}$ and era of diagnosis (2001-2005, or 2006-2011). ${ }^{26}$ Smoking data were missing in $7 \%$ of controls, 
and $10 \%$ of patients and were completed by multiple imputation using a fully conditional specification method with five imputations. SES was determined using the previously mentioned data on urbanicity, and the ward's average house value and percentage of households with low incomes were included as proxies.

\section{Definition of severe disease course}

The study endpoint was a severe disease course within three years after diagnosis. At this moment, there is no clear consensus on the definition of severe disease course within the IBD field. Most cohorts use composite scores consisting of several supposedly negative outcomes (i.e. surgery, hospitalization, medication use and disease progression). However, disease activity per yearly quarter of follow-up may better reflect a severe disease course since mucosal inflammation precedes negative outcomes used in composite scores. Moreover, the trend towards more aggressive treatment regimens complicate the use of treatment variables in composite scores. For the current study, we assessed both disease activity per quarter as a continuous variable and a composite score for severe disease course as a binomial variable.

As from diagnosis, each yearly quarter was assessed for disease activity in all patients. Disease activity was defined by either i) active disease on endoscopy or imaging, ii) hospitalization, iii) surgery or iv) treatment adjustment due to symptoms. i) Active disease on endoscopy or imaging comprised all reports in which the gastroenterologist or radiologist who performed the endoscopy or judged the imaging, respectively, considered lesions to be due to active CD. ii) Hospitalizations were only considered when patients were admitted for exacerbations of IBD. Elective admissions for endoscopy, drug administration, surgery, and admissions due to side effects of medication use were excluded. iii) Surgical procedures were considered when the indication for surgery was either active luminal disease, active internal fistula, structuring complications, or active perianal disease. Diagnostic procedures and procedures secondary to surgical complications were excluded. iv) Finally, a patient was considered as having disease activity when a treatment adjustment was made by the treating physician based on highly suggestive biochemical changes or symptoms alone. Changes solely due to trough levels or side effects were excluded. Also the prescription of 5-ASA drugs were not taken into account, since the effectiveness of these drugs in CD is barely supported by evidence. ${ }^{27}$

The composite score of severe disease course was defined as having one or more of following conditions: (I) surgery (i.e. resection or perianal surgery), (II) two or more $C D$ related hospitalizations due to exacerbation, extra-intestinal manifestations and/or surgery (but not hospitalizations due to medication side effects, surgery complications, or hospitalizations with a duration shorter than one day), (III) progression in behaviour of CD according to the Montreal classification ${ }^{19}$, (IV) two or more steroid courses (or steroid dependency defined as $>90$ days of continuous 
steroid use), or (V) biological use. The development of a (VI) fistula or (VII) stricture was also considered as a severe disease course. Patients not fulfilling any of the criteria were defined as having mild disease.

\section{Statistical analysis}

To assess the association between ambient air quality and IBD onset, case-control data was used in univariable conditional logistic regression analyses for the individual parameters of ambient air quality and the individual risk factors, adjusting for the matching parameters (i.e. year of birth and gender). Odds ratios (OR) with $95 \%$ confidence intervals $(95 \% \mathrm{Cl})$ and $p$-values were calculated. Parameters with a $p$-value $<0.10$ in the univariable analyses were included in the multivariable model, together with the matching parameters and known risk factors (i.e. smoking at index date and SES). In case of collinearity between parameters in the multivariable model, only the one with highest OR was used. Two-sided statistical significance was set at a p-value of $<0.05$. Sensitivity analyses were performed on non-smokers at index date, as the intake levels of airborne toxins via smoking may overshadow a possible effect of ambient air quality on IBD onset.

To assess the association between ambient air quality and disease course, both univariable linear and conditional logistic regression analyses were performed for the individual parameters of ambient air quality and for the individual risk factors, with disease activity per quarter and the composite score as dependent variables, respectively. ORs, $95 \% \mathrm{Cl}$, and $p$-values were calculated. Parameters with a $p$-value $<0.10$ in the univariable analyses were included in the multivariable model, together with all possible risk factors (i.e. smoking at diagnosis, SES, gender, age at diagnosis and era of diagnosis). The model was checked for normality, homoscedasticity, multicollinearity, and linearity. In case of collinearity between parameters in the multivariable model, only the one with highest OR was used. Statistical significance was set at $p$-value $<0.05$. Additional sensitivity analyses were performed. First, to prevent missing important associations, analyses were replicated using the separate components of the severe disease course definition as study endpoint. Second, analyses were done for non-smokers at diagnosis only, as the intake levels of airborne toxins via smoking may overshadow a possible effect of ambient air quality on IBD course.

Statistical analyses were performed with SPSS (version 25.0, SPSS Inc., Chicago, IL, USA).

\section{Ethical considerations}

This study has been approved by the Ethics Committee of the Maastricht University Medical Centre (NL31636.068.10) as part of the IBDSL cohort study, is 
registered in clinicalTrial.gov (NCT02130349) and meets the ethical standards of the revised version of the declaration of Helsinki. All patients and controls in this study gave their informed consent prior to their inclusion in the study.

\section{Results}

In total, 389 CD cases were matched to the same number of controls. CD cases had a mean age at diagnosis of 43.4 years (SD 15.2) and a stable address duration at index date of 15.6 years (SD 9.1), whereas in controls this was 43.6 years (SD 15.5) and 15.5 years (SD 9.5), respectively. The baseline characteristics are shown in Table 3.1, and the distribution of cases and controls over South Limburg is shown in Figure 3.1.

Table 3.1 Baseline characteristics of CD patients and controls.

\begin{tabular}{|c|c|c|c|c|c|c|}
\hline & & \multirow[b]{2}{*}{$\begin{array}{l}\text { Cases } \\
\mathrm{N}=\mathbf{3 8 9}\end{array}$} & \multirow[b]{2}{*}{$\begin{array}{c}\text { Controls } \\
\mathrm{N}=389\end{array}$} & \multicolumn{3}{|c|}{ CD with 3yrs FU } \\
\hline & & & & $\begin{array}{c}\text { Total } \\
\mathrm{N}=338\end{array}$ & $\begin{array}{l}\text { Mild } \S \\
N=164\end{array}$ & $\begin{array}{c}\text { Severe } \S \\
N=174\end{array}$ \\
\hline Male & $\mathrm{N}(\%)$ & $163(41.9)$ & $163(41.9)$ & $145(42.9)$ & $73(44.5)$ & $72(41.4)$ \\
\hline Age $(y r s)^{\dagger}$ & Mean (SD) & $43.4(15.2)$ & $43.6(15.5)$ & $44.1(15.0)$ & $45.6(14.8)$ & $42.7(15.0)$ \\
\hline Address duration (yrs) & Mean (SD) & $15.6(9.1)$ & $15.5(9.5)$ & $15.4(9.4)$ & $15.6(9.6)$ & $15.3(9.2)$ \\
\hline \multicolumn{7}{|l|}{ Phenotype $\ddagger$} \\
\hline L1 & $\mathrm{N}(\%)$ & $174(44.7)$ & - & $146(43.2)$ & $66(40.2)$ & $80(40.6)$ \\
\hline L2 & $\mathrm{N}(\%)$ & $126(32.4)$ & - & $110(32.5)$ & $57(34.8)$ & $53(30.5)$ \\
\hline L3 & $\mathrm{N}(\%)$ & $76(19.5)$ & - & $71(20.7)$ & $33(20.1)$ & $38(21.8)$ \\
\hline L4 & $\mathrm{N}(\%)$ & $13(3.3)$ & - & $11(3.3)$ & $8(4.9)$ & $3(1.7)$ \\
\hline B1 & $\mathrm{N}(\%)$ & $310(79.7)$ & - & $266(78.8)$ & $164(100)$ & $102(58.6)$ \\
\hline B2 & $\mathrm{N}(\%)$ & $53(13.6)$ & - & 47 (13.9) & 0 & $47(27.0)$ \\
\hline B3 & $\mathrm{N}(\%)$ & $26(6.7)$ & - & $25(7.4)$ & 0 & $25(14.4)$ \\
\hline
\end{tabular}

CD, Crohn's disease/ FU, follow-up / N, number/ SD, standard deviation/ yrs, years/ + , at diagnosis/ $¥$, phenotype at diagnosis, according to Montreal Classification. Disease location of CD was defined as ileal disease (L1), colonic disease (L2), ileocolonic disease (L3) or isolated upper disease (L4). Disease behaviour of $C D$ was defined as non-stricturing non-penetrating (B1), structuring (B2) or penetrating (B3)./ §, according to the composite score. 


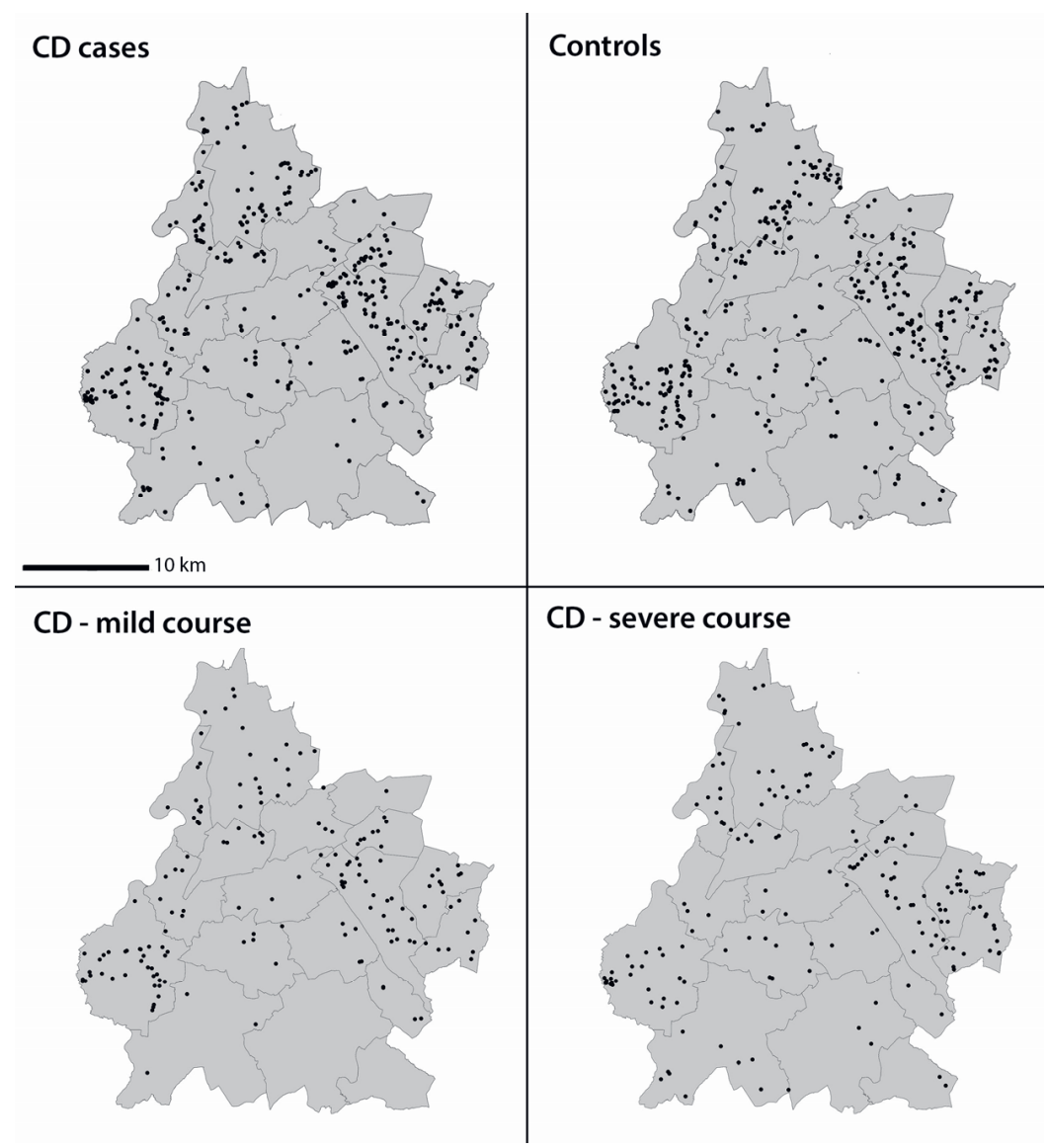

Figure 3.1 The distribution of Crohn's disease cases and controls over the South Limburg region with breakdown into mild and severe disease course within three years after diagnosis. Each subject is represented as a black dot.

\section{Ambient air quality in relation to $C D$ onset}

In the univariable analyses, cumulative road length within a 200 meter buffer (OR: 1.14, 95\% $\mathrm{Cl}: 1.01-1.28, \mathrm{p}=0.03$ ) and smoking at diagnosis (OR: $3.05,95 \% \mathrm{Cl}: 2.19-4.24$, $\mathrm{p}<0.01$ ) had $\mathrm{p}$-values below 0.10 , whereas all other parameters of ambient air quality and other risk factors had higher $p$-values. In the multivariable analyses only smoking at diagnosis was significantly associated with CD onset (OR: $3.05,95 \% \mathrm{Cl}: 2.20-4.24$, $\mathrm{p}<0.01$ ). Results from the uni- and multivariable analyses are shown in Table 3.2. In the sensitivity analyses on non-smokers at index (including 183 cases and 284 controls), no parameters of ambient air quality nor other risk factors were associated with $\mathrm{CD}$ onset. 


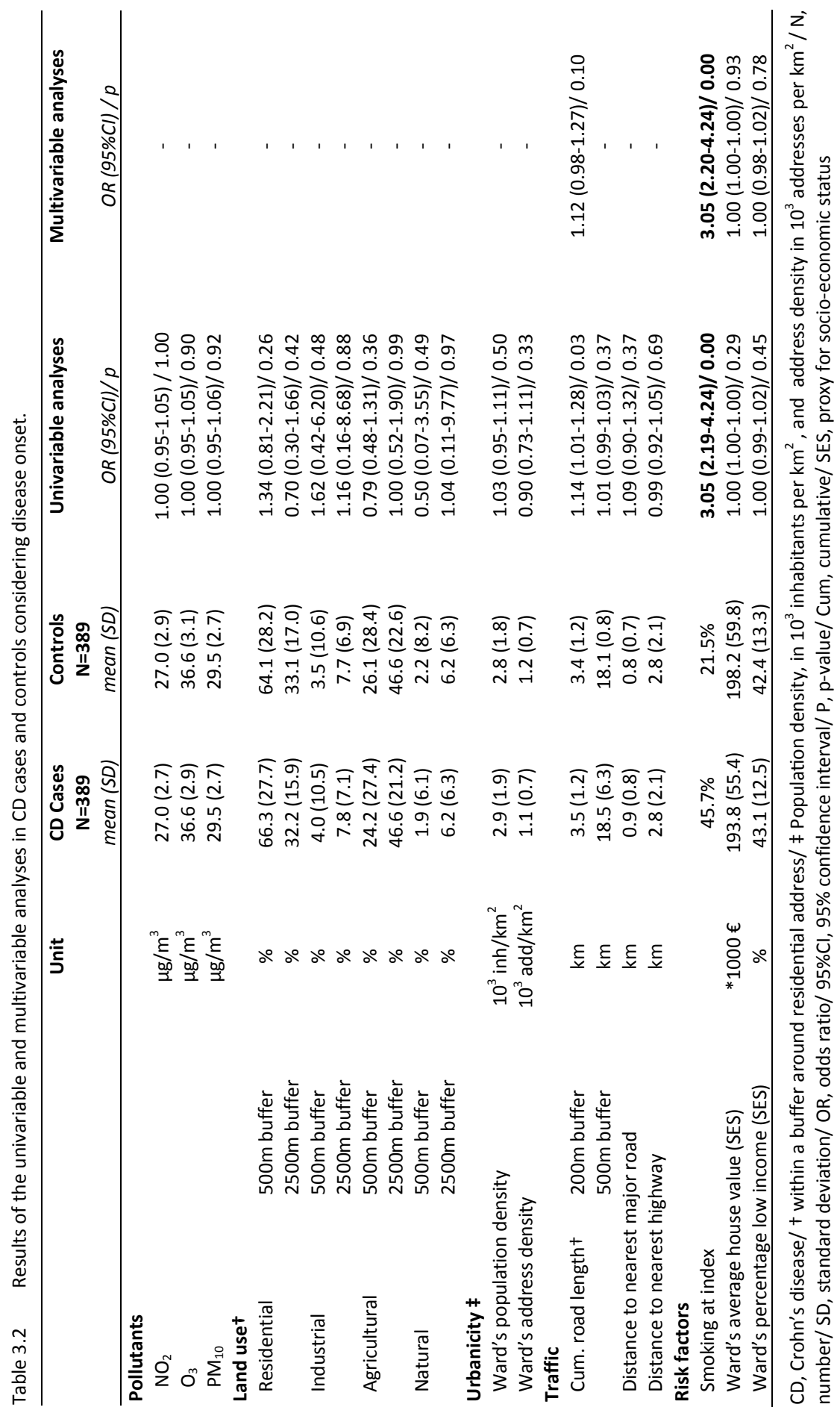




\section{Ambient air quality in relation to $C D$ disease course}

In total, $338 \mathrm{CD}$ patients had a stable residence for three years after diagnosis. Their baseline characteristics did not differ significantly from the total number of patients (data not shown). The mean number of quarters of disease activity was 2.78 (SD 1.72). Using the composite score, 174 (51\%) had a severe disease course after three years of follow up.

Considering disease activity by the number of active yearly quarters as continuous variable, $\mathrm{NO}_{2}$ concentration $(p=0.06), \mathrm{O}_{3}$ concentration $(p=0.02)$, industrial buffer zone of $2500 \mathrm{~m}(p=0.07)$, distance to nearest major road $(p=0.06)$ and smoking at diagnosis $(p=0.01)$ had a $p$-value below 0.10 in the univariable analyses. In the multivariable analysis, only smoking at diagnosis was positively associated with the number of quarters of disease activity $(p=0.02)$. Results are shown in Table 3.3.

In the multivariable sensitivity analysis using non-smokers only, no associations with increased number of active yearly quarters were found in the multivariable model.

Considering the composite score for severe disease course, $\mathrm{NO}_{2}$ concentration $(p=0.08)$, distance to the nearest major road $(p=0.02)$, distance to the nearest highway $(p=0.02)$, age at diagnosis $(p=0.08)$, and a ward's percentage of low incomes $(p=0.08)$ showed $p$-values below 0.10 in the univariable analyses. In the multivariable analysis, none of the parameters of ambient air quality and none of the possible risk factors were associated with a severe disease course. Results from the uni- and multivariable analyses are shown in Table 3.3.

In the multivariable sensitivity analyses on the separate components of the disease course definition (Supplementary Table S3.1), associations between the following were observed: more nature within $2500 \mathrm{~m}$ with surgery; a longer distance to the nearest major road, to the nearest highway, and a lower ward's average house value with $\geq 2$ hospitalizations; a longer distance to the nearest major road, a lower ward's average house value, and a lower ward's percentage of low income with disease progression; a younger age at diagnosis with $\geq 2$ steroid courses; female gender with biological use; and a higher cumulative road length within $200 \mathrm{~m}$ with the occurrence of fistulas. 


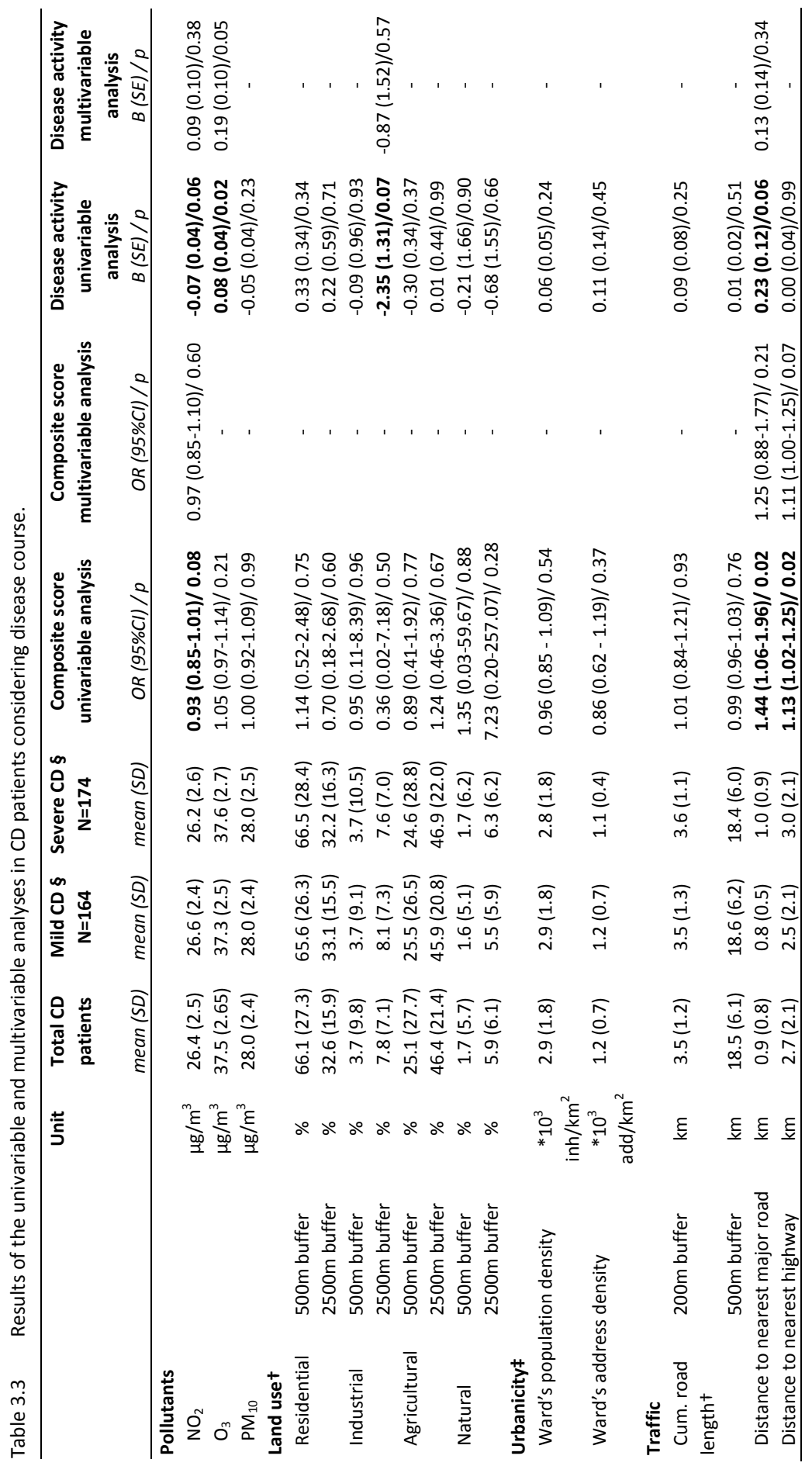




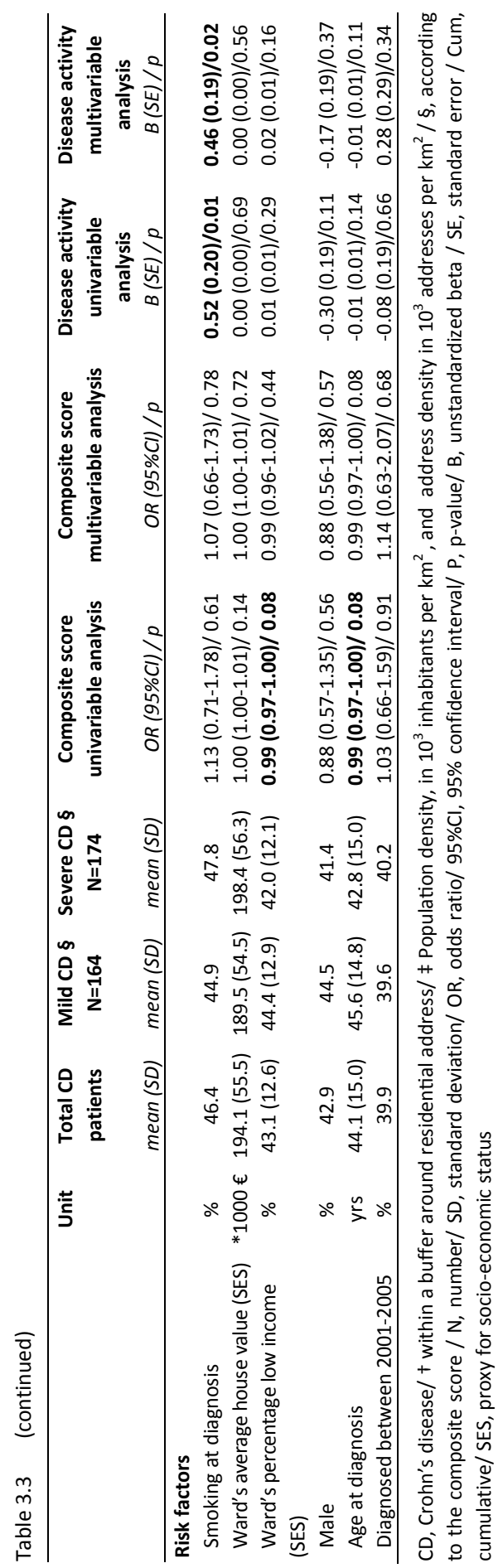




\section{Discussion}

In this IBDSL study, ambient air quality was neither associated with CD onset nor with a severe disease course within three years after diagnosis. Smoking at the index date/date of diagnosis however was associated with both disease onset and a higher number of yearly quarters with active disease during follow-up.

\section{Ambient air quality in relation to $C D$ onset}

Based on the findings from both the main and sensitivity analyses, ambient air quality is not a major risk factor for CD diagnosis in the area of South Limburg. None of the air pollutants, nor any of the parameters related to land use, urbanicity, or traffic were associated with $C D$ onset. Our findings are in line with two previous studies that reported no evident associations between ambient air pollution and CD in adults. In a study from 2010, Kaplan et al. used the general practice based THIN network from the United Kingdom for the identification of incident IBD cases (367 CD cases) and controls, and observed no associations between regional $\mathrm{NO}_{2}, \mathrm{SO}_{2}$ or $\mathrm{PM}_{10}$ concentrations and $C D$ incidence. ${ }^{15}$ Patients with early onset $C D \quad(\leq 23$ years at diagnosis), however, were more likely to live in regions with high levels of $\mathrm{NO}_{2}$ and $\mathrm{SO}_{2}$ which was explained by the higher susceptibility to toxic effects, the greater gastrointestinal absorption, and the less efficient metabolization of pollutants in children when compared to adults. ${ }^{15,28}$ As paediatric IBD was not included in our study, we could not confirm this finding. Moreover, outcomes may be affected by the use of an administrative database to identify IBD cases (i.e. being sensitive for poor case ascertainment) ${ }^{29}$ and the use of air pollution data on a regional rather than an individual level. In a study from 2016, Opstelten et al. did not find associations between $\mathrm{PM}_{10}, \mathrm{PM}_{2.5}$, soot, nitrogen oxides or traffic indicators and $\mathrm{CD}$ incidence in the European based EPIC cohort. ${ }^{16}$ Power was however limited in their study since only $38 \mathrm{CD}$ cases were identified.

In the present study, current smoking was a strong risk factor for CD onset which is in line with a recent meta-analysis. ${ }^{30}$ Though, it should be noted that odds ratios derived from case-control studies may be subject to a non-response bias. Such a bias occurs when certain persons are overrepresented in the response to health surveys, for instance healthier persons. ${ }^{31}$ Underestimation of current smoking status in controls leads to an overestimation of the odds ratios. Nevertheless, several mechanisms have been proposed to explain the association between smoking and CD, involving nicotine, oxidative stress, microbiota composition and gene-smoking interactions. $^{32-34}$

Even though this and other epidemiologic studies suggest no large role for ambient air quality in IBD onset, the hypothesis of ambient air quality affecting IBD onset should not be completely discarded yet. None of the studies, for instance, took 
the (genetic) susceptibility for poor air quality into account. It cannot be excluded that a given air pollutant contributes to onset in susceptible individuals. In addition, ambient air quality has only been studied in periods immediately prior to diagnosis, whereas poor ambient air quality in other key life stages, especially in early life with a developing intestinal microbiota and maturing immune system, may also have an effect on IBD onset in later life. Other study designs including these features are needed in future, in order to study whether the hypothesis can be completely rejected.

\section{Ambient air quality in relation to $C D$ disease course}

Next, we studied the association between ambient air quality and CD disease course, defined by both yearly quarters of active disease as well as a composite score. In the multivariable main analyses, none of the air pollutants and none of the parameters related to land use, urbanicity and traffic were associated neither to increased disease activity during follow-up nor to a severe disease course using the composite score. Though, the multivariable sensitivity analyses on separate components of the composite score revealed some new associations with parameters of ambient air quality. However, only a longer distance to the nearest major road was associated with more than one component ( $\geq 2$ hospitalizations and disease progression), and moreover, directed opposite to the expected. Because as much as 17 parameters of ambient air quality were tested in multiple sensitivity analysis, it seems reasonable to conclude that the observed associations arose by chance.

Smoking at diagnosis however was associated with a higher number of yearly quarters of disease activity during follow-up in the main analysis. This was in line with our expectations and supported by a recently published meta-analysis. ${ }^{9}$ Notably, smoking at diagnosis was not associated with a severe disease course when using the composite score as independent variable. This underlines the complexity of composite scores to describe disease course and supports our hypothesis that disease activity per quarter may reflect actual disease course better than classical outcome measures used in composite scores.

Based on the observations from the main and sensitivity analyses we reason that ambient air quality is not a major contributor in the disease course of South Limburg $C D$ patients. This was not in line with the only other study on this topic. Anantakrishnan et al. observed that a 1-log increase in the density of total pollutant emission was associated with a $40 \%$ increase in the county-level rate of hospitalizations in Wisconsin. ${ }^{17}$ These correlations were consistent on the level of individual pollutants (i.e. carbon monoxide, nitrous oxide, sulfur dioxide, volatile organic chemicals and particulate matter). Although the study was performed elegantly, it had several weaknesses. The authors used an administrative database not being designed for research purposes, and were not able to include smoking and 
other possible risk factors, such as age at diagnosis. Moreover, pollution and hospitalization data were studied on a county level, which is sensitive for aggregation bias. Such bias occurs when an association on an aggregate level does not represent the association at an individual level. ${ }^{35}$

\section{Strengths and limitations}

The strength of this study resides in its solid methodology. This includes the high number of available cases, the population-based character hereof (the distribution of presenting phenotypes resembled the distribution in the full IBDSL cohort), the high level of case-ascertainment, the adequate distribution of controls over South Limburg, the solid matching procedure, the ability to control for the most consistent risk factors for IBD, and the ability to analyse disease course both by yearly quarters of disease activity as well as a composite score of negative outcomes. In addition, we were able to use multiple parameters of ambient air quality which improves the sensitivity of the study and we were able to study ambient air quality data on an individual rather than a regional level, hereby minimizing aggregation bias.

This study has some limitations. First, some patients most probably resided elsewhere during parts of the day and had exposure profiles that to some extent deviated from the ones in this study. In addition, we were not able to correct for all airborne toxins (e.g. job-related exposures). Second, although previous associations between ambient air and health were detected in populations with similar size and exposure variability, mainly in the fields of pulmonology and gestation, ${ }^{36-39}$ it is possible that the exposure variability was too small in this region for a multifactorial disease as IBD. Third, GIS-maps were not available for every year and those closest to the diagnosis date were used, while the air quality parameters may vary over time. However, the largest gap was only seven years and we assume that the corresponding changes in air quality will be too subtle to influence our results. Fourth, only three years of follow-up were included to analyse disease course and some disease complications may take more time to develop. Though, by expanding the follow-up, many patients would be lost to follow up due to our stringent inclusion criteria concerning address stability. Finally, it was not possible to take (genetic) susceptibility to poor air quality into account. A given air pollutant may have had a causative role for an IBD exacerbation in susceptible persons, while identical concentrations of this pollutant did not lead to inflammation in non-susceptible persons. 


\section{Conclusion}

In conclusion, based on this study ambient air quality is not a strong contributing factor in the onset of $C D$ and the subsequent disease course in the South Limburg area of the Netherlands. 


\section{References}

1. Molodecky NA, Soon IS, Rabi DM, Ghali WA, Ferris M, Chernoff G, et al. Increasing incidence and prevalence of the inflammatory bowel diseases with time, based on systematic review. Gastroenterology. 2012;142(1):46-54 e42; quiz e30.

2. Wintjens D, Bergey F, Saccenti E, Jeuring S, van den Heuvel T, Romberg-Camps M, et al. Disease activity patterns of Crohn's disease in the first 10 years after diagnosis in the population-based IBD South Limburg cohort. J Crohns Colitis. 2020.

3. Van Assche G, Dignass A, Panes J, Beaugerie L, Karagiannis J, Allez M, et al. The second European evidence-based Consensus on the diagnosis and management of Crohn's disease: Definitions and diagnosis. J Crohns Colitis. 2010;4(1):7-27.

4. Halfvarson J, Bodin L, Tysk C, Lindberg E, Jarnerot G. Inflammatory bowel disease in a Swedish twin cohort: a long-term follow-up of concordance and clinical characteristics. Gastroenterology. 2003;124(7):1767-73.

5. Burisch J, Pedersen N, Cukovic-Cavka S, Brinar M, Kaimakliotis I, Duricova D, et al. East-West gradient in the incidence of inflammatory bowel disease in Europe: the ECCO-EpiCom inception cohort. Gut. 2014;63(4):588-97.

6. Barreiro-de Acosta M, Alvarez Castro A, Souto R, Iglesias M, Lorenzo A, Dominguez-Munoz JE. Emigration to western industrialized countries: A risk factor for developing inflammatory bowel disease. J Crohns Colitis. 2011;5(6):566-9.

7. Maaser C, Langholz E, Gordon H, Burisch J, Ellul P, Ramirez VH, et al. European Crohn's and Colitis Organisation Topical Review on Environmental Factors in IBD. J Crohns Colitis. 2017;11(8):905-20.

8. Mahid SS, Minor KS, Soto RE, Hornung CA, Galandiuk S. Smoking and inflammatory bowel disease: a meta-analysis. Mayo Clinic proceedings. 2006;81(11):1462-71.

9. To N, Gracie DJ, Ford AC. Systematic review with meta-analysis: the adverse effects of tobacco smoking on the natural history of Crohn's disease. Alimentary pharmacology \& therapeutics. 2016;43(5):549-61.

10. Papoutsopoulou S, Satsangi J, Campbell BJ, Probert CS. Review article: impact of cigarette smoking on intestinal inflammation-direct and indirect mechanisms. Aliment Pharmacol Ther. 2020;51(12):126885.

11. Salim SY, Kaplan GG, Madsen KL. Air pollution effects on the gut microbiota: a link between exposure and inflammatory disease. Gut microbes. 2014;5(2):215-9.

12. Kaplan GG, Dixon E, Panaccione R, Fong A, Chen L, Szyszkowicz M, et al. Effect of ambient air pollution on the incidence of appendicitis. CMAJ. 2009;181(9):591-7.

13. Orazzo F, Nespoli L, Ito K, Tassinari D, Giardina D, Funis M, et al. Air pollution, aeroallergens, and emergency room visits for acute respiratory diseases and gastroenteric disorders among young children in six Italian cities. Environmental health perspectives. 2009;117(11):1780-5.

14. Lopez-Abente G, Garcia-Perez J, Fernandez-Navarro P, Boldo E, Ramis R. Colorectal cancer mortality and industrial pollution in Spain. Bmc Public Health. 2012;12:589.

15. Kaplan GG, Hubbard J, Korzenik J, Sands BE, Panaccione R, Ghosh S, et al. The inflammatory bowel diseases and ambient air pollution: a novel association. Am J Gastroenterol. 2010;105(11):2412-9.

16. Opstelten JL, Beelen RMJ, Leenders M, Hoek G, Brunekreef B, van Schaik FDM, et al. Exposure to Ambient Air Pollution and the Risk of Inflammatory Bowel Disease: A European Nested Case-Control Study. Dig Dis Sci. 2016;61(10):2963-71.

17. Ananthakrishnan AN, McGinley EL, Binion DG, Saeian K. Ambient air pollution correlates with hospitalizations for inflammatory bowel disease: an ecologic analysis. Inflamm Bowel Dis. 2011;17(5):1138-45.

18. van den Heuvel TR, Jonkers DM, Jeuring SF, Romberg-Camps MJ, Oostenbrug LE, Zeegers MP, et al. Cohort Profile: The Inflammatory Bowel Disease South Limburg Cohort (IBDSL). Int J Epidemiol. 2017;46(2):e7.

19. Satsangi J, Silverberg MS, Vermeire S, Colombel JF. The Montreal classification of inflammatory bowel disease: controversies, consensus, and implications. Gut. 2006;55(6):749-53. 
20. Dennis M, Scaletta KL, James P. Evaluating urban environmental and ecological landscape characteristics as a function of land-sharing-sparing, urbanity and scale. PLoS One. 2019;14(7):e0215796.

21. Zou B, Xu S, Sternberg T, Fang X. Effect of Land Use and Cover Change on Air Quality in Urban Sprawl. Sustainability. 2016;8(7):677-91.

22. Rao M, George LA, Shandas V, Rosenstiel TN. Assessing the Potential of Land Use Modification to Mitigate Ambient $\mathrm{NO}(2)$ and Its Consequences for Respiratory Health. Int J Environ Res Public Health. 2017;14(7).

23. Velders GJM, Aben JMM, Geilenkirchen GP, Den Hollander HA, Van der Swaluw E, De Vries WJ, et al. Grootschalige concentratie- en depositie kaarten Nederland, Rapportage 2015. RIVM. 2015;20150119:1-99.

24. Wardle RA, Wardle AJ, Charadva C, Ghosh S, Moran GW. Literature review: impacts of socioeconomic status on the risk of inflammatory bowel disease and its outcomes. Eur J Gastroenterol Hepatol. 2017;29(8):879-84.

25. Beaugerie L, Seksik P, Nion-Larmurier I, Gendre JP, Cosnes J. Predictors of Crohn's disease. Gastroenterology. 2006;130(3):650-6.

26. Jeuring SF, van den Heuvel TR, Liu LY, Zeegers MP, Hameeteman WH, Romberg-Camps MJ, et al. Improvements in the Long-Term Outcome of Crohn's Disease Over the Past Two Decades and the Relation to Changes in Medical Management: Results from the Population-Based IBDSL Cohort. Am J Gastroenterol. 2017;112(2):325-36.

27. Lim WC, Wang Y, MacDonald JK, Hanauer S. Aminosalicylates for induction of remission or response in Crohn's disease. Cochrane Database Syst Rev. 2016;7:CD008870.

28. Sly PD, Flack F. Susceptibility of children to environmental pollutants. Annals of the New York Academy of Sciences. 2008;1140:163-83.

29. Kaplan GG. Pitfalls and perils of using administrative databases to evaluate the incidence of inflammatory bowel disease overtime. Inflamm Bowel Dis. 2014;20(10):1777-9.

30. Piovani D, Danese S, Peyrin-Biroulet L, Nikolopoulos GK, Lytras T, Bonovas S. Environmental Risk Factors for Inflammatory Bowel Diseases: An Umbrella Review of Meta-analyses. Gastroenterology. 2019;157(3):647-59 e4.

31. Hill A, Roberts J, Ewings P, Gunnell D. Non-response bias in a lifestyle survey. Journal of public health medicine. 1997;19(2):203-7.

32. Ng SC, Bernstein CN, Vatn MH, Lakatos PL, Loftus EV, Jr., Tysk C, et al. Geographical variability and environmental risk factors in inflammatory bowel disease. Gut. 2013;62(4):630-49.

33. Ananthakrishnan AN. Epidemiology and risk factors for IBD. Nature reviews Gastroenterology \& hepatology. 2015;12(4):205-17.

34. Wang MH, Achkar JP. Gene-environment interactions in inflammatory bowel disease pathogenesis. Current opinion in gastroenterology. 2015;31(4):277-82.

35. Last J. A dictionary of epidemiology. 4th ed. New York: Oxford University Press; 2000.

36. Nawrot TS, Vos R, Jacobs L, Verleden SE, Wauters S, Mertens V, et al. The impact of traffic air pollution on bronchiolitis obliterans syndrome and mortality after lung transplantation. Thorax. 2011;66(9):748-54.

37. Bijnens EM, Derom C, Gielen M, Winckelmans E, Fierens F, Vlietinck R, et al. Small for gestational age and exposure to particulate air pollution in the early-life environment of twins. Environmental research. 2016;148:39-45.

38. Bijnens E, Zeegers MP, Gielen M, Kicinski M, Hageman GJ, Pachen D, et al. Lower placental telomere length may be attributed to maternal residential traffic exposure; a twin study. Environment international. 2015;79:1-7.

39. Saenen ND, Vrijens K, Janssen BG, Madhloum N, Peusens M, Gyselaers W, et al. Placental Nitrosative Stress and Exposure to Ambient Air Pollution During Gestation: A Population Study. Am J Epidemiol. 2016;184(6):442-9. 


\section{Supporting information}

Table S3.1 Overview of significant associations in the multivariable sensitivity analyses in CD patients.

\begin{tabular}{|c|c|c|c|c|c|c|c|}
\hline & \multicolumn{7}{|c|}{ Separate components of disease course definition as study endpoint } \\
\hline & $\begin{array}{l}\text { Surgery } \\
\text { OR } \\
(95 \mathrm{Cl}) \\
/ p\end{array}$ & $\begin{array}{c}\geq 2 \\
\text { Hospital. } \\
\text { OR } \\
(95 \mathrm{Cl}) \\
\text { /p }\end{array}$ & $\begin{array}{c}\text { Progression } \\
\text { OR } \\
(95 \mathrm{Cl}) \\
/ \mathrm{p}\end{array}$ & $\begin{array}{l}\geq 2 \text { Steroid } \\
\text { courses } \\
\text { OR } \\
(95 \mathrm{Cl}) \\
/ \mathrm{p}\end{array}$ & $\begin{array}{c}\text { Biological } \\
\text { OR } \\
(95 \mathrm{Cl}) \\
/ \mathrm{p} \\
\end{array}$ & $\begin{array}{l}\text { Fistula } \\
\text { OR } \\
(95 \mathrm{Cl}) \\
/ \mathrm{p} \\
\end{array}$ & $\begin{array}{l}\text { Stricture } \\
\text { OR } \\
(95 \mathrm{Cl}) \\
/ \mathrm{p}\end{array}$ \\
\hline \multicolumn{8}{|l|}{ Ambient air quality } \\
\hline $\begin{array}{l}\text { Natural land use } \\
\text { in } 2500 \mathrm{~m} \text { buffer } \\
\text { zone }\end{array}$ & $\begin{array}{l}973.04 \\
(3.53- \\
26788)\end{array}$ & $*$ & $*$ & * & $*$ & $*$ & $*$ \\
\hline $\begin{array}{l}\text { Cum. road length } \\
\text { in } 200 \mathrm{~m} \text { buffer } \\
\text { zone }\end{array}$ & $\begin{array}{c}/ 0.02 \\
*\end{array}$ & * & $*$ & $*$ & $*$ & $\begin{array}{c}1.52 \\
(1.04-2.21) \\
/ 0.03\end{array}$ & $*$ \\
\hline $\begin{array}{l}\text { Distance to } \\
\text { nearest major road }\end{array}$ & $*$ & $\begin{array}{c}2.09 \\
(1.30-3.38) \\
/ 0.00\end{array}$ & $\begin{array}{c}1.98 \\
(1.28-3.06) \\
/ 0.00\end{array}$ & * & * & $*$ & $*$ \\
\hline $\begin{array}{l}\text { Distance to } \\
\text { nearest highway }\end{array}$ & $*$ & $\begin{array}{c}1.22 \\
(1.01-1.47) \\
/ 0.04\end{array}$ & $*$ & $*$ & $*$ & * & $*$ \\
\hline \multicolumn{8}{|l|}{ Risk factors } \\
\hline $\begin{array}{l}\text { Ward's average } \\
\text { house value }\end{array}$ & $*$ & $\begin{array}{c}0.95 \\
(0.91-1.00) \\
/ 0.03\end{array}$ & $\begin{array}{c}0.98 \\
(0.97- \\
1.00) / 0.01\end{array}$ & * & * & * & $*$ \\
\hline $\begin{array}{l}\text { Ward's percentage } \\
\text { low income }\end{array}$ & $*$ & $*$ & $\begin{array}{c}0.94 \\
(0.90-0.99) \\
/ 0.01\end{array}$ & $*$ & $*$ & $*$ & $*$ \\
\hline Male & $*$ & $*$ & $*$ & $*$ & $\begin{array}{c}0.49 \\
(0.25-0.95) \\
/ 0.03\end{array}$ & $*$ & $*$ \\
\hline Age at diagnosis & $*$ & $*$ & $*$ & $\begin{array}{c}0.97 \\
(0.95-0.99) \\
/ 0.01 \\
\end{array}$ & $*$ & $*$ & $*$ \\
\hline
\end{tabular}

Cum, cumulative/ $*$ value not significant/ NA, not applicable/ OR, odds ratio/ $95 \% \mathrm{Cl}, 95 \%$ confidence interval/ $P$, p-value/ 
Associations between ambient air quality and Crohn's disease 
20 


\section{Chapter 4}

\section{Novel perceived stress and life events precede flares of inflammatory bowel disease: a prospective 12-month follow-up study}

Dion S.J. Wintjens, Marin J. de Jong, Andrea E. van der Meulen-de Jong, Mariëlle J.L. Romberg-Camps, Marco C. Becx, Jeroen P.M.J. Maljaars, Ad A. van Bodegraven, Nofel Mahmmod, Tineke Markus, Jeoffrey J.L. Haans, Ad A.M. Masclee, Bjorn Winkens, Daisy M.A.E. Jonkers, Marie J. Pierik J Crohns Colitis 2019;13(4):410-416 


\begin{abstract}
Background

Inflammatory bowel disease (IBD) is characterized by recurrent disease flares. The impact of psychosocial wellbeing on the occurrence of flares is unclear. In this prospective study, we aimed to evaluate the association between patient reported psychosocial wellbeing and disease flares using continuous monitoring.
\end{abstract}

\title{
Methods
}

Consecutive IBD patients were recruited from the mylBDcoach telemedicine study cohort. During 12 months, participants reported on disease activity and anxiety, depression, fatigue, perceived stress, and life events every 1-3 months. Flares were defined using a combination of clinical disease activity and additional measurements. Generalized estimating equation models were used to assess associations between psychosocial wellbeing and flares over time. The influences of both the presence of psychosocial symptoms in general as well as novel psychosocial symptoms were analysed.

\section{Results}

In total, 417 patients were included. Forty-nine patients (11.8\%) experienced a flare during the study period. The occurrence of life events in the preceding 3 months was positively associated with flares (odds ratio $[O R]=1.81$; $95 \%$ confidence interval $[\mathrm{Cl}]=1.04-3.17)$, while the presence of anxiety, depression, fatigue and perceived stress in general was not. However, novel perceived stress (OR=2.92; 95\% $\mathrm{Cl}=1.44-5.90)$ was associated with flares.

\section{Conclusions}

The occurrence of life events and novel perceived stress are associated with disease flares in the next three months, while the presence of perceived stress in general is not. These findings underline the importance of continuous personalized monitoring of IBD patients and may contribute to the prevention of disease flares. 


\section{Introduction}

Inflammatory bowel disease (IBD), comprising Crohn's disease (CD) and ulcerative colitis (UC), is a chronic and disabling disease characterized by recurrent periods of disease activity. These flares warrant escalation of medical treatment and often require hospitalizations or surgery. Recurrent flares may also lead to irreversible bowel damage and disease progression (e.g. the occurrence of complications like fistula and stenosis). ${ }^{1,2}$ Although biochemical markers are available for early detection of disease activity $^{3}$, identification of the factors contributing to the emergence of flares might be an even more interesting approach to improve the outcome of IBD.

Regarding potentially flare-inducing factors, psychosocial wellbeing of patients is of interest. While not systematically monitored by healthcare professionals in routine care, a high prevalence of psychological disorders such as anxiety and depression is reported in the IBD population. ${ }^{4,5}$ This may be a consequence of the chronic disease itself, but it is also hypothesized that impaired psychosocial wellbeing can negatively impact gut health through multiple immune-neuroendocrine brain-gut interaction pathways. ${ }^{6,7}$

A large number of studies have investigated the association between psychosocial wellbeing and disease activity in IBD, although many are limited by their cross-sectional design, thereby potentially neglecting the aforementioned bi-directionality of the braingut axis. When taking into account only the longitudinal studies, contradictive results have been reported regarding the effects of anxiety and depression on flares. ${ }^{8}$ Perceived stress and life events have been studied more extensively and it has been reported that a positive association exists between flares and perceived stress in most longitudinal studies. ${ }^{9-14}$ In many studies, however, careful interpretation is advocated due to low sample size and the sole use of clinical disease activity indices to define flares, because these indices are poor predictors of mucosal inflammation. ${ }^{15}$ Also, perceived stress may affect intestinal motility and may magnify visceral sensitivity, leading to worsening of abdominal symptoms in the absence of inflammation. ${ }^{16,17}$ It remains debatable to what extent mood disorders and perceived stress are associated with disease flares. For instance, because both depression and perceived stress can be present for longer periods ${ }^{13,18}$, it may be relevant to focus on within-subject changes in psychosocial wellbeing rather than to analyse only the presence of impaired psychosocial wellbeing preceding flares, which has, to our knowledge, not been done before.

Recently, de Jong et al. showed that continuous monitoring at home with the telemedicine tool 'MylBDcoach' is safe and even reduced outpatient visits and hospital admissions. ${ }^{19}$ MylBDcoach continuously monitors patient reported disease activity and psychosocial wellbeing through questionnaires. This method of data collection may provide important insights into psychosocial wellbeing over time. In this prospective 
study, we aimed to evaluate which domains of psychosocial wellbeing, when impaired, were associated with future disease flares based on data from the mylBDcoach trial.

\section{Materials and methods}

\section{Design \& procedures}

All data used in this study were derived from the mylBDcoach study cohort. The design of this randomized controlled telemedicine study has previously been described in detail. ${ }^{19}$ In short, IBD patients were included in four hospitals in the Netherlands (i.e. two academic hospitals, Maastricht University Medical Centre and Leiden University Medical Centre, and two regional hospitals, Zuyderland Medical Centre Sittard and St. Antonius Hospital Nieuwegein). Patients between 18 and 75 years of age who had a histopathologically corroborated diagnosis of IBD were eligible for inclusion. Exclusion criteria comprised insufficient knowledge of the Dutch language, lack of internet access by computer, tablet or smartphone, or a hospital admission within 2 weeks prior to inclusion. Also, patients with an ileoanal pouch or ileorectal anastomosis were excluded. After inclusion, patients were randomized in a 1:1 ratio to standard care (control group) or to care through mylBDcoach (intervention group) and followed for at least 12 months. Details of the mylBDcoach telemedicine system have been described elsewhere. $^{20}$ In brief, mylBDcoach is a secure webpage which is accessible through computer, tablet or smartphone. The system provides monthly monitoring modules, including questions regarding disease activity, use of medication, treatment adherence, smoking status and psychosocial wellbeing. When patients achieved sustained remission (i.e. low clinical activity for three consecutive months), the system allowed to complete the monitoring module once every three months. When predefined thresholds, for instance on clinical disease activity, were exceeded, a healthcare provider of the local team contacted the patient for further assessment. The study was approved by the Medical Research Ethics Committee of the Maastricht University Medical Centre+, being applicable to all participating centres. This trial was registered at ClinicalTrials.gov (NCT02173002).

For the present study, we included all patients who received care through mylBDcoach (i.e. the intervention arm of the randomized study). Patients without a single period of documented remission during follow-up were excluded since this period of remission was required to analyse the association between the development of disease flares and preceding psychosocial wellbeing. Detailed baseline data at time of inclusion in MyIBDcoach (i.e. patient characteristics, disease phenotype, disease duration and previous treatments) were collected by scrutinizing patient files using standardized registration forms. During the 12 months of follow-up, questionnaires on disease activity 
(MIAH-questionnaire ${ }^{21}$ ) and psychosocial wellbeing (i.e. anxiety, depression, fatigue, perceived stress, and life-events) were completed every 1-3 months.

\section{Definitions}

In line with previous analyses based on the mylBDcoach tool, flares were defined as clinical symptoms (i.e. positive score on the MIAH-questionnaire or symptoms during outpatient visits) indicative of disease activity in combination with at least one of the following: concurrent calprotectin $>250 \mu \mathrm{g} / \mathrm{g}$ in the stool or active disease determined by endoscopy, magnetic resonance imaging or computed tomography. In daily practice, in case of clinically severe symptoms suggestive for IBD disease activity, the treating physician occasionally judged these symptoms to be evident enough to adjust therapy. Therefore, to capture all flares, also clinical episodes were defined as flares if symptoms suggestive of IBD disease activity resulted in a dose escalation or initiation of a new drug to induce remission.

Psychosocial parameters were assessed through a patient-reported questionnaire containing one question for each psychosocial domain of interest (Table 4.1). For anxiety, depression, and fatigue, questions could be answered on a 5-point Likert-scale (i.e. 'seldom or never', 'occasionally', 'regularly', 'often', or 'always or almost always'). Cut-offs were determined based on the smallest Euclidian distances compared to validated questionnaires (i.e. HADS- $\mathrm{A}^{22}, \mathrm{HADS}-\mathrm{D}^{22}$, and $\mathrm{VVV}^{23}$ ). The performance of the questionnaire is shown in Table 4.1. For perceived stress, we used a VAS-scale on which a patient could report on their current stress level (range from 1 to 10) in which a higher score reflects higher stress levels. This scale showed a moderate though significant correlation with the Cohen's Perceived Stress Scale (PSS; $r=0.654){ }^{24}$ However, note that the PSS is based on perceived stress during the previous month, while our scale measures current stress levels. A cut-off point of 4 , based on expert opinion of our team of gastroenterologists and our population's average, was used to differentiate low vs high perceived stress levels. The occurrence of life events was scored in a binary approach (i.e. yes/no). The underlying reason for the life event was answered as an open-ended question and was therefore neglected in the analysis. 
Table 4.1 Overview of psychosocial questionnaire used in the mylBDcoach telemedicine tool.

\begin{tabular}{|c|c|c|c|c|}
\hline Domain & Question & Scale & Cut-off & $\begin{array}{l}\text { Performance versus } \\
\text { validated } \\
\text { questionnaire } \\
\text { (sens/spec) }\end{array}$ \\
\hline Anxiety & $\begin{array}{l}\text { In the past two } \\
\text { weeks I ... felt } \\
\text { anxious. }\end{array}$ & Likert (1-5) & 2 (occasionally) & HADS-A ${ }^{22}(64 / 82)$ \\
\hline Depression & $\begin{array}{l}\text { In the past two } \\
\text { weeks I ... felt } \\
\text { miserable or } \\
\text { depressed. }\end{array}$ & Likert (1-5) & 3 (frequently) & HADS-D 22 (73/93) \\
\hline Fatigue & $\begin{array}{l}\text { In the past two } \\
\text { weeks I ... felt tired. }\end{array}$ & Likert (1-5) & 3 (frequently) & $\operatorname{VVV}^{23}(90 / 100)$ \\
\hline Perceived stress & $\begin{array}{l}\text { Rate your current } \\
\text { stress level on a } \\
\text { scale from } 1 \text { to } 10 \text {, } \\
\text { what number would } \\
\text { you give? }\end{array}$ & VAS $(1-10)$ & NA & $\mathrm{PSS}^{24}(\mathrm{R}=0.654)$ \\
\hline Life events & $\begin{array}{l}\text { Did you recently } \\
\text { experience any } \\
\text { important or drastic } \\
\text { events which } \\
\text { influenced your } \\
\text { feelings? }\end{array}$ & Dichotomous & NA & NA \\
\hline
\end{tabular}

VAS, visual analogue scale / NA, not applicable / sens, sensitivity / spec, specificity / HADS-D, Hospital Anxiety and Depression Scale - Depression / HADS-A, Hospital Anxiety and Depression Scale - Anxiety / VVV, Verkorte VermoeidheidVragenlijst (translated: Short Fatigue Questionnaire) / PSS, Perceived Stress Scale.

\section{Statistical analysis}

Baseline characteristics are presented as means with corresponding standard deviations (SD) for numerical variables with a normal distribution, as medians with corresponding interquartile ranges (IQR) for numerical variables without a normal distribution, and as number of patients (\%) for categorical variables. For comparison between groups, the independent-samples t-test and chi-square test or Fisher's exact test, when appropriate, were used for numerical and categorical variables, respectively.

Generalized estimating equation (GEE) models were used to identify associations between psychosocial wellbeing and the subsequent development of flares over time. This method is used to account for repeated measures within the same patient, where the covariance pattern was unstructured. Because it was unknown how long a patient was in remission when entering the study, the first 3 months of all patients were ignored in the analyses. Next, each month of follow-up was considered either as positive or negative with respect to flares, according to the aforementioned definition. Also, patient reported psychosocial wellbeing was assessed with intervals of 1 month using the aforementioned cut-offs. When active disease was present at baseline or when a flare occurred during follow-up, the subsequent 6 months were excluded from the analysis to correct for a potential effect of disease activity and the subsequent 
remission-induction therapy on the psychosocial wellbeing of a patient. This can be considered as a wash-out period for both gastrointestinal inflammation and psychosocial imbalance caused by the preceding flare. Because patients could choose to fill in the questionnaires either once every month or once every 3 months, all models estimate the effect of psychosocial wellbeing on disease activity in the next quarter.

In the first GEE model, the association between flares and the presence of psychosocial symptoms in general was assessed. Predefined cut-offs were used to indicate the presence or absence of all psychosocial factors available in mylBDcoach, regardless of the prior psychosocial wellbeing of the patient. In the second GEE model, the association between flares and novel psychosocial symptoms was assessed. Here, differences in psychosocial parameters over time were determined to separate novel symptoms from pre-existing symptoms. At each time point the alteration in psychosocial parameters was regarded as positive when this change exceeded the cutoff values of these parameters (e.g. from 'seldom or never feeling depressed' (i.e. score 1) to 'often feeling depressed' (i.e. score 4)) in the 3 months preceding this time point. Life events were only analysed in the first model, because life events are 'novel' by definition and therefore the second model is not applicable. To ensure a prospective association between the psychosocial parameters and subsequent flares, psychosocial parameters were not taken into account as predictors when positive at the same time point as the flare. For example, when a patient experienced a flare between time points 5 and 6 , the latter was regarded as 'time point of flare' and psychosocial scores from time points 3 to 5 were used in the model as explanatory variables.

All results were analysed using a multivariable model including gender, disease phenotype, disease duration at baseline, and smoking status at baseline to correct for their potential confounding effect on disease flares. Although our study was underpowered for additional confounders, medication use at baseline was added to the model as a sensitivity analysis. All analyses were conducted using a significance level of 0.05 . Two-sided $p$-values $\leq 0.05$ were considered as statistically significant.

\section{Results}

In total, 465 patients were allocated to the mylBDcoach intervention. ${ }^{19}$ Of these, nine never started using the application and 18 were lost to follow-up. After exclusion of these patients and those with IBD unclassified (IBD-U) $(n=3)$, those without any completed questionnaire $(n=11)$, and those without a single period of remission $(n=7)$, 417 patients were eligible for this study. Of these, 49 (11.8\%) developed a flare during follow-up (i.e. change from inactive to active disease). Two of these patients developed a second flare after remission was re-obtained. Flares were defined by clinical symptoms in combination with an elevated faecal calprotectin, active disease on endoscopy or imaging, and adjustment of therapy by a gastroenterologist in 14 (27.4\%), 
$21(41.2 \%)$, and $16(31.4 \%)$ cases, respectively. Baseline characteristics of these patients (i.e. relapsers) compared to those not developing a flare during follow-up (i.e. nonrelapsers) are presented in Table 4.2. No significant differences in baseline characteristics were found between relapsers and non-relapsers, except for a greater proportion of smokers in the latter group $(p=0.005)$. The average time from inclusion to their first disease flare for relapsers was $6.4(S D=2.6)$ months.

Table 4.2 Baseline characteristics, stratified by occurrence of disease flares.

\begin{tabular}{|c|c|c|c|}
\hline & $\begin{array}{l}\text { Relapsers } \\
(n=49)\end{array}$ & $\begin{array}{c}\text { Non-relapsers } \\
(n=368)\end{array}$ & p-value \\
\hline Crohn's disease, n (\%) & $26(53.1)$ & $222(60.3)$ & 0.331 \\
\hline Male, n (\%) & $15(30.6)$ & 158 (42.9) & 0.100 \\
\hline \multicolumn{4}{|l|}{ Montreal at baseline $^{\wedge}$} \\
\hline Age (CD \& UC) & & & 0.600 \\
\hline$A 1, n(\%)$ & $8(16.3)$ & $60(16.3)$ & \\
\hline$A 2, n(\%)$ & $26(53.1)$ & 219 (59.5) & \\
\hline$A 3, n(\%)$ & $15(30.6)$ & $89(24.2)$ & \\
\hline Disease location (CD) & & & 0.741 \\
\hline$L 1, n(\%)$ & $7(26.9)$ & 73 (32.9) & \\
\hline$L 2, n(\%)$ & $6(23.1)$ & $55(24.8)$ & \\
\hline$L 3, n(\%)$ & $13(50.0)$ & $94(42.3)$ & \\
\hline Disease behavior (CD) & & & 0.958 \\
\hline$B 1(C D), n(\%)$ & $16(61.6)$ & $134(60.6)$ & \\
\hline$B 2(C D), n(\%)$ & $7(26.9)$ & $57(25.8)$ & \\
\hline$B 3(C D), n(\%)$ & $3(11.5)$ & $30(13.6)$ & \\
\hline Disease extent (UC) & & & 0.768 \\
\hline$E 1(U C), n(\%)$ & $2(8.7)$ & $19(12.8)$ & \\
\hline$E 2(U C), n(\%)$ & $10(43.5)$ & $69(46.3)$ & \\
\hline E3 (UC), $n(\%)$ & $11(47.8)$ & 61 (40.9) & \\
\hline Age at baseline (years), mean (SD) & $46.08(15.24)$ & $43.95(13.71)$ & 0.313 \\
\hline Disease duration at baseline (years), median (IQR) & $4.65(3.38-17.8)$ & $10.8(5.2-20.8)$ & 0.172 \\
\hline Active disease at baseline, $\mathrm{n}(\%)$ & $4(8.2)$ & $28(7.6)$ & 0.908 \\
\hline Medication use at baseline & & & 0.434 \\
\hline No medication/5-ASA, $n(\%)$ & $15(30.6)$ & $142(39.3)$ & \\
\hline Immunomodulators, $\mathrm{n}(\%)$ & $16(32.7)$ & $93(25.8)$ & \\
\hline Biologics, n (\%) & $18(36.7)$ & 126 (34.9) & \\
\hline Current smoking at baseline, $\mathrm{n}(\%)$ & $1(2.0)$ & 65 (17.7) & $0.005^{*}$ \\
\hline History of IBD-related surgery at baseline, $n(\%)$ & $5(10.2)$ & $41(11.1)$ & 0.470 \\
\hline
\end{tabular}

$\mathrm{N}$, number of patients / CD, Crohn's disease / UC, Ulcerative colitis / SD, standard deviation / IQR, interquartile range/ 5-ASA, 5-aminosalicylic acid / *, p-value below $0.05 / \wedge$, classification according to Montreal Classification. ${ }^{36}$ Age was defined as below 17 (A1), between 17 and 40 (A2) and above 40 (A3). Disease location of CD was defined as ileal involvement (L1), exclusive colonic involvement (L2), ileocolonic involvement (L3). Disease behaviour of $C D$ was defined as non-stricturing/non-penetrating (B1), stricturing (B2), penetrating (B3). Disease extent of UC was defined as ulcerative proctitis (E1), left sided UC (E2) and extensive UC (E3). 
Regarding the presence of psychosocial symptoms in general, only the occurrence of life events (Odds ratio $(\mathrm{OR})=1.81,95 \%$ Confidence Interval $(95 \% \mathrm{Cl})=1.04-3.17$ ) was associated with flare development in the next three months (Table 4.3). Neither anxiety $(\mathrm{OR}=0.73,95 \% \mathrm{Cl}=0.38-1.39)$, depression $(\mathrm{OR}=1.33,95 \% \mathrm{Cl}=0.70-2.55)$, fatigue $(\mathrm{OR}=1.91$, $95 \% \mathrm{Cl}=0.98-3.73)$, nor perceived stress $(\mathrm{OR}=1.09,95 \% \mathrm{Cl}=0.62-1.91)$ were statistically significantly associated with flare development. Regarding novel psychosocial symptoms (i.e. alteration exceeding cut-off), only perceived stress (OR=2.92, $95 \% \mathrm{Cl}=1.44-5.90$ ) was associated with subsequent flares (Table 4.3), independent of the presence of other psychosocial factors in general. No statistically significant association with subsequent flares was found in this second GEE model for anxiety ( $O R=1.12,95 \% \mathrm{Cl}=0.50-2.51$ ), depression $(\mathrm{OR}=1.28,95 \% \mathrm{Cl}=0.54-3.07)$, and fatigue ( $O R=1.58,95 \% \mathrm{Cl}=0.79-3.15)$. All results were adjusted for gender, disease phenotype, disease duration, and smoking status. When results were analysed for CD and UC separately, the association between flares and both life events and perceived stress tended to be stronger in CD. However, due to the small number of relapses, the study was not powered to analyse these associations and the results should be interpreted with care.

In a first sensitivity analysis, medication use at baseline was added to the model. By applying this, all results remained similar. As a second sensitivity analysis, different cut-offs of the questions regarding depression, anxiety, fatigue, and perceived stress were used. For depression, anxiety, and fatigue, neither higher nor lower cut-offs changed the results. For novel perceived stress, a difference was observed. In case cutoffs higher than 4 were chosen, perceived stress was no longer statistically significant (cut-off 5: OR=1.52, $95 \% \mathrm{Cl}=0.67-3.45$ ), while cut-offs below 4 remained statistically significant (cut-off 3: OR=2.24, 95\% $\mathrm{Cl}=1.02-4.90$ ).

Table 4.3 Association between both the presence of psychosocial symptoms in general (GEE model 1) as well as novel psychosocial symptoms (GEE model 2) and disease flares.

\begin{tabular}{lcccc}
\hline & \multicolumn{2}{c}{$\begin{array}{c}\text { GEE model 1: presence of psychosocial } \\
\text { symptoms in general }\end{array}$} & \multicolumn{2}{c}{$\begin{array}{c}\text { GEE model 2: novel psychosocial } \\
\text { symptoms }\end{array}$} \\
\cline { 2 - 5 } & $\boldsymbol{O R}$ & $\mathbf{9 5 \% - C l}$ & $\mathbf{O R}$ & $\mathbf{9 5 \% - C I}$ \\
\hline Anxiety & 0.73 & $0.38-1.39$ & 1.12 & $0.50-2.51$ \\
Depression & 1.33 & $0.70-2.55$ & 1.28 & $0.54-3.07$ \\
Fatigue & 1.91 & $0.98-3.73$ & 1.58 & $0.79-3.15$ \\
Perceived stress & 1.09 & $0.62-1.91$ & 2.92 & $1.44-5.90^{* *}$ \\
Life events & 1.81 & $1.04-3.17^{*}$ & $\mathrm{NA}$ & $\mathrm{NA}$ \\
\hline
\end{tabular}

OR, Odds ratio / 95\%-Cl, 95\%-Confidence Interval / *, p-value below 0.05 / **, p-value below $0.01 / \mathrm{NA}$, not applicable. All analyses were adjusted for gender, disease phenotype, disease duration at baseline, and smoking status at baseline. 


\section{Discussion}

In this prospective continuous telemedicine monitoring study we evaluated the effect of psychosocial wellbeing on subsequent disease flares. A positive association was found between both life events as well as perceived stress and disease flares. We identified a relevant difference between the presence of perceived stress in general, irrespective of changes over time, and novel perceived stress. Only the latter was prospectively associated with occurrence of disease flares in the next 3 months. Anxiety, depression and fatigue were not associated with disease flares.

The observed association between disease activity and perceived stress has previously been described. However, the power of many studies was limited due to methodological flaws such as cross-sectional analyses, small sample size, and the lack of objective measurements of disease activity. ${ }^{25}$ Since IBD patients often experience IBS-like complaints, the sole use of clinical disease activity indices to define flares may give an overestimation of relapses and therefore additional markers of inflammation are needed. So far, only a limited number of longitudinal studies have used a combination of symptoms and additional measurements (e.g. calprotectin or endoscopy) to define flares. ${ }^{11,13,14,26}$ In a longitudinal study using a combination of clinical disease activity index and faecal calprotectin concentration, short-term perceived stress was positively associated with subsequent IBD symptoms, but not with 'objectively' assessed inflammation by faecal calprotectin measurement. ${ }^{13}$ These findings may explain some contradictory results from earlier studies and support our findings concerning the absence of an association between the presence of perceived stress in general and flares. Nonetheless, a difference between the presence of perceived stress in general and novel perceived stress was observed here. In many studies, 'short-term' perceived stress has been analysed by using a questionnaire comprising the past month (e.g. Cohen Perceived Stress Scale ${ }^{24}$ or Perceived Stress Questionnaire ${ }^{27}$ ). Unfortunately, these questionnaires are insensitive for perceived stress in the period prior to this month. Therefore, exposure time to perceived stress is unknown and both 'novel' and 'longer lasting' stress are measured. To analyse the effect of intra-individual changes of perceived stress over time, longitudinal follow-up of both the outcome variable (i.e. disease flares) and perceived stress is necessary. To our knowledge, in only a few studies, have both variables been repeatedly measured during follow-up. ${ }^{9-13,26}$ of these, none used the repetitive assessments to differentiate novel perceived stress from chronic or pre-existing perceived stress.

In the present study, we observed a clear difference between the effect of perceived stress in general and the effect of novel perceived stress. In healthy individuals, both internal and external stressors are in balance with behavioral and physiological adaptive responses. Perceived stress may become detrimental when this balance is disturbed (e.g. via acute stressors). ${ }^{28}$ It is hypothesized that perceived stress may affect the brain-gut axis through (I) activation of the hypothalamic-pituitary- 
adrenal axis and subsequent release of corticotropin releasing factor and cortisol, which have direct and indirect gastrointestinal immunostimulatory effects, (II) decreased activity of the vagal nerve and thereby a decreased anti-inflammatory effect, (III) increased activation of the sympathetic nervous system and subsequent increase of inflammatory cytokines, activation of the NF-kB pathway, and activation of mast cells, and (IV) peripheral release of substance $P$ by the enteric nervous system, acting as an inflammatory cytokine and stimulator of mast cells. ${ }^{6,16}$ It is hypothesized that after such disturbance, homeostasis usually returns in most individuals. ${ }^{28}$ Therefore, we suggest that during prolonged stress, individuals can adapt to this new situation. This might explain why, in our study, only novel perceived stress was associated with flares. However, another longitudinal study observed long-term perceived stress (i.e. covering 2 years prior to measurement) to be associated with flares in the following 8 months, while short-term perceived stress (i.e. covering the month prior to measurement) was not. ${ }^{26}$ However, their explanation of a proposed lengthy time scale for the evolution of effects of stress on the intestines was primarily based on animal studies. Coping strategies and consequent adaptation to chronic stress may be different in humans. It is hypothesized that chronic stress enhances the effects of acute stress through greater and more prolonged increases in sympathetic activation following a stressor although supporting evidence for this is scarce. ${ }^{16}$ Future studies regarding perceived stress and disease flares, using the same methodology as the present study, should be performed to validate our findings.

The occurrence of life events was also associated with the development of a flare in the next 3 months. The most frequently identified type of life events were workrelated (19.4\%; e.g. dismissal or reorganization), personal health issues (10.9\%), moving house or renovating a house $(10.9 \%)$, or the death of relatives or good friends $(9.1 \%)$. The effect of life events on future disease activity is smaller when compared to perceived stress. Although life events by definition are correlated with perceived stress, the way of coping will determine whether the life event as a stressor leads to more perceived stress or not. We speculate that only patients with insufficient coping strategies will experience an increase in perceived stress. Unfortunately, our study is not designed to analyse these effects. However, this hypothesis is supported by findings of another prospective study in which a combination of low stress and a good coping strategy was associated with the lowest risk of a disease flare. ${ }^{12}$ Debate remains as contradictory results on the influence of life events have been reported by others, possibly due to differences in study design and methodology.

In this study, no association was found between anxiety, depression or fatigue and subsequent disease flares. Anxiety and depression as comorbidities have extensively been studied in IBD patients and in a recent systematic review it has been shown that the prevalence rate of anxiety (20\%) and depression (15\%) is high in IBD compared to prevalence rates in the general population $\left(7.3 \%\right.$ and $3.2 \%$, respectively). ${ }^{5,30,31}$ However, a meta-analysis of prospective studies on the impact of a depressive state on 
disease activity showed no statistically significant association, which is in line with our study. ${ }^{32}$ The association between both anxiety and disease flares as well as fatigue and disease flares has not very frequently been studied. Anxiety seemed not to be associated, as in our study, with disease flares. ${ }^{11,12,33}$ Although longitudinal evidence for an association between fatigue and flares is lacking, a high prevalence of fatigue in active IBD has been observed. ${ }^{34}$ In our study, this association could not be confirmed.

The strength of this study is the systematic and continuous monitoring of both disease activity and psychosocial wellbeing over a 12-month period in a large study population. Additionally, we were able to analyse within-subject changes of psychosocial wellbeing. Also, we defined disease flares using a combination of clinical disease activity (i.e. MIAH-questionnaire) and additional parameters (i.e. faecal calprotectin, imaging or outpatient clinic visit with treatment adjustment). Some limitations also need to be addressed. First and most importantly, we did not use validated questionnaires for psychosocial wellbeing in the telemedicine tool. The questionnaires in MylBDcoach were designed to screen for several relevant aspects potentially associated with patients' wellbeing and these questionnaires had to be concise for repeated use in a daily clinical practice setting. We therefore chose to apply only one 'screening' question per domain to limit loss of adherence. However, previous studies have shown that single-question questionnaires can correlate well with comprehensive questionnaires (e.g. for perceived stress ${ }^{35}$ ). Second, we were not able to obtain reliable data on the use of non-steroidal anti-inflammatory drugs, the use of antibiotics or incident infections from the mylBDcoach tool, while several studies suggest that these variables are associated with disease flares. ${ }^{29}$ On the other hand, a large longitudinal population-based study showed no effect of either of these variables and therefore we believe that the potential confounding effect, if present, is only minimal. ${ }^{9}$

Currently, we believe that the merit of psychosocial wellbeing in IBD patients is underestimated and hardly routinely assessed in daily practice. In this study, we addressed that particular attention should be paid to novel perceived stress and life events and our data underline a possible need for tight psychosocial monitoring of IBD patients. Our findings concerning the association between novel perceived stress and disease flares need confirmation by future studies and such studies should take coping strategies into account. Eventually, personalized interventions in those who are at risk of developing flares are worthy of further study.

In conclusion, the occurrence of recent life events and novel perceived stress were prospectively associated with the incidence of IBD disease flares in the next 3 months, while the presence of perceived stress in general was not. Also, no association was found between disease flares and anxiety, depression, or fatigue. This study underlines the importance of continuous personalized monitoring of IBD patients, which may contribute to the prevention of disease flares. 


\section{References}

1. Torres J, Mehandru S, Colombel JF, Peyrin-Biroulet L. Crohn's disease. Lancet. 2017;389(10080): 1741-55.

2. Ungaro R, Mehandru S, Allen PB, Peyrin-Biroulet L, Colombel JF. Ulcerative colitis. Lancet. 2017;389(10080):1756-70.

3. Yarur AJ, Strobel SG, Deshpande AR, Abreu MT. Predictors of aggressive inflammatory bowel disease. Gastroenterol Hepatol (N Y). 2011;7(10):652-9.

4. Walker JR, Ediger JP, Graff LA, Greenfeld JM, Clara I, Lix L, et al. The Manitoba IBD cohort study: a population-based study of the prevalence of lifetime and 12-month anxiety and mood disorders. Am J Gastroenterol. 2008;103(8):1989-97.

5. Neuendorf R, Harding A, Stello N, Hanes D, Wahbeh H. Depression and anxiety in patients with Inflammatory Bowel Disease: A systematic review. J Psychosom Res. 2016;87:70-80.

6. Bonaz BL, Bernstein CN. Brain-gut interactions in inflammatory bowel disease. Gastroenterology. 2013;144(1):36-49.

7. Martin-Subero M, Anderson G, Kanchanatawan B, Berk M, Maes M. Comorbidity between depression and inflammatory bowel disease explained by immune-inflammatory, oxidative, and nitrosative stress; tryptophan catabolite; and gut-brain pathways. CNS Spectr. 2016;21(2):184-98.

8. Triantafillidis JK, Merikas E, Gikas A. Psychological factors and stress in inflammatory bowel disease. Expert Rev Gastroenterol Hepatol. 2013;7(3):225-38.

9. Bernstein CN, Singh S, Graff LA, Walker JR, Miller N, Cheang M. A prospective population-based study of triggers of symptomatic flares in IBD. Am J Gastroenterol. 2010;105(9):1994-2002.

10. Langhorst J, Hofstetter A, Wolfe F, Hauser W. Short-term stress, but not mucosal healing nor depression was predictive for the risk of relapse in patients with ulcerative colitis: a prospective 12-month followup study. Inflamm Bowel Dis. 2013;19(11):2380-6.

11. Bitton, A. Psychosocial determinants of relapse in ulcerative colitis: a longitudinal study. The American Journal of Gastroenterology. 2003;98(10):2203-8.

12. Bitton A, Dobkin PL, Edwardes MD, Sewitch MJ, Meddings JB, Rawal S, et al. Predicting relapse in Crohn's disease: a biopsychosocial model. Gut. 2008;57(10):1386-92.

13. Sexton KA, Walker JR, Graff LA, Bernstein MT, Beatie B, Miller N, et al. Evidence of Bidirectional Associations Between Perceived Stress and Symptom Activity: A Prospective Longitudinal Investigation in Inflammatory Bowel Disease. Inflamm Bowel Dis. 2017;23(3):473-83.

14. Camara RJ, Schoepfer AM, Pittet V, Begre S, von Kanel R, Swiss Inflammatory Bowel Disease Cohort Study G. Mood and nonmood components of perceived stress and exacerbation of Crohn's disease. Inflamm Bowel Dis. 2011;17(11):2358-65.

15. Gracie DJ, Williams CJ, Sood R, Mumtaz S, Bholah MH, Hamlin PJ, et al. Poor Correlation Between Clinical Disease Activity and Mucosal Inflammation, and the Role of Psychological Comorbidity, in Inflammatory Bowel Disease. Am J Gastroenterol. 2016;111(4):541-51.

16. Mawdsley JE, Rampton DS. Psychological stress in IBD: new insights into pathogenic and therapeutic implications. Gut. 2005;54(10):1481-91.

17. Agostini A, Ballotta D, Righi S, Moretti M, Bertani A, Scarcelli A, et al. Stress and brain functional changes in patients with Crohn's disease: A functional magnetic resonance imaging study. Neurogastroenterol Motil. 2017;29(10):1-10.

18. Trindade IA, Ferreira C, Moura-Ramos M, Pinto-Gouveia J. An 18-month study of the effects of IBD symptomatology and emotion regulation on depressed mood. Int J Colorectal Dis. 2017;32(5):651-60.

19. de Jong MJ, van der Meulen-de Jong AE, Romberg-Camps MJ, Becx MC, Maljaars JP, Cilissen M, et al. Telemedicine for management of inflammatory bowel disease (mylBDcoach): a pragmatic, multicentre, randomised controlled trial. Lancet. 2017.

20. de Jong $M$, van der Meulen-de Jong $A$, Romberg-Camps $M$, Degens J, Becx $M$, Markus $T$, et al. Development and Feasibility Study of a Telemedicine Tool for All Patients with IBD: MylBDcoach. Inflamm Bowel Dis. 2017;23(4):485-93. 
21. de Jong M, Van den Heuvel T, Romberg-Camps M, Winkens B, Markus T, Masclee A, et al. Development of a patient reported disease activity score to screen for mucosal inflammation in inflammatory bowel disease. Journal of Crohn's and Colitis. 2015.

22. Zigmond AS, Snaith RP. The hospital anxiety and depression scale. Acta Psychiatr Scand. 1983;67(6): 361-70.

23. Bleijenberg G KH, Gielissen M. De Verkorte VermoeidheidsVragenlijst voor het vaststellen van de ernst van chronische vermoeidheid. Bijblijven. 2009;25(1):19-21.

24. Cohen S, Kamarck T, Mermelstein R. A global measure of perceived stress. J Health Soc Behav. 1983;24(4):385-96.

25. Keefer L, Keshavarzian A, Mutlu E. Reconsidering the methodology of "stress" research in inflammatory bowel disease. J Crohns Colitis. 2008;2(3):193-201.

26. Levenstein S, Prantera C, Varvo V, Scribano ML, Andreoli A, Luzi C, et al. Stress and exacerbation in ulcerative colitis: a prospective study of patients enrolled in remission. Am J Gastroenterol. 2000;95(5):1213-20.

27. Levenstein S, Prantera C, Varvo V, Scribano ML, Berto E, Luzi C, et al. Development of the Perceived Stress Questionnaire: a new tool for psychosomatic research. J Psychosom Res. 1993;37(1):19-32.

28. Chrousos GP. Stress and disorders of the stress system. Nat Rev Endocrinol. 2009;5(7):374-81.

29. Singh S, Graff LA, Bernstein CN. Do NSAIDs, antibiotics, infections, or stress trigger flares in IBD? Am J Gastroenterol. 2009;104(5):1298-313; quiz 314.

30. Baxter AJ, Scott KM, Vos T, Whiteford HA. Global prevalence of anxiety disorders: a systematic review and meta-regression. Psychol Med. 2013;43(5):897-910.

31. Moussavi S, Chatterji S, Verdes E, Tandon A, Patel V, Ustun B. Depression, chronic diseases, and decrements in health: results from the World Health Surveys. Lancet. 2007;370(9590):851-8.

32. Alexakis C, Kumar S, Saxena S, Pollok R. Systematic review and meta-analysis: the impact of a depressive state on disease course in adult inflammatory bowel disease. Aliment Pharmacol Ther. 2017.

33. Dhingra R, Kedia S, Venigalla PM, Kumar S, Singh N, Bopanna S, et al. Evaluating clinical, dietary and psychological risk factors for relapse of ulcerative colitis in clinical, endoscopic and histological remission. J Gastroenterol Hepatol. 2017;32(10):1698-705.

34. Huppertz-Hauss G, Hoivik ML, Jelsness-Jorgensen LP, Opheim R, Henriksen M, Hoie O, et al. Fatigue in a population-based cohort of patients with inflammatory bowel disease 20 years after diagnosis: The IBSEN study. Scand J Gastroenterol. 2017;52(3):351-8.

35. Littman AJ, White E, Satia JA, Bowen DJ, Kristal AR. Reliability and validity of 2 single-item measures of psychosocial stress. Epidemiology. 2006;17(4):398-403.

36. Satsangi J, Silverberg MS, Vermeire S, Colombel JF. The Montreal classification of inflammatory bowel disease: controversies, consensus, and implications. Gut. 2006;55(6):749-53. 
Psychosocial wellbeing and flares in IBD 


$$
20
$$




\section{Chapter 5}

\section{Risk of impaired nutritional status and flare occurrence in IBD outpatients}

Corinne E.G.M. Spooren, Dion S.J. Wintjens, Marin J. de Jong, Andrea E. van der Meulen-de Jong, Mariëlle J.L. Romberg-Camps, Marco C. Becx, Jeroen P.W.J. Maljaars, Ad A. van Bodegraven, Nofel Mahmmod, Tineke Markus, Wim M. Hameeteman, Ad A.M. Masclee, Bjorn Winkens, Daisy M.A.E. Jonkers, Marieke J. Pierik

Dig Liver Dis. 2019;51(9):1265-1269 


\begin{abstract}
Background

Inflammatory bowel disease (IBD) patients are at risk of an impaired nutritional status. The impact thereof on the IBD relapse risk is clinically relevant, though sparsely investigated. The aim of this study was to explore the association between an impaired nutritional status risk and the occurrence of disease flares in IBD outpatients participating in a longitudinal telemedicine study.
\end{abstract}

\title{
Methods
}

IBD outpatients were recruited from the myIBDcoach study cohort, with one year clinical follow-up. Through mylBDcoach, a telemedicine tool, patients reported on disease activity and risk of impaired nutritional status (i.e., Short Nutritional Assessment Questionnaire $>1$ and/or $\mathrm{BMI}<18.5 \mathrm{~kg} / \mathrm{m}^{2}$ ) every one to three months. Data was analysed by generalized estimating equation modelling.

\section{Results}

In total, 417 patients were included. During follow-up, 49 patients (11.8\%) flared after initial clinical remission and 53 patients (12.7\%) showed an increased risk of impaired nutritional status. The risk of impaired nutritional status was associated with flare occurrence (OR 2.61 (95\% Cl 1.02-6.69)).

\section{Conclusions}

The risk of an impaired nutritional status was associated with subsequent flares in IBD outpatients. This emphasizes the importance of monitoring disease activity in IBD patients at risk of impaired nutritional status. 


\section{Introduction}

Inflammatory bowel disease (IBD) is a chronic inflammatory disease of the gastrointestinal tract, with Crohn's disease (CD) and ulcerative colitis (UC) as main subtypes. The disease course is characterized by a wide variation in duration and frequency of relapsing and quiescent periods between patients. Several factors have been associated with relapse risk, such as a high frequency of flares within the first year of diagnosis, ${ }^{1,2}$ poor medication adherence, ${ }^{3}$ and active smoking in CD patients. ${ }^{4}$ However, these do not sufficiently predict the disease course. Identification of further factors contributing to the development of relapses is therefore warranted.

IBD patients are at risk of an impaired nutritional status due to disease related changes in absorption and/or requirements, often in combination with an unbalanced dietary intake. ${ }^{5}$ Reported prevalences range from 16 to $75 \%$ in IBD patients. ${ }^{6-8}$ The variation may be due to heterogeneity in study methods and definitions used for defining an impaired nutritional status, in many publications often referred to as malnutrition. Defining malnutrition remains challenging. Therefore, the American Society of Parenteral and Enteral Nutrition (ASPEN) recommends diagnostic characteristics to identify malnutrition in adults, by which two of the following six criteria need to be fulfilled: i.e., low energy intake, weight loss, loss of muscle mass, loss of subcutaneous fat, fluid accumulation, and handgrip strength. ${ }^{9}$ However, validated screening tools to identify patients at risk of malnutrition, such as the Short Nutritional Assessment Questionnaire (SNAQ) and the Malnutrition Universal Screening Tool (MUST), are more often used, since these are less time consuming. ${ }^{10}$

An impaired nutritional status may impact disease course. Malnutrition, defined by the Subjective Global Assessment, which is a nutritional assessment instrument, has been found to be related to a diminished quality of life in hospitalized patients with IBD. ${ }^{11}$ In addition, radiologically assessed loss of muscle mass was found to be associated with an increased risk of intestinal resection and postoperative complications in IBD patients. ${ }^{12-15}$ Furthermore, higher disease activity was associated with a lower skeletal muscle index among UC patients. ${ }^{13}$ In previous cross-sectional and longitudinal studies, active disease was reported to affect body composition in both CD and UC patients. ${ }^{16-18}$ However, both CD and UC patients with quiescent disease can also suffer from an altered body composition (i.e., fat mass and fat free mass). ${ }^{19,20}$ Furthermore, in a prior study, the nutritional status of recently diagnosed IBD patients was shown to be affected negatively already at diagnosis. ${ }^{21}$ It can thus be hypothesized that an impaired nutritional status could be a risk factor for the development of disease activity. Therefore, as an explorative study, we aimed to analyse whether the risk of an impaired nutritional status was associated with flare occurrence in quiescent IBD outpatients in a longitudinal, observational study. 


\section{Materials and methods}

\section{Study design}

For the present longitudinal study, available data from the mylBDcoach study was used in an explorative analysis. MylBDcoach is a telemedicine tool, accessible on a secured webpage through computer, tablet or smartphone, for the monitoring of IBD patients at home. ${ }^{22}$ In the mylBDcoach trial, the effect of disease monitoring with mylBDcoach on healthcare utilization and quality of care was investigated. All consecutive IBD patients between 18-75 years, with sufficient knowledge of the Dutch language and internet access, from two tertiary referral centres and two non-academic hospitals in the Netherlands were eligible for inclusion for this trial and randomized in the mylBDcoach or standard care group. All patients had an established diagnosis of CD or UC, fulfilling the international diagnostic criteria. ${ }^{23}$

Every single month, patients in the telemedicine arm completed monitoring modules, comprising questions on disease activity, use of medication, smoking status, weight, and malnutrition risk based on the SNAQ. If a patient achieved remission (i.e., low clinical activity for three consecutive months), patients were allowed to complete the monitoring module once every three months. The study design is described in detail elsewhere. $^{24}$

The mylBDcoach study was approved by the Medical Research Ethics Committee of the Maastricht University Medical Centre+ (NL47697.068.14) and registered at ClinicalTrials.gov (NCT02173002) and the study protocol conformed to the provisions of the declaration of Helsinki. All patients gave written informed consent prior to participation. $^{22,24}$

Patients who were randomized to the mylBDcoach intervention group were included in the present study. Baseline characteristics (e.g., height, disease phenotype, duration, and medication use) were extracted from patient files using standardized registration forms. During the 12 months of follow-up, information on weight (to determine $\mathrm{BMI}$ ), disease activity by a symptom-based patient reported outcome measure (the Monitor IBD At Home (MIAH) questionnaire ${ }^{25}$ ), and risk for malnutrition (by the SNAQ) was obtained every one to three months.

In line with the mylBDcoach trial, disease activity (flares) were defined as clinical symptoms indicative of disease activity (i.e., positive score on the Monitor IBD At Home (MIAH) questionnaire ${ }^{25,26}$ or increased symptoms during outpatient visits) in combination with either a concurrent faecal calprotectin $>250 \mu \mathrm{g} / \mathrm{g}$, or disease activity on endoscopy, magnetic resonance imaging, or computed tomography. In daily clinical practice, in case of clinically severe symptoms suggestive of IBD disease activity, the treating physician occasionally judged these symptoms to be evident enough to adjust therapy. Therefore, to capture all flares, also symptoms indicative of disease activity 
resulting in dose escalation or initiation of a new drug were defined as disease activity. ${ }^{22}$ Otherwise patients were considered to be in remission.

The SNAQ was developed as a non-invasive screening tool to assess malnutrition in both in- and outpatient settings ${ }^{27,28}$ and comprises of three questions, i.e., unintentional weight loss over a predefined time period (depending on weight loss: 2 or 3 points), experience of decreased appetite during the last month (1 point), and/or use of supplemental drinks or tube feeding during the last month (1 point). For the present study, the risk of an impaired nutritional status was defined as a SNAQ $\geq 2$ points and/or $\mathrm{BMI}<18.5 \mathrm{~kg} / \mathrm{m}^{2}$. Both parameters were determined every one to three months.

\section{Statistical analysis}

Numerical variables were presented as means with corresponding standard deviation (SD) and categorical variables as numbers with percentages. Baseline characteristics were compared between groups (patients who relapse versus patients who do not relapse) by the independent samples t-test for numerical variables, and Chi-square test or Fisher's exact test when appropriate, for categorical variables. Generalized estimating equations model was used to identify an association between the risk of impaired nutritional status and the development of flares in the following three months. This method accounts for repeated measures within the same patient, with an unstructured covariance pattern.

At each time-point of measurement, flare status (yes/no), as well as the risk of impaired nutritional status (yes/no) was recorded. In patients with quiescent disease, the first three months were excluded from the analyses to prevent potential carry over effects of histological inflammation in clinical inactive patients at time of inclusion. When active disease was present at inclusion or during follow up, the following six months were excluded from the analyses as a wash out period, and to start the followup from a remissive state onwards.

For the generalized estimating equations model, all positive values on the risk of an impaired nutritional status in the three months preceding a flare were regarded as possible predictors.

Since we aimed to assess the prospective association, the risk of an impaired nutritional status measured at the same measurement moment as a flare was not considered as a predictor. Since patients were able to complete the questionnaires either every single or every three months, the flare status was determined for the subsequent three months after the risk of an impaired nutritional status was assessed. The generalized estimating equations model was adjusted for potential confounding effects of sex, disease phenotype, disease duration at inclusion, and smoking status at inclusion. Two-sided $p$-values $\leq 0.05$ were considered statistically significant. Statistical analysis was performed using IBM SPSS statistics for Windows, Version 22 (IBM, Armonk, NY). 


\section{Results}

In total, 465 IBD patients were allocated to the intervention group in the mylBDcoach trial. ${ }^{22}$ Patients who were not eligible, i.e., never started using the application, never achieved a period of remission or were lost to follow-up for other reasons were excluded from further analyses. Finally, 417 patients were included in the present study.

Baseline characteristics at inclusion, stratified by flare status during follow up, are presented in Table 5.1. During follow-up, 49 (11.8\%) individual patients ( $C D=26, U C=23$ ) experienced a flare after initial remission. Less active smokers were found among those that relapsed during follow-up compared to the 'non-relapsers' $(p=0.005)$. No other differences in baseline characteristics were found between these groups.

Table 5.1 Patient characteristics, stratified by occurrence of disease flares.

\begin{tabular}{|c|c|c|c|}
\hline & $\begin{array}{c}\text { Relapsers } \\
(n=49)\end{array}$ & $\begin{array}{c}\text { Non-relapsers } \\
(n=368)\end{array}$ & p-value \\
\hline Crohn's disease n (\%) & $26(53.1)$ & $222(60.3)$ & 0.331 \\
\hline Male, $\mathrm{n}(\%)$ & $15(30.6)$ & $158(42.9)$ & 0.100 \\
\hline BMI $\left(\mathrm{kg} / \mathrm{m}^{2}\right)$, mean (SD) & $25.37(4.3)$ & $25.14(4.0)$ & 0.705 \\
\hline \multicolumn{4}{|l|}{ Montreal at baseline ${ }^{a}$} \\
\hline Age (CD \& UC) & & & 0.600 \\
\hline$A 1,<17$ years, $n(\%)$ & $8(16.3)$ & $60(16.3)$ & \\
\hline$A 2,17-40$ years, $n(\%)$ & $26(53.1)$ & $219(59.5)$ & \\
\hline$A 3,>40$ years, $n(\%)$ & $15(30.6)$ & $89(24.2)$ & \\
\hline Disease location (CD) & & & 0.741 \\
\hline L1, ileal, n (\%) & 7 (26.9) & $73(32.9)$ & \\
\hline $\mathrm{L} 2$, colonic, $\mathrm{n}(\%)$ & $6(23.1)$ & $55(24.8)$ & \\
\hline L3, ileocolonic, n (\%) & $13(50.0)$ & $94(42.3)$ & \\
\hline Disease behaviour (CD) & & & 0.958 \\
\hline B1, non-stricturing non-penetrating, n (\%) & $16(61.5)$ & $134(60.6)$ & \\
\hline $\mathrm{B} 2$, stricturing, $\mathrm{n}(\%)$ & 7 (26.9) & $57(25.8)$ & \\
\hline B3, penetrating, $\mathrm{n}(\%)$ & $3(11.5)$ & $30(13.6)$ & \\
\hline Disease extent (UC) & & & 0.768 \\
\hline E1, proctitis, $n(\%)$ & $2(8.7)$ & $19(12.8)$ & \\
\hline E2, left-sided, $n(\%)$ & $10(43.5)$ & $69(46.3)$ & \\
\hline E3, pancolitis, n (\%) & $11(47.8)$ & $61(40.9)$ & \\
\hline Age at inclusion (years), mean (SD) & $46.08(15.2)$ & $43.95(13.7)$ & 0.313 \\
\hline Disease duration at inclusion (years), mean (SD) & $13.45(10.9)$ & $13.39(10.4)$ & 0.971 \\
\hline Active disease at inclusion, $\mathrm{n}(\%)$ & $4(8.2)$ & $28(7.6)$ & 0.908 \\
\hline Medication use at inclusion & & & 0.434 \\
\hline No medication/5-ASA, $n$ (\%) & $15(30.6)$ & $142(39.3)$ & \\
\hline Immunomodulators, $\mathrm{n}(\%)$ & $16(32.7)$ & $93(25.8)$ & \\
\hline Biologics, $\mathrm{n}(\%)$ & $18(36.7)$ & $126(34.9)$ & \\
\hline Current smoking at inclusion, $\mathrm{n}(\%)$ & $1(2.0)$ & $65(17.7)$ & $0.005^{b}$ \\
\hline
\end{tabular}

$\mathrm{n}$, number of patients / SD, standard deviation / BMI, body mass index / 5-ASA, 5-aminosalicylic acid / ${ }^{a}$, classification according to Montreal Classification ${ }^{45} /{ }^{b}$, p-value below 0.05 . 
At inclusion, six (1.4\%) patients had a BMI $<18.5 \mathrm{~kg} / \mathrm{m}^{2}, 216(51.8 \%)$ patients had a BMI of $18.5-25 \mathrm{~kg} / \mathrm{m}^{2}, 147$ (35.3\%) patients had a BMl of $25-30 \mathrm{~kg} / \mathrm{m}^{2}$, and $48(11.5 \%)$ patients had a BMI $>30 \mathrm{~kg} / \mathrm{m}^{2}$. In total, $53(12.7 \%)$ individual IBD patients were at risk of an impaired nutritional status based on a positive SNAQ score $(n=45), B M I<18.5 \mathrm{~kg} / \mathrm{m}^{2}$ $(n=5)$, or both $(n=3)$ during follow-up.

In the generalized estimating equations analyses, the risk of an impaired nutritional status was found to be associated with the occurrence of a flare in the following three months (OR $2.61(95 \% \mathrm{Cl} 1.02-6.69, \mathrm{p}=0.046))$. Furthermore, in this model female sex (OR $2.12(95 \% \mathrm{Cl} 1.08-4.15, \mathrm{p}=0.029)$ ) was also identified as a risk factor for the development of a flare, while active smoking showed a negative association (OR 0.14 (95\% Cl 0.02-0.97, p=0.047)) (Table 5.2).

In the generalized estimating equations model, medication use at time of inclusion was not incorporated as confounder due to the small number of relapsing patients during follow up. When medication use at time of inclusion was added to the model, a comparable increased risk was found (OR $2.48(95 \% \mathrm{Cl} 0.96-6.41, \mathrm{p}=0.061)$ ), though not significant.

Table 5.2 Multivariable generalized estimating equations model: association between impaired nutritional status risk in IBD and disease flares.

\begin{tabular}{lccc}
\hline & OR & 95\%-Cl & p-value \\
\hline Impaired nutritional status & 2.61 & $1.02-6.69$ & $0.046^{\mathrm{b}}$ \\
UC phenotype & 1.43 & $0.78-2.65$ & 0.251 \\
Sex, female & 2.12 & $1.08-4.15$ & $0.029^{\mathrm{b}}$ \\
Active smoker $^{\mathrm{a}}$ & 0.14 & $0.02-0.97$ & $0.047^{\mathrm{b}}$ \\
Disease duration $^{\mathrm{a}}$ & 1.01 & $0.98-1.04$ & 0.642 \\
\hline
\end{tabular}

OR, Odds ratio / 95\%-Cl, 95\%-Confidence Interval $/{ }^{a}$, at inclusion $/{ }^{b}$, p-value below 0.05 .

\section{Discussion}

In this longitudinal study in daily practice, the risk of an impaired nutritional status, defined by a positive SNAQ or BMI $<18.5 \mathrm{~kg} / \mathrm{m}^{2}$, was found to be associated with the occurrence of a flare.

IBD patients are at risk of an impaired nutritional status due to disease related changes in absorption and/or requirements, especially during active inflammation, often in combination with an unbalanced dietary intake. ${ }^{5}$ An impaired nutritional status is thereby a consequence of the disease, although it may also further impact disease course. Previous studies reported that a decreased skeletal muscle index increased the risk of an intestinal resection in hospitalized $C D$ patients with an exacerbation ${ }^{12}$ increased the need for colectomy in UC patients, ${ }^{13}$ predicted the need for rescue therapy in acute severe UC patients ${ }^{29}$, was associated with postoperative complications $^{14,15}$, and with anti-TNF treatment failure in IBD patients. ${ }^{30}$ An impaired 
nutritional status may contribute to the development of a flare or worse disease outcome by malnutrition induced changes in the immune system leading to altered $\mathrm{GI}$ hormone secretion (e.g., leptin), changes in immune cell populations, and/or increased intestinal permeability. ${ }^{31-34}$ A mice study on the effects of fasting showed, for example, that changes in immune response occur rather early after inducing nutritional deficiencies. ${ }^{32}$ After $48 \mathrm{~h}$, activated T cells from fasted mice showed decreased ability to secrete IL-2 and IFN-y when compared with control fed mice. A vicious circle may develop in which an impaired nutritional status and intestinal inflammation affect each other. Furthermore, malnutrition is found to affect the microbiota composition and activity, and thereby may also impact disease course. ${ }^{35}$ To our knowledge, the current study is the first to specifically analyse the association of impaired nutritional status risk on subsequent flare occurrence. Future studies should also address potential underlying mechanisms.

In the present study, the SNAQ in combination with BMI was used as screening method for risk of an impaired nutritional status, since the SNAQ alone may lead to underreporting in an outpatient setting. ${ }^{36}$ The SNAQ and MUST both contain questions on unintentional weight loss and food intake. In contrast to the SNAQ, a low BMI $\left(18.5-20\right.$ or $\left.<18.5 \mathrm{~kg} / \mathrm{m}^{2}\right)$ is taken into account in the MUST questionnaire. The MUST may however lead to overreporting of patients at risk in the outpatient setting. ${ }^{36}$ Therefore, in line with one of the diagnostic criteria for malnutrition by the European Society for Clinical Nutrition and Metabolism (ESPEN) ${ }^{10}$, only a BMI $<18.5 \mathrm{~kg} / \mathrm{m}^{2}$ was added to the SNAQ to capture all patients at risk of impaired nutritional status in the current study. Fifty-three patients were at risk of an impaired nutritional status during follow up, of which the majority of the patients $(n=45)$ had a positive SNAQ in combination with a $\mathrm{BMI}>18.5 \mathrm{~kg} / \mathrm{m}^{2}$, five patients had a $\mathrm{BMI}<18.5 \mathrm{~kg} / \mathrm{m}^{2}$ and a negative SNAQ, and three patients had both a positive SNAQ score and a $\mathrm{BMI}<18.5 \mathrm{~kg} / \mathrm{m}^{2}$.

The overall distribution of our patients over the different weight categories (according to the World Health Organization definitions) ${ }^{37}$ were comparable with percentages of overweight and obesity in a representative healthy population in SouthLimburg, a province in the Netherlands. ${ }^{38}$ The majority of the IBD patients in the present study had a normal BMI $(51.8 \%)$ while a significant proportion was overweight (35.3\%) or obese (11.5\%). Due to an unfavourable fat-muscle ratio, which is not necessarily reflected by $\mathrm{BMI}$, it cannot be excluded that patients with a BMI $18.5-25 \mathrm{~kg} / \mathrm{m}^{2}$ do have a decreased muscle mass and are thereby at risk of impaired nutritional status.

A commonly used model for analysing the body composition is the twocompartment model in which body weight is subdivided in fat mass and fat free mass. Skeletal muscle mass represents a large proportion of the fat free mass. Prior studies reported that changes in fat free mass, are not always captured by malnutrition screening questionnaires in IBD patients. ${ }^{20,39}$ This underlines the necessity in future 
studies to combine a malnutrition screening questionnaire with a simple, non-invasive body composition analysis, and also, to incorporate changes in fat free mass for timely identification of patients at risk. A technique which can be considered is the handgrip strength, as parameter of muscle strength. ${ }^{40}$

In the present study, flare development was also found to be positively associated with female sex and negatively with smoking status at time of inclusion. In CD for example, smoking is found to increase the risk of a flare, whereas in UC smoking cessation is. ${ }^{41}$ Our finding may be affected by analysis of the total IBD population. Separate analyses for CD and UC were not performed due to the limited sample size, but should be taken into account in future studies.

A major strength of the present study is the longitudinal design of the study in a relatively large, unselected outpatient study population. The study population was found to be representative for the general IBD population in the South Limburg area. ${ }^{22,42}$ Furthermore, by the use of telemedicine, disease activity, and malnutrition screening risk were measured repeatedly and standardized. However, some limitations of this study should be addressed. For the present explorative study, available data from the mylBDcoach study was used. Therefore, no sample size calculation has been performed, and we were not able to correct for all potential confounders for flare development, such as prior surgery, time since last flare, and prior smoking status. The present study shows a significant association between impaired nutritional status risk and flare occurrences in the entire IBD cohort. Separate analyses for CD and UC were not performed due to a small number of patients. However, these analyses are of interest since factors influencing flare occurrence may differ between these phenotypes, and should be included in future studies. Furthermore, ongoing histological inflammation at time of inclusion and during follow up cannot be completely excluded, since disease activity was monitored by clinical parameters. However, to prevent carry over effects of histological inflammation, the first three months from patients with quiescent disease were excluded from the analyses. Finally, it should be taken into account that flares can be affected by enteral nutrition, particularly in $\mathrm{CD} .{ }^{43}$ However, in the present study, use of enteral nutrition was limited and was not found to impact our findings (data not shown).

The aim of the present explorative study was to investigate an association between the risk of an impaired nutritional status and flare occurrence. In clinical practice, it has already been shown that early treatment of malnourished inpatients for any disease or operation, based on screening, leads to a shorter length of hospital stay and is cost-effective. ${ }^{44}$ Since this is the first longitudinal study analysing the association of impaired nutritional status risk on flare occurrences, our results should be confirmed in other cohorts. Larger longitudinal studies on the impact of an impaired nutritional status risk, incorporating body composition analysis and muscle strength, and taking confounders and separate analysis for CD and UC into account, are of special interest to confirm the actual effect on disease activity. Additionally, studies on timely dietary 
and/or physiotherapy interventions, aiming to improve nutritional status and treatment outcome are warranted.

In conclusion, in the present longitudinal observational study, we found an association between the presence of the risk of an impaired nutritional status and IBD flare occurrence. This emphasizes the importance of monitoring disease activity in IBD patients at risk of an impaired nutritional status. 


\section{References}

1. Munkholm P, Langholz E, Davidsen M, et al. Disease activity courses in a regional cohort of Crohn's disease patients. Scand J Gastroenterol 1995;30:699-706.

2. Hoie O, Wolters F, Riis L, et al. Ulcerative colitis: patient characteristics may predict 10-yr disease recurrence in a European-wide population-based cohort. Am J Gastroenterol 2007;102:1692-701.

3. Feagins LA, Iqbal R, Spechler SJ. Case-control study of factors that trigger inflammatory bowel disease flares. World J Gastroenterol 2014;20:4329-34.

4. Dutta AK, Chacko A. Influence of environmental factors on the onset and course of inflammatory bowel disease. World J Gastroenterol 2016;22:1088-100.

5. Hartman C, Eliakim R, Shamir R. Nutritional status and nutritional therapy in inflammatory bowel diseases. World J Gastroenterol 2009;15:2570-8.

6. Scaldaferri F, Pizzoferrato M, Lopetuso LR, et al. Nutrition and IBD: Malnutrition and/or Sarcopenia? A Practical Guide. Gastroenterol Res Pract 2017;2017:8646495.

7. Casanova MJ, Chaparro M, Molina B, et al. Prevalence of Malnutrition and Nutritional Characteristics of Patients With Inflammatory Bowel Disease. J Crohns Colitis 2017;11:1430-1439.

8. Mijac DD, Jankovic GL, Jorga J, et al. Nutritional status in patients with active inflammatory bowel disease: prevalence of malnutrition and methods for routine nutritional assessment. Eur J Intern Med 2010;21:315-9.

9. White JV, Guenter P, Jensen G, et al. Consensus statement: Academy of Nutrition and Dietetics and American Society for Parenteral and Enteral Nutrition: characteristics recommended for the identification and documentation of adult malnutrition (undernutrition). J Parenter Enteral Nutr 2012;36:275-83.

10. Cederholm T, Barazzoni R, Austin P, et al. ESPEN guidelines on definitions and terminology of clinical nutrition. Clin Nutr 2017;36:49-64.

11. Norman K, Kirchner $\mathrm{H}$, Lochs $\mathrm{H}$, et al. Malnutrition affects quality of life in gastroenterology patients. World J Gastroenterol 2006;12:3380-5.

12. Bamba S, Sasaki M, Takaoka A, et al. Sarcopenia is a predictive factor for intestinal resection in admitted patients with Crohn's disease. PLoS One 2017;12:e0180036.

13. Zhang $\mathrm{T}$, Ding $\mathrm{C}, \mathrm{Xie} \mathrm{T}$, et al. Skeletal muscle depletion correlates with disease activity in ulcerative colitis and is reversed after colectomy. Clin Nutr 2017;36:1586-92.

14. Pedersen M, Cromwell J, Nau P. Sarcopenia is a Predictor of Surgical Morbidity in Inflammatory Bowel Disease. Inflamm Bowel Dis 2017;23:1867-72.

15. Zhang T, Cao L, Cao T, et al. Prevalence of Sarcopenia and Its Impact on Postoperative Outcome in Patients With Crohn's Disease Undergoing Bowel Resection. J Parenter Enteral Nutr 2017;41:592-600.

16. Rocha R, Santana GO, Almeida N, et al. Analysis of fat and muscle mass in patients with inflammatory bowel disease during remission and active phase. Br J Nutr 2009;101:676-9.

17. Benjamin J, Makharia G, Ahuja V, et al. Body composition in Indian patients with Crohn's disease during active and remission phase. Trop Gastroenterol 2011;32:285-91.

18. Ripoli J, Miszputen SJ, Ambrogini O, Jr., et al. Nutritional follow-up of patients with ulcerative colitis during periods of intestinal inflammatory activity and remission. Arq Gastroenterol 2010;47:49-55.

19. Geerling BJ, Badart-Smook A, Stockbrugger RW, et al. Comprehensive nutritional status in patients with long-standing Crohn disease currently in remission. Am J Clin Nutr 1998;67:919-26.

20. Valentini L, Schaper L, Buning C, et al. Malnutrition and impaired muscle strength in patients with Crohn's disease and ulcerative colitis in remission. Nutrition 2008;24:694-702.

21. Geerling BJ, Badart-Smook A, Stockbrugger RW, et al. Comprehensive nutritional status in recently diagnosed patients with inflammatory bowel disease compared with population controls. Eur J Clin Nutr 2000;54:514-21.

22. de Jong MJ, van der Meulen-de Jong AE, Romberg-Camps MJ, et al. Telemedicine for management of inflammatory bowel disease (mylBDcoach): a pragmatic, multicentre, randomised controlled trial. Lancet 2017;390:959-68. 
23. Lennard-Jones JE. Classification of inflammatory bowel disease. Scand J Gastroenterol Suppl 1989;170:2-6; discussion 16-9.

24. de Jong $M$, van der Meulen-de Jong $A$, Romberg-Camps $M$, et al. Development and Feasibility Study of a Telemedicine Tool for All Patients with IBD: MylBDcoach. Inflamm Bowel Dis 2017;23:485-93.

25. De Jong $M$, Van den Heuvel $T$, Romberg-Camps $M$, et al. Development of a patient reported disease activity score to screen for mucosal inflammation in inflammatory bowel disease. J Crohns Colitis 2015;9:S192-3.

26. de Jong MJ, Roosen D, Degens J, et al. Development and validation of a patient-reported score to screen for mucosal inflammation in inflammatory bowel disease. J Crohns Colitis 2018.

27. Kruizenga HM, Seidell JC, de Vet HC, et al. Development and validation of a hospital screening tool for malnutrition: the short nutritional assessment questionnaire (SNAQ). Clin Nutr 2005;24:75-82.

28. Neelemaat F, Kruizenga HM, de Vet HC, et al. Screening malnutrition in hospital outpatients. Can the SNAQ malnutrition screening tool also be applied to this population? Clin Nutr 2008;27:439-46.

29. Cushing KC, Kordbacheh H, Gee MS, et al. Sarcopenia is a Novel Predictor of the Need for Rescue Therapy in Hospitalized Ulcerative Colitis Patients. J Crohns Colitis 2018;12(9):1036-41.

30. Holt DQ, Varma P, Strauss BJG, et al. Low muscle mass at initiation of anti-TNF therapy for inflammatory bowel disease is associated with early treatment failure: a retrospective analysis. Eur J Clin Nutr 2017;71:773-7.

31. Gerriets VA, Danzaki K, Kishton RJ, et al. Leptin directly promotes T-cell glycolytic metabolism to drive effector T-cell differentiation in a mouse model of autoimmunity. Eur J Immunol 2016;46:1970-83.

32. Saucillo DC, Gerriets VA, Sheng J, et al. Leptin metabolically licenses T cells for activation to link nutrition and immunity. J Immunol 2014;192:136-44.

33. Cohen S, Danzaki K, Maclver NJ. Nutritional effects on T-cell immunometabolism. Eur J Immunol 2017;47:225-235.

34. van der Hulst RR, von Meyenfeldt MF, van Kreel BK, et al. Gut permeability, intestinal morphology, and nutritional depletion. Nutrition 1998;14:1-6.

35. Jonkers DM. Microbial perturbations and modulation in conditions associated with malnutrition and malabsorption. Best Pract Res Clin Gastroenterol 2016;30:161-72.

36. Leistra E, Langius JA, Evers AM, et al. Validity of nutritional screening with MUST and SNAQ in hospital outpatients. Eur J Clin Nutr 2013;67:738-42.

37. Physical status: the use and interpretation of anthropometry. Report of a WHO Expert Committee. World Health Organization technical report series 1995;854:1-452.

38. Ministerie van Volksgezondheid Welzijn en Sport. Gezondheidsmonitor Volwassenen en Ouderen. 2018. https://www.volksgezondheidenzorg.info/onderwerp/gezondheidsmonitor-volwassenen-enouderen/regionaal

39. Csontos AA, Molnar A, Piri Z, et al. Malnutrition risk questionnaire combined with body composition measurement in malnutrition screening in inflammatory bowel disease. Revista espanola de enfermedades digestivas: organo oficial de la Sociedad Espanola de Patologia Digestiva 2017;109: 26-32.

40. Lu ZL, Wang TR, Qiao YQ, et al. Handgrip Strength Index Predicts Nutritional Status as a Complement to Body Mass Index in Crohn's Disease. J Crohns Colitis 2016;10:1395-400.

41. Cosnes J. Smoking and Diet: Impact on Disease Course? Dig Dis 2016;34:72-7.

42. van den Heuvel TR, Jonkers DM, Jeuring SF, et al. Cohort Profile: The Inflammatory Bowel Disease South Limburg Cohort (IBDSL). Int J Epidemiol 2017;46:e7.

43. Levine A, Sigall Boneh R, Wine E. Evolving role of diet in the pathogenesis and treatment of inflammatory bowel diseases. Gut 2018;67:1726-38.

44. Kruizenga HM, Van Tulder MW, Seidell JC, et al. Effectiveness and cost-effectiveness of early screening and treatment of malnourished patients. Am J Clin Nutr 2005;82:1082-9.

45. Satsangi J, Silverberg MS, Vermeire S, et al. The Montreal classification of inflammatory bowel disease: controversies, consensus, and implications. Gut 2006;55:749-53. 
Risk of impaired nutritional status and flares in IBD 


$$
20
$$




\section{Part III}

Intestinal and extra-intestinal cancer in IBD; consequences of long-standing disease activity and inherent treatments 


$$
20
$$




\section{Chapter 6}

\section{Inflammatory bowel disease, cancer and medication: cancer risk in the Dutch population-based IBDSL cohort}

Tim R.A. van den Heuvel, Dion S.J. Wintjens, Steven F.G. Jeuring, Maartje H.H. Wassink, Mariëlle J.L. Romberg-Camps, Liekele E. Oostenbrug, Sylvia Sanduleanu, Wim H. Hameeteman, Maurice P. Zeegers, Ad A.M. Masclee, Daisy M.A.E. Jonkers, Marie J. Pierik 


\begin{abstract}
Background

The management of inflammatory bowel disease (IBD) has changed since the mid1990 s (e.g. use of thiopurines/anti-TNF $\alpha$ agents, improved surveillance programs), possibly affecting cancer risk. To establish current cancer risk in IBD, updates are warranted from cohorts covering this time span, and detailed enough to study associations with phenotype and medication. We studied intestinal-, extra-intestinaland overall cancer risk in the Dutch population-based IBDSL cohort.
\end{abstract}

\title{
Methods
}

In total, 1157 Crohn's Disease (CD) and 1644 ulcerative colitis (UC) patients were diagnosed between 1991 and 2011, and followed until 2013. Standardized incidence ratios (SIR) were calculated for CD and UC separately, as well as for gender-, phenotype-, disease duration-, diagnosis era-, and medication groups.

\section{Results}

We found an increased risk for colorectal cancer in $C D$ patients with colon involvement (SIR 2.97; 95\%CI 1.08-6.46), but not in the total CD or UC population. In addition, CD patients were at increased risk for hematologic- $(2.41 ; 1.04-4.76)$, overall skin- 1.55 ; 1.06-2.19), skin squamous cell- (SCC; $3.83 ; 1.83-7.04)$, and overall cancer (1.28; 1.01-1.60), whereas UC patients had no increased risk for extra-intestinal- and overall cancer. Finally, in a medication analysis on $C D$ and $U C$ together, long term immunosuppression exposure ( $>12$ months) was associated with an increased risk for hematologic cancer, non-Hodgkin lymphoma, SCC and overall cancer, and this increase was mainly attributed to thiopurines.

\section{Conclusions}

IBD patients with long term immunosuppression exposure can be considered as having a higher cancer risk, and our data support the advice in recent IBD guidelines to consider skin cancer screening in these patients. 


\section{Introduction}

Inflammatory bowel disease (IBD), encompassing Crohn's disease (CD) and ulcerative colitis (UC), is a chronic inflammatory condition of the intestine, characterized by sequences of exacerbation and remission. Despite the broad spectrum of currently available drugs, a considerable number of patients will not reach (long term) clinical remission. ${ }^{1,2}$ The proportion of patients that have complete disappearance of mucosal inflammation on endoscopic re-evaluation is even lower, and also loss of treatment response frequently occurs. ${ }^{1,2}$ Therefore, chronic or frequently recurring inflammation is often unavoidable. Since Virchow first described leucocytes in neoplastic tissue, ${ }^{3}$ many studies have confirmed a clear link between chronic inflammation and carcinogenesis. ${ }^{4}$ In line, associations have been described between IBD and colorectal cancer ( $C R C)$, and the CRC risk was found to increase with the duration and anatomic extent of colitis. ${ }^{5,6}$

The CRC risk can best be studied in population-based IBD cohorts since the distribution of phenotypes is representative for the real IBD population. ${ }^{7,8}$ In addition, deeply characterized cohorts are preferred as they also enable the study of associations with phenotype, medication and other risk factors. In the most recent meta-analysis on population-based IBD cohorts, the CRC risk was 1.7 times higher compared to the general population, both in $C D$ and $U C .^{5} A$ decreasing trend over time has been observed, ${ }^{5,9}$ which was attributed to changes in IBD management, such as the widespread use of immunosuppressive agents (i.e. thiopurines and anti-TNF $\alpha$ agents, gradually introduced in the mid-1990s and early-2000s respectively) and improved CRC surveillance programs. ${ }^{10}$ These and other population-based meta-analyses, ${ }^{11,12}$ however, also included studies dating from a period prior to these landmark changes in IBD management and therefore the current risk may be even lower. An increased CRC risk, for instance, was not observed in CD nor UC in a Danish population-based study from 2013. ${ }^{13}$ Recent population-based updates on cancer risk, however, are limited and often lack detail to study medication effects.

Associations between IBD and increased risks for several extra-intestinal cancers have also been described. This may be related to IBD itself or to the use of immunosuppressive agents. ${ }^{14}$ There is evidence, for instance, that use of thiopurines and anti-TNF $\alpha$ agents is associated with an increased risk for lymphomas and nonmelanoma skin cancers (NMSC) in IBD. ${ }^{15}$ However, population-based data on the risk for extra-intestinal cancer subtypes are scarce as well, often lack detail to stratify risk according to IBD phenotype and medication, and mostly omit to include the overall cancer risk in IBD patients.

To reliably establish cancer risks in an era of major changes in IBD management, population-based cancer risk updates are required in settings detailed enough to study associations with IBD phenotype and medication use. We aimed to determine the risk for intestinal cancer, extra-intestinal cancer and overall cancer in IBD patients from a 
Dutch population-based IBD cohort, diagnosed between 1991 and 2011. We also aimed to define subgroups of patients with increased cancer risk based on gender, IBD phenotype, IBD duration, diagnosis era of IBD, and medication.

\section{Methods}

\section{Setting and data collection}

All IBD patients from the population-based IBD South Limburg cohort (IBDSL) were eligible for this study. The cohort has previously been described in detail. ${ }^{16}$ In brief, patients diagnosed with IBD between 1991 and 2011, while living in the well-defined region of South Limburg and being over 18 years of age at diagnosis, were included and followed prospectively. Data on demographics, phenotype (according to the Montreal classification), ${ }^{17}$ IBD medication (type, dosage and duration), complications, hospitalizations and surgery were collected at baseline and during follow-up, using standardized registration forms. A multi-faceted identification strategy, including hospitals, the nationwide Dutch pathology database (PALGA), ${ }^{18}$ and general practitioners, resulted in $93 \%$ completeness. As the remaining $7 \%$ was not likely to be associated with a certain IBD phenotype, ${ }^{16}$ an unselected population was assured. IBDSL has been approved by the Ethics Committee of the Maastricht University Medical Center (NL31636.068.10), is registered in ClinicalTrial.gov (NCT02130349) and meets the ethical standards of the revised version of the declaration of Helsinki. ${ }^{19}$

For this study, IBDSL patients were followed until 2013, or until lost-to-follow-up (i.e. death or migration outside the region). Cancer data were collected through medical chart review and a PALGA search. In order to detect any missed cancers, all patients were cross-checked in the Dutch cancer registry (IKNL), ${ }^{20}$ which contains information on all diagnosed cancers in The Netherlands since 1989 with over 95\% completeness. Date of cancer diagnosis, cancer type and cancer location were defined according to the International Classification of Diseases for Oncology (ICD-O).$^{21}$ In case of CRC, additional data were retrieved such as tumour-node-metastasis stage (TNM), ${ }^{22}$ differentiation stage, and location of metastases. We also determined whether patients were eligible for CRC surveillance according to the current Dutch IBD guidelines, ${ }^{23}$ irrespective of actually being included in surveillance. Dutch guidelines (published in 2015) advise surveillance from eight years after disease onset in IBD patients, except for UC patients with ulcerative proctitis and for CD patients 'with involvement of maximum one colon segment' $[\mathrm{sic}] .^{23}$ Only primary cancers were included in the current analyses. 


\section{Statistics}

Standardized incidence ratios (SIR), defined as the ratio of observed $(O)$ to expected (E) cancers, were calculated. Expected cancers were based on the local cancer incidences rates of Limburg, retrieved from the IKNL database. ${ }^{20}$ Gender-, age- and calendar year specific incidences were used to calculate the expected cancer rate of every patient year at risk, which were then accumulated into the overall expected cancer rate.

Patient years were recorded from the year of IBD diagnosis up to and including the year follow up ends (i.e. lost-to-follow-up or end-of-study). Patient years in which the patient was not at risk were censored, such as any patient year after the cancer-understudy was diagnosed, male patient years in female specific cancer analyses and vice versa, and patient years after total colectomy in CRC analysis. We also corrected for incomplete patient years (i.e. years in which diagnosis, lost-to-follow-up or censoring occurred). These patient years were considered having contributed half person years, in order to prevent overestimation.

SIRs were calculated for all intestinal cancer subtypes, all extra-intestinal cancer subtypes and overall cancer, for CD and UC separately. Ninety-five percent confidence intervals were determined by Byar's approximation $(\alpha=0.05) .{ }^{24}$ Cumulative incidence risks were calculated for a selection of cancer subtypes, according to the Kaplan-Meyer method.

\section{Subgroup analyses}

SIRs were also calculated for subgroups based on gender, IBD phenotype at diagnosis (according to the Montreal classification), ${ }^{17}$ IBD duration (first and second decade after IBD diagnosis) and era of IBD diagnosis (1991-2001 and 2001-2011; follow up ends two year after each era), for CD and UC separately.

SIRs were also calculated for medication groups, and to maintain sufficient power this medication analysis was performed for the total group of IBD (CD and UC combined). Three medication groups were distinguished. The immunosuppression exposure group comprised patient years after a patient had reached 12 months of cumulative thiopurine, anti-TNF $\alpha$ agents and/or methotrexate use. The thiopurine-only exposure group was based on patient years after a patient had reached 12 months of cumulative thiopurine use, and this group only included anti-TNF $\alpha$ agent and methotrexate naive patients. The immunosuppression naive group comprised all patient years in which a patient was naive for thiopurines, anti-TNF $\alpha$ agents and/or methotrexate. The immunosuppression naive group also included patient years preceding the first prescription in immunosuppression using patients, and, hereby, immune-time bias was minimized. ${ }^{25}$ A medication group including patient years in which a patient was only exposed to anti-TNF $\alpha$ agents, or only to methotrexate, was too small for analysis. Thiopurines used in South Limburg were azathioprine, 6-mercaptopurine and thioguanine, whereas registered anti-TNF $\alpha$ agents were 
infliximab, adalimumab and golimumab. Duration of exposure was based on Long et al., who found high NMSC risk in IBD patients with $>365$ days thiopurine use. ${ }^{26}$

\section{Results}

In total, 2801 IBDSL patients and 26898.5 patient years were analyzed. The 1157 CD patients were followed with a median follow-up of 8.1 years (IQR 4.3-13.6) and contributed to 10705 patient years. The 1644 UC patients were followed with a median follow up of 8.8 years (IQR 4.9-14.8) and contributed to 16193.5 patient years. Baseline characteristics are presented in Table 6.1.

\section{Intestinal cancer}

\section{Crohn's disease}

In the CD population, 11 CRCs were observed, which did not result in an increased risk compared to the background population (SIR 1.95; $95 \% \mathrm{Cl} 0.97-3.48$ )(Figure 6.1). However, the risk was found to be increased when only patients with colon involvement (with or without ileal involvement) at diagnosis were considered (SIR 2.97; $95 \% \mathrm{Cl}$ 1.08-6.46). An increased risk was also seen in females (SIR 2.96; $95 \% \mathrm{Cl}$ 1.27-5.83), but not in males (Table 6.2). No differences were found with regards to age at $\mathrm{CD}$ diagnosis, location at $\mathrm{CD}$ diagnosis (other than colon involvement), $C D$ duration and $C D$ diagnosis era. The five, ten, and 15 year cumulative incidence risks for CRC were $0.4 \%, 1.0 \%$, and $1.7 \%$ in the total CD population, and $0.5 \%, 0.7 \%$ and $1.9 \%$ in those CD patients with colon involvement at diagnosis, respectively. 
Table 6.1 Baseline characteristics of the total study population and per subgroup.

\begin{tabular}{|c|c|c|c|c|}
\hline & \multicolumn{2}{|l|}{ CD } & \multicolumn{2}{|l|}{ UC } \\
\hline & $\mathbf{N}$ & PYAR & $\mathbf{N}$ & PYAR \\
\hline Patients & 1157 & 10705 & 1644 & 16193.5 \\
\hline Age, median (IQR) * & 34.3 (24.3-46.9) & & $45.0(32.2-59.1)$ & \\
\hline Follow-up, median (IQR) & $8.1(4.3-13.6)$ & & $8.8(4.9-14.8)$ & \\
\hline Primary cancers & 79 & & 172 & \\
\hline \multicolumn{5}{|l|}{ Gender (\%) } \\
\hline Male & $430(37)$ & 4023.5 & $891(54)$ & 8902.5 \\
\hline Female & $727(63)$ & 6681.5 & $753(46)$ & 7291 \\
\hline \multicolumn{5}{|l|}{ Phenotype (\%) ** } \\
\hline $\mathrm{A} 2$ & $714(62)$ & 7103 & $684(42)$ & 7562.5 \\
\hline A3 & $443(38)$ & 3598 & $960(58)$ & 8631 \\
\hline L1 & $496(43)$ & 4903 & & \\
\hline L2 & 369 (32) & 3225 & & \\
\hline L3 & $266(23)$ & 2335.5 & & \\
\hline L4 \& L4 modifier & $123(11)$ & 992 & & \\
\hline E1 & & & $556(34)$ & 5245 \\
\hline E2 & & & 777 (48) & 8054 \\
\hline E3 & & & $296(18)$ & 2682 \\
\hline \multicolumn{5}{|l|}{ Disease duration $(\%) \neq$} \\
\hline 1st decade & $1157(100)$ & 7933 & $1644(100)$ & 11735 \\
\hline 2nd decade & $470(41)$ & 2761.5 & $728(44)$ & 4450 \\
\hline \multicolumn{5}{|l|}{ Diagnosis era (\%) \# } \\
\hline $1991-2001$ & $409(35)$ & 2290 & $684(42)$ & 3955 \\
\hline 2001-2011 & $748(65)$ & 3686 & $960(58)$ & 4875 \\
\hline
\end{tabular}

CD, Crohn's disease/ UC, ulcerative colitis/ N, number of patients/ PYAR, patient years at risk/ IQR, inter quartile range/ ${ }^{*}$, at diagnosis/**, phenotype according to Montreal Classification: diagnosed with CD or UC below 40 years of age (A2), or above 40 years of age (A3). Disease location of CD was defined as ileal involvement (L1), exclusive colonic involvement (L2), ileocolonic involvement (L3) or isolated upper disease (L4). L4 modifier is a modifier, added to L1-L3 when concomitant upper gastrointestinal disease is present. Disease extent of UC was defined as ulcerative proctitis (E1), left sided UC (E2) and extensive UC (E3)/ $\neq$, in decades after IBD diagnosis/\#, follow-up ends 2 years after era.

Characteristics of the observed CRCs are provided in Table 6.3. Of the 11 patients with CRC, three patients were diagnosed with TNM stage IV adenocarcinoma, two patients with TNM stage III, two patients with TNM stage II, two patients with TNM stage I and two patients with a neuroendocrine tumour (NET). Mean age at CRC diagnosis was 62.9 years (SD 16.5), mean CD duration at CRC diagnosis was 6.8 years (SD 5.9). According to the current Dutch guidelines, four of $11 \mathrm{CD}$ patients were eligible for CRC surveillance.

In addition, one cancer of the upper gastro intestinal tract (upper-Gl) was found, located in the stomach. The upper-GI cancer risk was comparable to the background population, as was the risk for cancers of the liver and bile ducts (Figure 6.1). 


\begin{tabular}{l|c|c|cc} 
Cancer type & O & E & SIR & $(95 \% C I)$ \\
\hline CRC & 11 & 5.65 & 1.95 & $(0.97-3.48)$ \\
Upper GI-tract & 1 & 2.58 & 0.39 & $(0.01-2.16)$ \\
Liver and bile ducts & 2 & 0.39 & 5.16 & $(0.58-18.64)$ \\
& & & & \\
Lung & 8 & 5.62 & 1.42 & $(0.61-2.80)$ \\
Urinary tract & 5 & 2.34 & 2.14 & $(0.69-5.00)$ \\
Breast & 1 & 8.72 & 0.11 & $(0.00-0.64)$ \\
Prostate & 1 & 4.43 & 0.23 & $(0.00-1.26)$ \\
Hematologic & 8 & 3.31 & $\mathbf{2 . 4 1}$ & $(1.04-4.76)$ \\
$\quad$ NHL & 3 & 1.67 & 1.80 & $(0.36-5.25)$ \\
Skin & 32 & 20.59 & 1.55 & $(1.06-2.19)$ \\
$\quad$ BCC & 17 & 14.75 & 1.15 & $(0.67-1.85)$ \\
$\quad$ SCC & 10 & 2.61 & $\mathbf{3 . 8 3}$ & $(1.83-7.04)$ \\
$\quad$ Melanoma & 5 & 2.75 & 1.82 & $(0.59-4.24)$ \\
Overall & & & & \\
& 79 & 61.64 & 1.28 & $(1.01-1.60)$
\end{tabular}

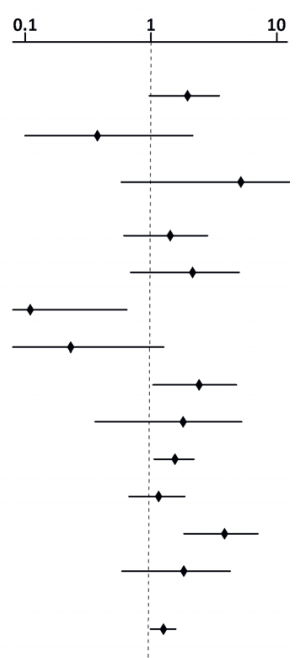

Figure 6.1 Standardized incidence ratios of intestinal, extra-intestinal subtypes and overall cancer in the CD population.

O, observed primary cancers/ E, expected primary cancers/ SIR, standardized incidence ratio/ $95 \% \mathrm{Cl}, 95 \%$ confidence interval by Byar's approximation/ CRC, colorectal cancer/ Upper GItract, upper gastrointestinal tract/ $\mathrm{NHL}$, non-Hodgkin lymphoma/ BCC, basal cell carcinoma/ SCC, squamous cell carcinoma.

\section{Ulcerative colitis}

In the UC population, the CRC risk was found to be similar to the background population. The 12 observed CRCs contributed to a SIR of $0.71(95 \% \mathrm{Cl} 0.37-1.24)$ (Figure 6.2 ) and to five, ten, and 15 year cumulative incidence risks of $0.2 \%, 0.5 \%$, and $1.5 \%$, respectively. No increased CRC risks were found in the subgroups analyzed (Table 6.2).

Characteristics of the observed CRCs are provided in Table 6.3. Of the 12 patients with CRC, no patients were diagnosed with TNM stage IV adenocarcinoma, three patients with TNM stage III, five patients with TNM stage II, three patients with TNM stage I and one patient with a NET. Mean age at CRC diagnosis was 62.6 years (SD 11.1), mean UC duration at CRC diagnosis was 9.3 years (SD 5.0). According to current Dutch guidelines, eight of $12 \mathrm{UC}$ patients were eligible for CRC surveillance.

In addition, five upper-GI cancers were observed (i.e. two oesophagus, three stomach) and two cancers of the liver and bile ducts, resulting in risk estimates comparable to the background (Figure 6.2). Of the latter, one was a cholangiocarcinoma but the patient was not diagnosed with primary sclerosing cholangitis (PSC). 


\section{Extra-intestinal cancer}

\section{Crohn's disease}

The risk for hematologic cancer was increased (SIR 2.41; 95\% $\mathrm{Cl}$ 1.04-4.76) (Figure 6.1), and was particularly high in patients $>40$ years of age at CD diagnosis (SIR $2.83 ; 95 \% \mathrm{Cl}$ 1.13-5.83), in the first decade after CD diagnosis (SIR 3.49; $95 \% \mathrm{Cl} 1.50-6.86$ ), and in patients diagnosed with CD between 2001 and 2011 (SIR 5.88; 95\%Cl 2.36-12.12)(all Table 6.2). Of the eight hematologic cancers, three were non-Hodgkin lymphoma's $(\mathrm{NHL})$, two chronic myelomonocytic leukaemia, one chronic myelogenous leukaemia, one refractory anaemia with excess blasts and one multiple myeloma.

The risk for overall skin cancer (i.e. NMSC and melanoma) was also increased (SIR 1.55; 95\% $\mathrm{Cl}$ 1.06-2.19)(Figure 6.1), and was associated with ileal localization at CD diagnosis (SIR 2.10; 95\% CI 1.33-3.15) and the first decade after CD diagnosis (SIR 1.86; 95\% Cl 1.21-2.75)(all Table 6.2). This increase was partly attributed to the excess of observed squamous cell carcinomas of the skin (SCC; 10 observed versus 2.61 expected; SIR 3.83; 95\%Cl 1.83-7.04)(Figure 6.1). SCC risk was associated with male gender (SIR $4.23 ; 95 \% \mathrm{Cl} 1.54-9.21$ ), $>40$ of age years at CD diagnosis (SIR $3.90 ; 95 \% \mathrm{Cl} 1.78-7.40$ ), ileal localization at CD diagnosis (SIR $5.31 ; 95 \% \mathrm{Cl} 2.29-10.47$ ), the first decade after CD diagnosis (SIR 4.12; 95\%Cl 1.65-8.49) and CD diagnosis era between 2001-2011 (SIR 5.13; $95 \% \mathrm{Cl}$ 1.65-11.97)(all Table 6.2). The risk for melanoma and basal cell carcinoma (BCC) was similar to the background population.

The risk for lung, prostate and urinary tract cancers was not increased in the total CD population. The risk for breast cancer was decreased in the total CD population (SIR $0.11 ; 95 \% \mathrm{Cl} 0.00-0.64$ )(Figure 6.1 ), but the number of observed breast cancers was too small for subgroup analyses. Other subgroup details as well as SIRs for less common cancer subtypes are presented in the online supplementary table.

\section{Ulcerative colitis}

In the total UC population, no altered risks were observed for any of the extra-intestinal cancer subtypes (Figure 6.2). Subgroup details as well as SIRs for less common cancer subtypes are presented in the online supplementary table. 


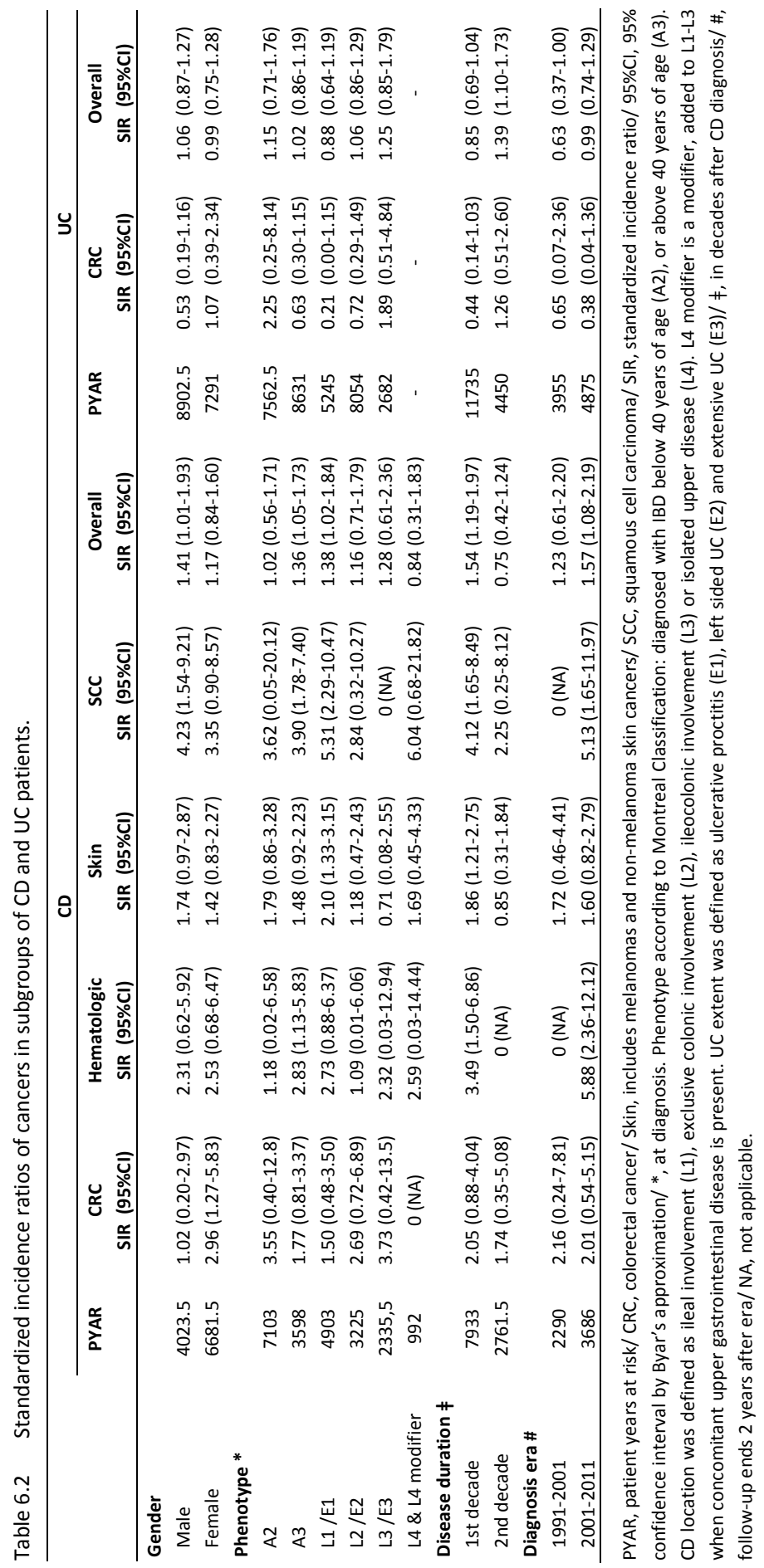




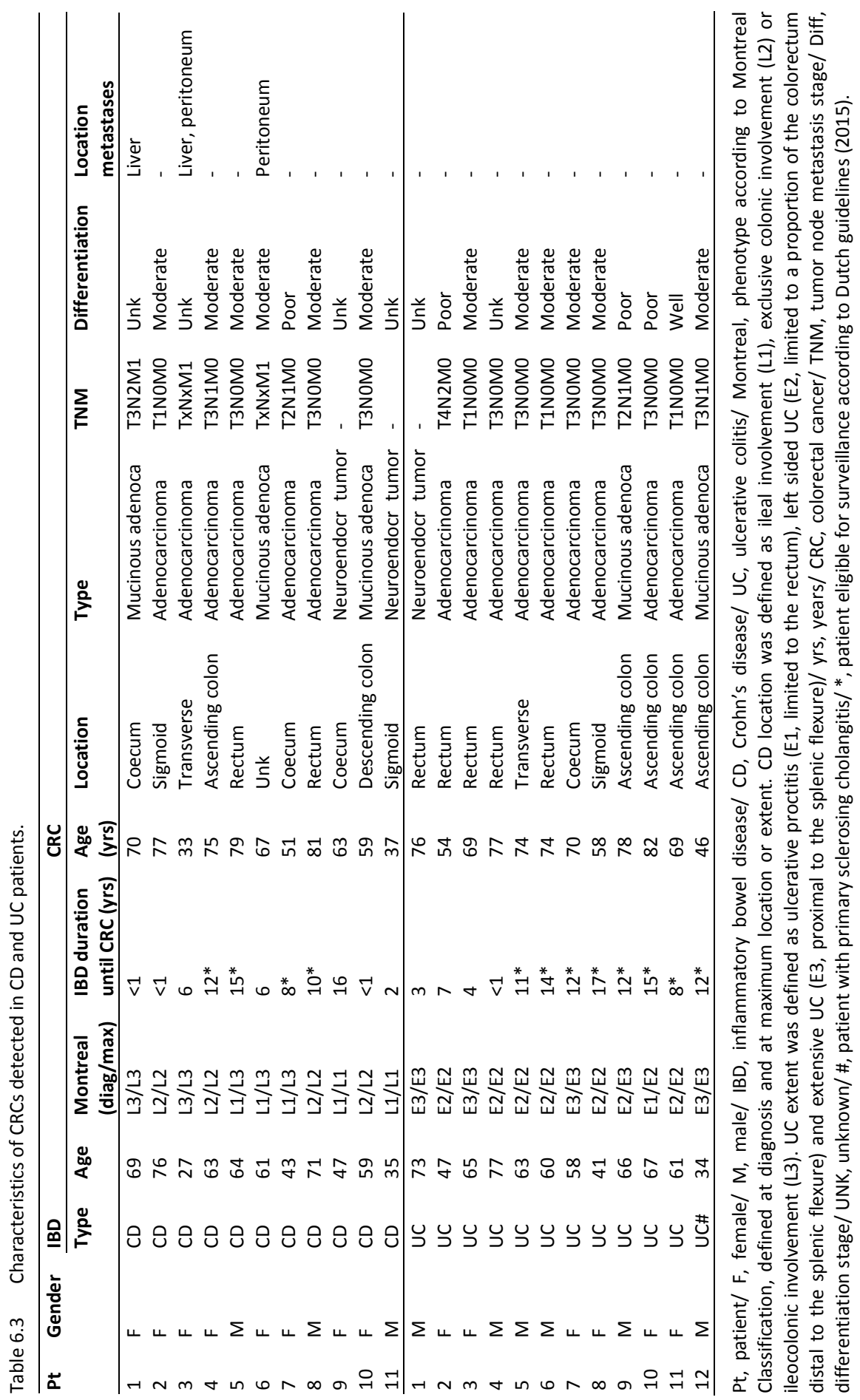




\section{Overall cancer}

\section{Crohn's disease}

Overall, 79 primary cancers were observed in $73 \mathrm{CD}$ patients, resulting in an increased overall cancer risk (SIR 1.28; 95\% CI 1.01-1.60)(Figure 6.1). This increase was associated with male gender (SIR 1.41; $95 \% \mathrm{Cl} 1.01-1.93$ ), $>40$ years of age at CD diagnosis (SIR 1.36; $95 \% \mathrm{Cl} 1.05-1.73$ ), ileal localization at $\mathrm{CD}$ diagnosis ( $\mathrm{SIR} 1.38 ; 95 \% \mathrm{Cl} 1.02-1.84$ ), first decade after CD diagnosis (SIR 1.54; 95\% Cl 1.19-1.97) and CD diagnosis in the 2001-2011 era (SIR 1.57; 95\%Cl 1.08-2.19)(all Table 6.2).

\section{Ulcerative colitis}

In the total UC population, 172 primary cancers were observed in 158 UC patients, and the overall cancer risk was similar to the background population (SIR $1.03 ; 95 \% \mathrm{Cl} 0.88$ 1.20)(Figure 6.2). The overall cancer risk was increased in the second decade after UC diagnosis (SIR 1.39; $95 \% \mathrm{Cl} 1.10-1.73$ ), whereas no differences were found in other subgroups (Table 6.2).

\begin{tabular}{l|c|c|cc} 
Cancer type & O & E & SIR & $(95 \% \mathrm{CI})$ \\
\hline CRC & 12 & 16.84 & 0.71 & $(0.37-1.24)$ \\
Upper Gl-tract & 5 & 8.20 & 0.61 & $(0.20-1.42)$ \\
Liver and bile ducts & 2 & 1.22 & 1.64 & $(0.18-5.92)$ \\
& & & & \\
Lung & 12 & 18.35 & 0.65 & $(0.34-1.14)$ \\
Urinary tract & 14 & 7.95 & 1.76 & $(0.96-2.95)$ \\
Breast & 15 & 13.79 & 1.09 & $(0.61-1.79)$ \\
Prostate & 25 & 18.26 & 1.37 & $(0.89-2.02)$ \\
Hematologic & 11 & 9.20 & 1.20 & $(0.60-2.14)$ \\
$\quad$ NHL & 6 & 4.77 & 1.26 & $(0.46-2.74)$ \\
Skin & 61 & 51.50 & 1.18 & $(0.91-1.52)$ \\
$\quad$ BCC & 44 & 36.93 & 1.19 & $(0.87-1.60)$ \\
$\quad$ SCC & 10 & 8.64 & 1.16 & $(0.55-2.13)$ \\
$\quad$ Melanoma & 7 & 4.80 & 1.46 & $(0.58-3.00)$ \\
Overall & 172 & 166.61 & 1.03 & $(0.88-1.20)$
\end{tabular}

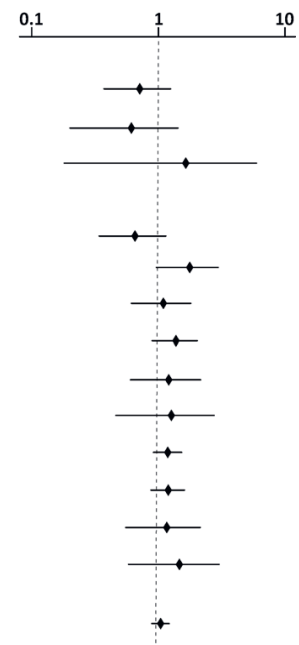

Figure 6.2 Standardized incidence ratios of intestinal, extra intestinal subtypes and overall cancer in the UC population.

$\mathrm{O}$, observed primary cancers/ E, expected primary cancers/ SIR, standardized incidence ratio/ $95 \% \mathrm{Cl}, 95 \%$ confidence interval by Byar's approximation/ CRC, colorectal cancer/ Upper GItract, upper gastrointestinal tract/ NHL, non-Hodgkin lymphoma/ BCC, basal cell carcinoma/ SCC, squamous cell carcinoma. 


\section{Medication analysis}

The medication analysis was performed on the combined group of $C D$ and UC patients. In the immunosuppression exposure group (890 patients, 5359 patient years), the risk was increased for hematologic cancer (SIR 3.12; 95\% CI 1.14-6.79), NHL (SIR 5.17; 95\% CI 1.67-12.07), overall skin cancer (SIR 1.95; 95\% CI 1.22-2.96), SCC (SIR 5.15; 95\%Cl 2.22-10.15) and overall cancer (SIR 1.48; 95\%CI 1.11-1.95)(all Table 6.4). The five and ten year cumulative incidences for hematologic cancer were $0.6 \%$ and $1.2 \%$, for $\mathrm{NHL}$ $0.4 \%$ and $1.0 \%$, for overall skin cancer $1.2 \%$ and $3.7 \%$, and for SCC $0.3 \%$ and $1.5 \%$, respectively. The risk profile in the thiopurine-only exposure group (456 patients, 2812 patient years) was comparable, including an increased risk for hematologic cancer (SIR 4.94; 95\%Cl 1.80-10.74), NHL (SIR 8.17; 95\%Cl 2.63-19.07), SCC (SIR 3.88; 95\%CI 1.04-9.93) and overall cancer (SIR 1.58; 95\% $\mathrm{Cl} 1.10-2.20)$, but no increased risk for overall skin cancer (all Table 6.4). The five and ten year cumulative incidences for hematologic cancer were $1.2 \%$ and $2.1 \%$, for NHL $0.9 \%$ and $1.7 \%$, and for SCC $0.0 \%$ and $1.8 \%$, respectively. The observed cancers in the immunosuppression naive group (2496 patients, 19773 patient years) did not lead to an altered overall cancer risk compared to the background, nor were any associations found for cancer subtypes (Table 6.4). 


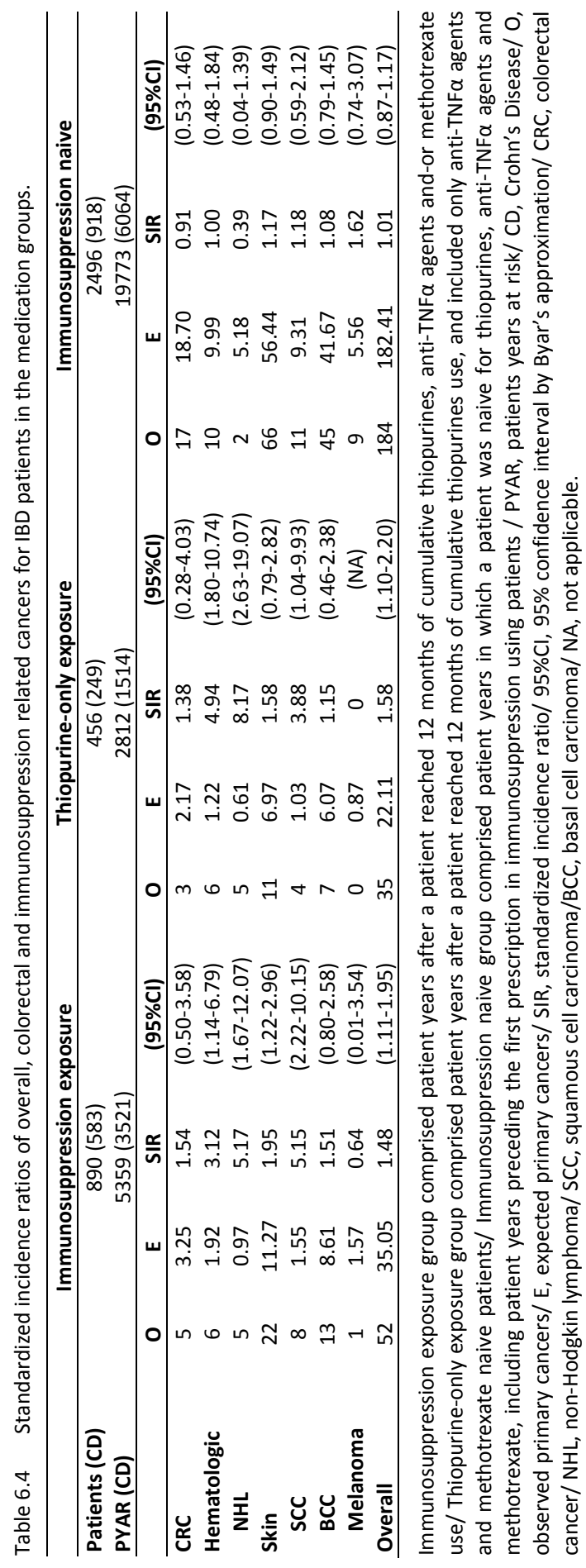




\section{Discussion}

This is the first Dutch population-based analysis on cancer risk in IBD, and adds to the ongoing discussion on the actual cancer risk in IBD in an era of marked therapeutic changes. In CD, key findings were an increased CRC risk in patients with colon involvement at diagnosis, but not in the total $C D$ population. The risk for hematologic cancer, overall skin cancer, skin SCC and overall cancer was also increased in CD patients. In UC, no increased risk was observed for intestinal, extra-intestinal or overall cancer. The medication analyses, performed on the combined group of $C D$ and UC patients, showed increased risks for hematologic cancer, NHL, SCC and overall cancer in both the immunosuppression and the thiopurine-only exposure group, whereas no increased cancer risk was observed in the immunosuppression naive group.

In this study, the CRC risk was not increased in the total CD or UC population, but was significantly increased in CD patients with colon involvement at diagnosis (with or without ileal involvement). This was in line with a recent Danish population-based study, ${ }^{13}$ and with two population-based meta-analyses that showed highest CRC risk in colonic CD. ${ }^{5,11}$ The difference in CRC risk between CD with colon involvement and UC may be explained by several factors. First, colectomy is a more common procedure in UC than in CD management, as reflected by a 7\% colectomy rate in our UC patients versus $2 \%$ in $C D$. Second, although there is some debate as to whether surveillance programs are effective in reducing CRC risk, a large and recent study demonstrated that the incidence of CRC was significantly lower in patients with a recent colonoscopy when compared to those without (Odds ratio $0.65 ; 0.95 \% \mathrm{Cl} 0.45-0.93$ ). ${ }^{27}$ The first Dutch surveillance guidelines have only been published in 2008, but UC surveillance already occurred frequently in the decade before. Adherence to CRC surveillance guidelines in the Netherlands is also better in UC than in CD. ${ }^{28}$ Third, 5-ASA agents are known of having the potential to reduce CRC risk, $^{29}$ and these agents are more frequently prescribed to the UC patients (98\%) than the CD patients (79\%) of the IBDSL cohort. Finally, CD patients are more frequent smokers than UC patients, ${ }^{30}$ and smoking is a known risk factor for CRC. ${ }^{31}$ To what extent smoking affected CD cancer risk in this study could not be explored as reliable data were not available.

Stratification by phenotype and demographics revealed several CD and UC subgroups to have increased $C R C$ risk profiles. In $C D$, female patients were at increased risk for $\mathrm{CRC}$, while $\mathrm{CRC}$ incidence in the general population is higher in males. ${ }^{32} \mathrm{~A}$ clear explanation for this increased risk in females is not readily available. In UC, the SIRs for CRC were higher in patients with larger disease extent and patients with longer disease duration. Although not statistically significant, these findings were in line with other studies. ${ }^{5,9,12}$ No decrease in CRC risk was observed over time, neither in CD nor in UC. We, therefore, could not confirm that diagnosis era, and thereby, changes in IBD 
management (e.g. increased use of immunosuppressive agents, improved surveillance programs and diagnostics) contributed to decreased CRC risk in IBD. ${ }^{5,10}$ It is important to note that a nationwide CRC screening program has only been implemented in the Netherlands in 2014, and therefore does not affect our findings in IBD.

Our results underline the relevance of strict (adherence to) surveillance guidelines. Although the first guidelines for surveillance were published in $2008,{ }^{33}$ and the majority of the observed CRCs were thus not diagnosed within the context of a surveillance program, 12 CRCs could hypothetically be prevented with adequate adherence to current guidelines (i.e. four out of 11 CRCs in CD, eight out of 12 CRCs in UC). Moreover, the surveillance target population warrants re-evaluation. Of all the CRCs that occurred in patients who were not eligible for surveillance, 60 percent (six out of ten CRCs) was found within eight years after IBD diagnosis in patients that had elderly-onset IBD (IBD diagnosis at $>55$ years of age). These IBD patients are not eligible for the aforementioned nationwide CRC screening program, in which elderly are regularly tested for occult faecal blood loss and are invited for colonoscopy when positive. Elderly-onset IBD patients may, therefore, benefit from earlier CRC surveillance, which should be assessed in future studies. It was currently not possible to elaborate on the efficacy of the surveillance program in the IBDSL cohort, since not all required data were available.

Little is known about the characteristics of CRCs in IBD patients, and therefore we described all CRCs observed in the IBDSL cohort. The observed CRCs did not differ from those in the background population in terms of TNM stage at presentation. The prevalence of mucinous adenocarcinoma, however, was relative high compared to the background population ( $22 \%$ vs. $8 \%$, respectively), ${ }^{34}$ but this should be interpreted with care due to the small numbers. Mucinous adenocarcinomas are associated with a poorer prognosis and survival, compared to other CRCs. ${ }^{35-37}$

In the extra-intestinal cancer analyses, we found CD patients to have an increased risk for hematologic cancer, overall skin cancer and SCC, whereas no associations were found with UC. Similar increased risks in CD were reported by others as well. ${ }^{38,39}$ We did not find an increased risk for lung cancer in CD, in contrast to others. ${ }^{13,38,40}$ This finding may however be subject to bias, as South Limburg has a high lung cancer incidence due to the coal mining history. ${ }^{20}$ The decreased breast cancer risk in CD is remarkable and requires further study. For the less common cancers (only in the online supplement), no associations were found, which should be interpreted with care because of the small numbers.

The overall cancer risk in CD was $28 \%$ higher than in the background population, but was not increased in the UC population. Similar findings were recently described in two other population-based cohorts. ${ }^{13,41}$ On one hand this could partially be explained by differences in smoking, but several lines of evidence point towards a possible 
immunosuppression effect as well. First, a considerable part of the observed cancers in CD patients from the IBDSL cohort were hematologic and skin cancers, which have previously been linked to immunosuppression use. ${ }^{15,42,43}$ The CD patients from the IBDSL cohort more frequently received immunosuppression than the UC patients $(63 \%$ versus $26 \%$, respectively). Second, if immunosuppression has any effect on cancer development, this can best be observed in the most recent decade as only then thiopurines became more widely used and the first anti-TNF $\alpha$ agent (infliximab for CD) was registered in the Netherlands in 1999. In this study, hematologic cancer and SCC risk were positively associated with a CD diagnosis in the last era (2001-2011), and in parallel, the increased overall cancer risk was also associated with a CD diagnosis in this era, suggesting collinearity. To study the effect of immuno-suppression, medication analyses were performed.

In the medication analyses, we observed an increased risk for hematologic cancer, $\mathrm{NHL}$, overall skin cancer, SCC and overall cancer in the immunosuppression exposure group, and as a nearly similar pattern was observed in the thiopurine-only exposure group, this increase was largely attributed to thiopurines. Confounding by indication in the immunosuppression and thiopurine-only exposure group cannot be excluded (more severe IBD patients are more likely to receive these drugs) but there is reason to believe that thiopurines themselves have an effect as well. Thiopurines are suppressing the immune system and have specific procarcinogenic effects. In case of hematologic cancers, for instance, azathioprine promotes clonal expansion of rare mismatch repair (MMR)-defective myeloid cells. ${ }^{14,44}$ A potential mechanism in NMSC carcinogenesis is the accumulation of 6-thioguanine in DNA. Under the action of ultraviolet A reactive oxygen species are produced, which in turn can lead to DNA mutations, oxidative stress and thus oncogenesis. ${ }^{14,45}$ Thiopurine exposure may also cause PTCH mutations, a candidate tumour suppressor gene, particularly in cancers from non-sun-exposed skin, such as BCC. ${ }^{14,46}$ Immunosuppression naive patients had no increased cancer risk. In a sensitivity analysis based on three rather than 12 months cumulative medication use, results were similar (data not shown).

Given the increased risks for overall skin cancer and SCC in the medication exposure groups, and given the high prevalence of skin cancer in the Netherlands, ${ }^{20}$ our data support the advice in recent IBD guidelines to consider skin cancer screening in patients with sustained immunosuppression. ${ }^{47}$ Moreover, skin cancers have been shown to be particularly aggressive in organ transplant recipients on severe immunosuppression. ${ }^{48}$ It must, however, be noted that the United States Preventive Service Task Force (USPSTF) concluded that current evidence is insufficient to assess the balance of benefits versus harms of skin cancer screening in the general population. ${ }^{49}$ Whether skin cancer screening in this targeted IBD population is effective, therefore, needs to be elucidated in future. 
A major strength of this study was the ability to assess cancer risk in a populationbased IBD cohort (gold standard), with over 93\% patient completeness and thereby comprising the full disease spectrum from mild to severe cases. In view of the factors previously discussed, selection bias was unlikely. ${ }^{16}$ Secondly, the IBDSL cohort contains long term (since 1991) and detailed medical data (including medication data), which was derived by thorough manual exploration of all patient files. This provided a level of detail which was extensive enough to allow subgroup analyses (i.e. by IBD phenotype, IBD medication, IBD diagnosis era, IBD duration, and gender) and which is difficult to achieve in cohorts from administrative databases. Third, cancer data were highly reliable as the observed cancers were cross-checked in several sources, and the expected cancers were age-, gender-, calendar year and region specific. Some limitations merit discussion. Foremost, observational research describes associations rather than causations. Second, the study covered a period longer than twenty years but follow up of the majority of IBD patients was shorter, and perhaps too short for the development of some IBD associated cancers. Longer term cancer risk in the IBDSL cohort can only be studies in the future. Third, although (sub)groups were large enough for the vast majority of analyses, power was modest for the lowest incident cancers. Finally, the medication analyses were based on prescription data, derived from medical files. But as non-adherence rates in IBD vary between $7-72 \%,{ }^{50}$ medication based associations may be even underestimated.

In conclusion, we have evaluated the current intestinal, extra-intestinal and overall cancer risk in a Dutch population-based IBD cohort, covering an era of marked therapeutic changes. In CD, we found an increased risk for CRC in patients with colon involvement at diagnosis, whereas no increased CRC risk was observed in the total CD and UC population. The characteristics of the observed CRCs underline the importance of strict (adherence to) surveillance guidelines and they also show that elderly-onset IBD patients may benefit from earlier CRC surveillance. Furthermore, the risk for hematologic cancer, overall skin cancer, SCC and overall cancer was increased in the CD population, whereas in UC no increased extra-intestinal or overall cancer risk was found. The medication analyses, performed on the combined group of $C D$ and UC patients, showed increased risks for hematologic cancer, NHL, SCC and overall cancer in both the immunosuppression and the thiopurine-only exposure group, which was attributed to thiopurines. IBD patients with long term exposure to immuno-suppression (or thiopurines-only) can be considered as having a higher cancer risk, and our data support the advice in recent IBD guidelines to consider skin cancer screening in patients with sustained immunosuppression. 


\section{References}

1. Dignass A, Lindsay JO, Sturm A, et al. Second European evidence-based consensus on the diagnosis and management of ulcerative colitis part 2: current management. J Crohns Colitis. 2012;6:991-1030

2. Dignass A, Van Assche G, Lindsay JO, et al. The second European evidence-based Consensus on the diagnosis and management of Crohn's disease: Current management. J Crohns Colitis. 2010;4:28-62

3. Virchow R. An adress on the address of pathological experiment. BMJ. 1881;2:198-203

4. Elinav E, Nowarski R, Thaiss CA, et al. Inflammation-induced cancer: crosstalk between tumours, immune cells and microorganisms. Nat Rev Cancer. 2013;13:759-771

5. Lutgens MW, van Oijen MG, van der Heijden GJ, et al. Declining risk of colorectal cancer in inflammatory bowel disease: an updated meta-analysis of population-based cohort studies. Inflamm Bowel Dis. 2013;19:789-799

6. Ullman TA, Itzkowitz SH. Intestinal inflammation and cancer. Gastroenterology. 2011;140:1807-1816

7. Zankel E, Rogler G, Andus T, et al. Crohn's disease patient characteristics in a tertiary referral center: comparison with patients from a population-based cohort. Eur J Gastroenterol Hepatol. 2005;17: 395-401

8. van den Heuvel T, Jonkers D, Jeuring S, et al. The relevance of population based IBD biobanks: a metaanalysis and introduction of the IBD-SL biobank cohort. J Crohns Colitis. 2014;8

9. Castano-Milla C, Chaparro M, Gisbert JP. Systematic review with meta-analysis: the declining risk of colorectal cancer in ulcerative colitis. Aliment Pharmacol Ther. 2014;39:645-659

10. Andersen NN, Jess T. Has the risk of colorectal cancer in inflammatory bowel disease decreased? World J Gastroenterol. 2013;19:7561-7568

11. Jess T, Gamborg M, Matzen P, et al. Increased risk of intestinal cancer in Crohn's disease: a metaanalysis of population-based cohort studies. Am J Gastroenterol. 2005;100:2724-2729

12. Jess T, Rungoe C, Peyrin-Biroulet L. Risk of colorectal cancer in patients with ulcerative colitis: a metaanalysis of population-based cohort studies. Clin Gastroenterol Hepatol. 2012;10:639-645

13. Jess $\mathrm{T}$, Horvath-Puho E, Fallingborg J, et al. Cancer risk in inflammatory bowel disease according to patient phenotype and treatment: a Danish population-based cohort study. Am J Gastroenterol. 2013;108:1869-1876

14. Magro F, Peyrin-Biroulet $\mathrm{L}$, Sokol H, et al. Extra-intestinal malignancies in inflammatory bowel disease: results of the 3rd ECCO Pathogenesis Scientific Workshop (III). J Crohns Colitis. 2014;8:31-44

15. Mason M, Siegel CA. Do inflammatory bowel disease therapies cause cancer? Inflamm Bowel Dis. 2013;19:1306-1321

16. van den Heuvel TR, Jonkers DM, Jeuring SF, et al. Cohort Profile: The Inflammatory Bowel Disease South Limburg Cohort (IBDSL). Int J Epidemiol. 2015

17. Satsangi J, Silverberg MS, Vermeire S, et al. The Montreal classification of inflammatory bowel disease: controversies, consensus, and implications. Gut. 2006;55:749-753

18. PALGA. http://www.palga.nl/. 2015

19. World Medical A. World Medical Association Declaration of Helsinki: ethical principles for medical research involving human subjects. JAMA. 2013;310:2191-2194

20. IKNL. http://www.cijfersoverkanker.nl/. 2015

21. ICD-O. http://codes.iarc.fr/. 2015

22. Edge S, Byrd D, Bird C, et al. AJCC Cancer Staging Manual; 2010

23. ICC. Handleiding behandeling IBD 2015;(revision 2009):1-119

24. Breslow NE, Day NE. Statistical Methods in Cancer Research. New York: Oxford University Press; 1987

25. Targownik LE, Suissa S. Understanding and Avoiding Immortal-Time Bias in Gastrointestinal Observational Research. Am J Gastroenterol. 2015;110(12):1647-50

26. Long MD, Herfarth $\mathrm{HH}$, Pipkin CA, et al. Increased risk for non-melanoma skin cancer in patients with inflammatory bowel disease. Clin Gastroenterol Hepatol. 2010;8:268-274

27. Ananthakrishnan AN, Cagan A, Cai T, et al. Colonoscopy is associated with a reduced risk for colon cancer and mortality in patients with inflammatory bowel diseases. Clin Gastroenterol Hepatol. 2015;13:322-329 e321 
28. van Rijn AF, Fockens P, Siersema PD, et al. Adherence to surveillance guidelines for dysplasia and colorectal carcinoma in ulcerative and Crohn's colitis patients in the Netherlands. World J Gastroenterol. 2009;15:226-230

29. Velayos FS, Terdiman JP, Walsh JM. Effect of 5-aminosalicylate use on colorectal cancer and dysplasia risk: a systematic review and metaanalysis of observational studies. Am J Gastroenterol. 2005;100:1345-1353

30. Cosnes J. Smoking, physical activity, nutrition and lifestyle: environmental factors and their impact on IBD. Dig Dis. 2010;28:411-417

31. WHO. International Agency for Research on Cancer. Personal habits and indoor combustions, a review of human carcinogens. 2012

32. WHO-GLOBOCAN. http://globocan.iarc.fr. 2015. Available

33. NVMDL. Richtlijn diagnostiek en behandeling van inflammatoire darmziekten bij volwassenen; 2008

34. le Clercq CM, Bouwens MW, Rondagh EJ, et al. Postcolonoscopy colorectal cancers are preventable: a population-based study. Gut. 2014;63:957-963

35. Negri FV, Wotherspoon A, Cunningham D, et al. Mucinous histology predicts for reduced fluorouracil responsiveness and survival in advanced colorectal cancer. Ann Oncol. 2005;16:1305-1310

36. Catalano V, Loupakis F, Graziano F, et al. Mucinous histology predicts for poor response rate and overall survival of patients with colorectal cancer and treated with first-line oxaliplatin- and/or irinotecanbased chemotherapy. Br J Cancer. 2009;100:881-887

37. Verhulst J, Ferdinande L, Demetter $\mathrm{P}$, et al. Mucinous subtype as prognostic factor in colorectal cancer: a systematic review and meta-analysis. J Clin Pathol. 2012;65:381-388

38. Kappelman MD, Farkas DK, Long MD, et al. Risk of cancer in patients with inflammatory bowel diseases: a nationwide population-based cohort study with 30 years of follow-up evaluation. Clin Gastroenterol Hepatol. 2014;12:265-273 e261

39. Jussila A, Virta $L$, Pukkala E, et al. Malignancies in patients with inflammatory bowel disease: a nationwide register study in Finland. Scand J Gastroenterol. 2013;48:1405-1413

40. Pedersen N, Duricova D, Elkjaer M, et al. Risk of extra-intestinal cancer in inflammatory bowel disease: meta-analysis of population-based cohort studies. Am J Gastroenterol. 2010;105:1480-1487

41. Yadav S, Singh S, Harmsen WS, et al. Effect of Medications on Risk of Cancer in Patients With Inflammatory Bowel Diseases: A Population-Based Cohort Study from Olmsted County, Minnesota. Mayo Clin Proc. 2015;90:738-746

42. Kotlyar DS, Lewis JD, Beaugerie L, et al. Risk of Lymphoma in Patients With Inflammatory Bowel Disease Treated With Azathioprine and 6-Mercaptopurine: A Meta-analysis. Clin Gastroenterol Hepatol. 2015;13(5):847-58.e4; quiz e48-50

43. Ariyaratnam J, Subramanian V. Association between thiopurine use and nonmelanoma skin cancers in patients with inflammatory bowel disease: a meta-analysis. Am J Gastroenterol. 2014;109:163-169

44. Offman J, Opelz G, Doehler B, et al. Defective DNA mismatch repair in acute myeloid leukemia/myelodysplastic syndrome after organ transplantation. Blood. 2004;104:822-828

45. O'Donovan P, Perrett CM, Zhang X, et al. Azathioprine and UVA light generate mutagenic oxidative DNA damage. Science. 2005;309:1871-1874

46. Harwood CA, Attard NR, O'Donovan P, et al. PTCH mutations in basal cell carcinomas from azathioprine-treated organ transplant recipients. $\mathrm{Br}$ j cancer. 2008;99:1276-1284

47. Axelrad J, Bernheim O, Colombel JF, et al. Risk of New or Recurrent Cancer in Patients With Inflammatory Bowel Disease and Previous Cancer Exposed to Immunosuppressive and Anti-Tumor Necrosis Factor Agents. Clin Gastroenterol Hepatol. 2016;14:58-64

48. Geissler EK. Skin cancer in solid organ transplant recipients: are mTOR inhibitors a game changer? Transplant Res. 2015;4:1

49. USPSTF. www.uspreventiveservicestaskforce.org. 2015. Available

50. Selinger CP, Robinson A, Leong RW. Clinical impact and drivers of non-adherence to maintenance medication for inflammatory bowel disease. Expert Opin Drug Saf. 2011;10:863-870 


$$
20
$$




\section{Chapter 7}

\section{Incidence and classification of postcolonoscopy colorectal cancers in inflammatory bowel disease: $\mathrm{A}$ Dutch population-based cohort study}

Dion S.J. Wintjens, Roel M.M. Bogie, Tim R.A. van den Heuvel, Chantal M. le Clercq, Liekele E. Oostenbrug, Mariëlle J.L. Romberg-Camps, Jan-Willem A. Straathof, Laurents P.S. Stassen, Ad A.M. Masclee, Daisy M.A.E. Jonkers, Silvia Sanduleanu-Dascalescu, Marie J. Pierik J Crohns Colitis 2018;12(7):777-783 


\begin{abstract}
Background

Patients with inflammatory bowel disease (IBD) colitis are at increased risk for colorectal cancer (CRC). We examined the proportion and most likely aetiology of potentially preventable postcolonoscopy CRCS (PCCRCS) in a population-based cohort. Furthermore, adherence to IBD surveillance guidelines was evaluated in both PCCRCs and the remainder of prevalent CRCs.
\end{abstract}

\title{
Methods
}

All IBD patients diagnosed from 1991 to 2011 in the South Limburg region of The Netherlands (i.e. IBDSL cohort) were included. CRC cases were cross-checked with the Dutch pathology database and cancer registry. PCCRCs were defined as cancers diagnosed within 6-60 months after a colonoscopy and were classified as attributable to 'inappropriate surveillance interval', 'inadequate bowel examination', 'incomplete resection', 'missed lesion' or 'newly developed cancer'.

\section{Results}

Twenty CRC cases were identified during 25,931 patient years of follow-up in 2,801 patients. The proportion of PCCRCs was $45.0 \%$. Of these, $55.6 \%$ could be considered a 'missed lesion', while other possible aetiologies occurred only once. Considering both PCCRCs $(n=9)$ and prevalent CRCs $(n=11)$, ten were detected after publication of the surveillance guideline, but only three patients were enrolled. Moreover, 6 CRCs $(30.0 \%)$ were detected before the recommended start of surveillance.

\section{Conclusions}

In the IBDSL cohort, $45.0 \%$ of all CRCs were considered to be PCCRCs, mainly classified as missed lesions. Additionally, a large proportion of CRCs in our cohort were observed before a surveillance endoscopy was performed. Therefore, stringent adherence to IBD surveillance guidelines, improving endoscopy techniques and adjusting the surveillance program may lead to a decrease in CRC incidence. 


\section{Introduction}

Over the past decades, the incidence of colorectal cancer (CRC) in patients with inflammatory bowel disease (IBD) appears to have decreased in many countries. ${ }^{1,2}$ Recent accurate population-based studies indicating a lower incidence have been published, and this decrease may partly be attributed to improved disease control and the implementation of international surveillance guidelines. ${ }^{3}$ However, patients with Crohn's disease (CD) with colonic involvement and patients with ulcerative colitis (UC) patients with left-sided or extensive colitis remain at increased risk of developing CRC. ${ }^{1,2,4-7}$

An upcoming area of interest is the incidence of potentially preventable postcolonoscopy CRCs (PCCRCs). These comprise all CRCs arising within 6 to 60 months after a full colonoscopy that was negative for CRC. In the general population PCCRCs constitute $2.9-3.7 \%$ of all CRCs. ${ }^{8,9}$ However, in patients with CD and UC, Wang et al. found much higher rates of $15.1 \%$ and $15.8 \%$, respectively. ${ }^{10}$ Apart from a limited number of studies using hospital-based or selected populations, data on PCCRC incidence from population-based cohorts are lacking. ${ }^{10-12}$

Several studies in the general population found missed lesions to be a major contributor to PCCRCs. ${ }^{9,13,14}$ In IBD, missed lesions are thought to occur even more frequently. ${ }^{10}$ This may be due to the large proportion of flat lesions in IBD and technical difficulties in the detection of dysplasia when mucosal inflammation is present. $^{15}$ Besides missed lesions, inappropriate surveillance intervals, incomplete resection of polyps and incomplete colonoscopies are important contributors to PCCRCs. ${ }^{9,14}$

In this study, we evaluated the proportion of PCCRCs in the population-based IBDSL cohort and determined the most likely aetiology for their occurrence. In addition, for both PCCRCs and prevalent CRCs, adherence to IBD surveillance guidelines was evaluated.

\section{Methods}

\section{Setting and data collection}

All IBD patients included in the population-based IBDSL cohort were eligible for this study. This cohort has previously been described in detail. ${ }^{16}$ In brief, all patients diagnosed with IBD between January 1991 and June 2011, of at least 18 years of age at diagnosis and living in the region of South Limburg were included. IBD was diagnosed by certified gastroenterologists based on the combination of endoscopic, radiological and/or histological findings. A multifaceted identification strategy involving hospitals, the nationwide Dutch pathology database (PALGA) ${ }^{17}$ and general practitioners, resulted in $93 \%$ completeness of our cohort. As the remaining patients were unlikely to be 
biased towards a specific phenotype, an unselected population was assured. The IBDSL study design has been approved by the Ethics Committee of the Maastricht University Medical Centre (NL31636.068.10), is registered in ClinicalTrial.gov (NCT02130349) and meets the ethical standards of the revised version of the Declaration of Helsinki. ${ }^{18}$

Cancer related data were obtained in order to study the overall cancer risk in the IBDSL cohort. ${ }^{7}$ In short, cancer data were collected through medical chart review and cross-checked with PALGA as well as the Dutch cancer registry (IKNL). ${ }^{17,19}$ All IBDSL patients were followed until 2013, or until lost-to-follow-up (i.e. death or permanent migration).

In this study, all of the observed CRC cases from the IBDSL cohort were included and additional data were retrieved from patients' medical files. Since both the algorithm for classifying PCCRCS and the IBD surveillance guidelines are not designed for neuro-endocrine tumours (NETs), we excluded these malignancies from the dataset. In addition to the previously collected tumour-node-metastasis stage (TNM), differentiation stage, location of metastases, and IBD to CRC interval, all colonoscopy findings prior to CRC diagnosis were gathered. Each patient's eligibility for the IBD surveillance program according to the then applicable Dutch IBD guidelines, regardless of whether they actually received surveillance, was also assessed. It should be noted that the first guideline on IBD surveillance in the Netherlands was published in the year 2008 and that this Dutch guideline was to a large extent in line with the European ECCO guidelines. This guideline advised surveillance from 8 years after IBD onset in the case of colonic involvement, except for UC patients with only ulcerative proctitis (Montreal classification $\mathrm{E1}^{20}$ ) and patients with only one inflamed colonic segment in $\mathrm{CD}$. Surveillance endoscopies should have been scheduled once every 3 years during the first decade of surveillance, followed by a surveillance endoscopy once every 2 years in the second decade and once every year in the third decade. A surveillance endoscopy should have been performed by either taking four random biopsies every $10 \mathrm{~cm}$ of least at nine different locations or by screening using chromoendoscopy. Patients with a concurrent diagnosis of primary sclerosing cholangitis (PSC) should have been enrolled immediately after diagnosis for annual surveillance endoscopies. ${ }^{21}$ Enrolment status in the surveillance program of all patients who were diagnosed with CRC was retrieved from patients' medical files and colonoscopy reports. Also, the applied IBD surveillance method (i.e. either multiple random biopsies or the use of chromoendoscopy) was retrieved from the latter.

\section{Definitions}

Colorectal cancers were classified according to the time of occurrence with respect to the index colonoscopy (i.e. the last colonoscopy in which no cancer was detected). In line with previous studies, we defined a CRC that occurred between 6 and 60 months after the index colonoscopy as 'PCCRC'. ${ }^{9,22-25}$ When a PCCRC occurred during a 
surveillance period (i.e. according to the Dutch IBD surveillance guidelines or Dutch post-polypectomy surveillance guidelines ${ }^{21,26-28}$ ) and before the date of the next recommended exam, it was considered as 'interval CRC' in agreement with the consensus of the Colorectal Cancer Screening Committee of the World Endoscopy Organization. ${ }^{29}$ CRCs that could not be classified as PCCRC were regarded as 'prevalent CRCs'. Sigmoidoscopies were not regarded as full endoscopies and therefore neglected.

For each PCCRC, the most likely aetiology (i.e. procedural factors or tumour biology) was determined according to a previously described algorithm (Figure 7.1). ${ }^{9,24,30}$ PCCRCs were classified as (i) 'inappropriate surveillance interval' when detected after the index colonoscopy without receiving adequate follow-up according to previously mentioned surveillance guidelines. It should be noted that these Dutch post-polypectomy surveillance guidelines have not been designed for IBD patients. However, since the IBD guidelines do not specify surveillance intervals after occurrence of dysplasia, we used these regular guidelines for the algorithm. (ii) 'Inadequate bowel examination' was defined as inadequate bowel preparation or incomplete intubation (i.e. caecum not visualized) during the index colonoscopy. (iii) 'Incomplete resection' was defined as the development of a CRC in the same anatomic segment as a previously resected advanced adenoma (i.e. villous component, adenoma $>10 \mathrm{~mm}$ or high-grade dysplasia). (iv) PCCRCs detected between 6-36 months after the index colonoscopy as well as advanced PCCRCs (i.e. > T1NOMO) between 6-60 months were defined as 'missed lesions'. (v) If a non-advanced PCCRC was observed after 36 months, it was considered to be a 'newly developed cancer'.

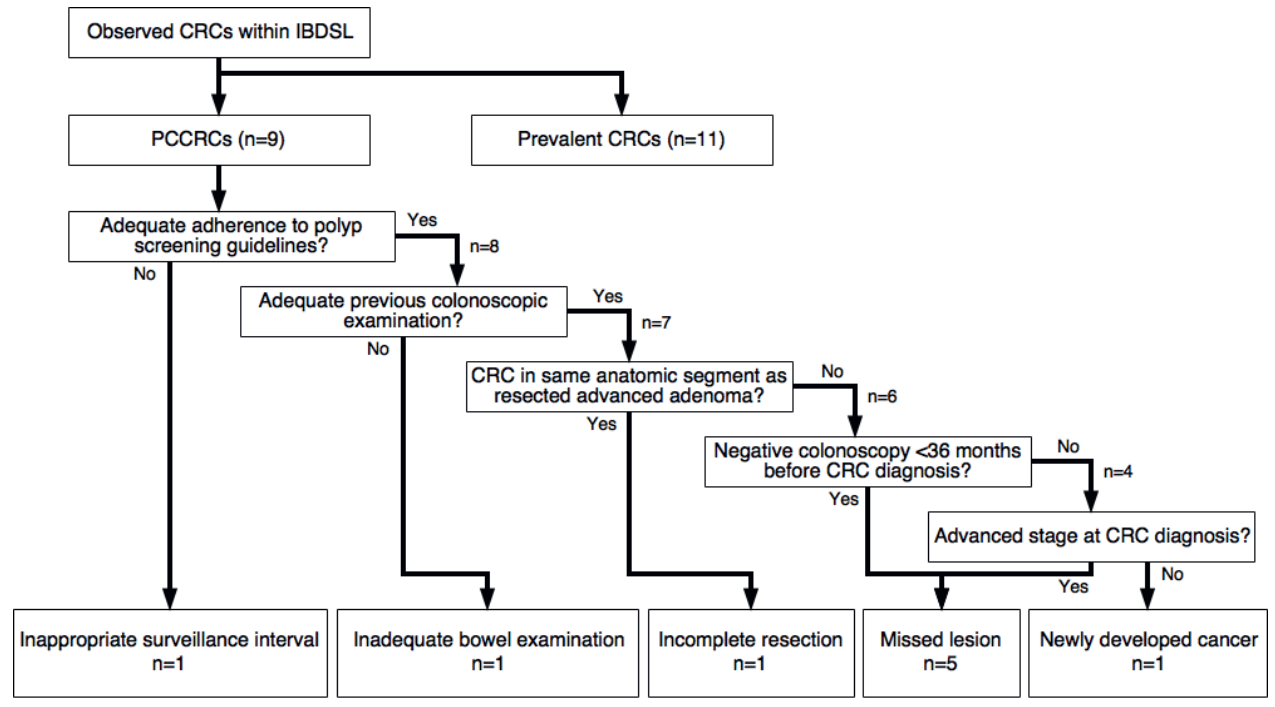

Figure 7.1 Algorithm to classify CRCs according to procedural factors or tumour biology. 


\section{Statistics}

Statistical analyses were performed with SPSS (version 20.0, SPSS Inc., Chicago, IL, USA) to describe cohort characteristics. Incidence rates were calculated per 1000 patient years at risk (PYAR). To correct for overestimation of the PYAR, the years after a colectomy were censored and the year of diagnosis and the year follow-up ended only counted as half patient years as described before. ${ }^{7}$ Due to low number of CRCs, further statistical analysis was not performed.

\section{Results}

In total, 2,801 IBD patients were included in the IBDSL cohort of which 1,644 had UC and 1,157 had CD. Baseline characteristics of the patients are shown in Table 7.1. The median follow-up was 8.8 (IQR 4.9-14.8) and 8.1 (IQR 4.3-13.6) years for UC and CD, respectively. As shown in our previous study, CRC incidence could be evaluated in 25,931 PYAR. ${ }^{7}$ After exclusion of NETs, 11 CRCs were observed in UC patients and 9 CRCs were observed in CD patients. The total incidence rate of CRC in our cohort was $0.77 / 1000$ patient years. A general description of all CRCs is published elsewhere. ${ }^{7}$

Of all CRCs, 9 (45.0\%) were considered to be PCCRCs. The PCCRC incidence rate was 0.39/1000 PYAR. Characteristics of the observed PCCRCs are provided in Table 7.2. Of the PCCRCs, $55.6 \%$ was observed in males and the mean age at CRC diagnosis was 71.6 years (range $34-83$ ). Six (54.5\%) PCCRCs were observed in UC and $3(33.3 \%)$ in CD patients. All UC patients with a PCCRC had at least a left-sided colitis (Montreal E2) and all CD patients with a PCCRC had colonic or ileocolonic disease (Montreal L2/3) during follow-up. PCCRCs were diagnosed on average 36.1 months (SD 17.2) after the index colonoscopy. Seven (77.8\%) patients had active disease on the index colonoscopy. One PCCRC was discovered during surgery, whereas all other PCCRCs were detected by endoscopy. Four (44.4\%) PCCRCs were located in the proximal colon and 3 (33.3\%) were detected in an early stage (T1NOMO). Most of the PCCRCs were characterized as regular adenocarcinoma, except for two mucinous adenocarcinomas. TNM-stages and cell differentiation can also be found in Table 7.2. None of the patients with a PCCRC was diagnosed with PSC at diagnosis or during follow-up. 
Table 7.1 Baseline characteristics of the total study population.

\begin{tabular}{|c|c|c|}
\hline & Ulcerative colitis & Crohn's disease \\
\hline Patients, $\mathrm{n}$ & 1,644 & 1,157 \\
\hline Male, $\mathrm{n}(\%)$ & $891(54)$ & $430(37)$ \\
\hline Age at diagnosis, median (IQR) & $45.0(32.2-59.1)$ & $34.3(24.3-46.9)$ \\
\hline Follow-up, median (IQR) & $8.8(4.9-14.8)$ & $8.1(4.3-13.6)$ \\
\hline Total number of PSC cases, $\mathrm{n}(\%)$ & $13(0.8)$ & $6(0.5)$ \\
\hline Total number of CRC, $\mathrm{n}$ & 11 & 9 \\
\hline Total number of PCCRC, $\mathrm{n}(\%)$ & $6(55)$ & $3(33)$ \\
\hline \multicolumn{3}{|l|}{ Phenotype at diagnosis* } \\
\hline $\mathrm{E} 1, \mathrm{n}(\%)$ & $556(34)$ & \\
\hline$E 2, n(\%)$ & $777(48)$ & \\
\hline$E 3, n(\%)$ & $296(18)$ & \\
\hline $\mathrm{L} 1, \mathrm{n}(\%)$ & & $496(43)$ \\
\hline $\mathrm{L} 2, \mathrm{n}(\%)$ & & $369(32)$ \\
\hline L3, n (\%) & & $266(23)$ \\
\hline L4, n (\%) & & $123(11)$ \\
\hline $\mathrm{B} 1, \mathrm{n}(\%)$ & & $894(78)$ \\
\hline $\mathrm{B} 2, \mathrm{n}(\%)$ & & $177(15)$ \\
\hline B3, n (\%) & & $84(7)$ \\
\hline $\mathrm{P}, \mathrm{n}(\%)$ & & $92(8)$ \\
\hline
\end{tabular}

$\mathrm{N}$, number of patients / IQR, inter quartile range /*, phenotype according to Montreal Classification. Disease extent of UC was defined as ulcerative proctitis (E1), left sided UC (E2) and extensive UC (E3). Disease location of CD was defined as ileal involvement (L1), exclusive colonic involvement (L2), ileocolonic involvement (L3) or isolated upper disease (L4). L4 is a modifier, added to L1-L3 when concomitant upper gastrointestinal disease is present. Disease behaviour of $C D$ was defined as non-stricturing/non-penetrating (B1), stricturing (B2), penetrating (B3). Perianal disease (P) is a modifier, added to B1-3 when perianal disease is present.

The most likely aetiology of the PCCRCs according to the algorithm is shown in Figure 7.1. Of all PCCRCs, 5 (55.6\%) could be considered as 'missed lesions'. 'Inappropriate surveillance interval', 'inadequate bowel examination', 'incomplete resection' and 'newly developed cancers' only occurred once in each of the categories and therefore each of them contributed to $11.1 \%$ of the PCCRCs. 


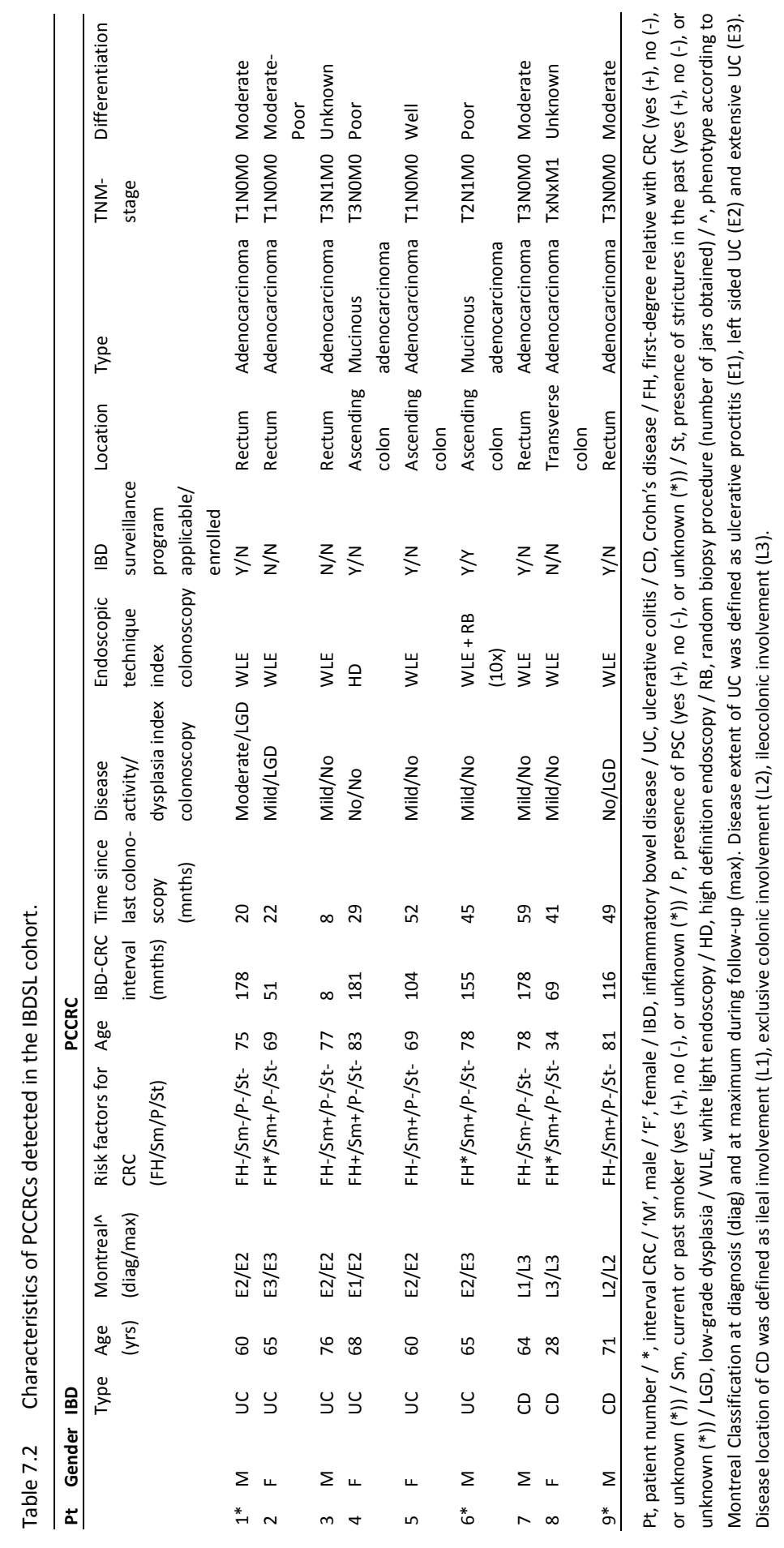


Since guideline adherence is applicable to both PCCRCs and prevalent CRCs, we analysed the adherence in all 20 CRC cases of the IBDSL cohort. All patients with CRC had at least a left-sided colitis (UC) or colonic involvement (CD) during follow-up and were eligible for surveillance. Ten out of the 20 CRCs (50.0\%) were found within the recommended surveillance time window and after the Dutch guideline for IBD patients was published (i.e. after 2008). Only three patients received adequate surveillance with chromoendoscopy or random biopsies, and only one of these received the first surveillance endoscopy within 8 years after diagnosis. Notably, $6(30.0 \%)$ CRCs were observed in eligible IBD patients before the recommended start of surveillance according to the current ECCO guidelines.

\section{Discussion}

This is the first population-based analysis of PCCRC incidence in IBD, in which we observed that $45.0 \%$ of all incident CRCs were considered to be PCCRCs. Regarding their aetiology, missed lesions attributed to $55.6 \%$ of the PCCRCs. Poor adherence to surveillance intervals, inadequate bowel examination, incomplete resection and newly developed cancer each accounted for one PCCRC. Ten (50.0\%) CRCs were found within the recommended surveillance time window, but only three patients had been enrolled at the time of CRC detection. Moreover, according to the current ECCO guidelines, six (30.0\%) CRCs in the IBDSL cohort were detected before surveillance was recommended.

Although the overall CRC incidence in our cohort was low (i.e. $0.77 / 1000$ patient years) ${ }^{7}$, a relatively large proportion of PCCRCs (45.0\% of all CRCs in our cohort) was found. The proportion of PCCRCs in a population-based cohort study in the general population of the same region, using the same definitions, was only $2.9 \%$. $^{9}$ The high rate of PCCRCs in our cohort may in part be explained by the frequent use of routine endoscopies to detect disease activity. These endoscopies are inferior in detecting dysplasia compared with chromoendoscopy or a random biopsy procedure (i.e. required methods for adequate IBD surveillance). Furthermore, disease activity may disguise dysplasia and hinder resection. As a consequence, poor dysplasia detection may occur during the performance of colonoscopies for other indications (e.g. followup of disease activity) and a false sense of safety can remain. So far, only a few studies have investigated PCCRC incidence in IBD. Wang et al. reported a proportion of PCCRCS of $15.1 \%$ and $15.8 \%$ in UC and CD, respectively, in an elderly (i.e. $>67$ years old) IBD population in the USA. ${ }^{10}$ These lower proportions of PCCRCs may be due to the more stringent definition (i.e. only CRCs within 36 months after a colonoscopy were considered to be PCCRC); though, $20 \%$ of the CRCs in our cohort would still have been classified as PCCRCs using the same definition. However, differences in guidelines, definitions and populations hinder a direct comparison. In surveillance cohorts, 
although different definitions have been used, the proportion of true interval CRCs, which is a subset of PCCRCs, still ranges from 21 to $29 \% .{ }^{11,12}$ Notably, six PCCRCs in this study, and one additional prevalent CRC in the remainder of cases, were diagnosed above the age of 75 . The current ECCO guideline does not make any recommendation on when to stop surveillance in IBD patients. ${ }^{3}$ Also the Dutch guideline which was available during the follow-up of this study did not include such recommendation. ${ }^{21}$ However, as stated in an update of this guideline in 2015 (i.e. after our follow-up ended) clinicians are advised to 'discuss further surveillance strategies with the patient when he/she reaches the age of $75^{\prime} .^{31}$ Since we observed a lot of PCCRCs in the elderly, we agree that continuation of surveillance, if no contra-indications exist, may be worthwhile and should be discussed by future guideline committees.

Fifty-six percent of the PCCRCs were defined as 'missed lesions' due to their rapid occurrence after an index colonoscopy or an advanced stage at diagnosis. Based on the dwell time between a newly developed neoplasm and an invasive carcinoma, we assume that neoplasia must have been present during the index colonoscopy. ${ }^{32,33}$ However, the turnover time from dysplasia to carcinoma in IBD may be shorter than in the general population given the frequent detection of advanced CRCs in IBD. ${ }^{34}$ This may be related to specific molecular pathways and differences in polyp morphology. ${ }^{35,36}$ Taking these factors into account, some PCCRCs classified as missed lesions by the algorithm may actually be newly developed CRCs. The rate of missed lesions in the present study is in line with a large study performed in the general population in the same region as our cohort. ${ }^{9}$ However, due to the increased occurrence of easily missed flat lesions in $\mathrm{IBD}^{13}$, we expected the percentage of missed lesions in the present study to be even larger. Next to a possible rapid turnover time from dysplasia to carcinoma and the increased occurrence of flat lesions in IBD, the high number of missed lesions may again be a consequence of the increased difficulty of dysplasia detection when mucosal inflammation is present. In addition, almost every index colonoscopy was performed using white light endoscopy (standard definition) which is considered to be inferior to high definition endoscopy and chromoendoscopy. Since procedural explanations for PCCRC incidence has only been scarcely investigated in IBD populations and different definitions are used, direct comparisons cannot be made. Mooiweer et al. studied the incidence of CRCs in a surveillance cohort and found $24 \%$ to be related to inadequate colonoscopies, $53 \%$ to be related to inadequate surveillance intervals and $12 \%$ to be related to inadequate management of dysplasia. ${ }^{12}$

Notably, 30.0\% of all CRC cases in our cohort were found in IBD patients with at least left-sided or segmental colitis before the recommended start of IBD surveillance (i.e. 8 years after IBD onset), which is in line with a previous nationwide study. ${ }^{37}$ Since current guidelines still advise the first surveillance endoscopy at 8 years after IBD onset, these findings raise the question of whether the surveillance guidelines in IBD are optimal. Since disease activity at diagnosis impairs the chance of CRC/dysplasia detection, inclusion of a first surveillance endoscopy after diagnosis when remission is 
achieved, should be taken into account and discussed by future guideline committees. Only when absence of dysplasia is guaranteed, can a patient be safely enrolled in the present IBD surveillance program. Since surveillance status was only available for patients with a history of CRC and not for the entire IBDSL cohort, adherence to IBD surveillance guidelines could not be assessed. As the overall incidence of CRC in our cohort was rather low ${ }^{7}$, we assumed that IBD surveillance was not inferior compared with other countries. According to the previous Dutch (applicable during our study period) and current ECCO guidelines, 10 out of the 20 CRCs (50.0\%) were found within the recommended surveillance time window and after the Dutch guideline for IBD patients was published (i.e. after 2008). Only three patients received adequate surveillance with chromoendoscopy or random biopsies and only one of these received the first surveillance endoscopy within 8 years after diagnosis. Therefore, nine patients with CRC could potentially have avoided CRC through more stringent adherence to IBD surveillance guidelines by medical practitioners. Although tight surveillance in UC was an international problem in the previous era ${ }^{38}$, van Rijn et al. performed a questionnaire-based study on guideline adherence in the Netherlands in which $95 \%$ of all UC patients and $65 \%$ of all CD patients appeared to receive some type of surveillance. ${ }^{39}$ However, only $27 \%$ of the Dutch gastroenterologists adhered to the international guidelines. ${ }^{39}$ Since the Dutch IBD guideline was introduced in 2008 and the study of van Rijn et al. was performed earlier, the current adherence in the Netherlands may have improved. Although the actual guideline adherence cannot be assessed from our dataset, the present study suggests that there is still room for improvement. Closer adherence by gastroenterologists may lead to improvement in this area, and general practitioners should also adhere to the guidelines more closely because patients with longstanding clinical remission might no longer be under the care of gastroenterologists.

The major strength of this study is the assessment of PCCRC incidence in a population-based IBD cohort thereby reflecting the full disease spectrum from mild to severe cases. Moreover, the IBDSL cohort includes detailed medical data from patients with IBD gathered through extensive manual exploration of patient files since 1991. This ensures very accurate data and a real-time estimation of the true incidence of CRC; therefore the proportion of PCCRCs we have determined is reliable. Several limitations should also be addressed. Most importantly, the algorithm used has been developed for sporadic CRCs and makes certain assumptions. For example, rectal cancer that is found 20 months after an index colonoscopy with incomplete caecal intubation is regarded as due to 'inadequate bowel examination' instead of 'missed lesion' due to the algorithm. However, neglecting these assumptions in our study will only lead to more 'missed lesions' and therefore, to the same conclusion. In addition, we did observe a low number of CRCs and therefore a low absolute number of PCCRCs in our cohort. Therefore, minor changes in the number of incident cases would have had a large impact on the percentages of the different aetiologies and incidence rates. 
Furthermore, some of the patients in this cohort had a relatively short follow-up time. As the risk of CRC is higher in patients with longstanding IBD, both CRC and PCCRC rates may be higher after a longer time period of follow-up. Finally, sigmoidoscopies were excluded in the algorithm we used. Since patients with UC are screened frequently for disease activity using a sigmoidoscopy, PCCRC rates may have been even higher if these endoscopies had been taken into account.

Since PCCRC rates were much higher for IBD patients in this population-based study compared with the rates in the general population, it is important that we continue to improve adherence to the IBD surveillance guidelines for patients under the care of gastroenterologists and also for patients being cared for by general practitioners. Also the guideline could be adapted to prevent CRCs between the diagnosis of IBD and the start of CRC screening. Because most of the PCCRCs were regarded as missed lesion, there is some room for improvement in dysplasia detection during endoscopy. The increasing awareness and appraisal of the IBD surveillance guideline and improvement of endoscopy techniques may lead to better results and hopefully a further decrease in the incidence of CRC, and of PCCRC in particular, in future studies.

In conclusion, this first population-based cohort study on PCCRC incidence in IBD shows that $45.0 \%$ of all CRCs were considered to be PCCRCs. Most of the PCCRCs were classified as missed lesions. Additionally, a large proportion of CRCs in our cohort were observed before an IBD surveillance endoscopy was performed, either due to lack of enrolment in the surveillance program or due to development of a CRC before the recommended start of surveillance. Therefore, stringent adherence to IBD surveillance guidelines, improving endoscopy techniques and adjusting the surveillance program may help to decrease both CRC incidence and the proportion of PCCRCs in IBD. 


\section{References}

1. Castano-Milla C, Chaparro M, Gisbert JP. Systematic review with meta-analysis: the declining risk of colorectal cancer in ulcerative colitis. Aliment Pharmacol Ther. 2014;39(7):645-59.

2. Lutgens MW, van Oijen MG, van der Heijden GJ, Vleggaar FP, Siersema PD, Oldenburg B. Declining risk of colorectal cancer in inflammatory bowel disease: an updated meta-analysis of population-based cohort studies. Inflamm Bowel Dis. 2013;19(4):789-99.

3. Annese V, Daperno M, Rutter MD, Amiot A, Bossuyt P, East J, et al. European evidence based consensus for endoscopy in inflammatory bowel disease. J Crohns Colitis. 2013;7(12):982-1018.

4. Jess T, Gamborg M, Matzen P, Munkholm P, Sorensen TI. Increased risk of intestinal cancer in Crohn's disease: a meta-analysis of population-based cohort studies. Am J Gastroenterol. 2005;100(12):2724-9.

5. Jess T, Rungoe C, Peyrin-Biroulet L. Risk of colorectal cancer in patients with ulcerative colitis: a metaanalysis of population-based cohort studies. Clin Gastroenterol Hepatol. 2012;10(6):639-45.

6. Jess T, Horvath-Puho E, Fallingborg J, Rasmussen HH, Jacobsen BA. Cancer risk in inflammatory bowel disease according to patient phenotype and treatment: a Danish population-based cohort study. Am J Gastroenterol. 2013;108(12):1869-76.

7. van den Heuvel TR, Wintjens DS, Jeuring SF, Wassink MH, Romberg-Camps MJ, Oostenbrug LE, et al. Inflammatory bowel disease, cancer and medication: Cancer risk in the Dutch population-based IBDSL cohort. Int J Cancer. 2016;139(6):1270-80.

8. Singh S, Singh PP, Murad MH, Singh H, Samadder NJ. Prevalence, risk factors, and outcomes of interval colorectal cancers: a systematic review and meta-analysis. Am J Gastroenterol. 2014;109(9):1375-89.

9. le Clercq CM, Bouwens MW, Rondagh EJ, Bakker CM, Keulen ET, de Ridder RJ, et al. Postcolonoscopy colorectal cancers are preventable: a population-based study. Gut. 2014;63(6):957-63.

10. Wang YR, Cangemi JR, Loftus EV, Jr., Picco MF. Rate of early/missed colorectal cancers after colonoscopy in older patients with or without inflammatory bowel disease in the United States. Am J Gastroenterol. 2013;108(3):444-9.

11. Choi CH, Rutter MD, Askari A, Lee GH, Warusavitarne J, Moorghen M, et al. Forty-Year Analysis of Colonoscopic Surveillance Program for Neoplasia in Ulcerative Colitis: An Updated Overview. Am J Gastroenterol. 2015;110(7):1022-34.

12. Mooiweer $E$, van der Meulen-de Jong $A E$, Ponsioen $C Y$, van der Woude $C J$, van Bodegraven $A A$, Jansen $\mathrm{JM}$, et al. Incidence of Interval Colorectal Cancer Among Inflammatory Bowel Disease Patients Undergoing Regular Colonoscopic Surveillance. Clin Gastroenterol Hepatol. 2015;13(9):1656-61.

13. Pohl H, Robertson DJ. Colorectal cancers detected after colonoscopy frequently result from missed lesions. Clin Gastroenterol Hepatol. 2010;8(10):858-64.

14. Robertson DJ, Lieberman DA, Winawer SJ, Ahnen DJ, Baron JA, Schatzkin A, et al. Colorectal cancers soon after colonoscopy: a pooled multicohort analysis. Gut. 2014;63(6):949-56.

15. Sanduleanu S, Rutter MD. Interval colorectal cancers in inflammatory bowel disease: the grim statistics and true stories. Gastrointest Endosc Clin N Am. 2014;24(3):337-48.

16. van den Heuvel TR, Jonkers DM, Jeuring SF, Romberg-Camps MJ, Oostenbrug LE, Zeegers MP, et al. Cohort Profile: The Inflammatory Bowel Disease South Limburg Cohort (IBDSL). Int J Epidemiol. 2015.

17. National pathology database: PALGA. (Accessed November 1, 2015, at https://www.palga.nl/).

18. World Medical A. World Medical Association Declaration of Helsinki: ethical principles for medical research involving human subjects. JAMA. 2013;310(20):2191-4.

19. Incidence rates of cancer in the Netherlands: IKNL. (Accessed November 1, 2015, at http://www.cijfersoverkanker.nl/).

20. Satsangi J, Silverberg MS, Vermeire S, Colombel JF. The Montreal classification of inflammatory bowel disease: controversies, consensus, and implications. Gut. 2006;55(6):749-53.

21. Nederlandse Vereniging van Maag-Darm-Leverartsen. Richtlijn Diagnostiek en Behandeling van Inflammatoire Darmziekten bij Volwassenen. 2008:1-307.

22. Farrar WD, Sawhney MS, Nelson DB, Lederle FA, Bond JH. Colorectal cancers found after a complete colonoscopy. Clin Gastroenterol Hepatol. 2006;4(10):1259-64. 
23. Horiuchi A, Nakayama Y, Kajiyama M, Kamijima T, Tanaka N. Invasive colorectal cancer within 5 years of negative colonoscopy in a Japanese population. Colorectal Dis. 2012;14(9):1090-4.

24. Huang Y, Gong W, Su B, Zhi F, Liu S, Jiang B. Risk and cause of interval colorectal cancer after colonoscopic polypectomy. Digestion. 2012;86(2):148-54.

25. Imperiale TF, Glowinski EA, Lin-Cooper C, Larkin GN, Rogge JD, Ransohoff DF. Five-year risk of colorectal neoplasia after negative screening colonoscopy. N Engl J Med. 2008;359(12):1218-24.

26. Nagengast FM KC. Herziene CBO-richtlijn 'Follow-up na poliepectomie'. Ned Tijdschr Geneeskd. 2001;145(2):2202-5.

27. Nagengast FM SP. Herziening Consensus Follow-up na poliepectomie. Ned Tijdschr Geneeskd. 1998;142(1353).

28. Snel P, de Wolf AN. [Consensus follow-up study after polypectomy]. Ned Tijdschr Geneeskd. 1988;132(11):489-91.

29. Sanduleanu S, le Clercq CM, Dekker E, Meijer GA, Rabeneck L, Rutter MD, et al. Definition and taxonomy of interval colorectal cancers: a proposal for standardising nomenclature. Gut. 2015;64(8):1257-67.

30. Pabby A, Schoen RE, Weissfeld JL, Burt R, Kikendall JW, Lance P, et al. Analysis of colorectal cancer occurrence during surveillance colonoscopy in the dietary Polyp Prevention Trial. Gastrointest Endosc. 2005;61(3):385-91.

31. Nederlandse Vereniging van Maag-Darm-Leverartsen. Handleiding behandeling IBD - 2014-2015 (Moderniseren van de Richtlijn IBD 2009). 2015:1-119.

32. Rudy DR, Zdon MJ. Update on colorectal cancer. Am Fam Physician. 2000;61(6):1759-70, 73-4.

33. Brenner H, Altenhofen L, Katalinic A, Lansdorp-Vogelaar I, Hoffmeister M. Sojourn time of preclinical colorectal cancer by sex and age: estimates from the German national screening colonoscopy database. Am J Epidemiol. 2011;174(10):1140-6.

34. Averboukh F, Ziv Y, Kariv Y, Zmora O, Dotan I, Klausner JM, et al. Colorectal carcinoma in inflammatory bowel disease: a comparison between Crohn's and ulcerative colitis. Colorectal Dis. 2011;13(11):1230-5.

35. Azer SA. Overview of molecular pathways in inflammatory bowel disease associated with colorectal cancer development. Eur J Gastroenterol Hepatol. 2013;25(3):271-81.

36. Sebastian S, Hernandez V, Myrelid P, Kariv R, Tsianos E, Toruner M, et al. Colorectal cancer in inflammatory bowel disease: results of the 3rd ECCO pathogenesis scientific workshop (I). J Crohns Colitis. 2014;8(1):5-18.

37. Lutgens MW, Vleggaar FP, Schipper ME, Stokkers PC, van der Woude CJ, Hommes DW, et al. High frequency of early colorectal cancer in inflammatory bowel disease. Gut. 2008;57(9):1246-51.

38. Lynch DA, Lobo AJ, Sobala GM, Dixon MF, Axon AT. Failure of colonoscopic surveillance in ulcerative colitis. Gut. 1993;34(8):1075-80.

39. van Rijn AF, Fockens P, Siersema PD, Oldenburg B. Adherence to surveillance guidelines for dysplasia and colorectal carcinoma in ulcerative and Crohn's colitis patients in the Netherlands. World J Gastroenterol. 2009;15(2):226-30. 
Postcolonoscopy colorectal cancers in IBD 


$$
20
$$


Chapter 8

General discussion 
Chapter 8 


\section{General discussion}

In this thesis, epidemiological patterns, modifiable risk factors, and consequences of both insufficiently controlled as well as overtreated inflammatory bowel disease activity were studied. The well-defined population-based Inflammatory Bowel Disease South Limburg (IBDSL) cohort was used as the primary study population to maximise the external validity of the findings.

In brief, we confirmed that Crohn's disease (CD) has a heterogeneous disease course in terms of disease activity patterns (Chapter 2), varying from a large group of patients with a quiescent course, at risk for overtreatment, to patients with a moderate to severe disease course, at risk for undertreatment. Unfortunately, early clinical characteristics at diagnosis only moderately predicted the observed patterns. To improve disease outcomes, potentially modifiable risk factors for disease activity were analysed in subsequent chapters. Although cigarette smoking is a well-known risk factor for disease activity in CD, we did not find an association between disease activity and ambient air quality in Chapter 3. Despite being undervalued in daily practice, we did observe an association with IBD disease activity for both perceived stress and an increased risk of malnutrition in Chapter $\mathbf{4}$ and 5, respectively. Both can serve as targets for future personalized interventions. In Chapter 6 and 7, the incidence of both intestinal and extra-intestinal cancer risks was analysed as a possible consequence of both long-term uncontrolled disease activity as well as long-term exposure to immunomodulatory drugs. The results can be used to optimise current cancer screening and surveillance guidelines.

In this final chapter, our findings are being discussed with respect to three key points for improvement of disease course: improved patient stratification, prevention of flares, and weighing risks when choosing treatment strategies. Altogether, these may provide guidance towards personalized medicine in IBD.

\section{Improved patient stratification}

The heterogeneity of IBD in presenting phenotypes and disease course is widely acknowledged, ${ }^{1,2}$ but data on long-term disease activity is scarce. We therefore analysed CD disease course in the real-life population-based IBDSL cohort based on disease activity patterns (Chapter 2). While up to one-third of the CD patients experience only one or two yearly quarters of disease activity in 10 years, others relapse frequently varying from a mild chronic intermittent to an almost continuously active disease activity pattern. Although disease activity patterns in UC are not yet analysed, we expect similar findings given the fact that two questionnaire-based studies on disease activity patterns within the same cohort showed similar distributions for $\mathrm{UC}$ and $\mathrm{CD} .{ }^{3,4}$ Probably due to improved healthcare in general, the introduction of new drugs, and changes in treatment strategies, some endpoints of the disease course 
have improved over time (e.g. decreased number of hospitalisations and surgical procedures in $\mathrm{CD},{ }^{5}$ decreased use of steroids in $\mathrm{IBD},{ }^{6}$ and a decreasing trend in colorectal cancer risk in IBD (Chapter 6)). Though, the lag of improvement in disease course on other major endpoints (e.g. the absence of improvement in late colectomy rates and hospitalisation rates in $\mathrm{UC}^{7}$ and the absence of improvement in disease progression in $C D^{5}$ ) is worrisome. These concerns are underlined by our findings in Chapter 2, since the proportion of patients with a quiescent pattern was higher in patients diagnosed between 1991 and 1998 (35.4\%) compared to patients diagnosed between 1999 and 2005 (19.0\%; data not shown in thesis). We believe that, amongst others, a personalized treatment selection based on risk profiling for each patient is essential to further improve disease course.

\section{Defining disease course}

To identify early predictive markers in the heterogeneous IBD population, an adequate description of disease course is crucial since the accuracy of the outcome measure primarily determines the value and reproducibility of the identified marker. The majority of the available studies use a composite score (including the need for hospitalisations, need for surgery, and need for certain drugs) that depends on recommendations in guidelines and therefore includes parameters that tend to change over time. ${ }^{8}$ This complicates its generalisability and, subsequently, its validity. For instance, patients with anti-TNF therapy as a first line treatment or patients who undergo early surgery can be in deep remission for years after treatment initiation, while being classified as 'severe $\mathrm{CD}^{\prime}$ ' using the commonly used composite score, thereby negatively affecting derived prediction models. Defining the disease course using disease activity per yearly quarter (Chapter $\mathbf{2}$ ) may overcome certain limitations. The impact of the differences between the outcome measures can be deduced from Chapter 3, in which two approaches were used to study the association between ambient air quality and disease severity. In the IBDSL cohort, $13.8 \%$ of the patients with a 'severe disease' using a composite score as outcome measure, never experienced any active yearly quarter after the first induction of remission (data not shown in thesis). Furthermore, smoking, which is a well-established risk factor of a severe disease course in $C D^{9}$, was associated with more quarters of active disease but not with the composite score in the same chapter. Also, early surgery was positively associated with a quiescent course when using disease activity per yearly quarter as outcome (Chapter 2), while surgery is frequently part of the composite score for a severe disease course. ${ }^{8}$ These conflicting findings underline the complexity of disease course description. Although multiple population-based cohorts have been established worldwide, most lack the clinical detail to define objective disease activity. Only a small number of cohorts have defined disease activity, but use clinical activity indices (reflecting symptoms rather than mucosal inflammation), ${ }^{10-12}$ or use estimations, for example, 
based on steroid prescriptions only. ${ }^{13}$ The cohorts from Olmsted County (USA), ${ }^{14}$ North Jutland County (Denmark), ${ }^{15}$ the IBSEN cohort (Norway), ${ }^{4}$ and the EC-IBD cohort (Europe $^{16}$ did define disease activity based on both symptoms and subsequent interventions. Validation of our definitions and findings within these cohorts would be a valuable approach towards improved disease course description.

\section{Abandoning the UC-CD dichotomy}

In addition to the need for more accurate outcome measures to describe the disease course, it is important to acknowledge the potential limitations of the traditional UC-CD dichotomy in the search for new classifiers/predictors. IBD patients at diagnosis are currently categorized primarily as either UC or CD, based on clinical, biochemical, endoscopic, imaging, and histopathological investigations. However, a definite reference standard is lacking, and a subset of patients cannot be categorized (i.e. IBD unclassified or 'IBD-U') or switch diagnosis over time. ${ }^{17}$ Accumulating evidence indicates that IBD is more complex than just the separation in two entities. For example, a recent large cohort study showed that late-onset $C D$ was not only clinically differentiated from intermediate onset $C D$, but also showed serological differences (i.e. more antineutrophil cytoplasmic antibody (ANCA) positive and less antisaccharomyces cerevisiae antibody (ASCA) positive) and differences in underlying genetic variations. ${ }^{18}$ All findings were considered UC-like characteristics highlighting the flaws of the strict UC-CD classification. In line with the findings above, also (very) early-onset IBD is characterised by specific clinical characteristics and genetics. ${ }^{19}$ Similar patterns have been observed in IBD patients with concurrent primary sclerosing cholangitis (PSC) who are characterized by more frequent proximal colonic involvement and backwash ileitis (in 'UC' PSC), less frequent relapses, and increased risk for colorectal carcinoma compared to non-PSC IBD patients. ${ }^{20}$ Of note, 'CD' PSC patients rarely have ileal disease and rarely develop stricturing or penetrating complications, alike non-PSC UC patients. $^{20}$

In many studies, including those in this thesis, data have been split for CD and UC, while IBD-U-patients were excluded from most analyses. To identify new classifications and predictors, we should discard the traditional dichotomy and study the complexity of IBD as a whole.

\section{Prediction of disease course}

State-of-the-art clinical classification at present is primarily based on the Montreal classification system (including age of diagnosis, disease location/extent, and disease behaviour). ${ }^{21}$ As shown in Chapter 2, the Montreal classification in CD patients did correlate only moderately with patients' disease activity patterns and its value can therefore be questioned. The addition of other factors (e.g. smoking and need for steroids at diagnosis) did not increase the predictive value of our models sufficiently. In 
literature, many parameters have been investigated to further improve prediction including serological variables (e.g. ASCA, anti-CBir1, anti-ompC, and pANCA), genetic mutations (e.g. NOD2), gene expression levels (e.g. transcriptional profiling of circulating CD8+ T cells and DNA methylation profiles) and even microbiome analyses. ${ }^{22-24}$ Although some results are promising, effects sizes of single 'predictors' are often small and external validation of risk models is frequently lacking, which complicate implementation in daily practice. Additionally, the complex interplay of drivers for inflammation in IBD implicates the presence of confounders (i.e. variables associated with both exposure and outcome of interest) and limits the interpretation of observed predictors when confounding is ignored. For instance, NOD2-mutations were hypothesized to predict severe disease since they have been linked to surgery. ${ }^{25}$ However, the association disappeared when data were corrected for disease location. ${ }^{26}$ At present, one of the most comprehensive risk stratifications for disease progression in newly diagnosed CD patients was performed in the RISK-study of Kugathasan et al. ${ }^{27}$, including genotypes, antimicrobial serologies, ileal gene expression, and ileal, rectal, and faecal microbiota. Although the study has provided a better insight into disease pathophysiology, the clinical application remains limited due to the moderate predictive properties of their models.

Despite the lack of good predictors, an increased exposure rate to immunomodulators and biologicals was observed in multiple cohort studies over the past years. ${ }^{5,7,28,29}$ This trend is supported by large trials promoting early combination therapy with immunomodulatory drugs and biologicals versus conventional step-up therapy or biological monotherapy. ${ }^{30-32}$ Also the implementation of endoscopic (or even histological) remission as a treatment goal, which is associated with more aggressive treatment, directs gastroenterologists worldwide towards these treatment strategies. Although the new treatment goals are linked to improved disease outcomes, ${ }^{33,34}$ the risk for overtreatment is increasing, stressing the need for improved patient stratification at diagnosis. This is underlined by the marked differences in treatment exposure between the distinct disease activity patterns in Chapter 2 (i.e. the low use of immunomodulators and biologicals in the quiescent group (10.2\%) compared to 86.7$100 \%$ in patients with the most severe patterns). Since our dataset expands over multiple decades, it was insensitive to the recent tendency towards more 'aggressive' treatment strategies. Future directions in this field should focus on combining prospectively collected longitudinal clinical data and accurately defined outcomes with data from the patients' genome, tissue or cell-specific transcriptome, proteome, metabolome and/or gut microbiome to find distinctive IBD subgroups and an accurate set of predictors to generate specific risk profiles and effectuate precision medicine as an important element of personalized medicine. 


\section{Flare prevention}

As a consequence of the unpredictability of IBD, tight control by monitoring disease activity and early intervention in case of flares is advocated in current guidelines to improve outcome in IBD. ${ }^{17}$ The complex interplay between the microbiome and environmental factors (i.e. patients' exposome) in a genetically susceptible host is hypothesized to be not only involved in disease onset, but also in flare development. Since some environmental risk factors are potentially modifiable, monitoring of these and application of personalized interventions may lead to prevention of flares and subsequent improvement of a patient's disease course.

As depicted by numerous studies, ${ }^{9,35}$ as well as in Chapter $\mathbf{2}$ and Chapter $\mathbf{3}$ of this thesis, cigarette smoking is the most substantiated environmental risk factor for a severe $C D$ disease course. Animal studies point to a disruption of tight junctions, decreased antimicrobial peptide synthesis, increased microvasculature, altered mucus synthesis, and oxidative DNA damage of colonocytes as direct effects of cigarette smoke, which impair gut barrier function and promote inflammation. ${ }^{36}$ Also, changes in immune cell population (e.g. increased Th1 response and CD8+ clonal expansion) and in microbiota composition have been observed and may contribute to inflammation. ${ }^{36}$ In our studies on flare occurrence in both CD and UC patients (Chapter 4 and Chapter 5), smoking was not identified as a risk factor, which may be due to the fact that smoking does not influence disease course negatively in UC. ${ }^{37}$ The cessation of smoking in CD appears highly effective (i.e. $65 \%$ risk reduction for flares). ${ }^{38}$ Moreover, from 1 year after cessation, CD patients follow the same course as non-smokers. Since other detrimental health effects are widely accepted, smoking should be advised against by gastroenterologists in all IBD patients, but especially in CD patients. Analogous to smoking, we hypothesized that air pollution could contribute to intestinal inflammation, but could not show this to be a major attributor to disease course of CD patients (Chapter 3). Still, small effects cannot be excluded yet since exposure variability in the South Limburg region is relatively small.

A highly relevant yet undervalued topic according to both professionals and patients is the role of nutritional status. ${ }^{39}$ As a disease of the gastrointestinal tract, IBD patients are prone to malnutrition and specific nutritional deficiencies. ${ }^{40}$ Both can be caused by loss of appetite (e.g. due to increased levels of cytokines), drug-nutrient interaction (e.g. corticosteroids decrease intestinal absorption), malabsorption (e.g. by inflamed mucosa or resected bowel parts), alterations in energy/nutrient requirements, or inadequate intake due to fear of abdominal pain or small bowel obstruction. ${ }^{41,42}$ While an impaired nutritional status in IBD is highly prevalent and widely accepted as a consequence of disease, the role in disease course is not yet clear. We observed a prospective association between a high risk of malnutrition and subsequent flares, using body mass index (BMI) and a Short Nutritional Assessment Questionnaire (SNAQ) as screening tools for malnutrition (Chapter 5). Although many parameters are being 
used to define malnutrition, a strict definition of an impaired nutritional status remains unclear. ${ }^{43}$ The use of body composition by imaging has been hypothesized as an alternative to questionnaires and BMI, but definite reference standards are lacking and excessive exposure to radiation is unwanted. ${ }^{43}$ Our group recently showed that a combination of the various markers was needed to capture the majority of patients at risk for an impaired nutritional status (Spooren et al. Submitted for publication). Regardless of the modality of screening, mounting evidence suggests a window of opportunity for flare prevention and improvement of general wellbeing through amelioration of patients' nutritional status. Several diets or dietary compounds have also been associated with disease onset and progression under the hypothesis that diet can both shape the microbiota composition and activity as well as by direct effects of diet on the intestinal epithelium and immune system. ${ }^{44,45}$ For instance, the intake of fruit and vegetables were found to be protective, whereas the intake of red meat was associated with a higher risk of IBD onset. ${ }^{46}$ Studies on the influence of food products on flare occurrence are scarce and the evidence on the efficacy of specific dietary interventions for maintenance of remission is conflicting or needs confirmation. ${ }^{40}$ Though, patients themselves strongly believe that diet can alter their disease activity. ${ }^{47}$ Our group recently investigated dietary patterns instead of single food compounds and found an association between a 'Western' dietary pattern and the occurrence of flares in IBD patients. ${ }^{48}$ Where current IBD guidelines merely advise monitoring weight in all patients, we recommend the continuous assessment of nutritional status in line with the recent quality of care standards and the ESPEN guideline of clinical nutrition. ${ }^{17,49,50}$ Personalized dietary interventions by trained dieticians, based on both treatment of undernutrition and improving diet quality, may eventually improve disease course in the long term.

Psychosocial wellbeing, encompassing anxiety, depression, perceived stress, social support, and fatigue, may also be involved in IBD disease course. The high prevalence of psychological distress in the IBD population, especially during episodes of disease activity, was the subject of many association studies and highlights the need for psychological support in many patients. ${ }^{51-53}$ Observed associations are thought to arise from an interplay between the gut microbiota and the nervous system, the so-called microbiota-gut-brain-axis. For example, reduced bacterial diversity, decreased taxa within the phylum Firmicutes, and increased Gammaproteobacteria are reported in both IBD patients as well as patients with mental disorders and have been found to induce inflammation in mice. ${ }^{52}$ Also, gut bacteria are known to metabolize tryptophan to different end-products including serotonin, and lack of tryptophan has been associated with both depression and IBD disease activity. ${ }^{52}$ Furthermore, psychological stress has been shown to increase gut permeability, which was also mediated by the gut microbiota. ${ }^{52}$ In order to analyse whether psychosocial disorders may precede disease flares instead of being caused by gut inflammation, we used a unique prospective approach using continuous measurements in Chapter 4. No associations 
were found with depression, anxiety, or fatigue, but perceived stress and the occurrence of life events were positively associated with subsequent flares. Apart from microbiota-gut-brain interactions, perceived stress (and analogous, life events) can affect the immune system through activation of the hypothalamic-pituitary-adrenals axis, decreased vagal nerve activity, increased activation of the sympathetic nervous system, and release of substance $P$ by the enteric nervous system. ${ }^{54,55}$ Despite a limited number of intervention trials, the best approach for patients with high perceived stress levels and the effects of other psychological interventions (e.g. the use of antidepressants) have yet to be unravelled, but monitoring of psychosocial status seems inevitable. ${ }^{56-60}$

Besides aforementioned associations, many others have been identified but inconsistent findings complicate interpretation. ${ }^{51}$ These inconsistencies are probably due to limitations in study designs and studied populations. In the first place, since frequently used cross-sectional designs neglect the possibility of bidirectional effects, a prospective longitudinal study design is needed to assure a causal relationship between two variables. Moreover, the heterogeneity of the IBD population requires large study cohorts to determine effect sizes in different subgroups of patients and correct for the large number of possible confounders without loss of required statistical power. Even when a prospective longitudinal design is chosen and a large cohort is established, outcomes of interest may be subject to certain effect modifiers. For instance, many associations are thought to be modulated at least in part by the host's microbiome, which differs between patients and even within patients over time. ${ }^{40,61}$ Also a patient's genetic susceptibility for environmental changes and coping strategies in case of psychosocial imbalances are examples of effect modifiers that are frequently not taken into account by current studies. Lastly, the knowledge gap on the exact pathophysiologic mechanism of inflammation in IBD patients hinders the identification of yet unknown confounders and effect modifiers. Thus, a holistic approach using large datasets containing detailed clinical characteristics (including data on patients' genome and microbiome) and continuous measurements of outcome variables (e.g. through eHealth applications) to study causality and correct for both effect modification and confounding is needed to disentangle the complexity of the mixture of environmental factors. ${ }^{62}$ Additionally, after observing causal relationships, further study of underlying pathophysiological mechanisms may identify (personalized) targets for interventions.

\section{Weighing the risks}

At all time, an individual risk-benefit analysis is needed to determine the most desirable treatment strategy. Current guidelines advocate early introduction of biologicals and immunosupressives or even combination therapy in high risk patients and increased implementation of these 'aggressive' treatment strategies is observed in many cohorts. As depicted in Chapter 2, a subgroup of patients with chronic continuous or 
intermittent disease activity patterns could benefit from these strategies, but a considerable number of patients with a mild disease course is at risk for overtreatment, especially since early markers cannot identify this group.

\section{Risks of overtreatment}

While the excessive use of corticosteroids is widely discouraged due to numerous side effects, other immunosuppressive drugs are frequently prescribed for long time periods. Many intervention trials focus on short-term and/or reversible side effects, such as renal impairment in 5-ASA users, myelosuppression and pancreatitis in thiopurine users, and leukopenia, thrombopenia and infusion reactions in relation to treatment with anti-TNF agents. ${ }^{63}$ Long-term effects of drug exposure can best be derived from large population-based cohort studies, but are frequently derived from post-hoc studies consisting of highly selected patient subgroups included in intervention trials.

In this thesis (Chapter 6), we analysed extraintestinal cancer as a potentially lethal long-term drug side effect using the population-based IBDSL cohort. We observed increased overall cancer risks in CD patients, but not in UC patients. More interestingly, cancer risk was not increased in the immunosuppression naïve group. The relation between cancer incidence and use of immunosuppressive drugs is supported by older reports of spontaneous regression of immunomodulator-related neoplasia following withdrawal. ${ }^{64-66}$ Our findings have also been confirmed by more recent publications and it is currently well-accepted that thiopurines primarily increase risks for hematologic malignancies (especially EBV-related tumours, hepatosplenic T-cell lymphoma and leukaemia) and non-melanoma skin cancers, and the use of anti-TNF increases the risk for melanoma. ${ }^{63}$ Moreover, in patients receiving combination therapy, the lymphoma risk is increased even more. ${ }^{67}$ The cancer risks for more recently developed biologicals (i.e. ustekinumab, vedolizumab, and tofacitinib) are yet to be established. Although absolute numbers are still low, current guidelines recommend lifelong use of sun protection measures and screening for dermatological malignancies on a regular base and caution is advised in risk groups for lymphomas (i.e. both young (<35yr) and old (>65yr) men, especially when being EBV-seronegative). ${ }^{68}$ In our opinion, the established association between drug exposure and cancer risks warrants the prevention of unwanted exposure to drugs in specific patient subgroups.

Next to the increased risk of cancer, the risk of infections is increased for many drugs used by IBD patients (i.e. corticosteroids, thiopurines, methotrexate, calcineurin inhibitors, anti-TNF agents, and other biologicals). ${ }^{69}$ While vaccination status is optimised and tuberculosis (and optionally hepatitis C, EBV, and HIV) are generally excluded in every newly diagnosed patient, ${ }^{17}$ an increased risk is observed for both opportunistic and serious infections (i.e. requiring hospitalisation). ${ }^{69}$ Infections are even considered one of the most common causes of death in IBD patients. ${ }^{70,71}$ Unfortunately, 
reliable incident data on mild and moderate infections are largely lacking, probably due to difficulties in registration since diagnosis and treatment hereof is mainly done by general practitioners. To overcome this important knowledge gap, standardised allcause infection registration is currently being implemented in the MylBDcoach telemedicine home-monitoring tool. This will provide important data on yet unknown risk factors for infection concerning patient and drug characteristics.

Other complications such as liver nodular regenerative hyperplasia in thiopurine users, demyelination and worsening of cardiac failure in anti-TNF users, and interstitial pneumonitis in methotrexate users have all been described but are rare and only applicable to a very small subset of patients. Next to these potentially severe side effects, IBD patients also report many other symptoms that may be related to the use of immunosuppressive therapy, such as various skin lesions and hair loss. ${ }^{72-74}$ Although not life-threatening, they can impact a patient's quality of life.

Eventually, the combination of a multi-omics approach with detailed and longterm clinical data can be used to determine a personalized therapeutic risk profile for each individual patient. A nice example of such patient-specific 'passport' is the very recent publication of Bangma et al. in which a pharmacogenetic passport was developed, which predicts toxicity of thiopurine and anti-TNF therapy in individual patients. ${ }^{75}$ Although the number needed to genotype was still rather high (i.e. 24 patients) and long-term risks are not taken into account, we believe that these kinds of strategies will contribute to tailor-made treatment strategies in the near future.

\section{Risks of undertreatment}

While the current tendency towards overtreatment carries risks as described above, the risk of undertreatment should also be addressed, especially in patients with a chronic continuous or moderate-severe chronic intermittent disease activity pattern (Chapter 2). Although stringent monitoring and modification of flare-inducing environmental factors may reduce the risk of uncontrolled inflammation, they cannot replace medical therapy in all patients. The risk of disease progression, often requiring surgery, is strongly linked to chronic inflammation and served as the substantiation for the implementation of more aggressive treatment regimens. ${ }^{76,77}$ Also aforementioned detrimental changes in nutritional status and psychosocial wellbeing are highly prevalent in active IBD and should be regarded as a risk of uncontrolled IBD with potentially significant impact on the perceived quality of life. . $3,78-80^{-1}$

In this thesis, the colorectal cancer (CRC) risk in the IBDSL population as a consequence of chronic (uncontrolled) intestinal inflammation was analysed in Chapter 6 and Chapter 7. ${ }^{81}$ Probably due to more aggressive disease control and the implementation of surveillance guidelines, the CRC risk was found to decrease over time (when comparing older and newer cohort studies) ${ }^{82}$ and did not differ from the background population (except for a subgroup of patients with colonic CD). Although 
aggressive control of inflammation may keep CRC risk low, strict adherence to surveillance guidelines is an effective alternative which does not carry the risks of overtreatment. Current surveillance guidelines however may need further improvement. In Chapter 7, we observed that 30\% of CRCs were found in the first 8 years after diagnosis, while surveillance is advised from 8 years onwards. These cases can be prevented if surveillance guidelines include a first surveillance endoscopy after remission is induced with initial treatment, especially in high-risk individuals. However, since the absolute numbers are small, cost-effectiveness should also be considered. Current guidelines already use patient characteristics associated with higher CRC risk (i.e. previous dysplasia, presence of colonic strictures, concomitant PSC, extensive disease, and positive family history) to determine surveillance intervals. ${ }^{83}$ Recently, a large multinational cohort study observed a strong association between negative findings on surveillance colonoscopies and subsequent low CRC risk and suggest to also add this parameter to the stratification algorithm. ${ }^{84}$ In addition, many associations with CRC risk have been observed in gene expression studies. Future studies should focus on translating these findings to clinical practice in order to contribute to personalized CRC surveillance strategies.

\section{Rising healthcare costs}

Next to the physical and psychological consequences of both overtreatment and undertreatment, the rise in IBD-related healthcare costs is a societal concern. ${ }^{85,86}$ Uncontrolled inflammation and subsequent hospitalisations and/or surgery are expensive and were found to be major cost drivers in the first year after diagnosis in a recent European study. ${ }^{85}$ Since risk factors for high costs were comparable to risk factors for severe IBD (e.g. smoking in CD and extensive disease in UC) in the same study, they can be regarded a possible consequence of undertreatment. Moreover, unemployment, sick leave, and presenteeism (i.e. indirect healthcare costs) are also common in IBD patients, especially during flares. ${ }^{87}$ On the other hand, due to the implementation of aggressive treatment strategies and stringent treatment goals, the use of immunomodulatory drugs increased and medication use has become the major cost driver in prevalent IBD cases. $^{85,86}$ Considering the large group of immunomodulator-naïve patients with a quiescent disease activity pattern in our cohort (Chapter 2), this may be indicative of partially redundant medication costs. Regardless whether the high economic burden of IBD is a consequence of overtreatment or undertreatment, we believe that individual risk-benefit balances contribute to the targeted use of healthcare resources and eventually lead to a reduction of costs. 


\section{Personalized medicine; the final goal}

We believe that personalized medicine is the key towards further improvement of the disease course in IBD. The required paradigm shifts have already been proven effective in other chronic inflammatory diseases like rheumatoid arthritis and even in several malignant disorders where prognosis has drastically improved over the past decades. ${ }^{88-}$ 90

The heterogeneity between IBD patients warrants improved stratification of patients based on accurate predictors of disease course. In our opinion, the use of large datasets including information on patients' genome, proteome, transcriptome, epigenome, metabolome, microbiome, and exposome together with precise longitudinal description of clinical and patient reported outcomes will provide insights in their complex interplay and the differences between and within IBD patients. Subsequently, new personalized treatment targets can be identified and a personalized risk profile together with the specific prediction of response and tolerance to therapy can be generated for every newly diagnosed IBD patient.

However, personalized medicine is more than just the development of predictive markers and tailor-made medical treatment regimens. As shown above, the strict monitoring of modifiable risk factors (such as psychosocial and lifestyle factors) can be an essential key towards personalized treatment plans as well. Combining these with the monitoring of disease activity using telemedicine tools such as the MylBDcoach can offer the perfect platform for prevention and early detection of flares, development of decision support tools, and guidance of both patients and gastroenterologists in selecting personalized interventions. Data from the MylBDcoach trial showed that patient satisfaction of home monitoring is high and during the recent COVID-19 pandemic, other applications of telehealth were applied to many other patient groups as well with high satisfaction rates in patients $(>80 \%)$ and health care providers $(>90 \%) .{ }^{91,92}$ Lastly, we believe that the patient's general wellbeing should also be addressed if we want to deliver complete personalized medicine. Although patients with active disease carry the highest disease burden, patients without luminal disease activity often experience disabling complaints. According to a recent observational study, the most frequently reported IBD-related symptoms in patients in remission were fatigue $(80.2 \%)$, loss of muscle strength $(78.2 \%)$, pain $(78.2 \%)$, and weight loss $(68.3 \%) .{ }^{93}$ Monitoring of patient-reported outcomes will improve patient-clinician communication, symptom management, patient satisfaction, and quality of life and subsequently may add to improvement of disease course..$^{94,95}$

In conclusion, to further improve disease outcome for the heterogeneous group of IBD patients, advances towards personalized medicine seem inevitable. In this thesis, we stressed the need for improved classification of IBD patients and personalized risk profiling at diagnosis to select appropriate treatment strategies, preventing both undertreatment and overtreatment. Future research should focus on an integrated 
holistic approach of large datasets containing both clinical, patient-reported, and multiomic data while assuring solid definitions of outcome measurements. In the meantime, maintenance of remission should be the aim, but the risk of infections, cancer, impact on subjective health trough drug related side effects, and excessive healthcare costs should be considered as well. Use of telemedicine tools enables tight monitoring of early markers of disease activity, flare-inducing environmental factors, and patients' general wellbeing and can guide personalized interventions when needed. By doing so, the right patient can be treated with the right interventions at the right time. 


\section{References}

1. Fumery M, Singh S, Dulai PS, Gower-Rousseau C, Peyrin-Biroulet L, Sandborn WJ. Natural History of Adult Ulcerative Colitis in Population-based Cohorts: A Systematic Review. Clin Gastroenterol Hepatol. 2018;16(3):343-56 e3.

2. Peyrin-Biroulet L, Loftus EV, Jr., Colombel JF, Sandborn WJ. The natural history of adult Crohn's disease in population-based cohorts. Am J Gastroenterol. 2010;105(2):289-97.

3. Solberg IC, Lygren I, Jahnsen J, Aadland E, Hoie O, Cvancarova M, et al. Clinical course during the first 10 years of ulcerative colitis: results from a population-based inception cohort (IBSEN Study). Scand J Gastroenterol. 2009;44(4):431-40.

4. Solberg IC, Vatn MH, Hoie O, Stray N, Sauar J, Jahnsen J, et al. Clinical course in Crohn's disease: results of a Norwegian population-based ten-year follow-up study. Clin Gastroenterol Hepatol. 2007;5(12):1430-8.

5. Jeuring SF, van den Heuvel TR, Liu LY, Zeegers MP, Hameeteman WH, Romberg-Camps MJ, et al. Improvements in the Long-Term Outcome of Crohn's Disease Over the Past Two Decades and the Relation to Changes in Medical Management: Results from the Population-Based IBDSL Cohort. Am J Gastroenterol. 2017;112(2):325-36.

6. Jeuring SFG, Biemans VBC, van den Heuvel TRA, Zeegers MP, Hameeteman WH, Romberg-Camps MJL, et al. Corticosteroid Sparing in Inflammatory Bowel Disease is More Often Achieved in the Immunomodulator and Biological Era-Results from the Dutch Population-Based IBDSL Cohort. Am J Gastroenterol. 2018;113(3):384-95.

7. Jeuring SF, Bours PH, Zeegers MP, Ambergen TW, van den Heuvel TR, Romberg-Camps MJ, et al. Disease Outcome of Ulcerative Colitis in an Era of Changing Treatment Strategies: Results from the Dutch Population-Based IBDSL Cohort. J Crohns Colitis. 2015;9(10):837-45.

8. Beaugerie L, Seksik P, Nion-Larmurier I, Gendre JP, Cosnes J. Predictors of Crohn's disease. Gastroenterology. 2006;130(3):650-6.

9. To N, Gracie DJ, Ford AC. Systematic review with meta-analysis: the adverse effects of tobacco smoking on the natural history of Crohn's disease. Aliment Pharmacol Ther. 2016;43(5):549-61.

10. Burisch J, Pedersen N, Cukovic-Cavka S, Turk N, Kaimakliotis I, Duricova D, et al. Initial disease course and treatment in an inflammatory bowel disease inception cohort in Europe: the ECCO-EpiCom cohort. Inflamm Bowel Dis. 2014;20(1):36-46.

11. Ng SC, Zeng Z, Niewiadomski O, Tang W, Bell S, Kamm MA, et al. Early Course of Inflammatory Bowe Disease in a Population-Based Inception Cohort Study From 8 Countries in Asia and Australia. Gastroenterology. 2016;150(1):86-95 e3; quiz e13-4.

12. Munkholm P, Langholz E, Davidsen M, Binder V. Disease activity courses in a regional cohort of Crohn's disease patients. Scand J Gastroenterol. 1995;30(7):699-706.

13. Blackwell J, Saxena S, Alexakis C, Bottle A, Cecil E, Majeed A, et al. The impact of smoking and smoking cessation on disease outcomes in ulcerative colitis: a nationwide population-based study. Aliment Pharmacol Ther. 2019;50(5):556-67.

14. Gollop JH, Phillips SF, Melton LJ, 3rd, Zinsmeister AR. Epidemiologic aspects of Crohn's disease: a population based study in Olmsted County, Minnesota, 1943-1982. Gut. 1988;29(1):49-56.

15. Jess T, Riis L, Vind I, Winther KV, Borg S, Binder V, et al. Changes in clinical characteristics, course, and prognosis of inflammatory bowel disease during the last 5 decades: a population-based study from Copenhagen, Denmark. Inflamm Bowel Dis. 2007;13(4):481-9.

16. Wolters FL, Russel MG, Sijbrandij J, Ambergen T, Odes S, Riis L, et al. Phenotype at diagnosis predicts recurrence rates in Crohn's disease. Gut. 2006;55(8):1124-30.

17. Maaser C, Sturm A, Vavricka SR, Kucharzik T, Fiorino G, Annese V, et al. ECCO-ESGAR Guideline for Diagnostic Assessment in IBD Part 1: Initial diagnosis, monitoring of known IBD, detection of complications. J Crohns Colitis. 2019;13(2):144-64.

18. Li D, Haritunians T, Landers C, Potdar AA, Yang S, Huang $H$, et al. Late-Onset Crohn's Disease Is A Subgroup Distinct in Genetic and Behavioral Risk Factors With UC-Like Characteristics. Inflamm Bowel Dis. $2018 ; 24(11): 2413-22$. 
19. Graham DB, Xavier RJ. Pathway paradigms revealed from the genetics of inflammatory bowel disease. Nature. 2020;578(7796):527-39.

20. Ricciuto A, Kamath BM, Griffiths AM. The IBD and PSC Phenotypes of PSC-IBD. Curr Gastroenterol Rep. 2018;20(4):16.

21. Torres J, Caprioli F, Katsanos KH, Lobaton T, Micic D, Zeroncio M, et al. Predicting Outcomes to Optimize Disease Management in Inflammatory Bowel Diseases. J Crohns Colitis. 2016;10(12):1385-94.

22. Siegel CA, Bernstein CN. Identifying Patients With Inflammatory Bowel Diseases at High vs Low Risk of Complications. Clin Gastroenterol Hepatol. 2020;18(6):1261-7.

23. Noor NM, Verstockt B, Parkes M, Lee JC. Personalised medicine in Crohn's disease. Lancet Gastroenterol Hepatol. 2020;5(1):80-92.

24. Somineni HK, Venkateswaran S, Kilaru V, Marigorta UM, Mo A, Okou DT, et al. Blood-Derived DNA Methylation Signatures of Crohn's Disease and Severity of Intestinal Inflammation. Gastroenterology. 2019;156(8):2254-65 e3.

25. Adler J, Rangwalla SC, Dwamena BA, Higgins PD. The prognostic power of the NOD2 genotype for complicated Crohn's disease: a meta-analysis. Am J Gastroenterol. 2011;106(4):699-712.

26. Cleynen I, Boucher G, Jostins L, Schumm LP, Zeissig S, Ahmad T, et al. Inherited determinants of Crohn's disease and ulcerative colitis phenotypes: a genetic association study. Lancet. 2016;387(10014):156-67.

27. Kugathasan S, Denson LA, Walters TD, Kim MO, Marigorta UM, Schirmer M, et al. Prediction of complicated disease course for children newly diagnosed with Crohn's disease: a multicentre inception cohort study. Lancet. 2017;389(10080):1710-8.

28. Burisch J, Katsanos KH, Christodoulou DK, Barros L, Magro F, Pedersen N, et al. Natural Disease Course of Ulcerative Colitis During the First Five Years of Follow-up in a European Population-based Inception Cohort-An Epi-IBD Study. J Crohns Colitis. 2019;13(2):198-208.

29. Burisch J, Kiudelis G, Kupcinskas L, Kievit HAL, Andersen KW, Andersen V, et al. Natural disease course of Crohn's disease during the first 5 years after diagnosis in a European population-based inception cohort: an Epi-IBD study. Gut. 2019;68(3):423-33.

30. D'Haens G, Baert F, van Assche G, Caenepeel P, Vergauwe P, Tuynman H, et al. Early combined immunosuppression or conventional management in patients with newly diagnosed Crohn's disease: an open randomised trial. Lancet. 2008;371(9613):660-7.

31. Colombel JF, Sandborn WJ, Reinisch W, Mantzaris GJ, Kornbluth A, Rachmilewitz D, et al. Infliximab, azathioprine, or combination therapy for Crohn's disease. N Engl J Med. 2010;362(15):1383-95.

32. Panaccione R, Ghosh S, Middleton S, Marquez JR, Scott BB, Flint L, et al. Combination therapy with infliximab and azathioprine is superior to monotherapy with either agent in ulcerative colitis. Gastroenterology. 2014;146(2):392-400 e3.

33. Shah SC, Colombel JF, Sands BE, Narula N. Mucosal Healing Is Associated With Improved Long-term Outcomes of Patients With Ulcerative Colitis: A Systematic Review and Meta-analysis. Clin Gastroenterol Hepatol. 2016;14(9):1245-55 e8.

34. Klenske E, Bojarski C, Waldner M, Rath T, Neurath MF, Atreya R. Targeting mucosal healing in Crohn's disease: what the clinician needs to know. Therap Adv Gastroenterol. 2019;12:1756284819856865.

35. Lee S, Kuenzig ME, Ricciuto A, Zhang Z, Shim HH, Panaccione R, et al. Smoking May Reduce the Effectiveness of Anti-TNF Therapies to Induce Clinical Response and Remission in Crohn's Disease: A Systematic Review and Meta-analysis. J Crohns Colitis. 2021;15(1):74-87.

36. Papoutsopoulou S, Satsangi J, Campbell BJ, Probert CS. Review article: impact of cigarette smoking on intestinal inflammation-direct and indirect mechanisms. Aliment Pharmacol Ther. 2020;51(12):1268-85.

37. To N, Ford AC, Gracie DJ. Systematic review with meta-analysis: the effect of tobacco smoking on the natural history of ulcerative colitis. Aliment Pharmacol Ther. 2016;44(2):117-26.

38. Cosnes J, Beaugerie L, Carbonnel F, Gendre JP. Smoking cessation and the course of Crohn's disease: an intervention study. Gastroenterology. 2001;120(5):1093-9.

39. Hart AL, Lomer M, Verjee A, Kemp K, Faiz O, Daly A, et al. What Are the Top 10 Research Questions in the Treatment of Inflammatory Bowel Disease? A Priority Setting Partnership with the James Lind Alliance. J Crohns Colitis. 2017;11(2):204-11. 
40. Sigall-Boneh R, Levine A, Lomer M, Wierdsma N, Allan P, Fiorino G, et al. Research Gaps in Diet and Nutrition in Inflammatory Bowel Disease. A Topical Review by D-ECCO Working Group [Dietitians of ECCO]. J Crohns Colitis. 2017;11(12):1407-19.

41. Krok KL, Lichtenstein GR. Nutrition in Crohn disease. Curr Opin Gastroenterol. 2003;19(2):148-53.

42. Gerasimidis K, McGrogan P, Edwards CA. The aetiology and impact of malnutrition in paediatric inflammatory bowel disease. J Hum Nutr Diet. 2011;24(4):313-26.

43. Cederholm T, Barazzoni R, Austin P, Ballmer P, Biolo G, Bischoff SC, et al. ESPEN guidelines on definitions and terminology of clinical nutrition. Clin Nutr. 2017;36(1):49-64.

44. Yao CK, Muir JG, Gibson PR. Review article: insights into colonic protein fermentation, its modulation and potential health implications. Aliment Pharmacol Ther. 2016;43(2):181-96.

45. Levine A, Sigall Boneh R, Wine E. Evolving role of diet in the pathogenesis and treatment of inflammatory bowel diseases. Gut. 2018;67(9):1726-38.

46. Piovani D, Danese S, Peyrin-Biroulet L, Nikolopoulos GK, Lytras T, Bonovas S. Environmental Risk Factors for Inflammatory Bowel Diseases: An Umbrella Review of Meta-analyses. Gastroenterology. 2019;157(3):647-59 e4.

47. Zallot C, Quilliot D, Chevaux JB, Peyrin-Biroulet C, Gueant-Rodriguez RM, Freling E, et al. Dietary beliefs and behavior among inflammatory bowel disease patients. Inflamm Bowel Dis. 2013;19(1):66-72.

48. Peters V, Spooren C, Pierik M, Weersma R, van Dullemen H, Festen E, et al. Dietary Intake Pattern is Associated with Occurrence of Flares in IBD Patients. J Crohns Colitis. 2021.

49. Fiorino G, Lytras T, Younge L, Fidalgo C, Coenen S, Chaparro M, et al. Quality of Care Standards in Inflammatory Bowel Diseases: a European Crohn's and Colitis Organisation [ECCO] Position Paper. J Crohns Colitis. 2020;14(8):1037-48.

50. Bischoff SC, Escher J, Hebuterne X, Klek S, Krznaric Z, Schneider S, et al. ESPEN practical guideline: Clinical Nutrition in inflammatory bowel disease. Clin Nutr. 2020;39(3):632-53.

51. Maaser C, Langholz E, Gordon H, Burisch J, Ellul P, Ramirez VH, et al. European Crohn's and Colitis Organisation Topical Review on Environmental Factors in IBD. J Crohns Colitis. 2017;11(8):905-20.

52. Thomann AK, Mak JWY, Zhang JW, Wuestenberg T, Ebert MP, Sung JJY, et al. Review article: bugs, inflammation and mood-a microbiota-based approach to psychiatric symptoms in inflammatory bowel diseases. Aliment Pharmacol Ther. 2020;52(2):247-66.

53. Neuendorf R, Harding A, Stello N, Hanes D, Wahbeh H. Depression and anxiety in patients with Inflammatory Bowel Disease: A systematic review. J Psychosom Res. 2016;87:70-80.

54. Bonaz BL, Bernstein CN. Brain-gut interactions in inflammatory bowel disease. Gastroenterology. 2013;144(1):36-49.

55. Mawdsley JE, Rampton DS. Psychological stress in IBD: new insights into pathogenic and therapeutic implications. Gut. 2005;54(10):1481-91.

56. Gonzalez-Moret R, Cebolla A, Cortes X, Banos RM, Navarrete J, de la Rubia JE, et al. The effect of a mindfulness-based therapy on different biomarkers among patients with inflammatory bowel disease: a randomised controlled trial. Sci Rep. 2020;10(1):6071.

57. Wynne B, McHugh L, Gao W, Keegan D, Byrne K, Rowan C, et al. Acceptance and Commitment Therapy Reduces Psychological Stress in Patients With Inflammatory Bowel Diseases. Gastroenterology. 2019;156(4):935-45 e1.

58. Daghaghzadeh H, Naji F, Afshar H, Sharbafchi MR, Feizi A, Maroufi M, et al. Efficacy of duloxetine add on in treatment of inflammatory bowel disease patients: A double-blind controlled study. J Res Med Sci. 2015;20(6):595-601.

59. Mikocka-Walus A, Hughes PA, Bampton P, Gordon A, Campaniello MA, Mavrangelos C, et al. Fluoxetine for Maintenance of Remission and to Improve Quality of Life in Patients with Crohn's Disease: a Pilot Randomized Placebo-Controlled Trial. J Crohns Colitis. 2017;11(4):509-14.

60. Mikocka-Walus A, Ford AC, Drossman DA. Antidepressants in inflammatory bowel disease. Nat Rev Gastroenterol Hepatol. 2020;17(3):184-92.

61. Clooney AG, Eckenberger J, Laserna-Mendieta E, Sexton KA, Bernstein MT, Vagianos K, et al. Ranking microbiome variance in inflammatory bowel disease: a large longitudinal intercontinental study. Gut. 2020. 
62. Vineis P, Robinson O, Chadeau-Hyam M, Dehghan A, Mudway I, Dagnino S. What is new in the exposome? Environ Int. 2020;143:105887.

63. Beaugerie L, Rahier JF, Kirchgesner J. Predicting, Preventing, and Managing Treatment-Related Complications in Patients With Inflammatory Bowel Diseases. Clin Gastroenterol Hepatol. 2020;18(6):1324-35 e2.

64. Dillon P, Thomas N, Sharpless N, Collichio F. Regression of advanced melanoma upon withdrawal of immunosuppression: case series and literature review. Med Oncol. 2010;27(4):1127-32.

65. Csuka ME, Hanson GA. Resolution of a soft-tissue sarcoma in a patient with rheumatoid arthritis after discontinuation of azathioprine therapy. Arch Intern Med. 1996;156(14):1573-6.

66. Larvol L, Soule JC, Le Tourneau A. Reversible lymphoma in the setting of azathioprine therapy for Crohn's disease. N Engl J Med. 1994;331(13):883-4.

67. Lemaitre M, Kirchgesner J, Rudnichi A, Carrat F, Zureik M, Carbonnel F, et al. Association Between Use of Thiopurines or Tumor Necrosis Factor Antagonists Alone or in Combination and Risk of Lymphoma in Patients With Inflammatory Bowel Disease. JAMA. 2017;318(17):1679-86.

68. Annese V, Beaugerie L, Egan L, Biancone L, Bolling C, Brandts C, et al. European Evidence-based Consensus: Inflammatory Bowel Disease and Malignancies. J Crohns Colitis. 2015;9(11):945-65.

69. Rahier JF, Magro F, Abreu C, Armuzzi A, Ben-Horin S, Chowers Y, et al. Second European evidencebased consensus on the prevention, diagnosis and management of opportunistic infections in inflammatory bowel disease. J Crohns Colitis. 2014;8(6):443-68.

70. Hutfless SM, Weng X, Liu L, Allison J, Herrinton LJ. Mortality by medication use among patients with inflammatory bowel disease, 1996-2003. Gastroenterology. 2007;133(6):1779-86.

71. Kassam Z, Belga S, Roifman I, Hirota S, Jijon H, Kaplan GG, et al. Inflammatory bowel disease causespecific mortality: a primer for clinicians. Inflamm Bowel Dis. 2014;20(12):2483-92.

72. Torres J, Buche S, Delaporte E, Colombel JF. Skin side effects of inflammatory bowel disease therapy. Inflamm Bowel Dis. 2013;19(5):1086-98.

73. Godat S, Fournier N, Safroneeva E, Juillerat P, Nydegger A, Straumann A, et al. Frequency and type of drug-related side effects necessitating treatment discontinuation in the Swiss Inflammatory Bowel Disease Cohort. Eur J Gastroenterol Hepatol. 2018;30(6):612-20.

74. Shah R, Abraham B, Hou J, Sellin J. Frequency and associated factors of hair loss among patients with inflammatory bowel disease. World J Gastroenterol. 2015;21(1):229-32.

75. Bangma A, Voskuil MD, Uniken Venema WTC, Brugge H, Hu S, Lanting P, et al. Predicted efficacy of a pharmacogenetic passport for inflammatory bowel disease. Aliment Pharmacol Ther. 2020;51(11): 1105-15.

76. Torres J, Bonovas S, Doherty G, Kucharzik T, Gisbert JP, Raine T, et al. ECCO Guidelines on Therapeutics in Crohn's Disease: Medical Treatment. J Crohns Colitis. 2020;14(1):4-22.

77. Harbord M, Eliakim R, Bettenworth D, Karmiris K, Katsanos K, Kopylov U, et al. Third European Evidence-based Consensus on Diagnosis and Management of Ulcerative Colitis. Part 2: Current Management. J Crohns Colitis. 2017;11(7):769-84.

78. Borren NZ, van der Woude CJ, Ananthakrishnan AN. Fatigue in IBD: epidemiology, pathophysiology and management. Nat Rev Gastroenterol Hepatol. 2019;16(4):247-59.

79. Mikocka-Walus A, Knowles SR, Keefer L, Graff L. Controversies Revisited: A Systematic Review of the Comorbidity of Depression and Anxiety with Inflammatory Bowel Diseases. Inflamm Bowel Dis. 2016;22(3):752-62.

80. Casanova MJ, Chaparro M, Molina B, Merino O, Batanero R, Duenas-Sadornil C, et al. Prevalence of Malnutrition and Nutritional Characteristics of Patients With Inflammatory Bowel Disease. J Crohns Colitis. 2017;11(12):1430-9.

81. Elinav E, Nowarski R, Thaiss CA, Hu B, Jin C, Flavell RA. Inflammation-induced cancer: crosstalk between tumours, immune cells and microorganisms. Nat Rev Cancer. 2013;13(11):759-71.

82. Lutgens MW, van Oijen MG, van der Heijden GJ, Vleggaar FP, Siersema PD, Oldenburg B. Declining risk of colorectal cancer in inflammatory bowel disease: an updated meta-analysis of population-based cohort studies. Inflamm Bowel Dis. 2013;19(4):789-99.

83. Annese V, Daperno M, Rutter MD, Amiot A, Bossuyt P, East J, et al. European evidence based consensus for endoscopy in inflammatory bowel disease. J Crohns Colitis. 2013;7(12):982-1018. 
84. Ten Hove JR, Shah SC, Shaffer SR, Bernstein CN, Castaneda D, Palmela C, et al. Consecutive negative findings on colonoscopy during surveillance predict a low risk of advanced neoplasia in patients with inflammatory bowel disease with long-standing colitis: results of a 15-year multicentre, multinational cohort study. Gut. 2019;68(4):615-22.

85. Burisch J, Vardi H, Schwartz D, Friger M, Kiudelis G, Kupcinskas J, et al. Health-care costs of inflammatory bowel disease in a pan-European, community-based, inception cohort during 5 years of follow-up: a population-based study. Lancet Gastroenterol Hepatol. 2020;5(5):454-64.

86. Targownik LE, Kaplan GG, Witt J, Bernstein CN, Singh H, Tennakoon A, et al. Longitudinal Trends in the Direct Costs and Health Care Utilization Ascribable to Inflammatory Bowel Disease in the Biologic Era: Results From a Canadian Population-Based Analysis. Am J Gastroenterol. 2020;115(1):128-37.

87. De Boer AG, Bennebroek Evertsz F, Stokkers PC, Bockting CL, Sanderman R, Hommes DW, et al. Employment status, difficulties at work and quality of life in inflammatory bowel disease patients. Eur J Gastroenterol Hepatol. 2016;28(10):1130-6.

88. Smolen JS, Aletaha D, Barton A, Burmester GR, Emery P, Firestein GS, et al. Rheumatoid arthritis. Nat Rev Dis Primers. 2018;4:18001.

89. Harbeck N, Gnant M. Breast cancer. Lancet. 2017;389(10074):1134-50.

90. Helgadottir H, Rocha Trocoli Drakensjo I, Girnita A. Personalized Medicine in Malignant Melanoma: Towards Patient Tailored Treatment. Front Oncol. 2018;8:202.

91. Dobrusin A, Hawa F, Gladshteyn M, Corsello P, Harlen K, Walsh CX, et al. Gastroenterologists and Patients Report High Satisfaction Rates With Telehealth Services During the Novel Coronavirus 2019 Pandemic. Clin Gastroenterol Hepatol. 2020;18(11):2393-7 e2.

92. de Jong MJ, van der Meulen-de Jong AE, Romberg-Camps MJ, Becx MC, Maljaars JP, Cilissen M, et al. Telemedicine for management of inflammatory bowel disease (mylBDcoach): a pragmatic, multicentre, randomised controlled trial. Lancet. 2017;390(10098):959-68.

93. Vegni E, Gilardi D, Bonovas S, Corro BE, Menichetti J, Leone D, et al. Illness Perception in Inflammatory Bowel Disease Patients is Different Between Patients With Active Disease or in Remission: A Prospective Cohort Study. J Crohns Colitis. 2019;13(4):417-23.

94. Restellini S, Lakatos PL. Patient-Reported Outcomes in Inflammatory Bowel Diseases: Another Piece in the Puzzle. J Crohns Colitis. 2021.

95. Basch E, Barbera L, Kerrigan CL, Velikova G. Implementation of Patient-Reported Outcomes in Routine Medical Care. Am Soc Clin Oncol Educ Book. 2018;38:122-34. 


$$
20
$$




\section{Addendum}

Summary

Samenvatting

Impact paragraph

List of publications

Dankwoord

Curriculum vitae 
Addendum 


\section{Summary}

Inflammatory bowel disease (IBD), encompassing Crohn's disease (CD) and ulcerative colitis (UC), is an inflammatory disorder of the gastrointestinal tract and is thought to arise from an interplay between environmental factors, the gut microbiome, and the immune system in genetically susceptible hosts. IBD is characterized by sequences of exacerbation and remission, which often require ongoing drug therapy or even surgery. As a consequence of active disease (i.e. exacerbations) and/or side effects of the prescribed drugs, IBD does have a large impact on a patient's quality of life. Along with an increasing incidence worldwide, the health economic burden increases, amongst others due to expensive treatments and high rates of work disability and unemployment.

To reduce the global burden of disease, new drugs are being developed and more aggressive treatment strategies have been deployed. In parallel, researchers have been trying to identify markers for a more severe disease course in order to stratify patients at diagnosis. Unfortunately, predicting disease course still remains challenging and, despite some improvements in long-term outcomes (e.g. decreased use of corticosteroids and decreased incidence of colorectal cancer), disease progression rates in $C D$ and hospitalization and surgery rates in UC remain relatively high. To further improve disease course, methodologically solid studies with accurate definitions are needed to further enhance patient stratification. Also, the role of currently undervalued environmental factors in the development of exacerbations, including changes in lifestyle and psychosocial status, may offer alternative targets for interventions and flare prevention. The modern tendency towards more aggressive medical treatment strategies also stresses the need for individual risk-benefit balances since overtreatment of patients may lead to serious complications such as infections or drugrelated cancer.

A personalized approach starting from diagnosis is essential towards improving patients' disease course. The aim of this thesis was to elucidate disease activity patterns, to explore the role of potentially modifiable environmental factors, and to study the long-term risks of both undertreatment and overtreatment in an attempt to guide gastroenterologists worldwide towards personalized medicine.

In Chapter 1, a general introduction on IBD was presented and the global disease burden was further addressed. Also the difficulties in interpreting disease course data, challenges in disease course modification, and the complexities of risk-benefit balances in the treatment of IBD were discussed in more detail.

In Chapter 2, the population-based IBD South Limburg (IBDSL) cohort, consisting of all patients diagnosed with IBD between 1991 and 2011 in the South Limburg region of the Netherlands, was used to describe the disease course of $432 \mathrm{CD}$ patients during the 
first ten years after diagnosis. We assessed each yearly quarter of follow-up for disease activity, which was defined by mucosal inflammation on endoscopy or imaging, hospitalisation or surgery due to active disease, or adjustment of treatment due to active disease. Hereby, six distinct disease activity patterns, ranging from a quiescent pattern ( $\leq 2$ active yearly quarters in 10 years) to a chronic continuous pattern ( $\geq 1$ quarter of disease activity per year in $\geq 8$ years) could be defined. Notably, $28.2 \%$ of the patients were classified as having a quiescent disease course pattern and $89.8 \%$ of those never received immunomodulators nor biologics. Using multivariable logistic regression models, associations between disease activity patterns and both patient and early disease course characteristics were assessed. Surgery at diagnosis (Odds ratio (OR) 2.99; 95\%-Confidence Interval $(95 \% \mathrm{Cl})$ 1.07-8.34) and higher age (OR $1.03 ; 95 \% \mathrm{Cl}$ 1.01-1.06) were positively associated with the quiescent pattern, whereas inverse associations were observed for ileocolonic location (OR $0.44 ; 95 \% \mathrm{Cl} 0.19-1.00$ ), smoking (OR 0.43; 95\% Cl 0.24-0.76), and need for steroids $<6$ months (OR $0.24 ; 95 \% \mathrm{Cl} 0.11$ 0.52). Partial least square discriminant analysis (PLS-DA) models containing several subsets of variables were built to differentiate between quiescent and severe disease course, but their predictive power was only moderate (maximal area under the receiver operating curve (AUROC) of 0.793). Given the complex risk-benefit balance of immunosuppressive drugs and increased use hereof over the past decades, our findings underline the importance of further improving patient stratification to prevent both overtreatment and undertreatment.

Since environmental factors play an important role in de development of IBD and are modifiable to some extent, they are interesting potential targets for flare prevention and disease course modification. Associations between disease activity and the patient's exposome, including air quality, psychosocial wellbeing, and nutritional status, were studied in the second part of this thesis.

In Chapter 3, the IBDSL cohort was used to study associations between ambient air quality and both CD diagnosis and disease course. The hypothesis was based on the strong link between cigarette smoking, which can be considered analogous to air pollution, and negative disease outcome in previous studies. In total, 389 CD patients were included and matched to healthy controls on gender, age, and residential address (which was stable for at least 3 years prior to inclusion). Both direct and indirect parameters of ambient air quality (i.e. air pollution levels, traffic exposure, land use, and urbanicity) were collected from geographic information systems (GIS) for all residential addresses and tested in multivariable logistic regression analyses with correction for known IBD risk factors. Next, for all CD patients with a stable residence for at least 3 years after inclusion $(n=338)$, disease course was analysed using both a composite score of negative outcomes (i.e. surgery, hospitalization, medication use, and disease progression) in a logistic regression model and disease activity per yearly quarter in a linear regression model, again with correction for known IBD risk factors. 
No significant associations between ambient air quality parameters and disease onset nor disease course were observed and therefore it was concluded that ambient air quality may not be a strong contributing factor in IBD in the South Limburg region. Nevertheless, we were not able to take lifetime exposure and/or non-residential exposure to air pollutants into account. Moreover, it must be noted that small effects, for instance in genetically susceptible patients, are still possible. Careful interpretation of the results is therefore warranted.

In Chapter 4, data from the MylBDcoach telemedicine trial were used to study the association between psychosocial factors and disease flares. The MylBDcoach study cohort consists of adult IBD patients from two academic and two regional hospitals in the Netherlands who were randomly assigned to either standard care (i.e. outpatient clinic visits on a regular basis) or patient monitoring at home using the MylBDcoach application. For our study, 417 patients who were assigned to the home monitoring application were followed during 12 months. Patients reported on disease activity (using the validated Monitor IBD At Home (MIAH) questionnaire), anxiety, depression, fatigue, perceived stress, and life events every 1-3 months. A flare was defined as clinical disease activity in combination with elevated stool calprotectin levels, disease activity on endoscopy or imaging, or adjustment of therapy due to increased symptoms by the treating physician. Generalized estimating equation (GEE) models were used to identify prospective associations between all psychosocial variables and disease flares in three subsequent months with correction for known IBD risk factors. Only the occurrence of life events (OR 1.81; $95 \% \mathrm{Cl}$ 1.04-3.17) and novel perceived stress (OR 2.92; $95 \% \mathrm{Cl} 1.44-5.90)$ were significantly associated with flare development. Our findings underline the importance of continuous monitoring of psychosocial status in IBD patients and may contribute to the prevention of disease flares. Future studies should analyse whether personalized interventions (e.g. mindfulness for patients with high stress levels) are indeed beneficial.

In Chapter 5, the same study population and definition for disease flares as in chapter 4 were used to analyse the association between an impaired nutritional status and disease activity. In addition to the MIAH questionnaire, the 417 included patients also reported on weight loss and loss of appetite every 1-3 months during the 12month follow-up. A high risk of impaired nutritional status was defined by a BMI $<18.5$ $\mathrm{kg} / \mathrm{m}^{2}$ and/or a Short Nutritional Assessment Questionnaire (SNAQ) score $\geq 2$. In our GEE models, again correcting for known IBD risk factors, a high risk of impaired nutritional status was associated with flare occurrence in the subsequent 3 months (OR $2.61 ; 95 \% \mathrm{Cl} 1.02-6.69)$. Whether personalized interventions to improve nutritional status (e.g. specific diets and physiotherapy) can prevent disease flares should be further investigated.

Since both uncontrolled disease activity and prolonged drug exposure can affect a patient's disease course in the long term, all risks should be weighed when selecting 
treatment strategies. The occurrence of cancer is a possible complication in both undertreated patients (i.e. colorectal cancer (CRC)) and overtreated patients (i.e. drugrelated cancer). In the third part of this thesis, cancer risk was analysed in the population-based IBDSL cohort.

In Chapter 6, standardized incidence ratios (SIRs) were calculated for both intestinal and extra-intestinal cancers in 2,801 IBD patients of the IBDSL cohort. Subgroup analyses were performed to determine gender- and phenotype-specific cancer risks. Moreover, patients were stratified according to their exposure to IBDrelated drug therapy. In general, CD patients were at increased risk for overall cancer (SIR 1.28; $95 \% \mathrm{Cl} 1.01-1.60$ ), mainly due to increased risks for hematologic cancer (SIR $2.41 ; 95 \% \mathrm{Cl} 1.04-4.76$ ) and squamous cell cancer (SIR 3.83; $95 \% \mathrm{Cl} 1.83-7.04)$. Only CD patients with colon involvement appeared to be at increased risk for CRC (SIR 2.97; $95 \% \mathrm{Cl}$ 1.08-6.46). UC patients were not at increased risk for any cancer subtype. In the medication subgroup analysis (analysing $C D$ and UC together), long term immunosuppression use (i.e. $>12$ months of exposure to thiopurines, anti- TNF $\alpha$ agents and/or methotrexate) was associated with an increase risk for overall cancer (SIR 1.48; $95 \% \mathrm{Cl}$ 1.11-1.95). Again, hematologic cancer (SIR 3.12; $95 \% \mathrm{Cl} 1.14-6.79$ ) and skin cancer (SIR 1.95; 95\% CI 1.22-2.96) risks were most accountable. Our results underline the importance of skin cancer screening, especially in patients with prolonged exposure to immunosuppressive drugs. In order to optimise cancer screening and/or surveillance strategies, patient specific characteristics need to be identified.

In Chapter 7, all observed CRC cases $(n=20)$ from the previous chapter were evaluated in further detail. As primary aim, the incidence and aetiology of potentially preventable postcolonoscopy CRCS (PCCRCs) were analysed. This subgroup of CRCs is defined as cancers diagnosed within 6-60 months after a colonoscopy and can be classified, following a disease-specific algorithm, as 'inappropriate surveillance interval', 'inadequate bowel examination', 'incomplete resection of dysplasia', 'missed lesion' or 'newly developed cancer'. In the IBDSL study cohort, a high proportion of PCCRCs (45\%) was observed. Of these, $55.6 \%$ could be considered a missed lesion. As surveillance guidelines have been implemented to prevent CRC development secondary to colitisassociated dysplasia, we also analysed guideline adherence for both PCCRCs and prevalent CRCs in this chapter as a secondary aim. Ten out of the 20 CRCs in the IBDSL cohort were detected within the recommended surveillance time window and after publication of the Dutch guideline in 2008, while only one patient received adequately timed and adequately performed surveillance. Notably, six CRCs (30.0\%) were observed in eligible patients before the recommended start of surveillance (i.e. after 8 years start of complaints). Despite low absolute cancer risks, it is important that we increase our dysplasia detection rates and continue to improve adherence to surveillance guidelines. Further, we believe that including a surveillance endoscopy after first induction of remission, at least in high-risk patients, may lead to a reduction in CRCs $<8$ years after diagnosis. 
In the final chapter (Chapter 8), the findings of this thesis were discussed with respect to global improvement of IBD's disease course. First, we stressed the need for further improvement of patient stratification and postulated that an accurate and uniform description of disease course using objective and independent outcome measurements should be the starting point. In addition, we hypothesised that IBD is likely more complex than the traditional UC-CD dichotomy. Therefore, we encouraged future studies to focus on combining all clinical IBD data with data from the patients' genome, tissue or cell-specific transcriptome, proteome, metabolome and/or gut microbiome to identify distinctive IBD subgroups and an accurate set of predictors to generate personalized risk profiles that predict disease severity and aid gastroenterologists in determining treatment strategies. Furthermore, we suggested the use of (home) monitoring of lifestyle factors and psychosocial status to select patients for personalized interventions and subsequently prevent flare occurrence. We encouraged future researchers to further disentangle the complex mixture of environmental factors and their interaction with the genetic susceptibility and hostmicrobe interaction in patients to correct for both effect modification and confounding. As a last part of the discussion, we reviewed the most important risks of both overtreatment, including drug-induced cancer and infections, and undertreatment, including disease progression and CRC. We proposed that these risks should be considered when assessing risk-benefit balances in patients. Eventually, we concluded that enhancing patient stratification, prevention of flares using patient monitoring, and weighing of risks when choosing treatment strategies are key steps towards personalized medicine and eventually contribute to improved long-term outcomes in IBD. 
Addendum 


\section{Nederlandse samenvatting}

Inflammatoire darmziekten (IBD), waaronder de ziekte van Crohn (ZvC) en colitis ulcerosa (CU), zijn ontstekingsziekten van het maagdarmstelsel en worden veroorzaakt door een wisselwerking tussen omgevingsfactoren, het darm-microbioom en het immuunsysteem in een genetisch gevoelige gastheer. IBD wordt gekenmerkt door afwisselende periodes van opvlammingen en remissie waardoor vaak langdurige medicamenteuze therapie of zelfs operatieve ingrepen nodig zijn. Als gevolg van ziekteactiviteit en/of bijwerkingen van de voorgeschreven medicijnen kan IBD een grote impact hebben op het leven van een patiënt. Samen met een wereldwijde toename in incidentie neemt ook de druk op het landelijke zorgstelsel toe, onder meer door de hoge kosten van behandelingen en een hoog percentage ziekteverlof en arbeidsongeschiktheid.

Ter vermindering van de algemene ziektelast zijn er constant nieuwe medicijnen in ontwikkeling en krijgen agressievere behandelstrategieën de afgelopen jaren steeds vaker de voorkeur. Tegelijkertijd hebben onderzoekers geprobeerd om markers voor een ernstig ziektebeloop te identificeren om patiënten bij de diagnose te kunnen stratificeren. Helaas blijft het voorspellen van het ziektebeloop nog steeds een uitdaging en, ondanks enkele verbeteringen in de lange termijn resultaten (bijv. verminderd gebruik van corticosteroïden en verminderde incidentie van colorectaal carcinoom), blijven de percentages van ziekteprogressie bij ZvC en ziekenhuisopnames en operaties bij CU relatief hoog. Om het ziektebeloop verder te verbeteren, is het optimaliseren van de patiëntstratificatie ten tijde van diagnose middels methodologisch solide onderzoeken met nauwkeurige definities van de uitkomstmaten essentieel. Daarnaast kunnen onderbelichte omgevingsfactoren die mogelijk geassocieerd zijn met darmontsteking, waaronder leefstijl en psychosociale factoren, ook targets bieden voor interventies en preventie van opvlammingen. De huidige tendens richting agressievere medische behandelingsstrategieën maakt het tevens noodzakelijk om een individuele balans op te maken ten aanzien van risico's en voordelen van medicamenteuze therapieën, met name gezien overbehandeling van patiënten kan leiden tot ernstige complicaties zoals infecties of zelfs geneesmiddel-gerelateerde maligniteiten.

In onze optiek is een gepersonaliseerde benadering vanaf diagnose essentieel om het ziektebeloop van patiënten te verbeteren. Het doel van dit proefschrift was om inzicht te krijgen in ziekteactiviteitspatronen, de rol van potentieel modificeerbare omgevingsfactoren te bestuderen en de mogelijke risico's van zowel onder- als overbehandeling op de lange termijn verder in kaart te brengen. Op deze manier hebben we gepoogd om gastro-enterologen wereldwijd op weg te helpen naar het zogeheten 'personalized medicine'.

In Hoofdstuk 1 werd een algemene inleiding over IBD gegeven en werd de wereldwijde ziektelast besproken. Daarnaast werden de moeilijkheden bij de 
interpretatie van studies betreffende het ziektebeloop, de uitdagingen in het modificeren van het ziektebeloop en de complexiteit van de risicoanalyse in de behandeling van IBD beschreven.

In Hoofdstuk 2 werd het ziektebeloop van 432 ZvC-patiënten tijdens de eerste tien jaar na diagnose bestudeerd. De patiënten maakten deel uit van het populatiegebaseerde IBD Zuid-Limburg (IBDZL) cohort dat bestaat uit alle patiënten gediagnosticeerd met IBD tussen 1991 en 2011 in de regio Zuid-Limburg. Allereerst werd de ziekteactiviteit van elk jaarlijks kwartaal van follow-up bepaald. Hierbij werd actieve ziekte gedefinieerd als: slijmvliesontsteking op endoscopie of beeldvorming, een ziekenhuisopname of een operatie als gevolg van ziekteactiviteit, of een aanpassing van de behandeling als gevolg van ziekteactiviteit. Uiteindelijk werden de patiënten toegewezen aan een van de zes vooraf gedefinieerde ziekteactiviteitspatronen, variërend van een rustig ( $\leq 2$ kwartalen met actieve ziekte) tot een chronisch continu patroon ( $\geq 1$ kwartalen met actieve ziekte per jaar voor ten minste 8 jaar). Opvallenderwijs bleek $28,2 \%$ van de patiënten een rustig ziektebeloop te kennen, waarbij $89,8 \%$ van hen nooit was blootgesteld aan immunomodulatoren of biologicals. Multivariabele logistische regressiemodellen werden gebruikt om associaties tussen ziekteactiviteitspatronen en zowel patiëntkarakteristieken als kenmerken vanuit het vroege ziektebeloop te bestuderen. Chirurgie bij diagnose (Odds ratio (OR) 2.99; 95\%betrouwbaarheidsinterval (95\% BI) 1.07-8.34) en een hogere leeftijd (OR 1.03; 95\% BI 1.01-1.06) waren positief geassocieerd met het rustige patroon, terwijl ileocolische ziektelokalisatie (OR 0.44; 95\% BI 0.19-1.00), roken (OR $0.43 ; 95 \% \mathrm{Cl} 0.24-0.76$ ), en gebruik aan corticosteroïden $<6$ maanden na diagnose (OR 0.24; 95\% BI 0.11-0.52) negatief geassocieerd waren. 'Partial least square discriminant analysis' (PLS-DA) modellen werden gebruikt (met subsets van verschillende klinische variabelen) om een rustig ziektebeloop van een ernstig ziektebeloop te onderscheiden, maar de voorspellende kracht was slechts matig (maximale 'area under the receiver operating curve' (AUROC) van 0,793). In het kader van de complexe balans tussen de voor- en nadelen van immunosuppressieve geneesmiddelen en het toegenomen gebruik hiervan in de afgelopen decennia, onderstrepen onze bevindingen het belang van verbeterde patiëntstratificatie om zowel overbehandeling als onderbehandeling te voorkomen.

Aangezien omgevingsfactoren een belangrijke rol bij de ontwikkeling van IBD lijken te spelen en tot op zekere hoogte modificeerbaar zijn, kunnen ze gezien worden als potentieel doel voor de preventie van flares en het verbeteren van het ziektebeloop. Associaties tussen ziekteactiviteit en het zogeheten 'exposoom' van de patiënt, waaronder luchtkwaliteit, psychosociaal welbevinden en voedingsstatus, werden bestudeerd in het tweede deel van dit proefschrift.

In Hoofdstuk $\mathbf{3}$ werd het IBDZL-cohort gebruikt om associaties tussen luchtkwaliteit en zowel diagnose als ziektebeloop van ZvC te bestuderen. De rationale 
achter deze studie berust op het sterke verband tussen het roken van sigaretten en negatieve ziekte-uitkomsten in eerdere studies. In totaal werden 389 ZvC-patiënten geïncludeerd en gematcht met gezonde controles op basis van geslacht, leeftijd en adres (dat stabiel moest zijn gedurende ten minste 3 jaar voorafgaand aan inclusie). Zowel directe als indirecte parameters van luchtkwaliteit (o.a. luchtverontreinigingsniveaus, verkeersblootstelling, landgebruik en stedelijkheid) werden verzameld uit geografische informatiesystemen (GIS). Deze werden getest in multivariabele logistieke regressieanalyses met correctie voor reeds bekende risicofactoren voor IBD. Vervolgens werd voor alle ZvC-patiënten met een stabiel verblijf gedurende ten minste 3 jaar na inclusie $(n=338)$ het ziektebeloop geanalyseerd met behulp van zowel een samengestelde score van negatieve uitkomsten (d.w.z. chirurgie, ziekenhuisopname, medicatiegebruik en ziekteprogressie) als ook aan de hand van ziekteactiviteit per kwartaal. Hiervoor werden respectievelijk logistische en lineaire regressiemodellen gebruikt, wederom met correctie voor bekende IBDrisicofactoren. Er werden geen significante associaties tussen de parameters van luchtkwaliteit en diagnose en/of ziektebeloop gevonden en daarom werd geconcludeerd dat luchtkwaliteit geen sterk bijdragende factor in IBD zou zijn in de regio Zuid-Limburg. Helaas konden we in deze studie geen rekening houden met de blootstelling aan luchtkwaliteit eerder in het leven van de patiënten en blootstelling aan de beschreven parameters buiten de woonplaats. Bovendien moet worden opgemerkt dat we kleine effecten, bijvoorbeeld bij genetisch gevoelige patiënten, niet kunnen uitsluiten. We pleiten derhalve voor een voorzichtige interpretatie van de resultaten.

In Hoofdstuk 4 werden data uit de MijnIBDcoach-studie gebruikt om de associatie tussen psychosociale factoren en opvlammingen van IBD te bestuderen. Het MijnIBDcoach-studiecohort bestaat uit volwassen IBD-patiënten uit twee academische en twee regionale ziekenhuizen in Nederland die gerandomiseerd werden voor ofwel standaardzorg (d.w.z. regelmatige polikliniekbezoeken) of monitoring met behulp van de mijnIBDcoach thuismonitoringapplicatie. Voor onze studie werden 417 patiënten geïncludeerd die mijnIBDcoach gebruikten gedurende 12 maanden. Patiënten rapporteerden elke 1-3 maanden hun ziekteactiviteit (met behulp van de gevalideerde Monitor IBD At Home (MIAH) -vragenlijst) en symptomen van angst, depressie, vermoeidheid, psychologische stress en levensgebeurtenissen. Een opvlamming werd gedefinieerd als klinische ziekteactiviteit in combinatie met verhoogde calprotectinespiegels in de ontlasting, ziekteactiviteit op basis van endoscopie of beeldvorming, of aanpassing van de therapie op vanwege klachten door de behandelende arts. Generalized estimating equations (GEE) modellen werden gebruikt om mogelijke associaties tussen alle psychosociale variabelen en opvlammingen van de ziekte in de drie maanden na het meetmoment te identificeren waarbij werd gecorrigeerd voor bekende IBD-risicofactoren. Alleen het optreden van levensgebeurtenissen (OR 1,81; $95 \% \mathrm{BI} 1,04-3,17$ ) en nieuwe psychologische stress (OR 2,92; 95\% BI 1,44-5,90) 
warensignificant geassocieerd met een opvlamming. Onze bevindingen onderstrepen het belang van continue monitoring van de psychosociale status bij IBD-patiënten en kunnen bijdragen aan het voorkomen van opvlammingen van IBD. Toekomstige studies zullen moeten uitwijzen of gepersonaliseerde interventies (bijv. mindfulness voor patiënten met een hoog stressniveau) inderdaad een gunstig effect hebben op het ziektebeloop.

In Hoofdstuk 5 werden dezelfde studiepopulatie en definitie voor opvlammingen van IBD gebruikt als in hoofdstuk 4 om het verband tussen een verminderde voedingstoestand en ziekteactiviteit te analyseren. Naast de MIAH-vragenlijst rapporteerden de 417 geïncludeerde patiënten ook elke 1-3 maanden over gewichtsverlies en afgenomen eetlust tijdens de 12-maanden follow-up. Een hoog risico op een verminderde voedingstoestand werd gedefinieerd als een $\mathrm{BMI}<18,5 \mathrm{~kg} / \mathrm{m}^{2}$ en/of een Short Nutritional Assessment Questionnaire (SNAQ) -score $\geq 2$. In onze GEEmodellen, wederom corrigerend voor bekende IBD-risicofactoren, bleek een hoog risico op een verminderde voedingsstatus inderdaad geassocieerd met het optreden van opvlammingen in de daaropvolgende drie maanden (OR 2,61; 95\% BI 1,02-6,69). Of individuele interventies om de voedingstoestand te verbeteren (bijv. een specifiek dieet of fysiotherapie) kan voorkomen dat de ziekte opvlamt, moet nog verder worden onderzocht.

Zowel ongecontroleerde ziekteactiviteit als langdurige blootstelling aan geneesmiddelen kunnen het ziektebeloop van een patiënt op lange termijn negatief beïnvloeden. Maligniteiten zijn een belangrijke complicatie bij zowel onderbehandelde patiënten (bijv. colorectaal carcinoom (CRC)) als overbehandelde patiënten (bijv. geneesmiddel-gerelateerde maligniteiten). In het derde deel van dit proefschrift werd het risico op maligniteiten geanalyseerd in het populatie-gebaseerde IBDZL-cohort.

In Hoofdstuk 6 werden 'standardized incidence ratio's' (SIRs) berekend voor zowel intestinale als extra-intestinale maligniteiten bij 2.801 IBD-patiënten van het IBDZLcohort. Er werden subgroep analyses uitgevoerd om geslacht- en fenotype-specifieke risico 's te bepalen. Daarnaast werden patiënten ook nog gestratificeerd op basis van blootstelling aan immuun modulerende medicatie. Over het algemeen hadden ZvCpatiënten een algemeen verhoogd risico op maligniteiten (SIR 1,28; 95\% BI 1,01-1,60), voornamelijk als gevolg van een verhoogd risico op hematologische maligniteiten (SIR 2,41; 95\% BI 1,04-4,76) en plaveiselcelcarcinoom (SIR 3,83;95\% BI 1,83-7,04). Alleen ZvC-patiënten met betrokkenheid van het colon hadden een verhoogd risico op CRC (SIR 2,97; 95\% BI 1,08-6,46). Bij CU-patiënten werd geen verhoogd risico op enige vorm van maligniteiten gevonden. In de medicatie subgroep analyse (waarbij data van ZvCen CU-patiënten samen werden geanalyseerd) werd een associatie gevonden tussen langdurig gebruik van immuunsuppressie (d.w.z. >12 maanden blootstelling aan thiopurines, anti- TNF $\alpha$-middelen en/of methotrexaat) en een verhoogd risico op maligniteiten (SIR 1.48; 95 \% BI 1,11-1,95). Opnieuw was dit met name toe te schrijven 
aan hematologische (SIR 3.12; 95\% BI 1.14-6.79) en dermatologische maligniteiten (SIR 1.95; 95\% BI 1.22-2.96). Onze resultaten onderstrepen het belang van screening op huidkanker, vooral bij patiënten die langdurig zijn blootgesteld aan immuunsuppressiva. Om de screening op maligniteiten en/of surveillancestrategieën verder te optimaliseren, is het belangrijk dat in de toekomst specifieke associaties met patiëntkarakteristieken worden geïdentificeerd.

In Hoofdstuk 7 werden alle geobserveerde CRC's $(n=20)$ uit het vorige hoofdstuk verder onderzocht. Als belangrijkste doel werd de incidentie en etiologie van potentieel vermijdbare 'postcolonoscopy CRC's' (PCCRC's) geanalyseerd. Deze subgroep van CRC's wordt gedefinieerd als CRC's die binnen 6-60 maanden na een volledige colonoscopie worden gediagnosticeerd. Een PCCRC kan volgens een algoritme worden geclassificeerd als 'inadequaat surveillance-interval', 'onvolledig darmonderzoek', 'onvolledige resectie van dysplasie', 'gemiste laesie' of 'nieuw ontwikkelde maligniteit'. In het IBDZLstudiecohort werd een hoog percentage PCCRC's (45\%) gevonden, waarbij 55,6\% kon worden geclassificeerd als een gemiste laesie. Aangezien surveillance richtlijnen zijn geïmplementeerd om het ontstaan van CRC secundair aan colitis-geassocieerde dysplasie te voorkomen, hebben we in dit hoofdstuk ook de naleving van richtlijnen voor zowel PCCRC's als de overige CRC's geanalyseerd. Tien van de 20 CRC's in het IBDZL-cohort werden gedetecteerd binnen het aanbevolen surveillance-interval en na publicatie van de Nederlandse richtlijn in 2008, terwijl slechts één patiënt op het juiste moment een adequaat uitgevoerde surveillance coloscopie onderging. Tevens werden een zestal CRC's (30\%) gevonden in patiënten vóór de aanbevolen start van de surveillance (d.w.z. 8 jaar na het begin van darmklachten). Ondanks de lage absolute maligniteitsrisico's is het belangrijk dat we onze detectiepercentages voor dysplasie verhogen en de naleving van surveillancerichtlijnen blijven verbeteren. Ook zijn wij van mening dat het opnemen van een surveillance-endoscopie na de eerste inductie van remissie, in ieder geval bij hoogrisicopatiënten, kan leiden tot een vermindering van CRC's binnen 8 jaar na diagnose.

In het laatste hoofdstuk (hoofdstuk 8) werden de resultaten van dit proefschrift bediscussieerd met betrekking tot de algehele verbetering van het ziektebeloop in IBD. Allereerst benadrukten we de noodzaak van verdere verbetering van de patiëntstratificatie, waarbij een nauwkeurige en uniforme beschrijving van het ziektebeloop met objectieve en onafhankelijke uitkomstmetingen het uitgangspunt dient te zijn. We stelden daarbij dat IBD mogelijk complexer is dan de traditionele opsplitsing tussen $\mathrm{CU}$ en ZvC en spoorden onderzoekers aan om zich te richten op het combineren van klinische IBD data met het genoom, het weefsel- of celspecifieke transcriptoom, het proteoom, het metaboloom en/of het microbioom van patiënten. Dit kan bijdragen aan het vinden van voorspellers voor specifieke IBD-subgroepen om vervolgens gepersonaliseerde risicoprofielen te genereren die de ernst van de ziekte voorspellen en daarmee gastro-enterologen helpen om de juiste behandelstrategie te 
bepalen. Ten tweede bespraken we het belang van (thuis)monitoring van leefstijlfactoren en psychosociale factoren om patiënten te selecteren die een hoger risico op een flare hebben en derhalve in aanmerking komen voor gepersonaliseerde interventies. Ook adviseerden we toekomstige onderzoekers om het complexe samenspel tussen omgevingsfactoren verder te onderzoeken waarbij rekening dient te worden gehouden met genetische gevoeligheid en de samenstelling van het microbioom van patiënten om te kunnen corrigeren voor effectmodificatie en invloed van zogeheten confounders. Ten derde gaven we een overzicht van de belangrijkste risico's van zowel overbehandeling (zoals geneesmiddel-gerelateerde maligniteiten en infecties) als onderbehandeling (zoals ziekteprogressie en CRC). We raadden aan om met deze risico's rekening te houden bij het opstellen van een behandelplan. Ten slotte concludeerden we dat het verbeteren van de patiëntstratificatie, het voorkomen van opvlammingen met behulp van patiëntmonitoring en het afwegen van risico's bij het kiezen van behandelstrategieën, belangrijke stappen zijn richting 'personalized medicine' en uiteindelijk zullen bijdragen aan betere lange termijn resultaten bij IBD. 


\section{Impact paragraph}

Inflammatory bowel disease (IBD), encompassing Crohn's disease (CD) and ulcerative colitis (UC), is a chronic inflammatory condition of the intestine, characterized by sequences of exacerbation (i.e. flares) and remission. ${ }^{1,2}$ Recurrent flares may lead to intestinal complications (like fistulas, abscesses, and strictures), but also malnutrition or even colorectal cancer and have a major negative impact on subjective health and social functioning. To control disease activity, numerous drugs have been developed, but these are associated with side effects and high costs. In general, IBD is associated with a significant impact on patients' quality of life. ${ }^{3}$ Due to an increasing number of new IBD cases per year and subsequently an increased use of expensive treatments and disease-related work disability, ${ }^{4}$ the health economic burden of disease increases as well. ${ }^{5}$

To date, over 240.000 manuscripts on IBD have been published, ${ }^{6}$ but many aspects related to IBD remain unclear. The studies in this thesis comprise a broad spectrum of subjects related to flare occurrence and inherent treatment in IBD patients. In this paragraph, the findings will be discussed in the light of both scientific and societal impact, including the relevance for stakeholders such as healthcare professionals, patients, policy makers, insurance companies, and society in general.

\section{Part I: Analysing disease course}

The complexity of IBD's disease course was highlighted in Chapter 2. By using the welldefined population-based IBD South Limburg (IBDSL) cohort, comprising the full range of patients with a quiescent to those with a severe disease course, we analysed unique disease activity patterns as the main study outcome instead of outcomes used in most other studies that are dependent on local or international guidelines (e.g. need for surgery and received medical treatment). The observed diversity in disease activity patterns underlines the need for personalized selection of treatment strategies to prevent both overtreatment and undertreatment and may have impact for several stakeholders.

First, the graphically displayed heterogeneity of the disease course may be used by gastroenterologists and patient associations when explaining disease phenotypes and shaping patients' expectations, hereby contributing to patients' disease-related knowledge. Since we are not able to predict the patterns very accurately, we encourage future researchers to analyse their datasets using our disease course definitions and incorporate novel predictors (e.g. data on genetics and microbiota). Special attention should be paid to the large proportion of CD patients with a quiescent disease activity pattern since current studies (including leading trials) tend to focus on prediction of severe disease and treatment hereof. ${ }^{7}$ Eventually, stratification of patients according to the predicted disease activity pattern may contribute to accurate selection of costly 
drugs for those in need and prevention of potentially harmful drug exposure in those who are not. Policy makers can use the predicted patterns to generate personalized monitoring plans in which, for instance, the frequency of outpatient clinic visits and endoscopic follow-up is adjusted on an individual basis. Furthermore, IBD prediction models may be used by healthcare professionals in negotiations with insurance companies and subsequently may improve reimbursement models. Even life insurance companies, which currently determine the height of premiums on the sole diagnosis of a specific chronic illness, could take the predicted disease course into account to distinguish mild from severe IBD cases.

\section{Part II: Modifying disease activity}

To improve disease outcomes on the long-term, it is important to monitor disease activity and intervene immediately in case of a flare. However, since flares are triggered by environmental factors, amongst others through changes in a patient's microbiome composition and immune status, flares may be prevented by modifying a patient's environment. In the second part of this thesis, the link between disease activity and lifestyle and psychosocial factors was analysed in Chapter 3, 4, and 5. The observed association between disease activity and perceived stress, life events, and a higher risk for malnutrition underlines the need to monitor these factors in IBD patients.

Using our findings, both patients and gastroenterologists can be convinced about the importance of flare prevention and subsequently become more engaged to frequently monitor the environmental risk factors besides disease activity. Moreover, patients can be more easily motivated to adhere to lifestyle and psychosocial interventions. Also, further increasing disease-related knowledge may lead to a reduction in patients' worries and concerns and is associated with positive disease outcomes. 8 , 9 Improving patient education in general may therefore lead to better disease control and more efficient use of healthcare resources and eventually improve their subjective health and decrease the economic burden of IBD. The MyIBDcoach home-monitoring tool (Chapter $\mathbf{4}$ and $\mathbf{5}$ ) offers a perfect platform for patients to report on lifestyle and psychosocial factors besides the monitoring of disease activity parameters (e.g. disease activity questionnaires and faecal calprotectin) and may be used to select patient at risk for flares. Subsequent personalized interventions are probably most effective when a multidisciplinary approach is used (e.g. involvement of trained dieticians, psychologists, and nurse practitioners). Eventually, decreasing disease activity and preventing disease flares may result in decreased need for expensive medical treatments, hospitalisations, and surgical procedures (i.e. direct healthcare costs) as well as decreased work loss and/or increased work productivity (i.e. indirect healthcare costs). The MylBDcoach tool has already been proven to satisfy both patient and doctor in a cost-effective way. ${ }^{10,11}$ Policy makers could use our study results and other available studies on lifestyle and psychosocial status to determine 
which items should be included in the monitoring modules. Future researchers should further investigate the impact of other environmental factors and ideally take into account all other parameters that affect the results, such as a patient's genome and microbiome, to identify causal relationships and new targets for intervention.

\section{Part III: Managing long-term complications}

Both uncontrolled intestinal inflammation and unnecessary drug exposure are unwanted since they may contribute to complications in the long-term. Gaining insight in these complications is important, but requires detailed clinical data from patients with a long follow-up. We were able to study the incidence of cancer using the IBDSL cohort containing almost 3.000 patients who had been followed since IBD diagnosis (starting in the year 1991). Despite the fact that the risk for colorectal cancer (CRC), which is a complication of chronic intestinal inflammation, has decreased over time (Chapter 6), still a certain number of CRCs could have been prevented (Chapter 7). Moreover, we linked the occurrence of several extra-intestinal malignancies (e.g. skin cancer and leukaemia) to immunosuppressive drug exposure (Chapter 6).

Again, our findings are important to better inform patients and expand their disease-related knowledge. Warning patients for potentially lethal complications of chronic inflammation may improve engagement to proposed treatment strategies, especially since currently compliance to drug therapies is a major concern. ${ }^{12,}{ }^{13}$ In addition, the observed relation between extra-intestinal malignancies and immunosuppressive drug exposure may be used to persuade patients to adapt lifestyle in order to reduce disease activity in non-pharmacological manners (e.g. quit smoking and improving nutritional status). Also, patients can be advised on preventive measurements when immunosuppressives are prescribed. For instance, the use of sunscreens and avoidance of long sun exposure, especially when thiopurines are being prescribed, is already recommended by most recent guidelines. ${ }^{7,14}$ Furthermore, our results may contribute to adjustments in CRC surveillance guidelines. While current guidelines still advise a first surveillance colonoscopy at 8 years after disease onset, we suggest to perform the first surveillance immediately after induction of remission to prevent the relatively large number of CRC cases within 8 years after diagnosis (Chapter 7). Especially since the absolute risks for both drug-related cancers and CRC remain low, future researchers should focus on the identification of associated patient characteristics to further personalise surveillance strategies.

In conclusion, the findings of this thesis can be primarily used to improve diseaserelated knowledge in patients and to provide guidance for gastroenterologists when selecting treatment strategies to ameliorate a patient's disease course. Furthermore, our findings will stimulate future researchers to use big data warehouses, in which existing databases (such as datasets from the IBDSL cohort and the MyIBDCoach home- 


\section{Addendum}

monitoring tool) are being combined, to answer the remaining research questions in the quest for personalized medicine. 


\section{References}

1. Roda G, Chien Ng S, Kotze PG, Argollo M, Panaccione R, Spinelli A, et al. Crohn's disease. Nat Rev Dis Primers. 2020;6(1):22.

2. Feuerstein JD, Moss AC, Farraye FA. Ulcerative Colitis. Mayo Clinic proceedings. 2019;94(7):1357-73.

3. Hoivik ML, Bernklev T, Solberg IC, Cvancarova M, Lygren I, Jahnsen J, et al. Patients with Crohn's disease experience reduced general health and vitality in the chronic stage: ten-year results from the IBSEN study. J Crohns Colitis. 2012;6(4):441-53.

4. Ng SC, Shi HY, Hamidi N, Underwood FE, Tang W, Benchimol El, et al. Worldwide incidence and prevalence of inflammatory bowel disease in the 21st century: a systematic review of population-based studies. The Lancet. 2017;390(10114):2769-78.

5. van der Valk ME, Mangen MJ, Leenders M, Dijkstra G, van Bodegraven AA, Fidder HH, et al. Healthcare costs of inflammatory bowel disease have shifted from hospitalisation and surgery towards antiTNFalpha therapy: results from the COIN study. Gut. 2014;63(1):72-9.

6. Chen X, Yang K, Xu Y, Li K. Top-100 highest-cited original articles in inflammatory bowel disease: A bibliometric analysis. Medicine (Baltimore). 2019;98(20):e15718.

7. Torres J, Bonovas S, Doherty G, Kucharzik T, Gisbert JP, Raine T, et al. ECCO Guidelines on Therapeutics in Crohn's Disease: Medical Treatment. J Crohns Colitis. 2020;14(1):4-22.

8. Moser G, Tillinger W, Sachs G, Genser D, Maier-Dobersberger T, Spiess K, et al. Disease-related worries and concerns: a study on out-patients with inflammatory bowel disease. Eur J Gastroenterol Hepatol. 1995;7(9):853-8.

9. Park J, Yoon H, Shin CM, Park YS, Kim N, Lee DH. Higher levels of disease-related knowledge reduce medical acceleration in patients with inflammatory bowel disease. PLoS One. 2020;15(6):e0233654.

10. de Jong MJ, Boonen A, van der Meulen-de Jong AE, Romberg-Camps MJ, van Bodegraven $A A$, Mahmmod N, et al. Cost-effectiveness of Telemedicine-directed Specialized vs Standard Care for Patients With Inflammatory Bowel Diseases in a Randomized Trial. Clin Gastroenterol Hepatol. 2020;18(8):1744-52.

11. de Jong MJ, van der Meulen-de Jong AE, Romberg-Camps MJ, Becx MC, Maljaars JP, Cilissen M, et al. Telemedicine for management of inflammatory bowel disease (mylBDcoach): a pragmatic, multicentre, randomised controlled trial. Lancet. 2017;390(10098):959-68.

12. Spekhorst LM, Hummel TZ, Benninga MA, van Rheenen PF, Kindermann A. Adherence to Oral Maintenance Treatment in Adolescents With Inflammatory Bowel Disease. J Pediatr Gastroenterol Nutr. 2016;62(2):264-70.

13. Chan W, Chen A, Tiao D, Selinger C, Leong R. Medication adherence in inflammatory bowel disease. Intest Res. 2017;15(4):434-45.

14. Annese V, Beaugerie L, Egan L, Biancone L, Bolling C, Brandts C, et al. European Evidence-based Consensus: Inflammatory Bowel Disease and Malignancies. J Crohns Colitis. 2015;9(11):945-65. 
Addendum 


\section{List of publications}

\section{Within this thesis}

T.R.A. van den Heuvel, D.S.J. Wintjens, S.F.G. Jeuring, M.H.H. Wassink, M.J.L. RombergCamps, L.E. Oostenbrug, S. Sanduleanu, W.H Hameeteman, M.P. Zeegers, A.A. Masclee, D.M. Jonkers, M.J. Pierik. Inflammatory bowel disease, cancer and medication: cancer risk in the Dutch population based IBDSL cohort. Int J Cancer. 2016 May 11

D.S.J. Wintjens, R.M.M. Bogie, T.R.A. van den Heuvel, C.M.C. le Clercq, L.E. Oostenbrug, M.J.L. Romberg-Camps, J.W. Straathof, L.P.S. Stassen, A.A.M. Masclee, D.M.A.E. Jonkers, S. Sanduleanu-Dascalescu, M.J. Pierik. Incidence and classification of postcolonoscopy colorectal cancers in inflammatory bowel disease: A Dutch population-based cohort study. J Crohns Colitis. 2018 Apr 10

D.S.J. Wintjens, M.J. de Jong, A.E. van der Meulen-de Jong, M.J. Romberg-Camps, M.C. Becx, J.P. Maljaars, A.A. van Bodegraven, N. Mahmmod, T. Markus, J. Haans, A.A.M. Masclee, B. Winkens, D.M.A.E. Jonkers, M.J. Pierik. Novel Perceived Stress and Life Events Precede Flares of Inflammatory Bowel Disease: A Prospective 12-Month FollowUp Study. J Crohns Colitis. 2019 Mar 30

C.E.G.M. Spooren, D.S.J. Wintjens, M.J. de Jong, A.E. van der Meulen-de Jong, M.J.L. Romberg-Camps, M.C. Becx, J.P.W.J. Maljaars, A.A. van Bodegraven, N. Mahmmod, T. Markus, W.M. Hameeteman, A.A.M. Masclee, B. Winkens, D.M.A.E. Jonkers, M.J. Pierik. Risk of impaired nutritional status and flare occurrence in IBD outpatients. Dig Liver Dis. 2019 Sep

D.S.J. Wintjens, F. Bergey, E. Saccenti, S.F.G. Jeuring, T.R.A. van den Heuvel, M.J.L. Romberg-Camps, L.E. Oostenbrug, A.A.M. Masclee, V. Martins dos Santos, D.M.A.E. Jonkers, M.J. Pierik. Disease activity patterns of Crohn's disease in the first 10 years after diagnosis in the population-based IBD South Limburg cohort. J Crohns Colitis. 2020 Aug 26 


\section{Outside this thesis}

B. Meijer, C.J.J. Mulder, C.Y. Ponsioen, C.J. van der Woude, A.E. van der Meulen, D.S.J. Wintjens, G. Dijkstra, F. Hoentjen, B. Oldenburg, A.A. van Bodegraven, N.K.H. de Boer, on behalf of the Dutch Initiative on Crohn and Colitis and Parelsnoer Institute. Methotrexate and thioguanine rescue therapy for conventional thiopurine failing ulcerative colitis patients: a multi-center database study on tolerability and effectiveness. Inflamm Bow Dis. 2018 Apr 13

G. Galazzo, D.I. Tedjo, D.S.J. Wintjens, P.H.M. Savelkoul, A.A.M. Masclee, A.G.L. Bodelier, M.J. Pierik, D.M.A.E. Jonkers, J. Penders. Faecal Microbiota Dynamics and their Relation to Disease Course in Crohn's Disease. J Crohns Colitis. 2019 Sep 27

S. Bosch, D.S.J. Wintjens, A. Wicaksono, J. Kuijvenhoven, R. van der Hulst, P. Stokkers, E. Daulton, M.J. Pierik, J.A. Covington, T.G.J. de Meij, N.K.H. de Boer. The faecal scent of inflammatory bowel disease: Detection and monitoring based on volatile organic compound analysis. Dig Liver Dis. 2020 Jul;52(7):745-752.

A. Rezazadeh Ardabili*, D. Goudkade*, D.S.J. Wintjens, M.J.L. Romberg-Camps, B. Winkens, H. Grabsch, M.J. Pierik, D.M.A.E. Jonkers. Histopathological features at diagnosis to predict long-term disease course of Crohn's disease. J Crohns Colitis. 2021 May 14

\section{Submitted articles}

D.S.J. Wintjens*, T.R.A. van den Heuvel*, E.M. Bijnens, B.P.M. Verhaegh, S.F.G. Jeuring, T.S. Nawrot, M.P. Zeegers, A.A.M. Masclee, L.E. Oostenbrug, M.J.L. Romberg-Camps, J.W.A. Straathof, D.M.A.E. Jonkers, M.J. Pierik. Ambient air quality is not a major risk factor in the onset nor disease course of Crohn's disease - an ecologic analysis in a Dutch population-based cohort.

S. Bosch, D.S.J. Wintjens, A. Wicaksono, M.J. Pierik, J.A. Covington, T.G.J. de Meij, N.K.H. de Boer. Prediction of inflammatory bowel disease course based on faecal volatile organic compounds. 


\section{Awards and grants}

2017 UEGW Travel grant

Continuous monitoring with the telemedicine tool mylBDcoach shows an association between novel stress and inflammatory bowel disease flares

2017 Nomination 'Pélerin Pitchprijs'

Assessment of disease activity patterns during the first 10 years after diagnosis in a population-based Crohn's Disease cohort shows a quiescent disease course for a substantial proportion of the population

2018 Young ECCO Abstract Award

Assessment of disease activity patterns during the first 10 years after diagnosis in a population-based Crohn's Disease cohort shows a quiescent disease course for a substantial proportion of the population 
Addendum 


\section{Dankwoord}

Vanaf de onderzoeksstage tijdens mijn studie Geneeskunde tot aan het schrijven van dit dankwoord ben ik afhankelijk geweest van een grote hoeveelheid 'derden'. Sommigen heel dichtbij en sommigen wat verder weg (zowel letterlijk als figuurlijk). Hoewel deze afhankelijkheid mij soms in de weg heeft gezeten, is het gedurende mijn promotietraject wel duidelijk geworden dat het succesvol afronden van mijn proefschrift nooit mogelijk was geweest zonder alle andere betrokkenen. Ik ben me er ter degen van bewust dat het dankwoord kritischer zal worden bekeken dan alle andere hoofdstukken (althans, door de meeste lezers) en ik hoop dan ook dat ik niemand vergeet of teleurstel. Mocht dit toch zo zijn, dan ligt dat vast aan mijn geheugen en niet aan zijn of haar bijdrage!

Prof. dr. Jonkers, beste Daisy, uiteraard begint mijn dankwoord met alle lof voor jou. Jij bent vanaf mijn WESP-stage al verantwoordelijk voor heel wat rode lijnen in eerste drafts van manuscripten (gelukkig namen die richting het einde van mijn promotietraject af in hoeveelheid) en hebt mij meer dan eens gewezen op mijn soms 'wollige' manier van schrijven. Hoewel je het beoordelen van de medisch inhoudelijke aspecten vaak overliet aan Marieke, bewaakte jij de rode draad in de manuscripten en de 'message'. Ondanks je functie als mijn baas heb ik altijd het gevoel gehad dat ik zo bij je binnen kon lopen voor vragen en die laagdrempeligheid is erg fijn.

Prof. dr. Pierik, beste Marieke, samen met Daisy vormde jij het vaste duo dat verantwoordelijk is voor de kwaliteit van dit proefschrift. Als het aan jou had gelegen, waren er inmiddels al veel meer studies uitgevoerd met alle data die verzameld zijn binnen het IBDZL cohort. Maar de grote hoeveelheid aan goede ideeën wordt tegengewerkt door het beperkt aantal uren in een dag. Gelukkig zal jij er altijd voor zorgen dat er nieuwe PhD studenten worden overtuigd om zich te storten op de nieuwe projecten. Marieke, de samenwerking gedurende de afgelopen jaren was zeer prettig en ik ben blij dat jij op de juiste momenten mijn manuscripten hebt voorzien van een terechte kritische noot.

Dr. Straathof, beste Jan Willem, jij was degene die mij opbelde, terwijl ik genoot van een alcoholische versnapering op Tenerife, om me te vertellen dat ik was aangenomen voor zowel het promotietraject binnen de IBD alsook voor de MDL-opleiding. Sindsdien hebben we samengewerkt zowel op wetenschappelijk vlak en in de kliniek. Helaas zijn niet alle projecten die we in het begin bedacht hadden succesvol afgerond, maar ik ben heel blij met alle support die je mij toch hebt kunnen bieden. Jouw alternatieve visie op veel dingen zorgde voor de broodnodige prikkeling om out-of-the-box te denken en dat kwam ook in de afgelopen jaren vaak van pas. 
Prof. dr. Masclee, beste $A d$, ik weet nog goed dat ik barstte van de zenuwen toen ik als student voor het eerst zat te wachten voor je kantoor voor een kennismakingsgesprek. Samen bespraken we mijn wensen voor de toekomst (promoveren, in opleiding etc.) en je gaf aan dat ik vooral geduldig moest zijn en dat uiteindelijk alles wel goed zou komen. Het A4-tje met mijn naam en wensen verdween in 'de map' en ik kon weer vertrekken... Nu, enkele jaren later, heb ik me voor niks zorgen gemaakt en hebben we inmiddels op vele fronten prettig kunnen samenwerken. Met name grote dank voor nog net die puntjes op de ' $i$ ' die jij als laatste auteur op veel stukken steeds nog wist toe te voegen.

Beste prof. dr. Smidt, prof. dr. Louis, prof. dr. Van der Woude, prof. dr. Strik en prof. dr. Hemmelder, ik wil jullie als beoordelingscommissie bedanken voor het kritisch beoordelen van dit proefschrift. Ik hoop dat jullie, ondanks de enorme voorkennis, toch nog iets hebben kunnen leren vanuit dit boekwerk.

Beste onderzoekers van het IBD-team,

Bij het schrijven van dit dankwoord kwam ik er eigenlijk pas achter hoe groot ons team eigenlijk is geworden.

Beste Tim, als stagebegeleider was jij degene die mij als student binnen het team verwelkomde in 2014. Ik heb kunnen profiteren van je expertise op epidemiologisch gebied en was dan ook zeer verheugd toen ik na een lange tijd 'onder jou' eindelijk je collega zou worden. Helaas bleek dat maar voor korte duur door jouw vertrek naar Medtronic. Toch zal ik onze samenwerking nooit vergeten. Van inclusieavonden organiseren in het Zuyderland tot een potje voetballen op UNS 40. Ook de tourpoule was de moeite waard en samen kregen wij menig collega mee in onze liefde voor de Tour de France.

Beste Steven, ik zie jou net als Tim als een van de grondleggers van mijn promotietraject. Een deel van mijn werk borduurde voort op dat van jou. Dank dus voor al jouw speurwerk in de niet te lezen dossiers in JIM en je altijd voortreffelijke documentatie van alles. Dit maakte het leven voor mij een heel stuk makkelijker!

Beste Vince, jij kwam als buitenstaander binnen de groep, maar wij konden het samen meer dan prima vinden. Elke dinsdag was er ruimte voor serieuze gesprekken, maar ook voor de broodnodige small talk. Ik was jaloers op je discipline, zowel in je werk als in het eten van kwark (en het sporten dat daarop volgde). Oh ja, nog bedankt dat je me hebt leren strijken in ons appartementje in Wenen!

Beste Marin, samen met Marieke heb jij de IBDCoach ontwikkeld en ook succesvol uitgerold. De waardevolle data die uit jouw project zijn voortgekomen, vormden de basis voor twee van mijn hoofdstukken. Derhalve is mijn dank dus groot!

Beste Sofie, vanuit het toenmalige VUmc kwam jij naar Maastricht om samen met ons een aantal VOC-studies te doen. Ons doel was simpel: met een spateltje een specifiek aantal milligram bevroren poep van een aantal jaar oud los hakken uit een 
potje om dit later op te warmen voor analyses in Engeland... Het afzuigsysteem in het lab werkte gelukkig prima tegen de nare geurtjes en het spatscherm beschermde ons tegen rondvliegende deeltjes, maar het waren iedere keer opnieuw spannende dagen. Gelukkig heeft het inmiddels geleid tot een mooie publicatie en hopelijk volgen er nog meer!

Ook alle andere IBD-onderzoekers Ashkan, Bas, Corinne, Evelien, Greetje, Heike, Laura, Pan en Rob wil ik heel hard bedanken voor alle bijdrages aan dit boekje. Sommigen voor hun werk als co-auteur, anderen voor hun waardevolle input tijdens de wekelijkse IBD-meetings.

Beste Bjorn, graag wil ik even stilstaan bij de enorme behulpzaamheid die jou typeert. Altijd bereikbaar voor methodologisch advies en altijd bereid om mijn 'kleine vraagjes' via de mail te beantwoorden. Dit in combinatie met een gezonde dosis humor hebben mij door de statistische jungle heen gesleept. Zonder jou zouden de gebruikte modellen voor mij namelijk nog steeds een grote black box zijn geweest.

Team LifeGlimmer/Universiteit van Wageningen, prof. dr. Martins dos Santos, Edoardo, Francois, dank voor de samenwerking op methodologisch vlak aangaande mijn studie naar het ziektebeloop van de ziekte van Crohn. Jullie niet-medische achtergrond leidde soms tot bijzondere associaties en bevindingen die voor ons vaak stof tot nadenken vormden. Ook het text-mining project was fantastisch om te mogen doen ondanks dat de resultaten helaas vooralsnog wat tegenvallen. Dank!

Beste IBD-dokters en verpleegkundig specialisten van het MUMC+ en het Zuyderland, ook jullie verdienen een eervolle vermelding in dit proefschrift voor jullie jarenlange inzet voor het IBDZL cohort. Een populatiegebaseerd cohort stelt niks voor als niet iedereen zijn uiterste best doet om alle patiënten te includeren en dat hebben jullie al zeer lange tijd met succes gedaan!

Dr. Lieverse, Beste Louis, ook nog een speciaal woordje van dank aan jouw adres. Tijdens mijn vooropleiding heb jij altijd interesse getoond in mijn promotietraject en was je zeer begaan als het een keertje tegenzat. Zelfs in de drukke COVID-tijden zorgde je ervoor dat ik juist extra tijd kreeg om mijn introductie van mijn proefschrift te gaan schrijven. Dit waren grote stappen in de afronding van mijn thesis, waarvoor heel erg veel dank!

Beste studenten, velen van jullie hebben eindeloos naar Excel-sheets zitten staren en op de meest onmogelijke manieren doktershandschriften proberen te ontcijferen om mij van alle benodigde data te voorzien. Zonder jullie was dit proefschrift nog lang niet af geweest. Ik (en samen met mij nog vele anderen) zijn jullie eeuwig dankbaar. We 
zullen jullie niet snel vergeten, want jullie namen zijn voor altijd gekoppeld aan de databases; het wachtwoord begint namelijk nog steeds met jullie voorletters!

Beste niet-IBD onderzoekers van de UNS40/50, Anke, Annick, Bram, Ellen, Gonny, Lisa, Lonne, Mark, Martine, Montserrat, Pauline, Quirine, Roel, Tim, Toon, Wenke, Wiesje, Yala en Zsa Zsa, jullie hebben mijn promotietijd toch bijzonder veel kleur gegeven. Eindeloze dagen achter de computer zijn eigenlijk niks voor mij en ik was dan ook (te) vaak buiten mijn kamer te vinden. Er was altijd wel iemand beschikbaar voor een praatje of een kop koffie! Op momenten dat jullie allemaal wel serieus aan het werk waren, bedacht ik op de achtergrond de nodige office pranks waar velen van jullie slachtoffer van zijn geworden; dank voor jullie eindeloze naïviteit! Tim, Bram en Toon, sinds de komst van de tafelvoetbaltafel op UNS50 is onze productiviteit hard achteruit gegaan. Samen streden wij dagelijks voor de winst en was er toch af en toe iemand die vanwege een 0-score onder de tafel door moest kruipen. En Mark, sinterklaas zal voor mij nooit meer hetzelfde zijn sinds de goedheiligman mij oversloeg bij het uitdelen van lekkernijen.. Ook de jaarlijkse labuitjes, de Zuiderzee klassieker en de fantastische congressen (o.a. in Barcelona en Wenen) zal ik nooit vergeten!

Beste collega MDL AIOS, dank voor jullie interesse in mijn promotietraject en de prettige afleiding die jullie genereren op de soms drukke doordeweekse dagen. De nodige 'daily struggles' schepten al snel een band en het groepsgevoel is dan ook zeer groot. Met de aankomende schaarste van banen zijn we eigenlijk elkaars concurrenten, maar zo voelt dat nooit. Ik kijk ernaar uit om nog jaren met jullie samen te werken!

Beste MDL-artsen in MMC Veldhoven, ook jullie wil ik bedanken voor de interesse die jullie tijdens mijn vooropleiding in het MMC toonden in mijn promotietraject. In het bijzonder wil ik Paul en Jan bedanken. Naast de getoonde interesse hebben jullie mij, enigszins stiekem tussen mijn interne stages door, geïntroduceerd in de wondere wereld van de endoscopie. Jullie faciliteerden mijn allereerste poliepectomie en lieten mij 'mijn gang gaan' tijdens een aantal van jullie eigen programma's. Het was een zeer aangename samenwerking, heel veel dank!

Beste MDL-artsen in het MUMC+, doordat ik mijn studie Geneeskunde, veel van mijn co-schappen en mijn onderzoeksstage allemaal in het MUMC+ heb doorlopen, kruiste mijn pad heel vaak met dat van jullie. Waar ik vroeger alleen nog maar kon dromen van een opleidingsplaats en eenieder van jullie met ' $u$ ' en 'dokter' aansprak, heb ik inmiddels met iedereen een fijne collegiale band en is de afstand vele malen minder tot zelfs afwezig. Dank voor jullie dagelijkse begeleiding! En Zlatan en Daniël, ik weet dat mijn boekje niet zo dik is als dat van jullie, maar ik ben toch stiekem wel trots dat ik een poging heb gedaan! 
Beste Tim, eigenlijk heb ik nooit echt getwijfeld over wie van de collega's ik zou vragen als paranimf. Ondanks dat ik jou in het begin af en toe een typische AKO-student vond (die toch alles wel beter wist), bleken wij een extreem goede match. Het 'niet voor elkaar onder willen doen' (zowel op medisch inhoudelijk/researchkundig vlak alsook tijdens onze onderlinge informele competities) bracht in ons beiden het beste naar boven. Sinds mijn terugkomst op de UNS40 in 2016 hebben wij dagelijks de nodige koppen koffie verorberd onder het genot van onder andere de Dumpert Top 5. Zoals eerder omschreven was ook jij lid van 'het tafelvoetbalteam' en ook naast het werk schoten wij goed met elkaar op. Ik zal nooit vergeten hoe jij tijdens het wielrennen een keer helemaal leeggefietst was en toen nog een bergje moest trotseren. Het door jou gekozen tempo leidde tot een automatische pauze van je Garmin. Helaas voor jou was die melding ook te horen voor de passerende wielrenners (waaronder ik). En oh ja, die deuk in mijn auto na de bruiloft van Yala staat ook voor eeuwig op mijn netvlies gebrand..

Beste Timo, wij zijn al een team sinds wij hebben leren lopen. Hoewel je in principe niks te maken hebt met de inhoud van dit boekje, weet ik dat ik altijd op je kan rekenen en dat is dan ook precies de reden dat jij de andere paranimf moest zijn. Misschien dat ik je van tevoren wel even moet inlichten over een paar inhoudelijke zaken, want je moet het tenslotte wel kunnen overnemen als ik tijdens mijn verdediging in zou storten. Vriend, ik ben trots dat je naast me staat op de belangrijke momenten in mijn leven. Zo was je mijn getuige op mijn bruiloft en sta je strakjes ook naast me tijdens mijn verdediging.

Lieve vrienden, zoals al aangegeven, ben ik iemand die vaak op zoek is naar afleiding. En hoewel ik genoeg plezier heb beleefd op het werk, heb ik altijd enorm uitgekeken naar de avonden en/of weekenden met jullie. Helaas zijn die evenementen niet altijd goed geweest voor mijn proefschrift; ik herinner me nog wel een aantal moeizame day afters op de UNS40.. Toch ben ik ervan overtuigd dat mijn geluk deels door jullie wordt bepaald en dat jullie derhalve toch bij hebben gedragen aan het voltooien van mijn wetenschappelijke missie. Gilles, jou wil ik in het bijzonder nog bedanken voor al je efforts voor het design van mijn cover.

Lieve papa, mama en Esmée, wat bof ik toch met zo'n fijn gezin. Jullie hebben altijd interesse getoond in mijn onderzoek en ondanks dat jullie het soms niet echt leken te begrijpen, deden jullie altijd alsof! In de periode tussen mijn vooropleiding en de vervolgopleiding werd de oude kamer van Esmée mijn 'thuiswerkkantoor' (vanwege de COVID pandemie). Daar heb ik mijn proefschrift grotendeels af kunnen schrijven onder het genot van de nodige koekjes en zoetigheidjes die mama op haar vrije dagen altijd kwam brengen! Jullie zijn mijn steun en toeverlaat en het voelt altijd enorm fijn om 'thuis' te komen in het ouderlijk huis. Dank voor alles! 
Lieve Elise, jij bent het mooiste dat mij ooit is overkomen. Aangezien wij elkaar hebben leren kennen tijdens mijn promotietraject, had jij in het begin niet per se een positieve invloed op de productiviteit... Heel wat uurtjes gingen verloren aan dagdromen, een klein wandelingetje rondom het ziekenhuis of een extra dagje vrij. Toch vond ik bij jou de stabiliteit en rust die ik nodig had om later tijdens mijn opleiding tot MDL-arts tijd te besteden aan het afronden van mijn proefschrift. Ik kijk uit naar de rest van mijn leven met jou! 


\section{Curriculum vitae}

Dion Suzanne Justus was born on March 29, 1991, in Maastricht, The Netherlands. After graduation from the Sint Maartens college in Maastricht in 2009, he studied Medicine at the Maastricht University. In 2012, the BSc degree was obtained and in 2015 he received the MSc degree with distinction. During his master, the foundations were laid for this thesis due to his participation as a student researcher in several IBD South Limburg (IBDSL) cohort studies. Before he started as a PhD candidate, Dion worked as a resident (ANIOS) at the Gastroenterology department of the Amphia

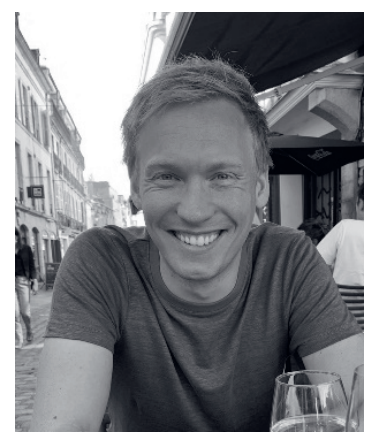
Medical Centre (Breda, NL) until 2016. Afterwards, he started with his PhD track at the department of Internal Medicine, division of Gastroenterology and Hepatology, within NUTRIM, School of Nutrition and Translational Research in Metabolism, and simultaneously with the gastroenterology training (AIOS) at the Maxima Medical Centre (MMC; Veldhoven, NL).

The PhD track was part of the IBD research program of the IBDSL cohort and was supervised by prof. dr. D.M.A.E. Jonkers, prof. dr. M.J. Pierik, and dr. J.W.A. Straathof. Part of his work is displayed within this thesis and several studies were presented at national and international conferences. In 2018, he was awarded with the Young ECCO Abstract Award. Besides his scientific activities, Dion followed the Problem-based learning course and obtained a certificate for Tutoring/teaching skills at the Maastricht University after which he participated as a tutor in several teaching programs for Medicine students.

After completion of the first two years of his Gastroenterology training at the MMC under supervision of dr. A.G. Lieverse, he continued his training at the Maastricht University Medical Centre in 2020. Currently, he is also part of the board of the NVMDL i.o., the youth department of the Dutch national professional association of gastroenterology specialists, in which he was recently appointed as secretary. 
